Digitized by the Internet Archive in 2008 with funding from Microsoft Corporation 


\section{PUBLICATIONS OF THE UNIVERSITY OF}

MANCHESTER

\section{CLASSICAL SERIES}

No. II.

The Authorship of the

Platonic Epistles 
Sherratt \& Hughes

Publishers to the Victoria University of Manchester

34 Cross Street, Manchester.

33 Soho Square, London, W.

Agents for the United States

Longmans, Green \& Co.

443-449 Fourth Avenue, New York 


\title{
THE AUTHORSHIP
}

OF THE

\section{PLATONIC EPISTLES}

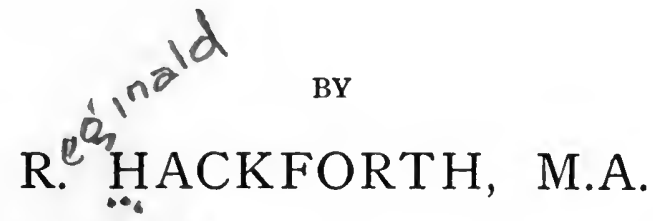

Sometime Assistant Lecturer in Classics in the University of Manchester; Fellow and Classical Lecturer of Sidney Sussex College, Cambridge

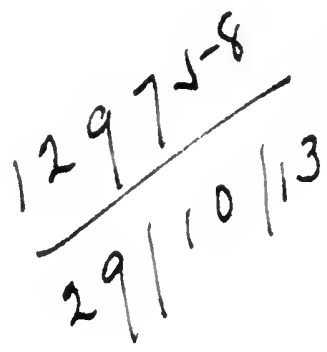

\section{MANCHESTER}

At The University Press

I9I 3 
Publications of the University of Manchester No. LXXII

$$
\begin{aligned}
& P A \\
& 4279 \\
& E 6413
\end{aligned}
$$

ALL RIGHTS RESERVED. 


\section{CONTENTS.}

$\begin{array}{llllllll}\text { Preface } & \ldots & \ldots & \ldots & \ldots & \ldots & \ldots & \text { vii }\end{array}$

List of Authorities $\quad \ldots \quad \ldots \quad \ldots \quad \ldots$ viii

$\begin{array}{lllllll}\text { Introduction } & \ldots & \ldots & \ldots & \ldots & \ldots & 1\end{array}$

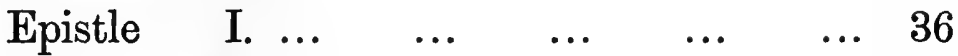

$\begin{array}{lllllll}\text { Epistle } & \text { II. ... } & \ldots & \ldots & \ldots & \ldots & 40\end{array}$

$\begin{array}{lllllll}\text { Epistle III. ... } & \ldots & \ldots & \ldots & \ldots & 52\end{array}$

$\begin{array}{lllllll}\text { Epistle IV. ... } & \ldots & \ldots & \ldots & \ldots & 69\end{array}$

$\begin{array}{lllllll}\text { Epistle } & \text { V. ... } & \ldots & \ldots & \ldots & \ldots & 73\end{array}$

$\begin{array}{lllllll}\text { Epistle V1. .. } & \ldots & \ldots & \ldots & \ldots & 76\end{array}$

$\begin{array}{llllll}\text { Epistle VII. ... } & \ldots & \ldots & \ldots & \ldots & 84\end{array}$

$\begin{array}{llllll}\text { Epistle VIII. ... } & \ldots & \ldots & \ldots & \ldots & 132\end{array}$

$\begin{array}{lllllll}\text { Epistle IX. } \ldots & \ldots & \ldots & \ldots & \ldots & 155\end{array}$

$\begin{array}{lllllll}\text { Epistle X. .. } & \ldots & \ldots & \ldots & \ldots & 158\end{array}$

$\begin{array}{lllllll}\text { Epistle } & \text { XI. ... } & \ldots & \ldots & \ldots & \ldots & 159\end{array}$

$\begin{array}{llllll}\text { Epistle XII. ... } & \ldots & \ldots & \ldots & \ldots 163\end{array}$

$\begin{array}{llllll}\text { Epistle XIII. ... } & \ldots & \ldots & \ldots & \ldots & 166\end{array}$

$\begin{array}{lllllll}\text { Conclusion } & \ldots & \ldots & \ldots & \ldots & \ldots & 188\end{array}$

Appendix A. Examples of certain characteristic words and expressions found in the Laws which have analogies in the Epistles

Appendix B. Parallel passages in the Dialogues

... 197

Appendix C. Chronological Table ... ... 199 $\begin{array}{lllllll}\text { Index } & \ldots & \ldots & \ldots & \ldots & \ldots & \ldots 201\end{array}$ 



\section{PREFACE.}

No apology is needed for one more attempt to solve the problem of the authorship of the Platonic Epistles. Any addition to our scanty knowledge of Plato's life and his relations with his contemporaries is valuable in a high degree.

The present condition of the problem is stated in my general introduction. The plan of this essay is to treat each Epistle, as far as possible, separately - a necessity of criticism which cannot be said to have been wholly observed by previous writers. A considerable amount of my argument necessarily consists in the upholding or refuting of the arguments of others, but I have endeavoured not to carry this to excess.

Subjective expressions of opinion, and vague generalities I have steadfastly avoided; my arguments are based on cumulative evidence, the force of which, I may be pardoned for saying, can only be appreciated by careful consideration, on the part of readers, of what may at first appear trivial points.

Cambridge,

R. HACKFORTH.

5th January, 1913. 


\section{LIS'T OF AU'IHORI'IIES.}

The principal works consulted are the following:

Adam, Rudolf. Ueber die platonischen Briefe (in Archiv für Geschichte der Philosophie, N.F. xvi., 1910).

Ast, $F$. Lexicon Platonicum.

Campbell, Lewis. Sophist and Politicus of Plato (Introduction). On Plato's Use of Language

(in Jowett and Campbell's Republic, vol. ii). Grote, George. History of Greece, vol. x, xi. Plato and the other Companions of Socrates. Karsten, H. T. Commentatio Critica de Platonis quae feruntur Epistulis. (Trajecti ad Rhenum, 1864).

Meyer, Ed. Geschichte des Alterthums, vol. v. Raeder, Hans. Ueber die Echtheit der platonischen Briefe (in Rhein. Mus., vol. 61, 1906).

Reinhold, H. De Platonis Epistulis (Quedlinburg, 1886).

Richards, Herbert. The Platonic Letters (in Class. Rev., xiv, 1900).

Riddell, James. Digest of Platonic Idioms (in his edition of the Apology, 1867).

Ritter, Constantin. Plato's Gesetze (1896), Neue

Untersuchungen über Platon (1910).

Steinhart, Karl. Platon's Briefe (1866). (In Müller and Steinharts, Plato, vol. viii.) Susemihl, Franz. Griechischen Litteratur in der Alexandrinerkeit, vol. ii.

Note. - I regret that Prof. A. E. Taylor's article on Epistle VII., in Mind, July, 1912, came into my hands too late to be made use of. 


\section{GENERAL INTRODUCTION.}

THE establishment of a genuine canon has long been the attempt of Platonic scholars. Except in the case of works definitely referred to by Aristotle, we are dependent for external evidence upon the testimony of Diogenes Laertius, living in the third century A.D. or later: and he does not pretend to have certain knowledge on the point. $\mathrm{He}$ had, for example, doubts as to the Epinomis (iii. 37). Allian (V.H. viii. 2) speaks in a similar way of the Hipparchus. Diogenes has, however, preserved (iii. 60-6r) the arrangement of Plato's writings made by a contemporary of Tiberius named Thrasyllus, who divided them into tetralogies. In the last tetralogy are included thirteen Epistles, which are evidently identical with those that have come down to us. ${ }^{1}$ Diogenes also records an arrangement in trilogies made by Aristophanes of Byzantium, one of which is given as Crito, Phaedo, Epistles. The question at once arises whether the I 3 Epistles known to Thrasyllus

I. With the five Epistles xiv-xviii added in Hermann's text from various sources, I am not concerned. No one supposes these genuine. Diogenes indeed speaks of one Epistle as $\pi \rho \grave{s}$ A A while our text gives $\pi \rho \partial ̀ s$ A But this is clearly a slip. 
were identical with the Epistles known to Aristophanes.

There is really no evidence to show that this is the case. Grote, indeed, believed it to be so: he contends strongly for the authority of the whole Thrasylean canon: but it is generally admitted that he did not prove his case, though no doubt Thrasyllus followed Aristophanes to some extent. But however this may be, even Aristophanes is separated by more than a hundred years from Plato-a long enough time for spurious works to become attached to Plato's name. Grote would remove this difficulty by supposing that the genuine works of Plato would have been carefully preserved and set apart in the library attached to the Academy. But that such a library existed is an assumption, which Gomperz indeed claims to have disproved. ${ }^{1}$

It may be doubted whether the earliest disciples of the Academy would have set such store by Plato's writings as Grote supposed: certainly Plato would not himself have encouraged their careful preservation, if we may judge from his low opinion of the written word as expressed in the Phaedrus and the Seventh Epistle.

Moreover, the authorities of the hypothetical Academic Library have no more right to be regarded as above suspicion than other possible

I. In his Plat. Aufsätze, a work which I have been unable to procure. 
forgers : on the contrary, they might be specially tempted in that direction, and specially able from their position to impose both on members of the school and outsiders.

These few considerations are enough to show that the Platonic Corpus, as it has reached us, does not carry with it any exceptional stamp of authenticity: and that the Epistles have just as much or as little à-priori claim to be authentic as any dialogue not quoted by Aristotle, such as the Protagoras.

There is, however, a consideration which at once differentiates the position of the Epistles from that of the Dialogues, namely the certainty that the forging of letters was a widespread practice throughout the Alexandrian period. The best account of these spurious letters is probably that given in Susemihl's Griechischen Litteratur in der Alexandrinerkeit, ii, pp. 579-599, and the letters themselves are collected in Hercher's Epistolographi Graeci. The great mass of the compositions in Hercher no one supposes to be genuine, but certain individual letters, e.g., of Isocrates and Aristotle still have their champions. The reason for the forgeries was doubtless that mentioned by Galen (xv. Iog Kühn), and first brought to light in Bentley's Phalaris, namely the desire to gain money by selling them to the rival libraries of Alexandria and Pergamum.

No widespread attention seems to have been 
given to this branch of literature until the appearance of the Dissertation upon Phalaris in I697. Since then the tendency has been to regard all ancient letters as spurious with little or no examination: and it is only within recent years that a reaction in favour of a more critical method has set in.

On the whole the Platonic Epistles have been less suspected than most. A short account ${ }^{1}$ may now be given of such criticism as they have had.

In the first place, that doubt was thrown in antiquity on Ep. xii. appears from the note $\dot{\alpha} \nu \tau \iota \lambda \epsilon^{\prime} \gamma \epsilon \tau \alpha \iota \dot{s}$ ơ $\Pi \lambda \alpha \dot{\tau} \tau \omega \nu o s$ appended thereto in three MSS. (Burnet's A.Z.O.) In the so-called

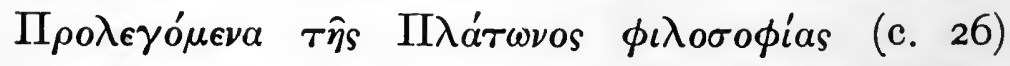
it is said that Proclus rejected the letters $\delta \iota \dot{a}$ rò

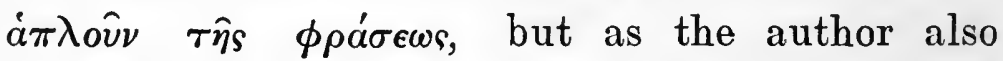
remarks that Proclus rejected the Republic and

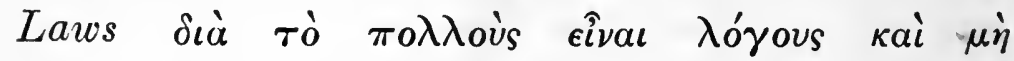
$\delta \iota \alpha \lambda o \gamma \iota \kappa \hat{\omega} s$ $\gamma \epsilon \gamma \rho a ́ \phi \theta a \iota$ we need not attach very great importance to the statement. These are the only indications, so far as I know, of any doubt felt about the Platonic authorship in antiquity: Dionysius of Halicarnassus, who has sometimes been cited as holding the letters to be spurious, merely suggests that they are rather $\delta \eta \mu \eta \gamma o \rho i a l$ than real letters, not thereby implying any opinion as to authorship. A list of writers who

I. This account is based upon Susemih1 (op. cit.) and Raeder's article presently to be named. 
refer to or quote from them may be found in Odau's dissertation mentioned infra p. II. Amongst them are Cicero, who quotes v, vii, viii, ix, and Plutarch who makes a large use, often quoting passages verbatim of iv, vi, vii, viii, xiii.

After the Renaissance doubts seem to have arisen as to Ep. xiii, and Ficinus omits it from his translation. It was rejected in 1678 (twenty years before Bentley's Phalaris) by Cudworth, the Cambridge Platonist, who thought the sentence in

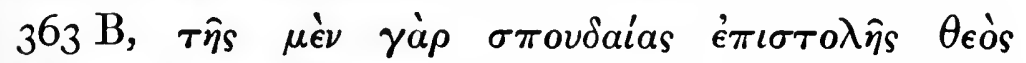

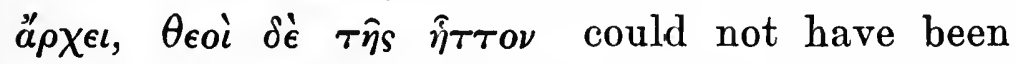
written by such a polytheist as was Plato, but must have been the work of a Christian forger.

Bentley does not appear to have undertaken a regular examination of the Epistles, but judging from his reference to ii. (Phalaris Ed. Wagner, p. 55I) and his defence of xiii. against Cudworth's conjecture (Remarks upon a late Discourse of Free-Thinking, c. 46) he regarded them as genuine.

The first attack on the letters as a whole was made by Meiners in 1782 . He attacks in particular ii, xi, and xiii : his arguments were partly answered by Tennemann. Morgenstein (1794) held vii, Boeckh and Grimm (1815) iii, vii and viii, as genuine.

A thorough-going attack was made in 1816 by Ast (Platon's Leben und Schriften, 504 sqq.). This is the earliest work known to the present 
writer. Ast's criticisms of the Platonic canon in general were extraordinarily subjective, and his treatment of the Epistles is less argument than abuse. He accuses the writer or writers of 'plumpe Ruhmredigkeit,' 'Abgeschmacktheit,' 'affektirte Mystik,' 'Weitschweifigkeit,' 'Dunkelheit und Verworrenheit' and the like. Some of these charges may be well founded but Ast did little to substantiate them.

More serious seems to have been the work of Socher, which appeared in I820. Recognising the apologetic tone of vii and viii., the most important letters, he suggested that they were composed by members of the Academy shortly after Plato's death, with the design of defending his actions as a practical politician at Syracuse. Stallbaum (1827) seems inclined to believe in vii. In 1835 Salomon assigned the greatest importance and antiquity to iii, vii and viii, but without believing them genuine. K. F. Hermann in I839 while partially agreeing with Socher regarded vii as ' an authentic document for Plato's inward and outward biography,' and Uberweg in I86I pronounced practically the same judgment. Wiegand (I859), going further than these, believed that the substance of vii came from Plato, but that it was edited and put in epistolary form by a member of the school; the other letters he regarded as of later date.

All thirteen are defended as Platonic by Grote 
(Hist. of Greece, x, pp. 603 sqq.; Plato and the other Companions of Socrates, i, 220 sqq.: the former work appeared in 1852, the latter in 1865). Criticising Ast, Grote remarks "the proper conclusion from his premises appears to me to be that Plato wrote letters which, when tried by our canons about letter writing, seem awkward, pedantic, and in bad taste." But apart from merely impressionistic judgment Grote bases his opinion on the inclusion of the Epistles in the Thrasylean canon, for the genuineness of the whole of which he contends. This, as I have indicated, is insecure argument. Grote's chief service in the matter is that he has incorporated information given in Epp. vii and viii into his History, thus helping to show how those epistles make a coherent picture not discrepant with our knowledge of Plato's life derived from other sources.

It will be seen that down to this time no scholar had attempted an adequate criticism of all the Epistles, though many had put forward judgments more or less substantiated. The general tendency was clearly in favour of vii and against the rest.

In 1864 appeared a Commentatio critica de Platonis quae feruntur Epistolis by H. T. Karsten, the first piece of really important criticism, and the earliest work of which detailed account is taken in the present Essay. It is, as a later critic has remarked, "a veritable arsenal" of objections 
to the Platonic authorship. Karsten rejects in the most decided terms the authenticity of all thirteen letters, though he devotes the greater part of his space to iii, vii and viii. The thesis he maintains is that "Antiquissimam esse vii, hanc veluti principium et exemplum fuisse ceteris: proxime cum hac cohaerere viii (ad Dionis amicos) et iii (ad Dionysium), tum ii (ad Dionysium) et iv (ad Dionem), deinde Epp. ad diversos $\mathbf{v}$, vi, ix, $\mathbf{x}$. Ab his voluntate dissentire duas reliquas ad Dionysium (i et xiii), denique prorsus ineptas esse xi et xii."

This work is curiously uneven in merit: the author has certainly noted a number of important points, both on the side of subject-matter and on that of language. He is, however, obviously under the influence of Ast, and his criticism is largely prejudiced thereby, particularly in his judgments as to sentiments which he deems unworthy of the philosopher, and language which he deems unplatonic.

He /as done much service in drawing attention to parallel passages, both between different letters (especially ii, iii and vii) and between the letters and the Dialogues. But unfortunately he has never faced the question of the difference between genuine echoes and conscious imitation, which is a particularly important question in regard to ii and iii. His treatment, again, of the philosophical interlude in vii is quite inadequate: and, 
as to language, he is obviously insufficiently acquainted with Plato's later style, particularly as exemplified in the Laws.

If he had written four years later, after the publication of Lewis Campbell's edition of the Sophist and Politicus, he might have produced a far more valuable work. Nevertheless his dissertation remains one of the most considerable writings on the Epistles down to the present day; and has been largely used by later commentators.

Two years later (I 866) appeared Steinhart's German translation of the letters (except vii), with a General Introduction and Special Notes and introduction to each letter. (This is included in vol. viii of Müller and Steinhart's Plato.) It is curious that Steinhart does not appear to have known Karsten's work, though he also rejects the Epistles in toto. He is a good deal less prejudiced than Karsten, and his work contains much that is valuable, especially in regard to the letters which I hope to show spurious. He has, however, little to say on the question of language, reserving his criticism for general sentiments and style. The notes are particularly useful in historical matters. He believes that greater weight attaches to the Syracusan letters, which may have been compiled from genuine Platonic remains by disciples of the second generation. The other letters he assigns to the later Alexandrian period.

After these two works criticism seems to have 
been silenced for many years. Campbell's work above mentioned had a very important bearing on the question, owing to his careful researches on the marked alteration in style in the later dialogues. It should have become obvious that the language of the Epistles, if genuine, might be expected to resemble that of the Parmenides, Sophist, Politicus, Philebus, Timaeus, Critias, and Laws rather than that of the Symposium and Republic, seeing that no letter purports to be earlier than 366, when Plato was already over 60. But no writer seems to have been impressed by this consideration (probably because Campbell's work was long unknown in Germany) until C. Ritter published his Platonische Untersuchungen in I888. Basing his judgment on minute stylistic considerations, such as the use of particles, he boldly declared (p. 105) that "The whole diction of the letter (i.e., vii) is precisely that of the Laws." He hints guardedly at the possibility of iv, $v$ and viii being genuine, and even ii, ix and $x$ he regards as not certainly spurious. All these judgments were based on stylistic affinity with the Laws. Meanwhile Christ in his Platonische Studien $^{1}$ (1885) defended Ep. xiii, though strangely enough he rejected vii and viii.

In I886 appeared a short work by $H$. Reinhold, attempting to prove the authenticity of the whole

I. I have not been able to find a copy of this work. 
collection. Although this writer has ably discussed certain objections, almost all on the historical side, yet he certainly does not prove all that he claims; his discussion is very largely confined to vii and viii.

In $1896 \mathrm{C}$. Ritter edited the Laws, and took occasion in a short appendix to reiterate his belief in vii and viii, with the important exception of a large section in vii, which he believed to be interpolated. He added further arguments to his previous stylistic observations.

Fr. Blass, in his Attische Beredsamkeit (iii, 2, ${ }_{3}^{8} 8$ sqq.) and his paper in Rhein. Mus., vol. 54, expresses his belief in the genuineness of all apparently except $\mathrm{i}$ and xii : but he hardly claims to be a special student of this subject. Another opinion, incidental but to my mind of great weight, is that of E. Meyer in vol. v. of his Geschichte des Alterthums (1902). Meyer's judgment is of course based on historical considerations and therefore is of most consequence in regard to vii and viii: he implies, however, a belief in ii, iii, iv, v, vi, ix, xiii. His most important references to the letters are confined to unobtrusive footnotes, but they are most valuable for realising the situation presupposed in vii and viii.

In $1906, M$. Odau, published a dissertation (Quaestiones de Pl. epistula septima et octava) attempting to prove that vii and viii really form 
one letter, which has been separated into two as the result of extensive interpolation. His work is somewhat incoherent and to my mind entirely unconvincing.

Reference should also be made to two short papers, by Rudolf Adam in Archiv für Geschichte der Philosophie (N.F. xvi), and by H. Richards in Classical Review (1900). ${ }^{1}$ This latter, the only piece of set criticism in English that I know of, hardly professes to be more than a statement of opinion. The author brings forward a number of the most obvious objections against the Epistles, taking them over for the most part from Karsten and Steinhart. He is perhaps the first writer freely to admit the large platonic character of the language in the more important letters.

The last two criticisms which have appeared call for more detailed notice. I refer to the two papers by Hans Raeder in Rhein. Mus. (1906) and the last chapter (Die dem Plato und Speusippos zugeschriebenen Briefe) of C. Ritter's Neue Untersuchungen über Platon (München I9Io).

Of Raeder's papers, which defend all except Ep. i, the first (pp. 427-47I) deals chiefly with language, and is by far the more valuable. $\mathrm{He}$ first assigns dates to the Epistles, as far as possible, on internal evidence, with the result that ii and xiii appear considerably earlier in composition than the rest (excluding vi, ix, $x$, xii, to

I. Now included in his Platonica (I9II). 
which he cannot assign dates, and leaving $\mathrm{i}$ out of account as plainly spurious). He then attacks the question of Hiatus, following the lead of Blass and Janell, who had recently proved that in the later dialogues of Plato the Hiatus is consciously avoided. The result of his computation is that just those two Epistles, ii and xii, which were seen to be the earliest, fail to show avoidance of Hiatus.

Obviously this conclusion, if valid, is most important. In estimating its value it will be convenient to transcribe part of the table given by Raeder (p. 442).

(For the distinction between "zulässige" and "fehlerhafte" Hiatus see his page 44I):-

\begin{tabular}{|c|c|c|c|}
\hline Epistle. & $\begin{array}{l}\text { No. of pages } \\
\text { (Didot). }\end{array}$ & $\begin{array}{l}\text { Faulty Hiatus } \\
\text { (Fehlerhafte). }\end{array}$ & $\begin{array}{l}\text { Average of } \\
\text { Faulty Hiatus } \\
\text { on each page. }\end{array}$ \\
\hline I. & 0.6 & 4 & $6 \cdot 67$ \\
\hline II. & $3^{\circ} 4$ & 93 & $27^{\circ} 35$ \\
\hline III. & 34 & 10 & $2^{\circ} 94$ \\
\hline IV. & 099 & 14 & I 5.56 \\
\hline V. & $0 \cdot \overline{6}$ & 2 & 333 \\
\hline VI. & $0^{\circ} 9$ & 2 & 2.22 \\
\hline VII. & $20^{\circ} 0$ & I 84 & $9^{\circ} 20$ \\
\hline VIII. & $3^{\circ} 9$ & 34 & $8 \cdot 72$ \\
\hline IX. & $0^{\circ} 4$ & 3 & $7 \cdot 50$ \\
\hline X. & 0.15 & o & $0^{\circ} 00$ \\
\hline XI. & 0.6 & 6 & $10^{\circ} 00$ \\
\hline XII. & $0^{\circ} 2$ & 9 & $45^{\circ}$ oo \\
\hline XIII. & $2 \cdot 9$ & 86 & $29^{\circ} 66$ \\
\hline
\end{tabular}




\section{I4 AUTHORSHIP OF PLATONIC EPISTLES}

Now if we cut out from this table all letters occupying less than one page (Didot) ${ }^{1}$ we are left with the following averages:-

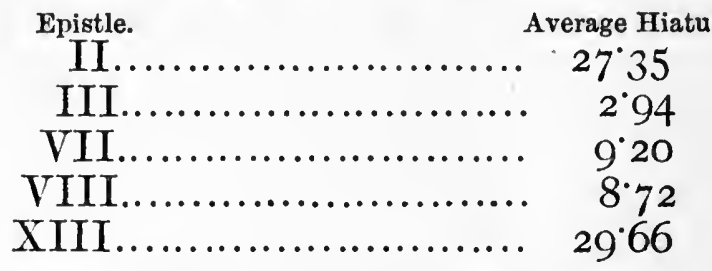

and adding those of more than $\frac{2}{3}$ page:-

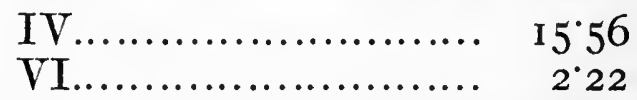

From this it may fairly be argued that iii, vi, vii, viii on the whole avoid Hiatus. ii and xiii on the whole do not.

This, however, is not enough. What Raeder failed to note was that these Hiatus are not always evenly distributed throughout the Epistle in question. For example, in Hermann's text Ep. ii occupies 5 complete pages and 2 fractions of pages. On the complete pages the number of Hiatus is respectively $15,25,19,8,8$.

In iii, out of ro Hiatus 3 occur within 6 lines (Hermann). In the complete pages of vii the numbers are: $-3,4,4,1,3,5,3,4,3,3,7$, II, 7 , $7,3,4,5,5,4,8,8,3,6$, І $3,6,6,8$, o, $7,8,6,8$. In viii, $2,6,7,6,6,3$. In xiii the numbers are fairly constant.

It is evident that we cannot say more than that some Epistles (notably iii, vii, viii) usually avoid from.

I. Raeder admits that these are too short to argue 
Hiatus, while others (viz., ii and xiii) usually do not avoid it. Now these two letters, ii and xiii, are certainly not enough to bear the weight of Raeder's argument as to early date. The fluctuations in ii show that the writer could avoid Hiatus when so inclined, while as to xiii its wholly unliterary style must be taken into account: it is more of a purely private communication than any other and would not, I think, have avoided Hiatus had it been written in 35I instead of in 366 .

My general opinion is that clear cases of conscious avoidance of Hiatus may be used as a presumption or slight ${ }^{1}$ confirmatory evidence, in the case of Epistles which on other grounds we see reason to attribute to Plato: this will be the case with iii, vii and viii. But the negative evidence of non-avoidance cannot be allowed any weight.

The rest of Raeder's first paper is concerned with vocabulary. He first collects words not found in the Dialogues, and endeavours to show that they are not really unplatonic. $\mathrm{He}$ next gives a valuable list of 245 rare words common to the Epistles and the Dialogues, of which ${ }_{13} 8$

I. "Slight": since the considerations adduced on p. 34 as to lexical affinity apply to Hiatus-avoidance also : and moreover it was becoming fashionable, as is well known, in the time of Demosthenes and the later Orators. Nevertheless if letters such as iii., vii. and viii. had shown no sign of this literary characteristic, we should have had considerable ground for rejecting them. 
occur in the Laws and many in Sophist, Politicus, Philebus, Timaeus, Critias. Herein he was of course following the lead of Lewis Campbell's and Ritter's stylistic researches. After this he attempts to confirm the affinity to the later Dialogues by means of what is more definitely termed Stylometry. Collecting from Schanz, Lina and Ritter certain small points of style which these writers had adduced as characteristic of late Platonism, and which are best known to English readers from Lutoslawski's Origin and Growth of Plato's Logic, he draws up a stylometric table (p. 465) under 20 heads. This table does not seem to prove very much : in any case it is very dangerous to use its results otherwise than for each letter taken separately. Many of the occurrences are too few in number to bear the weight of any inference. Nevertheless in a few points, notably in regard to vii and viii I have found a discriminating use of the table helpful. A great deal more useful are the parallels adduced between certain commonly recurring expressions in the Epistles and the Laws, which are not treated stylometrically. ${ }^{1}$ These go a long way towards proving the authenticity of iii, vii and viii, particularly the two latter, but the other Epistles they hardly affect at all.

It is convenient here to state our general position in regard to Stylometry (used technically in

I. See Appendix A. 
Lutoslawski's sense) as applied to these Epistles. Whatever may be its value in regard to comparisons between Dialogues I believe it is best avoided here. In the first place, a large number of Lutoslawski's 500 points are necessarily peculiar to the dialogue form of question and answer. Secondly, one would naturally expect the style, so far as it can be reckoned by measurement of definite "points," to differ in a writer's letters from that of his dialogues. I say advisedly, so far as it can be reckoned by measurement: it is in the less measurable points that resemblances are likely to occur, and do as a matter of fact occur.

The dangers that beset the stylometrician may be illustrated from a comparison of C. Ritter's views, based on Stylometry, as expressed in I888, and the same writer's views, based on general grounds, in I9IO. In his earlier work (Plat. Untersuchungen), as was said above, he includes ii, $v$, ix as being possibly genuine, and as to xiii he remarks that its style is more closely related to the Republic than to the Laws, which is tantamount to admitting that on purely stylometric grounds he would hold it genuine. In the Neue Untersuchungen, on the other hand, he rejects xiii with great vehemence, ii with hardly less, $\mathrm{v}$ and ix also quite decidedly. He admits that "In the Epistles the form of Question and Answer is almost wholly absent, and such instances as do 
occur are mostly so short that we lack the necessary foundation for a comparison of diction."

Raeder's second paper (pp. 5I I-542) is much less valuable. It is indeed helpful on some historical difficulties, but less so than Meyer's earlier work. The philosophical passages of ii and vii are inadequately treated.

Finally we come to Ritter's work in the Neue Untersuchungen. A very large part of this is concerned with Ep. xiii, against which he has collected most previous objections and added many others. These will be noticed in the proper place. In regard to the other letters he upholds the authenticity of iii, vii, viii, and tentatively of iv and $x$, while rejecting definitely ii, vi, xii.

Apart from the discussion on xiii and the incidental remarks on other letters, Ritter criticises somewhat elaborately Raeder's general stylistic discoveries which we have noticed above.

The Hiatus question indeed he dismisses in few lines as deceptive : with regard to Raeder's list of rare words, he seeks to minimise its force by contending that it is only to be expected that any word, rare or common, should occur in the latest group of dialogues rather than elsewhere, owing to the fact that that group (viz., Soph. Pol. Phil. Tim. Crit. Laws) embraces more than one-third of the genuine compositions of Plato (p. 35o). In regard to every word, in particular every word of rare occurrence, we ought to expect it to occur 
more frequently in the late dialogues than in those of the second or the first group.

Proceeding on this axiom he compares, by means of two tables, the number of times of occurrence, in each group of Dialogues, of all Raeder's rare words for each letter with the number of times they might be expected to occur in that group, taking into consideration its extent. The groups which he now uses are four in number, viz. :-

Group $\mathrm{I}_{2}$. Crat. Symp. Phaedo. ... 200 pages

Group $\mathrm{I}_{1}$. Hipp. II, Laches, Charm.

(Hermann).

Crito. Protag. Euthyphro Apol.

Gorg. Euthyd. Meno. Lysis.

Menex. $\quad \ldots \quad \ldots \quad \ldots \quad 467$ pages

Group II. Rep. Theaet. Phaedrus

Parmenides $\ldots \ldots \ldots \quad \ldots \quad \ldots \quad 537$ pages Group III. Soph. Pol. Phï. Tim.

Critias. Laws $\quad \ldots \quad \ldots \quad \ldots \quad 775$ pages

I may quote his results for Ep. ii and Ep. xiii, which are the most important for our purpose.

(a) Number of occurrences of Raeder's Rare Words :-

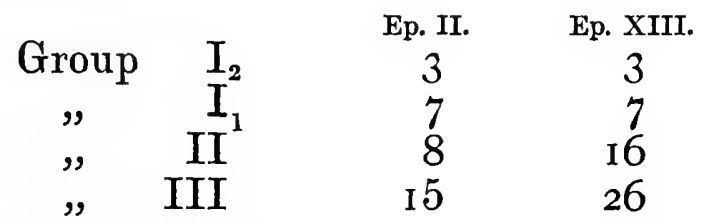

(b) Number of instances in which these words might have been expected to occur, taking into account the extent of each group. ${ }^{1}$

I. These figures are found by using $I_{2}$ as unit and multiplying by $2 \cdot 2,2 \cdot 4,3 \cdot 5$ for Groups $I_{1}$, II, III respectively. 


$\begin{array}{cccc} & & \text { Ep. II. } & \text { Ep. XIII. } \\ \text { Group } & \text { I }_{1} & 6 \cdot 6 & 6 \cdot 6 \\ , & \text { II } & 7 \cdot 2 & 7^{\circ} 2 \\ , & \text { III } & \text { IO'5 } & \text { I0.5 }\end{array}$

i.e., in Ep. ii we have nearly 5 more instances of rare words also occurring in Group iii, than would be expected, in Ep. xiii I6 more instances; which points to a late date for both these Epistles (as against Raeder's early date).

I have thought it worth while to refer to this ingenious treatment of the question, because it is a good example of the perverse use of stylometry. The fallacy consists in applying the treatment to rare words, whereas it is only applicable to common words. If a writer, e.g., uses the word "periphery" once in a book of 200 pages, it is quite unreasonable to expect him to use it three times in a book of 600 pages, or twice in a book of 400 pages. Still less reasonable would be the expectation if the three books were written at widely different ages. Yet another fallacy appears when we reflect that we are not concerned with the occurrence, or opportunity for occurrence, of one single rare word but of rare words in general.

I may illustrate this fallacy by Ep. ii. The 3 rare words of Ep. ii, which occur in Group $i_{2}$ are

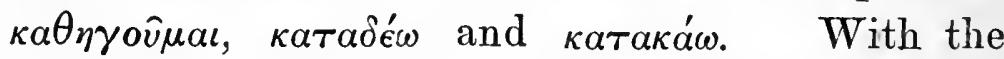
exception of $\kappa a \tau a \delta \delta^{\prime} \omega$ the I5 rare words of Ep. ii which occur in Group iii are all different words from these. Now it might conceivably be argued 
(the argument would not involve this particular fallacy) that because the proportion of $i_{2}$ to iii is that of $\mathrm{I}$ to 3.5 ( 2 to 7 ) therefore the actual words $\kappa \alpha \theta \eta \gamma о \hat{v} \mu \alpha \iota, \kappa \alpha \tau \alpha \delta^{\prime} \epsilon \omega, \kappa \alpha \tau \alpha \kappa a ́ \omega$ ought to occur 3.5 oftener in Group iii than in Group $i_{2}$. But it is obviously ridiculous to argue that certain other words ought to occur 3.5 times oftener. The fallacy arises of course from overlooking the fact that "rare words" form an artificial class whose members possess only the property of rarity in common.

Raeder's list of 245 rare words is, however, open to serious criticism on the ground of their arbitrary selection. In the following table I have endeavoured, by the use of such lexica as exist, to determine more accurately which of the words may reasonably be claimed as characteristically Platonic: my result is that the 245 words are reduced to $126 .{ }^{1}$

I. The table gives the number of occurrences in those Attic prose authors for whom indices or lexica have been compiled. I have used von Essen for Thucydides, Sauppe for Xenophon, Preuss for Demosthenes and Isocrates, Forman for Andocides, Lycurgus and Dinarchus, Bonitz for Aristotle. Sauppe unfortunately is admittedly incomplete, but I do not think this has any appreciable effect on the statistics. The figures in the column headed "Other Orators" are taken from Reiske, and do not, of course, include Hyperides. I have not filled in this column when the figure for Demosthenes is high, nor have I recorded the figure o in this column or in that of Xenophon.

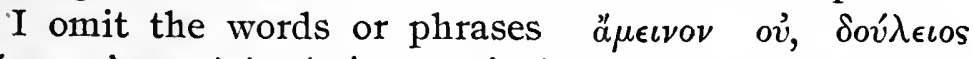

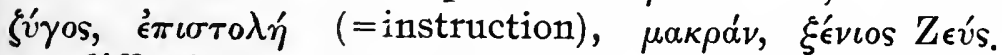
as difficult of verification : also $\delta \alpha \dot{\phi} \phi \nu \eta$ and $\theta \dot{\omega} \rho \alpha \dot{\xi}$ as non-evidential. 


\section{AUTHORSHIP OF PLATONIC EPISTLES}

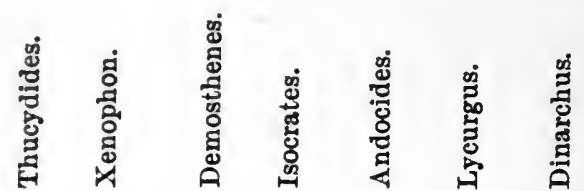

$\dot{\alpha} \beta$ ov $\lambda \epsilon^{\prime} \omega$ - - 0

$\dot{a} \delta \circ \xi_{i \alpha} \quad-\quad-\quad I$

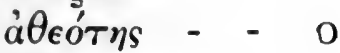

$\dot{a} \theta \epsilon \rho \alpha \pi \epsilon v \sigma i \alpha$ - $\mathrm{o}$

aivıruós - - o

$\dot{\alpha} \lambda \iota \tau \eta \rho \iota \dot{\delta} \eta \bar{s}-0$

$\dot{\alpha} \lambda \lambda$ о

$\dot{\alpha} \lambda$ oría - - I

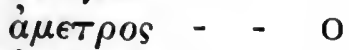

$\dot{a} \mu \nu \eta \hat{\mu} \mu \omega \nu$ - $\quad-0$

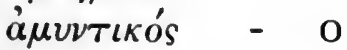

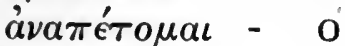

$\dot{\alpha} \nu \alpha \sigma o \beta \dot{c} \omega$ - 0

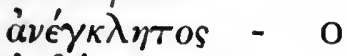

$\dot{\alpha} \nu \theta \dot{a} \pi \tau o \mu \alpha \iota-2$

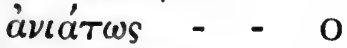

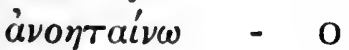

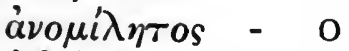

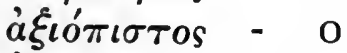

ämai $\rho \omega$ - - freq.

$\dot{\alpha} \pi \dot{\alpha} \dot{\xi}_{i o s}-\quad \mathrm{o}$

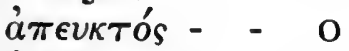

$\dot{\alpha} \pi \lambda \dot{\eta} \sigma \tau \omega s \quad-\quad 0$

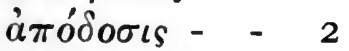

$\dot{\alpha} \pi \dot{\theta} \theta \epsilon \sigma \iota \varsigma$ - $\quad 0$

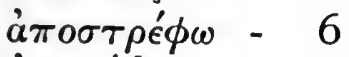

$\dot{\alpha} \pi 0 \sigma \dot{\omega} \xi \omega$ - $-\quad$ o

I 0

o

$\begin{array}{lll}1 & 0 & 0\end{array}$

$\begin{array}{lll}0 & 0 & 0\end{array}$

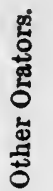

$\begin{array}{llll}0 & 0 & 0 & 0\end{array}$

$\begin{array}{lllll}0 & 0 & 0 & 0 & 0\end{array}$

$\begin{array}{lllll}0 & 0 & 0 & 0 & 0\end{array}$

$\begin{array}{lllll}0 & 0 & 0 & 0 & 0\end{array}$

$\begin{array}{lllll}0 & 0 & 0 & 0 & 0\end{array}$

$\begin{array}{lllll}\text { I } & \text { I } & \text { O } & \text { O } & \text { O }\end{array}$

$\begin{array}{lllll}0 & 0 & 0 & 0 & 0\end{array}$

$\begin{array}{lllll}0 & 0 & 0 & 0 & 0\end{array}$

$\begin{array}{lllll}0 & 0 & 0 & 0 & 0\end{array}$

$\begin{array}{lllll}0 & 0 & 0 & 0 & 0\end{array}$

$\begin{array}{lllll}0 & 0 & 0 & 0 & 0\end{array}$

$\begin{array}{lllll}0 & 2 & 0 & 0 & 0\end{array}$

$\begin{array}{lllll}0 & 0 & 0 & 0 & 0\end{array}$

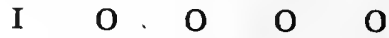

$\begin{array}{lllll}0 & 0 & 0 & 0 & 0\end{array}$

$\begin{array}{lllll}0 & 0 & 0 & 0 & 0\end{array}$

$\begin{array}{lllll}4 & 0 & 0 & 0 & \text { I }\end{array}$

$\begin{array}{lllll}6 & 0 & 0 & 0 & \text { I }\end{array}$

$\begin{array}{lllll}0 & 0 & 0 & 0 & 0\end{array}$

$\begin{array}{lllll}0 & 0 & 0 & 0 & 0\end{array}$

$\begin{array}{lllll}0 & 5 & 0 & 0 & 0\end{array}$

$\begin{array}{lllll}\text { I } & 3 & 0 & 0 & 0\end{array}$

$\begin{array}{lllll}0 & 0 & 0 & 0 & 0\end{array}$

$\begin{array}{lllll}3 & \text { I } & 0 & 0 & \text { I }\end{array}$

Ant. I

à $\pi \rho \epsilon \in \epsilon \epsilon \iota$ - $\mathrm{O}$

$\begin{array}{llllll}3 & \mathrm{I} & 0 & 0 & 0 & 0\end{array}$

Ant. I

$\begin{array}{llllll}0 & 0 & 0 & 0 & 0\end{array}$

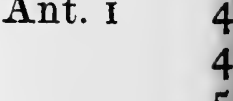

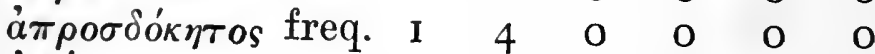

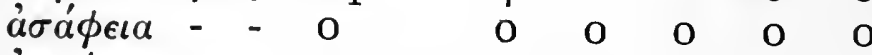
$\begin{array}{lllllllll}\dot{a} \sigma \chi \dot{\eta} \mu \omega \nu & - & 0 & \mathrm{I} & 0 & 0 & 0 & 0 & 0\end{array}$ $\stackrel{\alpha}{\alpha \tau \tau \omega} \boldsymbol{-}-\mathrm{O}$

$\begin{array}{lllll}\text { I } & 0 & 0 & 0 & 0\end{array}$

Aesch. 23

I. Abbreviations : Ant. $=$ Antiphon, Isae $=$ Isaeus, Aesch. $=$ Aeschines, Lys. $=$ L ysias . 


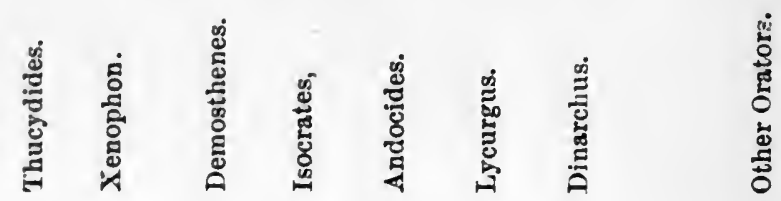

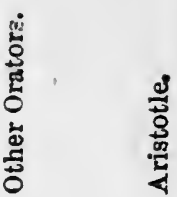

$\dot{\epsilon} \mu \beta \rho \imath \theta \dot{\gamma}$ s - 0

$\dot{\epsilon} \mu \mu \epsilon \lambda \dot{\eta} s$ - - $\mathrm{O}$

$\begin{array}{lllll}0 & \text { I } & 0 & 0 & 0\end{array}$

$\begin{array}{lllll}0 & 0 & 0 & 0 & 0\end{array}$

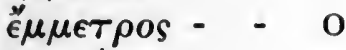

$\dot{\epsilon} \mu \pi \epsilon i \rho \omega s$ - 0

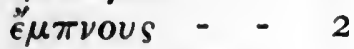

$\dot{\epsilon} \mu \pi о \rho \epsilon \dot{o} \mu \mu \iota$ - I

$\ddot{\epsilon} \nu \delta \epsilon \iota \xi \iota s \quad-\quad 0$

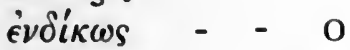

évıávoเos - - 4

$\dot{\epsilon} \nu \tau o \lambda \dot{\eta}$ - -0

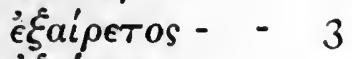

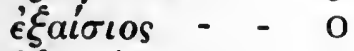

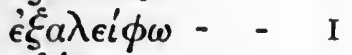

$\dot{\epsilon} \xi \dot{\xi} \pi \tau \omega-\quad$ - 0

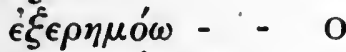

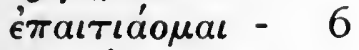

є̇ $\alpha \alpha \alpha \dot{\gamma} \gamma \omega$ - - 2

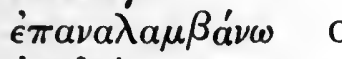

$\dot{\epsilon} \pi \iota \delta \epsilon \eta \dot{s}$ - - 0

$\dot{\epsilon} \pi \iota \delta \eta \mu \epsilon^{\prime} \omega$ - - I

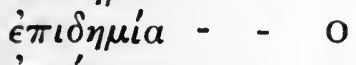

є̇лı́́єкєıа - - 4

є்

$\epsilon \pi \iota \epsilon \bar{\lambda} \dot{s}$ - -3

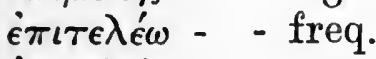

є̇

I I

o

$\begin{array}{lll}0 & 0 & 0\end{array}$

$\begin{array}{lllll}2 & 0 & 0 & 0 & 0\end{array}$

$\begin{array}{lllll}0 & 0 & 0 & 0 & 0\end{array}$

$\begin{array}{lllll}I & 0 & 0 & 0 & 0\end{array}$

freq. $0 \quad 5 \quad 0 \quad 0$

$\begin{array}{lllll}0 & 0 & 0 & 0 & 0\end{array}$

$\begin{array}{llllll}\text { I } & \text { I } & \text { O } & \text { O } & 0 & 0\end{array}$

$\begin{array}{lllll}0 & 0 & 0 & 0 & 0\end{array}$

freq. $2 \quad 2 \quad$ I $\quad 0$

$\begin{array}{llllll} & \mathrm{O} & \mathrm{O} & \mathrm{O} & \mathrm{O} & \mathrm{O}\end{array}$

freq. $5 \quad 4 \quad$ I $\quad$ O

$\begin{array}{lllll} & 0 & 0 & 0 & 0\end{array}$

I freq. 0 o 0 o

30000

$\begin{array}{llllll}3 & 2 & \text { I } & 0 & 0 & 0\end{array}$

4
5

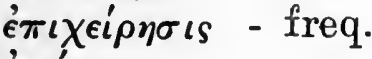

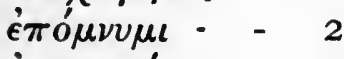

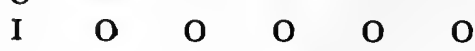

$\begin{array}{llllll}I & I & 0 & 0 & 0 & 0\end{array}$

freq. 2 I $O \quad I$

Ant. 2

I

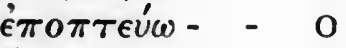

єै $\rho \rho \omega$ - - - 0

$\begin{array}{lllll}0 & 0 & 0 & 0 & 0\end{array}$

7 freq. 0 o 0

5 o 00 o 0

$\begin{array}{lllll}3 & 2 & 0 & 0 & 0\end{array}$

3 freq. O I 0

$\begin{array}{lllll}0 & 0 & 0 & 0 & 0\end{array}$

o

o

0

5

I

o

4

o

4

o

Ant. I 0

Aesch. 3

I

o

2

0

freq.

0 freq. freq.

$\begin{array}{lllll}0 & 0 & 0 & 0 & \text { I }\end{array}$

$\mathrm{O}$

2

$\begin{array}{lllll}0 & 0 & 0 & 0 & 0\end{array}$

$\begin{array}{lllll}0 & 0 & 0 & 0 & 0\end{array}$

erarpela - - I 1

o

єтацрєі́a - - I

єưarís - - - 0

$\epsilon \dot{v} \delta o \xi i a$ - - 0

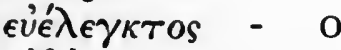

єنं日éws - - - 3

$\begin{array}{lllll}2 & 5 & \mathrm{I} & \mathrm{O} & \mathrm{O}\end{array}$

$\begin{array}{lllll}I & 0 & 0 & 0 & I\end{array}$

freq. $4 \quad 0 \quad 0 \quad 0$

$\begin{array}{lllll}0 & 0 & 0 & 0 & 0\end{array}$

freq. $0 \quad 0 \quad 0 \quad 0$ 


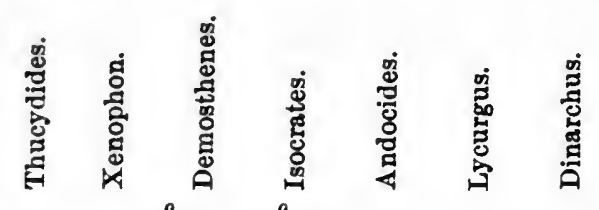
$\kappa \eta \delta \epsilon \sigma \tau i ́ s$ - 0 freq. freq. I I 0

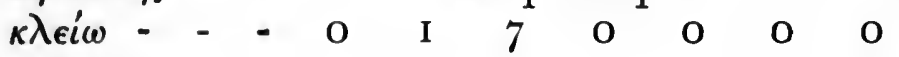
$\kappa \lambda \hat{\eta} \sigma \iota s-\quad-\quad 0$

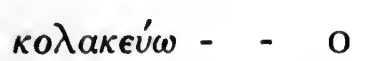

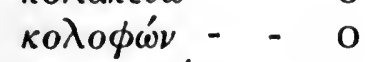
$\lambda \alpha \iota \mu \alpha \rho \gamma i ́ a-0$ $\lambda \alpha \mu \pi \omega$ - - 0

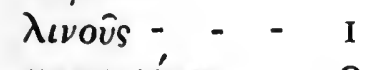

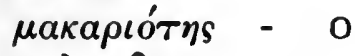
$\mu a \lambda a \kappa \hat{\omega} s$ - $\quad$ I $\mu \alpha \lambda \theta a \kappa i \xi o \mu a \iota \quad 0$ $\mu \epsilon \iota$ \}óvws - 4 $\mu \in \tau \alpha \sigma \tau \alpha \sigma \iota \mathrm{s}-4$ не́тоХо - - 2

\begin{tabular}{|c|c|c|c|c|c|}
\hline & freq & 6 & I & O & I \\
\hline & 0 & o & 0 & o & 0 \\
\hline$I(?)$ & 0 & o & o & o & 0 \\
\hline & 0 & o & 0 & 0 & 0 \\
\hline & o & O & o & 0 & O \\
\hline & 0 & 0 & 0 & 0 & 0 \\
\hline 2 & 0 & O & o & o & -0 \\
\hline & 0 & 0 & 0 & o & 0 \\
\hline & $\mathbf{O}$ & 3 & 0 & 0 & 0 \\
\hline I & I & 2 & I & O & O \\
\hline & I & 0 & O & 0 & O \\
\hline
\end{tabular}

$\mu \eta \kappa \dot{\nu} \nu$ - -6

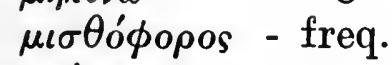

$\begin{array}{lllll}0 & 2 & 0 & 0 & 0\end{array}$

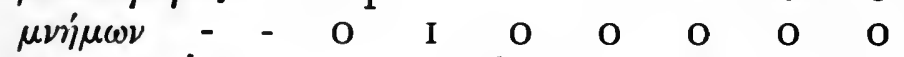
$\mu \nu \eta \sigma \iota к \alpha \kappa \epsilon^{\prime} \omega$ - 2 I freq. $3 \quad 8 \quad 0 \quad$ o

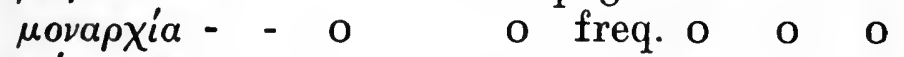

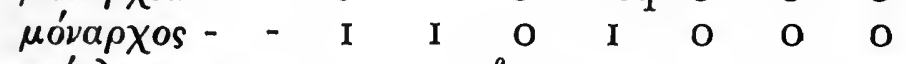
vaúk $\lambda \eta p \rho s$ - 2 freq. I 0 I 0

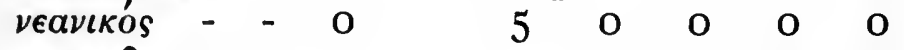

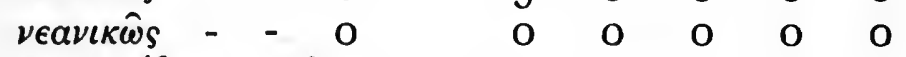

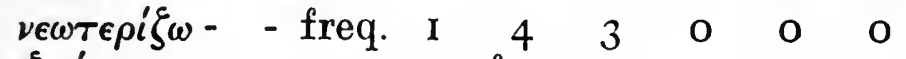

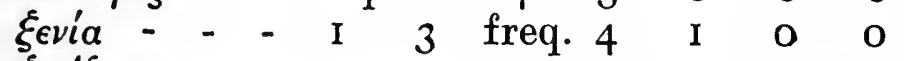

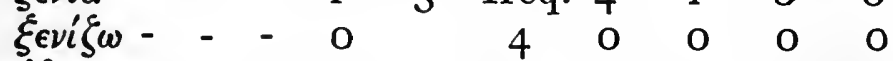
ôveios - - 0

$\begin{array}{lllll}4 & 0 & 0 & 0 & 0 \\ 0 & 0 & 0 & 1 & 0\end{array}$

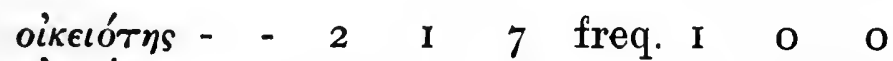

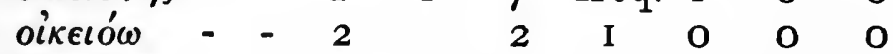

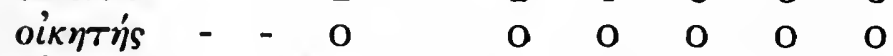

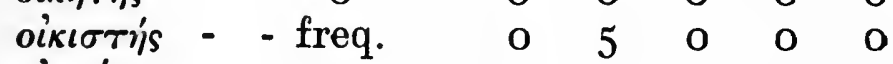

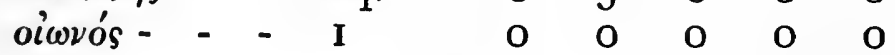

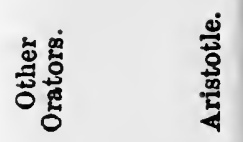

I

Aesch. I 4 Ant. I

3

o

I

3

I

I

3

0

o

Lys. I freq. Ant. I I Lys. I

5
3
2
0
freq.
6
0
7
1
5
freq.

Aesch. I 0 Isae. 27 Lys. I 


\begin{tabular}{|c|c|c|c|c|c|c|c|c|c|c|}
\hline & & 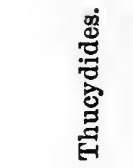 & 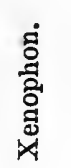 & 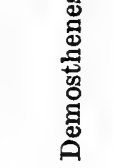 & 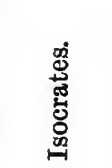 & 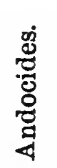 & 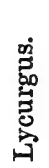 & 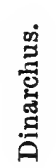 & $\begin{array}{l}\text { 姞总 } \\
\text { 总 }\end{array}$ & 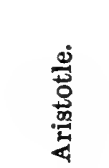 \\
\hline ó $\lambda \epsilon^{\prime} \theta \rho \iota$ s & $-\quad-$ & -0 & & o & o & 0 & $\mathrm{O}$ & $\mathrm{o}$ & & 0 \\
\hline 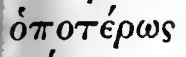 & & $-\quad I$ & & I & I & 0 & 0 & o & & freq. \\
\hline та́укакоs & & -0 & & $\mathrm{O}$ & o & 0 & 0 & o & & I \\
\hline$\pi \alpha \lambda \iota \nu \omega \delta \delta^{\prime} \alpha$ & & $-\quad 0$ & & $\mathrm{O}$ & I & $\mathrm{o}$ & $\mathrm{O}$ & o & & o \\
\hline$\pi \alpha \rho \alpha \kappa \epsilon \prime \lambda \epsilon 乙$ & $\nu \mu \alpha-$ & o & & $\mathrm{O}$ & o & $\mathrm{O}$ & $\mathrm{O}$ & 0 & & o \\
\hline$\pi \alpha \rho \alpha \kappa \iota \nu \delta v$ & $\nu \nu \in v^{\prime} \omega$ & 2 & & 0 & o & 2 & o & 0 & Aesch. I & o \\
\hline$\pi \alpha \rho \alpha \kappa o u ́ \omega$ & & $-\quad 0$ & & $\mathrm{o}$ & o & o & o & $\mathrm{O}$ & & 0 \\
\hline$\pi \alpha \rho a \pi o \delta \iota$ & $\xi \omega-$ & $-\quad 0$ & & $\mathrm{O}$ & o & $\mathrm{o}$ & $\mathrm{O}$ & 0 & & o \\
\hline$\pi \alpha \rho \alpha \phi \rho о \sigma$ & Túvn- & $\mathrm{O}$ & & o & $\mathrm{O}$ & 0 & $\mathrm{O}$ & $\mathrm{O}$ & & o \\
\hline$\pi \hat{\alpha} v \lambda \alpha$ & - & I & I & o & o & o & 0 & 0 & & 6 \\
\hline 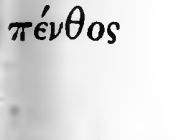 & - & $-\quad 0$ & & 3 & o & $\mathrm{O}$ & $\mathrm{O}$ & o & $\begin{array}{c}\text { Isae. I } \\
\text { Ant. I } \\
\text { Lys. I }\end{array}$ & I \\
\hline$\pi \epsilon \rho \iota \alpha ́ \pi \tau \omega$ & & -0 & & 2 & o & o & 0 & 0 & & 4 \\
\hline$\pi \epsilon \rho \iota \theta \epsilon^{\prime} \omega$ & - & -0 & & $\mathrm{O}$ & o & o & o & 0 & & I \\
\hline$\pi \epsilon \rho \iota \phi \alpha \nu \omega \hat{s}$ & & $-\quad I$ & & freq. & o & I & 0 & o & & \\
\hline$\pi \epsilon \rho \nu \sigma \iota \nu o ́ s$ & & $-\quad 0$ & I & 0 & o & o & 0 & o & & 2 \\
\hline$\pi \lambda a ́$ ávos & - & $-\quad 0$ & I & I & 3 & 0 & 0 & 0 & & o \\
\hline$\pi \circ \delta \eta \gamma^{\prime} \epsilon$ & $-\quad-$ & $-\quad 0$ & & o & O & 0 & 0 & o & & o \\
\hline$\pi о \mu \pi \dot{\eta}$ & $-\quad-$ & -7 & & 7 & o & $\mathrm{I}$ & o & $\mathrm{o}$ & & o \\
\hline 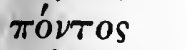 & - & 6 & & $\mathrm{O}$ & o & $\mathrm{o}$ & $\mathrm{O}$ & 0 & & o \\
\hline 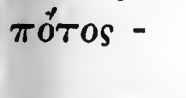 & - & $-\quad 2$ & & I & 2 & 0 & 0 & 0 & $\begin{array}{c}\text { Aesch. } 2 \\
\text { Lys. I }\end{array}$ & I \\
\hline$\pi \rho о \alpha \gamma о \rho \epsilon$ & $\dot{v} \omega-$ & -5 & I & 4 & 2 & o & $\mathrm{O}$ & o & & 4 \\
\hline$\pi \rho \circ a ́ \gamma \omega$ & $-\quad-$ & - freq. & & freq. & freq. & I & I & o & & o \\
\hline$\pi \rho \circ \iota^{\prime} \xi-$ & $-\quad-$ & $-\quad 0$ & & freq. & I & I & o & I & & 2 \\
\hline$\pi \rho о \kappa \rho i ́ \nu \omega$ & - & I & & freq. & freq. & o & 0 & o & & 4 \\
\hline$\pi \rho \circ \pi \eta \lambda \alpha \kappa$ & $x^{\prime} \xi \omega-$ & 2 & I & freq. & o & 2 & $\mathrm{O}$ & 0 & & 4 \\
\hline$\left.\pi \rho o \sigma \beta_{\iota} \alpha ́\right\}$ & $o \mu \alpha \iota$ & I & & 0 & o & o & $\mathrm{O}$ & 0 & & I \\
\hline$\pi \rho o ́ \sigma \rho \eta \sigma \iota$ & & $\mathrm{O}$ & I & o & $\mathrm{O}$ & $\mathrm{O}$ & $\mathrm{O}$ & $\mathrm{o}$ & & o \\
\hline$\pi \rho o ́ \sigma \phi о \rho c$ & & 6 & & I & $\mathrm{O}$ & 0 & $\mathrm{O}$ & o & & 2 \\
\hline$\pi \rho \circ \sigma \phi v \eta \dot{s}$ & & 0 & & 0 & o & $\mathrm{O}$ & 0 & 0 & & 2 \\
\hline$\pi \rho \circ \sigma \phi \dot{o} о \mu$ & ual - & -0 & & o & o & o & o & 0 & & freq. \\
\hline$\pi \tau \alpha{ }^{\prime} \omega$ - & $-\quad-$ & -7 & I & 4 & 0 & 0 & $\mathrm{O}$ & $\mathrm{o}$ & & 4 \\
\hline$\stackrel{\rho}{\rho} a \theta v \mu i ́ a$ & $-\quad-$ & $-\quad I$ & & freq. & freq. & o & I & I & & 3 \\
\hline 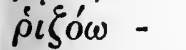 & $-\quad-$ & -0 & I & 0 & o & 0 & $\mathrm{O}$ & 0 & & 2 \\
\hline
\end{tabular}




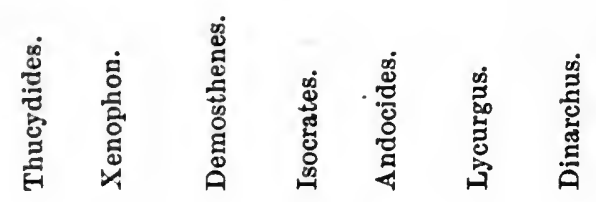

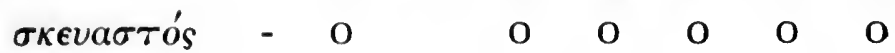

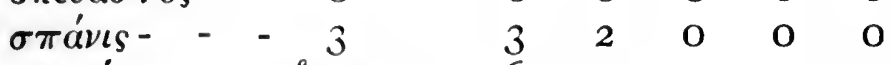

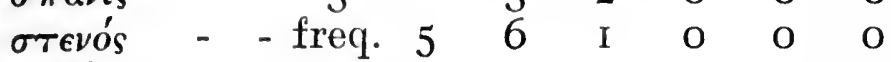
$\sigma v \xi^{\prime} \dot{\alpha} \omega$ - - $\quad$ - 0

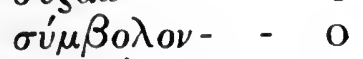
$\sigma v \mu \mu \alpha \dot{\rho} \tau v \rho-0$ $\sigma \nu \mu \pi \alpha \rho \alpha \kappa \alpha \lambda \epsilon \dot{\epsilon} \omega \quad$ о $\sigma v \mu \pi \epsilon \rho a i v \omega$ - 0 $\sigma \nu \mu \pi o \lambda \epsilon \mu \epsilon^{\prime} \omega$ - freq.

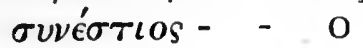
$\sigma \nu \nu \epsilon \phi \epsilon^{\prime} \lambda \kappa \omega-\mathrm{o}$

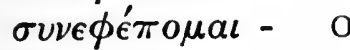

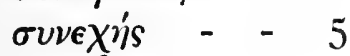

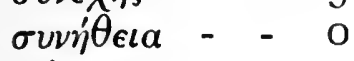
$\begin{array}{lllll}4 & 0 & 0 & 0 & 0\end{array}$ freq. I I $O \quad O$ $\begin{array}{lllll}0 & 0 & 0 & 0 & 0\end{array}$ $\begin{array}{lllll}0 & 0 & 0 & O & I\end{array}$

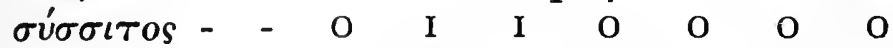
$\sigma \phi a \gamma i^{-}$- - I freq. 4 freq. o 0 o

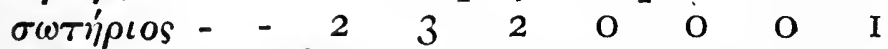

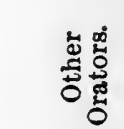
䔡 2 Lys. I 3 freq. freq. freq.

o 0 freq. $\begin{array}{lllll}3 & 2 & I & 0 & 0\end{array}$

$\begin{array}{lllll}0 & 0 & 0 & 0 & 0\end{array}$ $\begin{array}{llllll}3 & 0 & 0 & 0 & 0 & 0\end{array}$ 4 0 $\begin{array}{lllll}6 & 0 & 0 & 0 & 0\end{array}$ freq. freq. $\tau \alpha \dot{\lambda} \alpha \nu \tau o \nu$ - - freq. freq. freq. freq. 2 freq. $\tau o ́ \lambda \mu \alpha$ - - freq. freq. freq. 2 o I

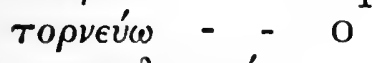

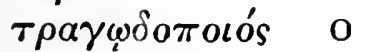

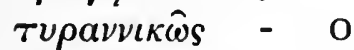
$\dot{\nu} \beta \rho \dot{\sigma} \tau \iota \kappa \hat{\omega} s-0$ iл́́ iтó $\mu \nu \eta \mu \alpha$ - 2 $\dot{v} \pi \hat{\sigma} \sigma \chi \epsilon \sigma \iota s^{-} \quad-\quad 2$ iтофаív $\phi a \iota \delta \rho u ́ v \omega$ - - $\mathrm{O}$ $\phi_{\iota} \lambda \epsilon \lambda \lambda \eta \nu$ - - 0

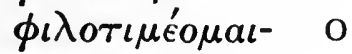
$\phi \lambda a \hat{u} \rho o s$ - -0 $\begin{array}{lllll}0 & 0 & 0 & 0 & 0\end{array}$ $\begin{array}{lllll}0 & 0 & 0 & 0 & 0\end{array}$ O $\begin{array}{lllll}0 & 2 & 0 & 0 & 0\end{array}$ freq. $O \quad O \quad O \quad 0$ $\begin{array}{llllll}I & I & O & 0 & 0 & 0\end{array}$ freq. 6 o 40 freq. freq. $\mathrm{O}$ o $\mathrm{I}$

$\begin{array}{lllll}I & 2 & 0 & 0 & I\end{array}$
$\begin{array}{llllll}I & 0 & 0 & 0 & 0 & 0\end{array}$

$$
\begin{array}{lllll}
0 & 4 & 0 & 0 & 0
\end{array}
$$
freq. freq. $0 \quad 2 \quad 0$ o фoveús - - - 0 I freq. freq. 0 o 0 фvyás - - - freq. I freq. $6 \begin{array}{llll}6 & 4 & 0 & 6\end{array}$

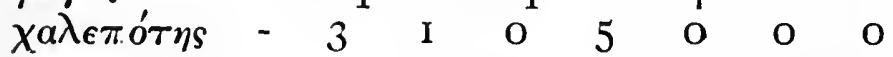

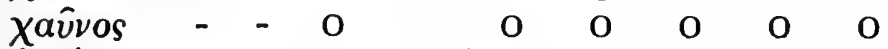

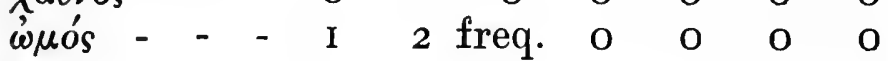

Ant. I o 5 6 freq. freq. 
The I 26 words I select as Platonic, on the basis of these statistics, are as follows, the figure appended denoting the Epistle in which the word occurs.

$A$. Thirty-two words not occurring in any of these authors:-

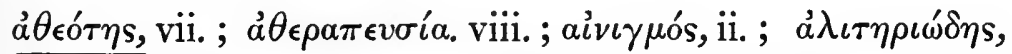

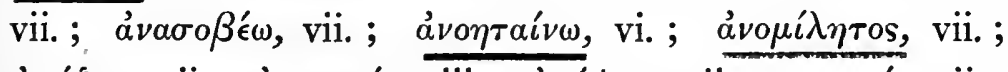

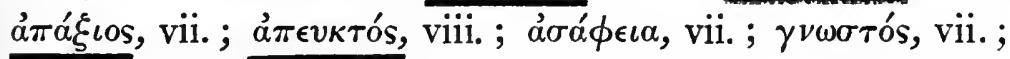

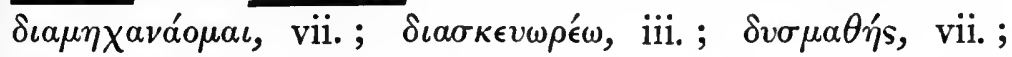

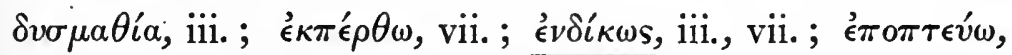

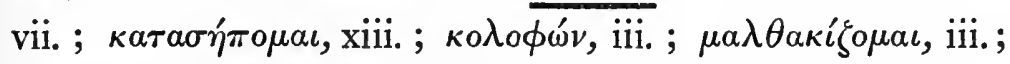

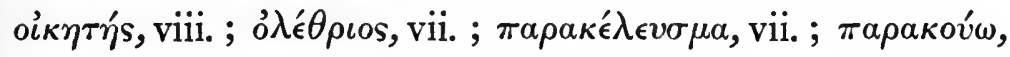

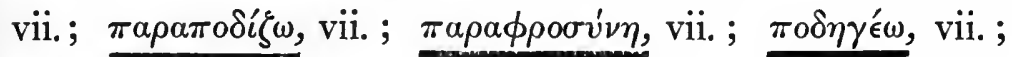

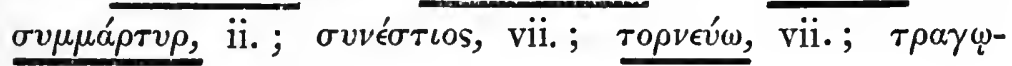

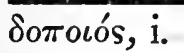

B. Ninety-four other $\operatorname{words}^{1}:-$

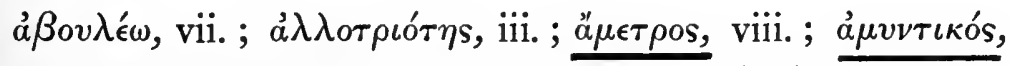

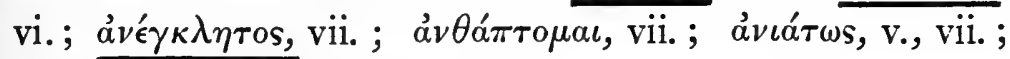

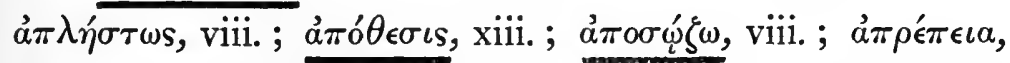

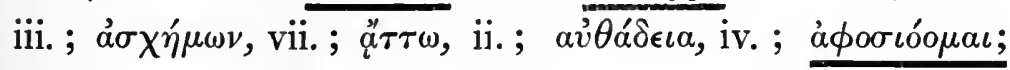

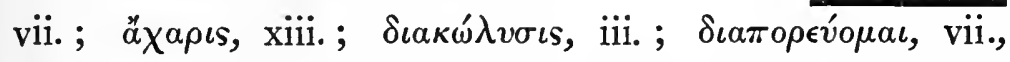

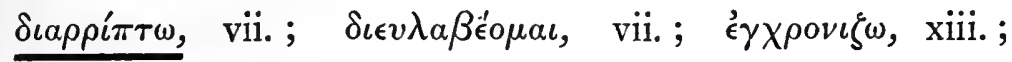

I. I have not selected these on any rigid principle, but on a combination of the total number of occurrences with the number of authors in which they occur. Each word must find its own justification by inspection. 


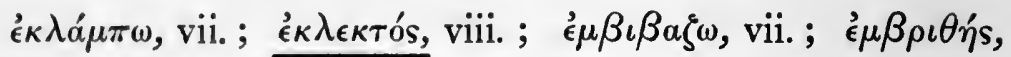

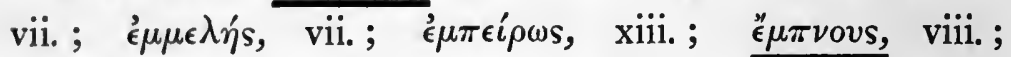

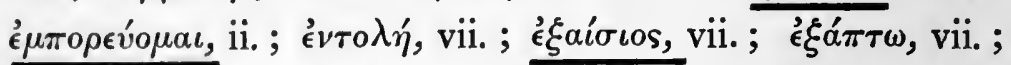

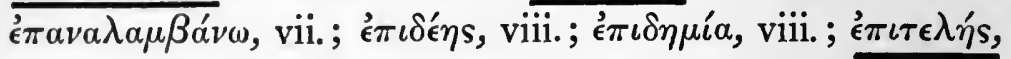

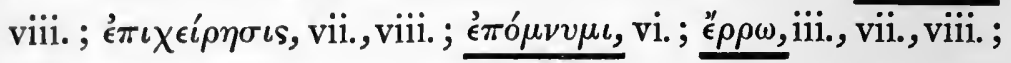

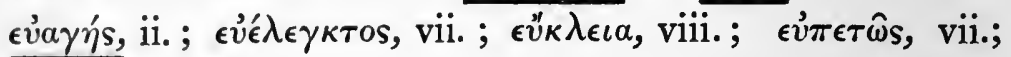

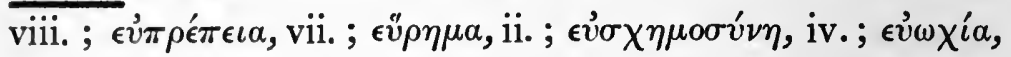

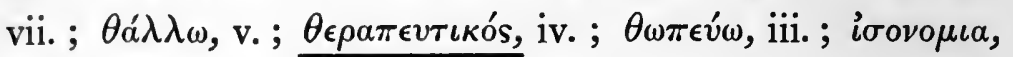
vii. ; $\kappa \alpha \theta \alpha \rho \epsilon \omega^{\omega}$, viii.; $\kappa \alpha \theta \eta \gamma^{\prime} \epsilon \rho \alpha \iota$, ii ; $\kappa \alpha \tau \alpha \delta^{\prime} \epsilon$, ii. ;

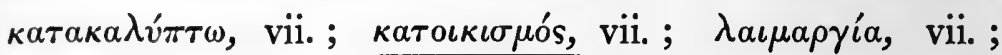

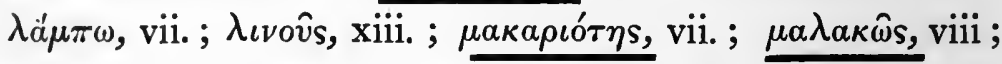

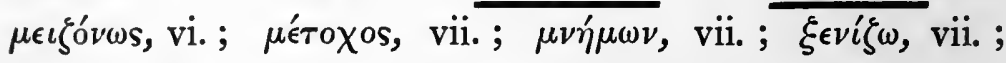

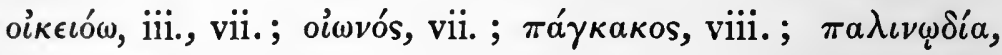

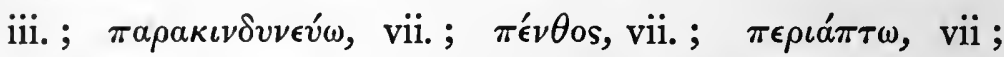
$\pi \epsilon \rho \iota \theta^{\prime} \omega$, vii. ; $\pi \epsilon \rho v \sigma \iota v o ́ s$, viii. ; $\pi \lambda \lambda^{\prime} \nu o s$, vii. ; $\pi \rho \circ \sigma \beta \iota a ́ \xi o \mu \alpha \iota$,

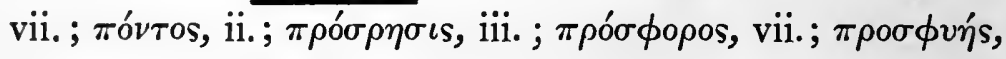

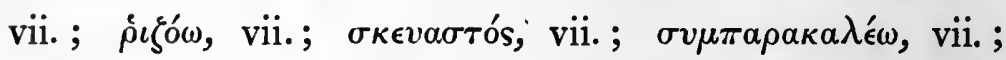

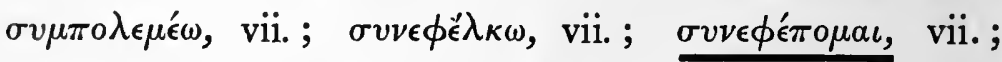

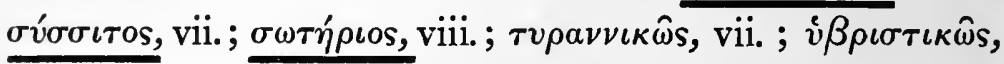

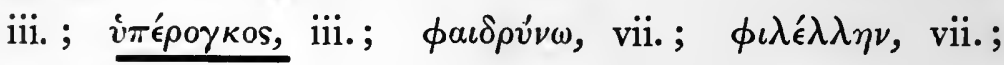
фovєús, vii.

The 38 words underlined occur, in Plato, only in the Sophist, Politicus, Philebus, Timaeus, Critias, Laws (Epinomis, Theages, the genuineness of which does not concern us as the particular words there occurring are also found in the aforementioned dialogues). 
The distribution is as follows:-

$\begin{array}{ccc}\text { Epistle. } & 126 \text { rare words. } & 38 \text { special words. } \\ \text { I. } & \text { I } & 0 \\ \text { II. } & 9 & 4 \\ \text { III. } & \text { I } 4 & 3 \\ \text { IV. } & 3 & \text { I } \\ \text { V. } & 2 & 0 \\ \text { VI. } & 3 & 2 \\ \text { VII. } & 75 & \text { I } 9 \\ \text { VIII. } & \text { I } & 9 \\ \text { IX. } & 0 & 0 \\ \text { X. } & 0 & 0 \\ \text { XI. } & \text { I } & \text { I } \\ \text { XII. } & 0 & 0 \\ \text { XIII. } & 6 & \text { I }\end{array}$

Those Epistles which show 9 or more occurrences in the first column, and 3 or more in the second, are ii, iii, vii, viii. For these we may assert lexical affinity with the later dialogues. In saying this we do not deny all affinity in the case of the remaining Epistles, but merely assert that there is apparently no evidence upon which to claim it. We cannot even, as yet, assert a greater affinity in ii, iii, vii and viii than in the rest, because these Epistles are the longest: in fact, the above investigations give us no comparative results, as between one Epistle and another. To get any such result, we must take the average occurrences per page of the 126 rare words. ${ }^{1}$ These are shown in the following table, in which the number of pages (Didot) is taken from Raeder (p. 442):-

I. In the case of the 38 words, the figures are too small for averages to have any value. 


\begin{tabular}{|c|c|c|c|}
\hline Epistle. & $\begin{array}{l}\text { Occurrence of } \\
\text { rare words. }\end{array}$ & $\begin{array}{l}\text { No. of } \\
\text { pages. }\end{array}$ & $\begin{array}{l}\text { Average } \\
\text { per page. }\end{array}$ \\
\hline I. & I & $\cdot 6$ & $1^{\circ} 6$ \\
\hline II. & 9 & $3^{\circ} 4$ & $2 \cdot 6$ \\
\hline III. & 14 & 34 & $4 \cdot I$ \\
\hline IT. & 3 & 9 & 33 \\
\hline $\mathrm{V}$ & 2 & $\cdot 6$ & 33 \\
\hline VI. & 3 & 9 & 33 \\
\hline VII. & 75 & $20^{\circ} 0$ & 37 \\
\hline VIII. & I9 & $3^{\circ} 9$ & $4^{\cdot} 8$ \\
\hline IX. & o & 0.4 & $\mathrm{o}$ \\
\hline $\mathrm{X}$ & $\mathrm{O}$ & 0.1 & o \\
\hline XI. & I & 0.6 & $I^{\circ} 6$ \\
\hline XII. & o & $0^{\circ} 2$ & 0 \\
\hline XIII. & 6 & $2^{\circ} 9$ & $2 \circ 0$ \\
\hline
\end{tabular}

iii, vii and viii appear at the head of the list. No doubt the calculating of averages in a question of rarities is of questionable utility. I would lay but little stress on the comparative result, as the difference in average between many letters is very small. What seems to me of more importance, however, is the fact that the process of averaging upholds our assertion of lexical affinity for iii, vii and viii. ${ }^{1}$

I. It would be further upheld if we take statistics in the case of Class A above (words not found in any of the authors investigated). These are the figures :-

\begin{tabular}{|c|c|c|c|c|c|}
\hline \multirow{2}{*}{ Ep. I. } & $\begin{array}{l}\text { Occurrence } \\
\text { of rare } \\
\text { words. }\end{array}$ & \multicolumn{2}{|c|}{$\begin{array}{cc}\text { No. } & \text { Average } \\
\text { of } & \text { per } \\
\text { pages. } & \text { page. }\end{array}$} & \multicolumn{2}{|c|}{$\begin{array}{ccc}\begin{array}{c}\text { Occurrence } \\
\text { of rare }\end{array} & \begin{array}{c}\text { No. } \\
\text { of } \\
\text { words. }\end{array} & \begin{array}{c}\text { Averag } \\
\text { perges. }\end{array} \\
\text { peage. }\end{array}$} \\
\hline & $1 \ldots$ & 0.6 . & & Ep. VIII. $\ldots 3 .$. & $3 \cdot 9 \ldots \cdot 7$ \\
\hline II. & 2 & $3 \cdot 4$ & $\cdot 5$ & XI. $\ldots 1 \ldots$ & $0 \cdot 6$ \\
\hline III. & 5 & $3 \cdot 4$ & $1 \cdot 4$ & XIII. ... 1 & $2 \cdot 9$ \\
\hline I. & 20 & $20^{\circ} 0$ & 1 & & \\
\hline
\end{tabular}

In this table $i$. and $x i$. appear at the head in the averages : but as the average rests on one word only, this has no significance. The striking feature here is the difference in average between ii. and iii. 
The object of all this discussion is to estimate more closely the value of Raeder's researches. It will be remembered that he claimed to have established

I. A lexical affinity between the Epistles in general and the later dialogues, especially the Laws.

2. (a) An affinity, resting on the avoidance of Hiatus between the Epistles other than ii and xiii and the late dialogues;

(b) an absence of affinity (on the same ground) between ii and xiii and those dialogues.

Our discussion has, I think, shewn that in regard to

I, this lexical affinity can only be said to exist in iii, vii and viii :

and in regard to

2, that the Hiatus-avoidance statistics, only being valid as positive, not as negative evidence, show an affinity in regard to rii, vii and viii.

The coincidence is welcome and, I believe, of some significance. Assuming these results as valid, what inference are we entitled to make as regards authenticity? We must, I fear, face the fact that no amount of affinity can afford an exact proof of Platonic authorship: but we may say that the stronger it is the more Platonic is the 
language of the letters in question: that is, either they are the work of Plato, or the forger has been very skilful. In cases where we find affinity to the later dialogues in particular, it might seem at first sight that we can infer much more; and Raeder himself certainly implies this assumption. But it should be recognised that a forger of letters purporting to belong to Plato's old age would naturally imitate the later dialogues-that is, if we suppose him to have known the chronology of the dialogues, a knowledge we have no right to assume him not to have possessed. Nevertheless, the establishment of this lexical affinity is by no means useless. For if we had not been able to establish it we must have rejected the letters out of hand: and an obvious preliminary to establishing Platonic authorship is to establish Platonic diction. It is not too much to say that lexical affinity, to the later dialogues in particular, affords us a presumption in favour of authenticity, a presumption which must be confirmed by other considerations: and on this principle the remarks on language in the following pages must be interpreted. Proof of authenticity; if proof be possible, must be sought by a detailed examination of each Epistle: and in this examination, I may now conveniently state, the presumption which we have formed in favour of iii, vii and viii will be confirmed, and these three letters I believe 
to be Platonic beyond all reasonable doubt: iv and xiii show evidence of authenticity only next to these: ix, $x$ and $x i$ must be left doubtful, chiefly because of their brevity: while i, ii, v, vi, xii are unquestionably spurious.

Such a conclusion is about what might have been expected : for it is unlikely on the one hand that Plato should not have written some such letters, owing to his connexion with Western Hellas, unlikely also that the general belief of antiquity should be quite groundless : it is only natural, on the other hand, that some forged letters should be ascribed to the great philosopher, as they were to so many others. It may fairly be said that the genuine letters are also the most interesting. We may now proceed to an enquiry into each separate Epistle. 


\section{EPISTLE I.}

The superscription of the first Epistle is given

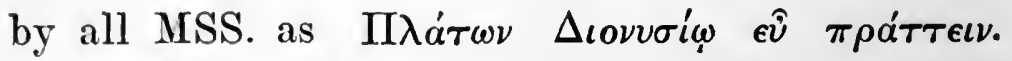
Its ascription to Dion ${ }^{1}$ instead of to Plato appears to be due originally to Ficinus, and has been since adopted by many editors, presumably because the document is not quite so inappropriate to Dion as to Plato.

Plato is represented as reproaching Dionysius for his ill-treatment: although he has protected

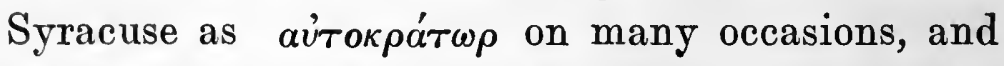
has spent so much time at the court of Dionysius, he has been treated with more insult than a beggar. The journey-money which Dionysius had given him he now returns by the bearer of the letter: it was insufficient and brought nothing but shame alike to the giver and the recipient. The tyrant may get another in future to treat as he had treated Plato. In the hour of distress that is to come he will wish he had acted otherwise-a thought which induces our writer to quote Tragedy and Lyric poetry on the advantages of friendship.

The document merits but little discussion, for

I. If the author were Dion, as Steinhart pertinently asks, why does he not write in Doric? 
whether Plato or Dion be intended as the author, it is a gross and palpable forgery, which no scholar, as far as I know, has attempted to defend. It is the single Epistle which Raeder rejects. The objections to it, which are the common property of all commentators, may be stated as follows :-

(I) That Plato should speak of himself as

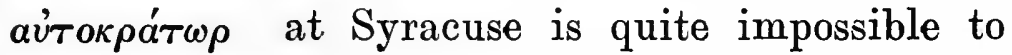
reconcile with all that we know of his sojourn there. On the other hand if we could suppose Dion to be intended as author, not only is

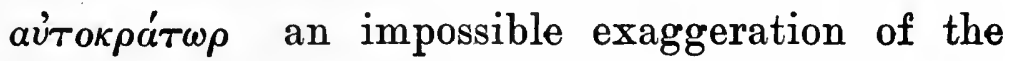
influence he possessed even under the elder

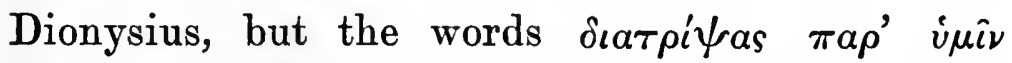

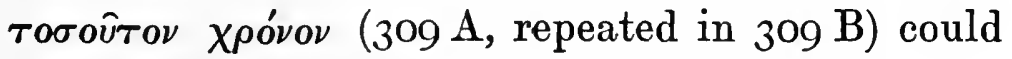
not have been used by a native of Syracuse.

(2) The attitude towards Dionysius is at variance with that shown by Plato in the later letters (iii, vii and viii), which we shall have reason to regard as genuine. This might perhaps be explained if we regard the Epistle as written in the first heat of passion after Plato's departure in 360 B.c. : but such a supposition is incompatible with the numerous poetical quotations, which strike one as frigid and forced and over-frequent. (Besides those printed as quotations in Burnet's

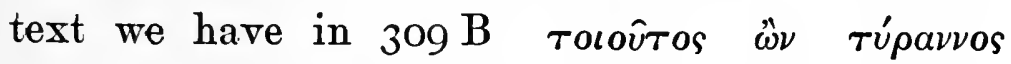

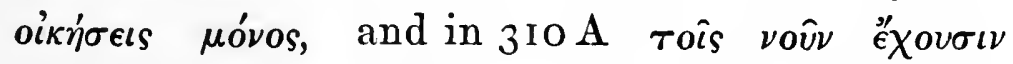

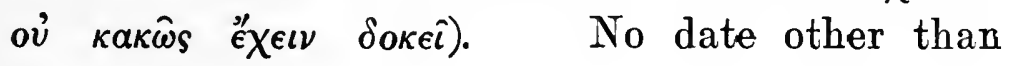


360 is possible, for Plato did not come to a complete rupture with Dionysius until his final departure from Syracuse in that year.

(3) It is improbable that either Plato or anyone

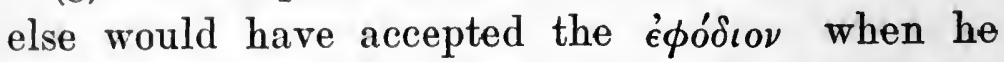
was, ex hypothesi, enraged with the tyrant, and yet have returned it shortly afterwards with the comments given in our letter. Raeder believes that the notion came to our author from Ep. vii $350 \mathrm{~B}$, where Dionysius gives Plato $\dot{\epsilon} \phi o ́ \delta \iota \alpha$ at his final departure. This is very probable and I would add that, on the supposition that Plato wrote Ep. vii, he would certainly not have there mentioned this present if, as our present letter maintains, he subsequently returned it as an insult. There will not be much doubt as to the respective claims of Ep. $i$ and Ep. vii to authenticity.

(4) In $309 \mathrm{D} \delta \iota \tau^{\prime} \iota$ is used for öтเ. No other instance of this occurs in the Platonic Epistles or Dialogues. According to Ritter it occurs in Demosthenes, but only in spurious insertions, and once in Isocrates, where (as in our passage) a repeated ő $\iota$ would have caused Hiatus.

I may perhaps point out an inaccuracy in Steinhart who remarks that according to Ep. vii "Dion was despatched from Syracuse in honourable fashion," and sees herein a discrepancy with the present Epistle. This is not so : vid. vii $329 \mathrm{c}$,

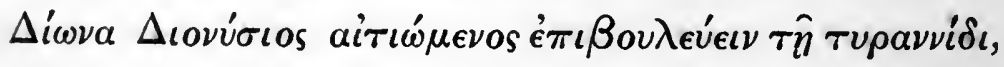




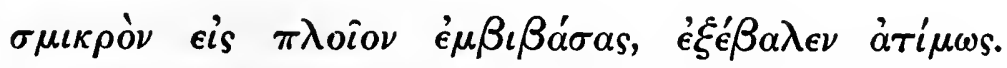
$\sigma v \nu \epsilon \theta \epsilon \lambda \omega$ and $\dot{\alpha} \pi \alpha{ }^{\prime} \nu \rho \omega \pi$ os do not occur in Plato, but there is no reason why they should not. They both belong to the vocabulary of Tragedy, which has many words in common with Plato. 


\section{EPISTLE II.}

This letter is addressed to Dionysius, and its main theme is the relations which should subsist between him and Plato. Plato denies that he or his friends have spoken ill of Dionysius, and desires that in the event of any further accusations of the kind the tyrant should communicate with him. The famous friendship of Plato and Dionysius will go down to posterity, like the friendship of other famous rulers and sages: and this thought leads the writer to a digression on the immortality which consists in fame. Plato's reason for coming to Sicily was that "philosophy might be honoured of the people," but that aim was foiled owing to the distrust of Dionysius. Does the tyrant despise philosophy, or think himself a better philosopher than Plato? He must declare himself. If he has respect for philosophy, he will honour it in the person of Plato: it is from Dionysius to Plato that honour is due, not from Plato to Dionysius.

At this point (312 D) the writer passes to metaphysics, undertaking to answer Dionysius' difficulties about "the Nature of the First Principle." But he must only speak in enigmas, lest the letter should fall into the hands of others and be understood. As the writer has at all events 
succeeded in making his explanation an enigma to us, I postpone it for subsequent discussion.

His explanation, continues our author at $3 \mathrm{I}_{3} \mathrm{C}_{5}$, has incidentally answered the question of the proper relations between the philosopher and the tyrant: for Dionysius will, by acting in accord-

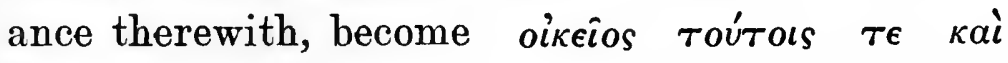
$\dot{\eta} \mu \hat{i} \nu . \quad$ As an intermediary in this philosophical correspondence they will continue to employ Archedemus: but care must be taken lest the precious cargo be endangered: for philosophy to the many is foolishness. It is only after many years' study that wisdom and truth flash out upon their pursuers: therefore is there special need of careful and accurate memory. Memory is better than writing: that is why there exists no writing of Plato's, his reputed works coming from Socrates "fashioned fair and young."

After a farewell greeting with an exhortation to Dionysius to burn the letter after frequent perusal, we have a further paragraph which forms a kind of postscript. This contains, first, a recommendation of one Polyxenus, whom Plato is sending out; secondly, Dionysius is asked to behave as a true friend to Philistion, and if possible to lend his services to Speusippus-a request in which Speusippus joins. Finally there are references to the release of "the man from the quarries" to Hegesippus and Lysiclides, of all of whom we know nothing from other sources. 
The question of date is very important in this letter. It is clear from $310 D$ that it purports to have been composed shortly after the Olympic games: and the question is between the Olympia of 364 and 360 в.c. Raeder and Reinhold, who regard the letter as genuine, give the earlier date and Ritter holds that we should have to do so if we supposed the authenticity. Grote, Karsten, and Holm are in favour of the later date, identifying this visit to Olympia with that mentioned in Ep. vii 350 B, which certainly is a reference to the celebration of 360 B.C. But the later date will not fit the situation, if we believe in the general accuracy (which no one has doubted) of the accounts given in Epp. vii and iii of Plato's relations with Dionysius. For according to those accounts Plato had completely and finally given up any hopes he had had of making Dionysius into a philosopher-king, before the end of his last visit to Syracuse (cf. especially vii $345 \mathrm{D}, \tau$ oút $\omega \nu$

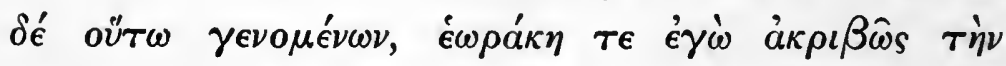

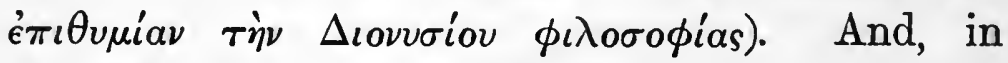
general, the attitude of Plato in this letter cannot be compatible with one who had lately gone through the experiences described at vii 348-50, iii 3 I8.

We must then suppose the date to be 364 B.C., involving another visit of Plato to Olympia in that year. A suspicion naturally arises at once that this may be due to a forger copying from 
Ep. vii. There is, however, a definite inconsistency with the supposition of this date, in 3 I $2 \mathrm{~A}$, which seems to have escaped the notice of commentators. The writer there says that his aims in his visit to Syracuse (the visit of $367-6$, ex hypothesi) were foiled owing to the distrust of Dionysius-

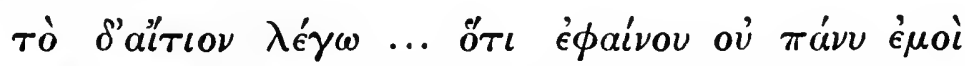

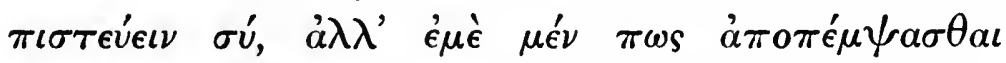

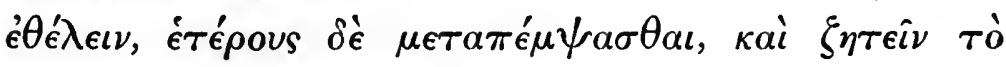

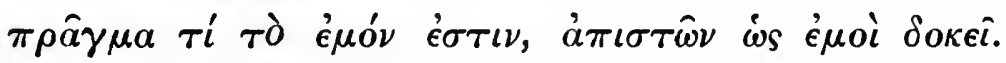
On the other hand at vii $329 \mathrm{D}$ we are told that after the banishment of Dion which occurred $\mu \eta \nu \grave{i} \sigma \chi \epsilon \delta \dot{o} \nu$ ‘ $\sigma \omega s \quad \tau \epsilon \tau \alpha \dot{\alpha} \rho \tau \omega$ after Plato's arrival in 367 B.C. Dionysius protected Plato, treating him with marked kindness and begging him to

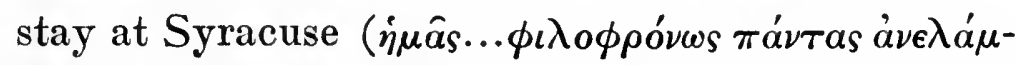

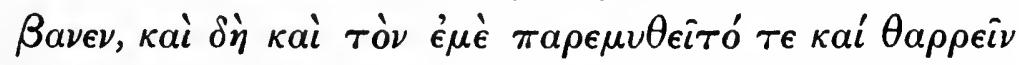

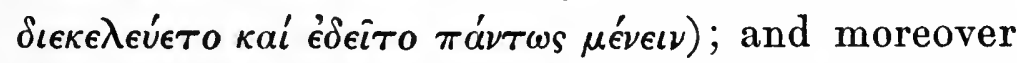
he had difficulty in getting away when he desired

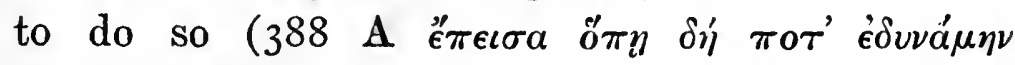

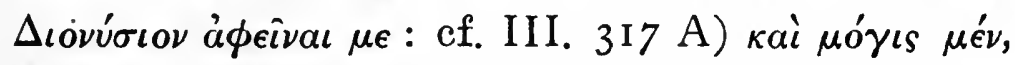

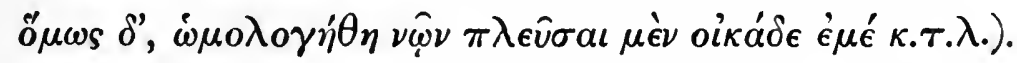

Nor is inconsistency wanting within the limits of the Epistle itself: for how, as Rudolf Adam asks, are we to reconcile the suspicion that

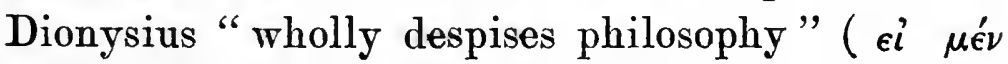

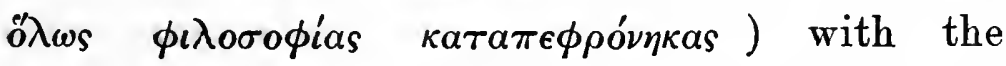
esoteric metaphysical explanations given him in 
the second half of the letter, not to mention the encomiums of $314 \mathrm{D}$ ?

At 312B ( $\left.\dot{\epsilon} \pi \epsilon \sigma^{\prime} \tau \epsilon \iota \lambda \alpha s\right)$ the writer implies that the philosopher is answering Dionysius, who has raised the question of what should be his relations with Plato: whereas in the earlier part of the letter Plato is plainly represented as raising the question himself.

In $3 \mathrm{I} 2 \mathrm{~A}$ we are told that the object of Plato's visit in 367 B.C. was that "philosophy might be honoured of the people." Not only is no such object referred to in Ep. iii and Ep. vii, but it is foreign to Plato's whole convictions (cf. especially

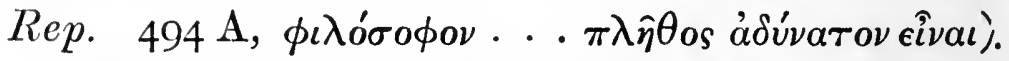

Adam further contends that our forger betrays himself through his fondness for Platonic reminiscences. We have already hinted at a possible copying from Ep. vii, and shall be confirmed in that suspicion by our examination of the metaphysical digression. But I will first give a conspectus of the reminiscences detected by Adam.

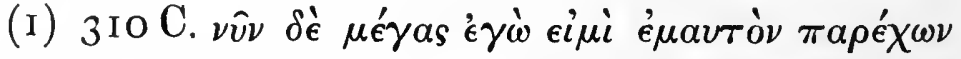

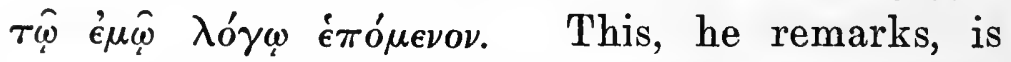
dragged in abruptly and inappropriately: he sees

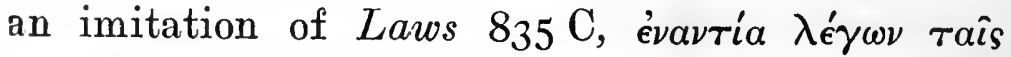

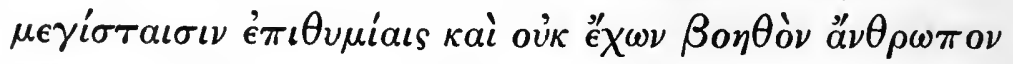

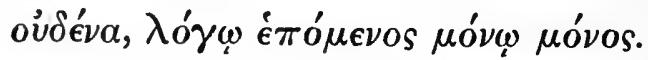

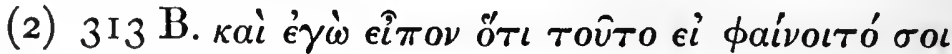

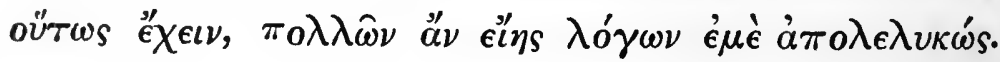




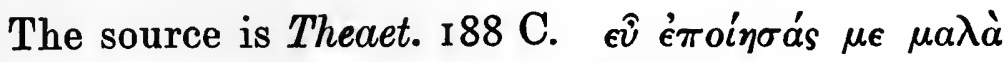

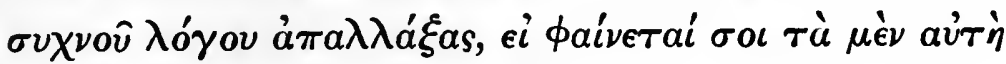

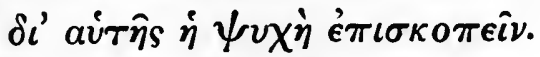

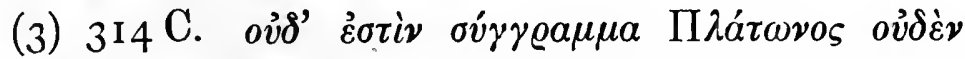
ov่ $\delta^{\prime}$ है $\sigma \tau a l$. This is copied from Ep. vii $34 \mathrm{I} \mathrm{C}$,

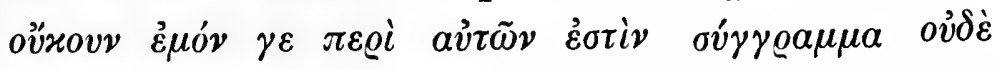

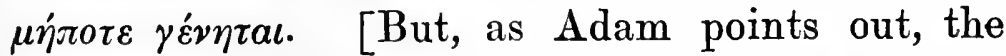

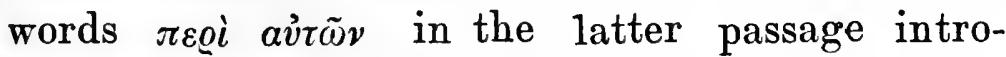
duce an important limitation, which the forger of Ep. ii has overlooked. Plato had not said that he wrote nothing at all, but that he wrote nothing explaining the nature of those $\pi \circ \lambda \lambda \dot{\alpha}$ xai $\mu \dot{\varepsilon} \gamma \iota \sigma \tau a$ which Dionysius claimed to understand. ${ }^{1}$ The explanation that the Plato of

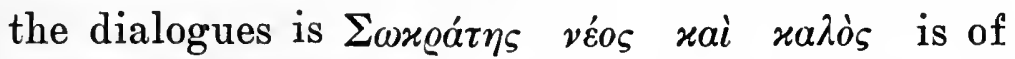
course due to this writer's own ingeniousness: it reappears, as Ritter points out in No. 15 of the so-called Socratic Epistles, which contains the

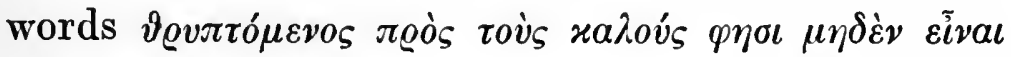

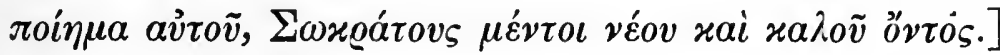

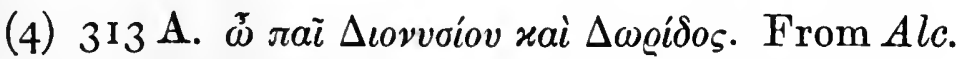

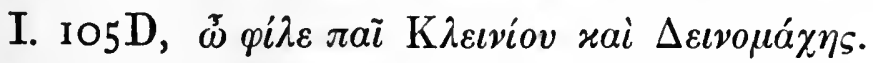

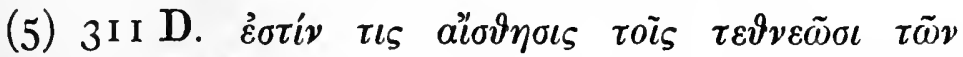

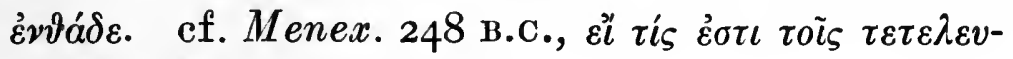

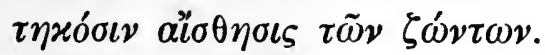

(6) 3 Iо E. हैл

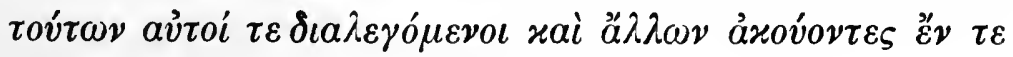

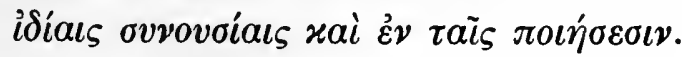

I. See pp. 59, 7 r. 
This, Adam holds, looks like a clumsy imitation

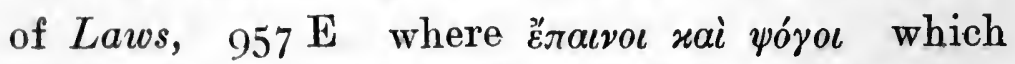

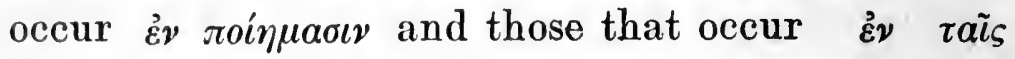

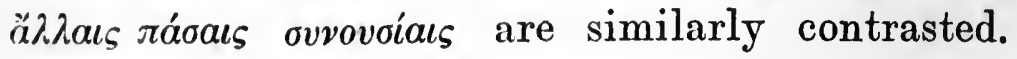
(I may add that Plato probably did not use for noinua, though a passage in the Ion (53 I D) does so).

(7) The remarks on the desire for posthumous fame seem a reminiscence of the famous passage in Symp. 208 D. Especially we should compare

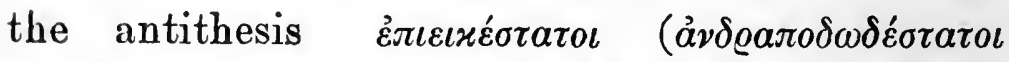

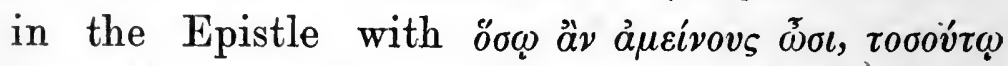
$\mu \tilde{a} \lambda \lambda o v$ in the dialogue. How fond our writer is of this antithesis is evident from the twofold repetition of it a few lines later, first inthe form

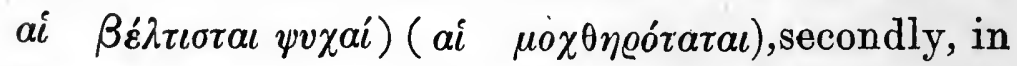

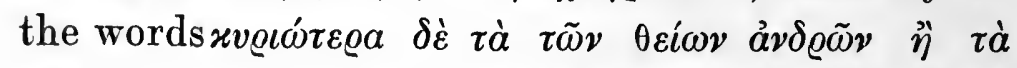
$\tau \tilde{\omega} \nu \mu \dot{\eta}^{\prime}$, which last sentence again reminds us

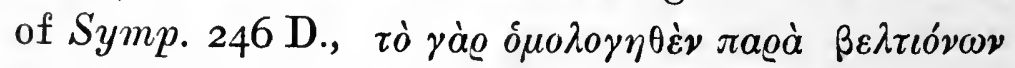

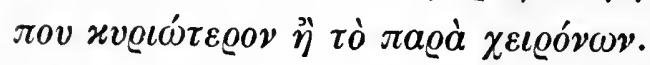

A few minor parallels which Adam adduces I omit. Of those quoted (I), (3) and (7) are, I think, cogent, (2) and (6) might be genuine reminiscences. (3) is, in my opinion, enough in itself to prove the spuriousness of the Epistle, or at all events, of the latter half thereof.

Ritter remarks on the obvious parallel between

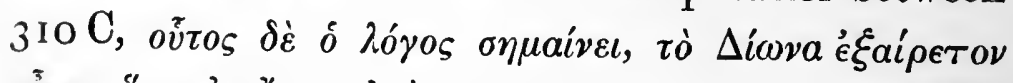

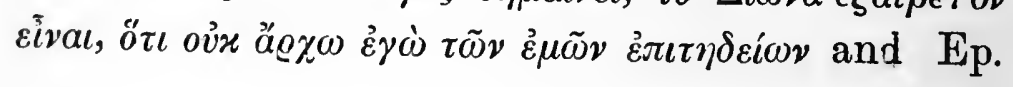




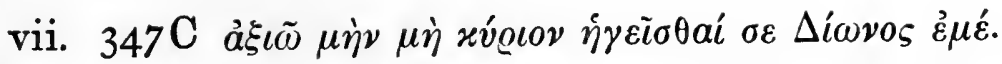

$I$ add these additional parallels, which are somewhat long to quote:-

$$
\begin{aligned}
& \text { ii } 3 \text { Io E-vii } 335 \mathrm{D} \text {. } \\
& \text { ii } 3 \text { I } 4 \mathrm{~A}-\mathrm{vii} 34 \mathrm{I} \text { E. }
\end{aligned}
$$

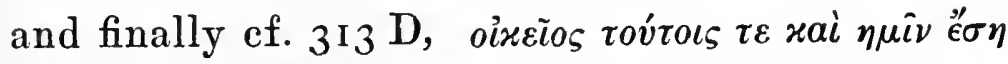
with vii. $340 \mathrm{C} \dot{\varepsilon} \dot{\alpha} \nu \mu \dot{\varepsilon} v$ öv

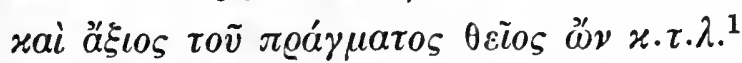

Lastly, we come to the metaphysical passage which purports to explain, $\delta i$ aivi $\mu \tilde{\omega} \nu$, the

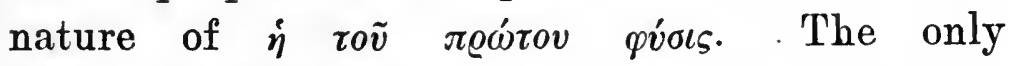
serious attempt to explain this, so far as I know, is that of Raeder (pp. 533-7) who regards the $\beta \alpha \sigma l^{-}$ $\lambda \varepsilon v^{\prime}$, the Second and the Third as representing

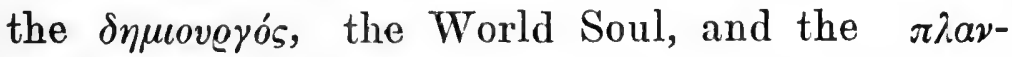
$\omega \mu \varepsilon \dot{v} \eta$ airía of the Timaeus. But in order to obtain this equation he misinterprets the words

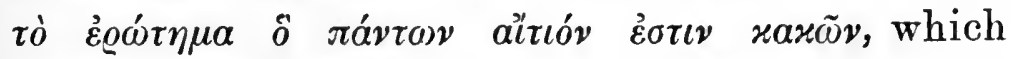
contain no reference to any metaphysical Principle of Evil, but merely mean "the question that gives all the trouble." Raeder has really been led astray by approaching this passage from a consideration of the mysterious invocation at the close of Ep. vi-with which it has in reality no

I. It is necessary here to repeat the caution against over-ready suspicion of imitation: see Appendix B. But, as we are about to see, the metaphysical passage is incontestably an imitation of Ep. vii. : from this it is fair to argue to other imitations of that Epistle, and to be more readily suspicious of imitations of the Dialogues. 
connexion whatever (see supra, p. 44 sqq.). He should surely rather have been led by the numerous resemblances to Ep. vii, to think of the metaphysical digression in that dialogue.

Strange to say, neither he nor others seem to have perceived that our forger speaks in riddles here for the simple reason that he wants to reproduce the substance of the metaphysics in Ep. vii, and is unable properly to understand them. How far he actually does understand Ep. vii 342 A $s q q$. is perhaps impossible to determine, but we can, I think, quite certainly discern his meaning here by comparing the doctrine which Plato enunciates there.

I do not wish in this place to explain that doctrine in detail. It is enough to say that Plato

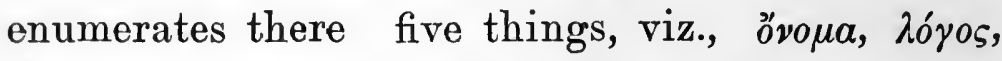

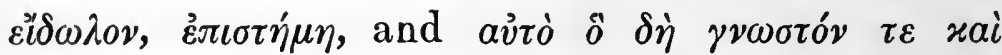

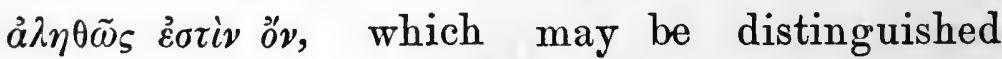
with regard to any object of inquiry. Further, he distinguishes the apprehension of the first four and the apprehension of the fifth (the Idea) as that of $\pi \circ o^{\nu} \tau \iota$ and $\tau \dot{o} \tau i$ respectively.

This latter distinction our writer doubtless does not understand, though he probably alludes to it

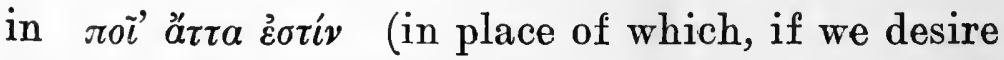
to make him a little more intelligible we might

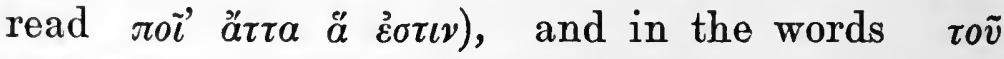

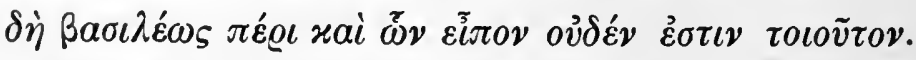

But why in place of the five things distin- 
guished in Ep. vii have we only three distinguished here? Simply, I take it, owing to bungling and hasty reading, or perhaps we should rather say, to superficial and unintelligent reminiscence. Our writer remembered or noticed, that the metaphysical passage in question began thus:

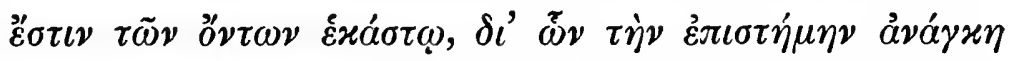

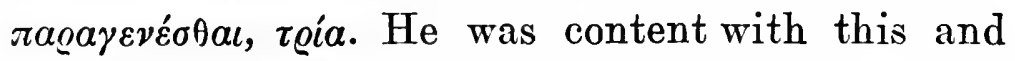

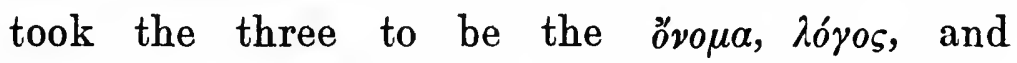
Idea, whereas the third is in reality the $\varepsilon$ l $\delta \omega \lambda o v$ or sense-object. Thus then we are enabled to understand the mysterious sentence $\delta \varepsilon v i \tau \varepsilon o v$ v $\delta \dot{\varepsilon}$

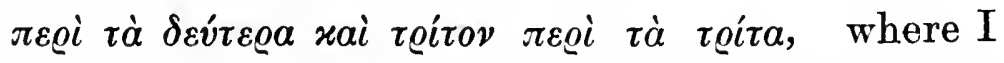
read $\pi \varepsilon \varrho i$, not $\pi \varepsilon \underline{\varrho} \iota$ as Burnet and Raeder. Our

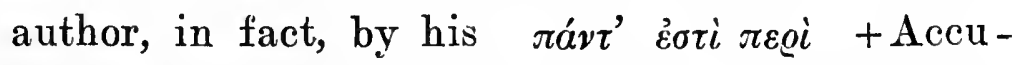
sative intends the same meaning as Plato gives

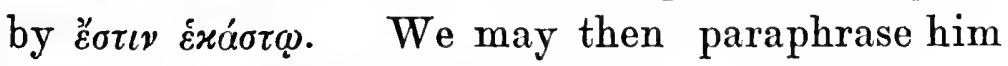
thus: "Everything is referable to, or may be regarded in the aspect of, primarily an Idea, secondarily that which ranks second (the hóros), thirdly, that which ranks third (the ovora)." He then goes on to explain, or rather to obscure Plato's explanation, that apprehension of a thing as hóros or övoua is always unsatisfying, and that it is the ignorance of the nature of the Idea that causes the travail of the soul. (The words $\dot{\eta}$ ov $v$

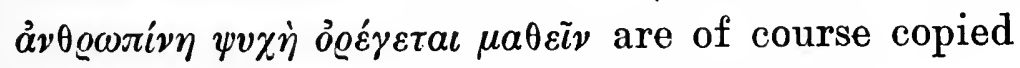

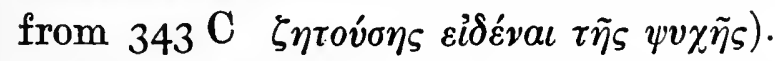

It may be added incidentally that the very fact that the metaphysical digression (which is re- 
garded with suspicion even by commentators such as Ritter who accept the rest of Ep. vii as authentic), is thought worthy of imitation in the present Epistle, is evidence in favour of that portion of Ep. vii having been regarded as genuine by this writer and as not likely to be suspected by his readers.

Having seen that the writer copies from Ep. vii in single points, we may point out that it is highly probable that the central idea of the letter, namely the dishonour ( $\left.\dot{\alpha} \tau \iota \mu^{\prime} \alpha\right)$ inflicted by Dionysius upon Plato, is suggested by Ep. vii $350 \mathrm{C}$, $\pi \tilde{\omega} \varsigma$ aै $\nu$,

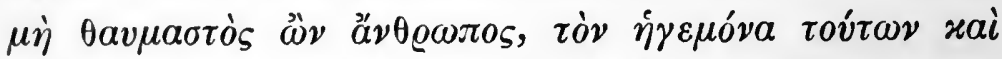

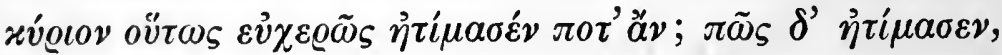

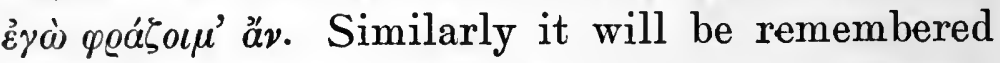
that Ep. i was probably woven round the words

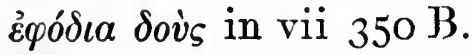

It is not improbable that the latter part of the letter (3I4 D-end) takes Ep. xiii as its model: e.g., the reference to Dionysius' release of "the man in the stone-quarries" may have been

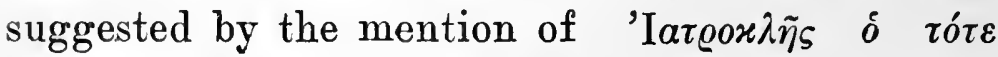

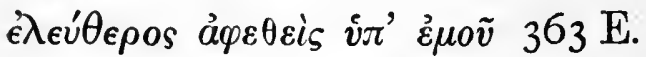

The Hiatus average is given by Raeder as $27^{\circ} 35^{2}$ which of course is very high. It should be observed, however, that of the 93 " faulty" Hiatus 79 occur between the beginning and 3 I 3 b 4 (about I oo lines of Burnet's text), 5 between 3 I $_{3} \mathrm{~b}_{4}$ and 3 I4 c 6 (about 46 lines), 9 in the last 20 lines. Thus we may say that although on the whole the 
hiatus is not avoided, yet in places the writer consciously avoids it, doubtless for purposes of imitation.

The style is in general a good imitation of the Platonic. The Transitional $\delta \eta^{\prime}$ (see p. I82) is frequent, $\sigma \chi \varepsilon \delta o ́ v$ occurs thrice, there are several instances of the Rhetorical question answered ${ }^{1}$

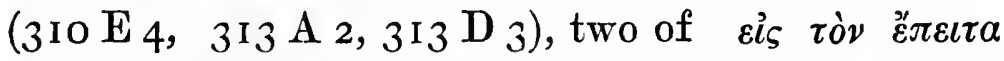

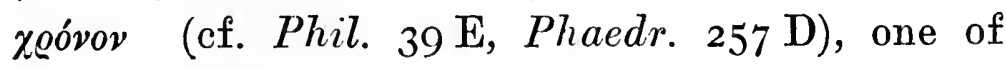

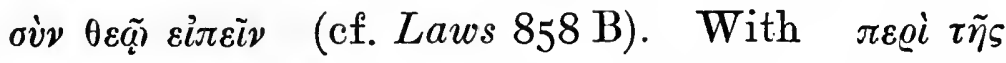

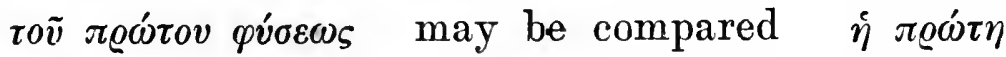
pv́ols in Laws $886 \mathrm{C}$. There is a harsh anacoluthon in $3_{13} \mathrm{~B}_{3-4}$, where an Optative follows an Infinitival construction in Indirect Statement. This is very possibly copied from vii $328 \mathrm{C} 2$.

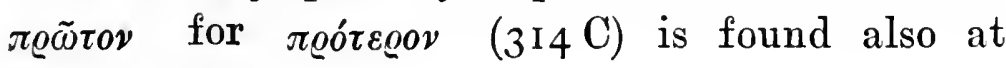
Laws $918 \mathrm{~A}$.

The list of pairs of kings and sages in 3 I I A B strikes one as too long: Steinhart remarks that it looks like a schoolboy anxious to quote all the instances he can.

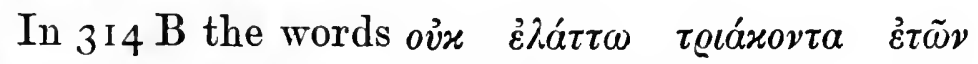

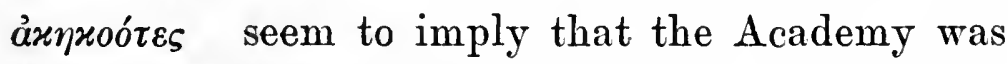
founded at least as early as 394 B.C., whereas the date usually recognised is about 387 B.c., i.e., after the first Sicilian journey, which, according to vii $324 \mathrm{~A}$, took place in that year approximately.

I. See p. Ig6. 


\section{EPISTLE III.}

This letter, supposing it to be authentic, must have been written in $358-7$, that is to say shortly before the expedition of Dion to Sicily in 357: for in $315 \mathrm{~d}$ it is implied that Dion's project is known to Dionysius, and the writer's object is to reply to charges made against him by the tyrant arising out of his (real or supposed) co-operation with Dion.

The introductory paragraph consists of a short discussion as to the proper form of salutation

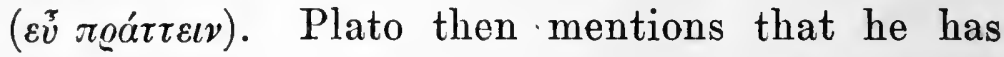
been informed of Dionysius' complaints against him-namely, that whereas he had dissuaded the tyrant from re-establishing the fallen Greek cities of Sicily, he is now urging Dion to accomplish this work. He indignantly repudiates the charge; he had surely suffered enough from slander and misrepresentation during his late stay at Syracuse, when every fault of Dionysius was imputed to him. Dionysius knew well how false those misrepresentations were, and how little it had been his desire to interfere in Syracusan politics. So far from deserving this new slander from Dionysius, the latter should have defended him in the face of these defamations. As it is, he must 
defend himself on the two charges, first showing that he acted reasonably in keeping clear of Syracusan politics, secondly, that it was not his dissuasion that kept Dionysius from his project relating to the Greek cities.

A short narrative now follows of Plato's disappointment in his first visit to Dionysius II. and the reasons for his departure. Then he passes on to his second visit, explaining how his reluctance was only overcome by the tyrant's promises of restitution to Dion. These promises were not fulfilled on his arrival : on the contrary, Dionysius first pretended to compromise regarding the restitution of Dion's property, and later rounded upon Plato for his championship of Dion, accusing him of unfaithfulness towards himself. If an alienation did arise between philosopher and tyrant surely it was not unnatural.

Turning to the second charge, Plato recounts a conversation which occurred between himself and Dionysius some twenty days before his final departure. Dionysius had recalled to him a previous colloquy, at which Plato had urged him to the restoration of the Siceliot cities, but only on the condition that he be first "educated." On the occasion of the second conversation, says Plato, Dionysius admitted his recollection of this conditional advice. This being so, Dionysius had no right to bring the charge he brought: moreover Plato could bring even more convincing proof, if 
there were any prospect of a fair inquiry into the matter. If Dionysius confesses his falsity, he will sing a palinode: if not, Plato has the means of satisfaction.

This letter is clearly intended as a " semi-open" document. Plato is writing no doubt primarily to Dionysius, but he is aware that his letter is likely to fall into the hands of others. This explains what at first seems strange, namely, that he gives a fairly detailed account of his relations with the tyrant on both his visits to Syracuse.

In this respect it resembles Ep. vii, and the supporters of the "Unechtheit" have naturally suggested that it is based upon vii, and have drawn attention to the correspondences between the two letters both in matter and language.

I will therefore begin by examining the supposed imitations.

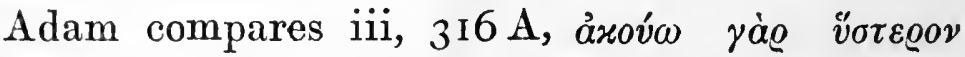

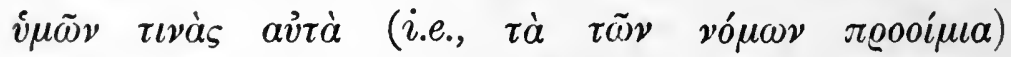

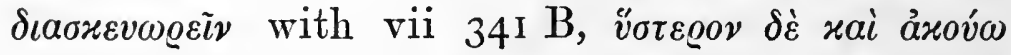

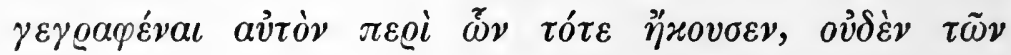

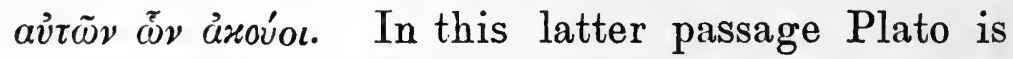
complaining of misrepresentations of his philosophy contained in a kind of metaphysical Handbook composed by Dionysius. Adam contends that the author of Ep. iii is assuming that the work of Dionysius referred to in Ep. vii consisted

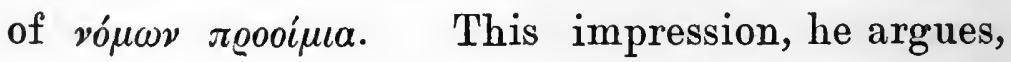


was derived from the words with which the writer of Ep. vii concludes thedigression on the incommunicability of knowledge about i $\pi \varrho \omega ́ \tau \eta ~ \varphi v ́ \sigma \varsigma ~$

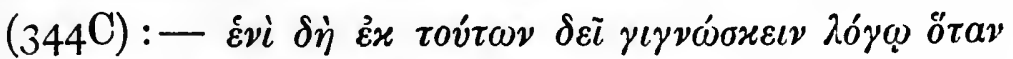

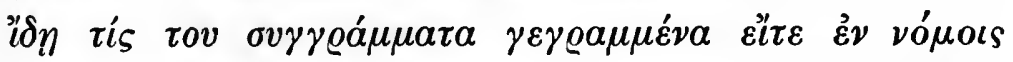

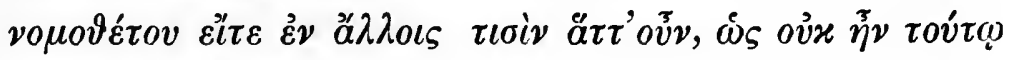

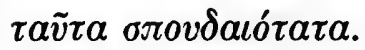

To this argument it may be replied that

(I) It is difficult to see why the passage last

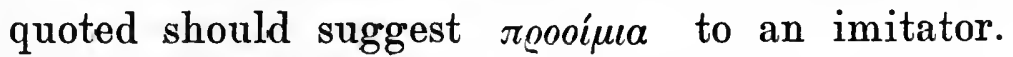

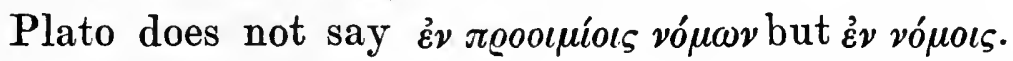

(2) The supposed mistake of the imitator as to the character of Dionysius' publication could hardly have been made by one who had read Ep. vii, 34I, as Adam assumes his imitator to have done. In fact the very sentence which Adam quotes as his reason for assuming imitation makes it abundantly clear that Dionysius had written a garbled account of Plato's oral teaching ( $\pi \varepsilon \varrho i ~ \omega \tilde{\nu}$

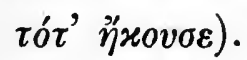

Does Adam think that his " imitator" imagined that Plato propounded his " proems" in a lecture? This is surely absurd.

A second imitation is found in $317 \mathrm{E}$, where Adam compares the sentence $\dot{\varepsilon} \lambda \theta \dot{\omega} \nu \delta \dot{\varepsilon}-0 \tilde{\iota} \sigma \theta \alpha$ $\gamma \dot{\alpha} \varrho$

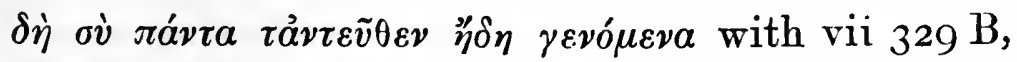
$\dot{\varepsilon} \lambda \theta \dot{\omega} \nu \delta \dot{\varepsilon}-o \vec{v} \gamma \dot{\alpha} \varrho \delta \varepsilon \dot{\imath} \mu \eta x v ́ v \varepsilon \iota \nu$. This is no more than a natural coincidence of expression, due to the fact that in both passages the writer passes from a description of his attitude before journeying to 


\section{AUTHORSHIP OF PLATONIC EPISTLES}

Sicily to an account of his experiences there. It may be remarked that the two passages refer to different visits.

Thirdly, it is objected that two conversations from Ep. vii (349 A, $349 \mathrm{E}$ ) are "contaminated" in $319 \mathrm{~A}$. I think that no commentator has compared the conversations in the two letters with sufficient care. In Ep. iii we are concerned with two passages, $318 \mathrm{C}$ and $319 \mathrm{~A}$. In the former of these we are told that Dionysius charged Plato with slighting him in favour of Dion and his friends, the ground of the charge being that he had, in concert with Theodotes and Eurybius petitioned against the banishment of Heraclides. (Incidentally I would remark that for the sense of this passage it is necessary to read $\bar{\varepsilon}^{\xi} \xi \varepsilon \beta \alpha \lambda \lambda \varepsilon \varsigma$ for $\left.\varepsilon_{\varepsilon} \xi \varepsilon \hat{\varepsilon} \beta \lambda \varepsilon \varsigma\right)$.

This account I believe to refer to the same occasion as that in $349 \mathrm{DE}$, where again the charge is made by Dionysius in reference to a supposed conspiracy between Plato and Theodotes for sheltering Heraclides. The details are not precisely the same in the two passages, but I see no inconsistency. The Seventh Epistle gives more particulars, e.g., that Plato received the message when living at the house of Archedemus, and through the mouth of a messenger, whereas in Ep. iii no scene is given, and the charge merely intro-

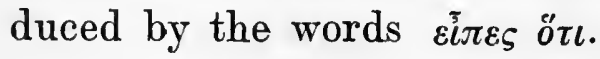

As for the conversation recorded at 3I9 A sqq., 
I do not believe this to be referred to at all in Ep. vii. It took place "about twenty days" before Plato's final departure, $\dot{\varepsilon} \nu \tau \tilde{\varphi} x \dot{\eta} \pi \omega$. Now in Ep. vii the last few weeks of Plato's sojourn are passed over in a few words. In $350 \mathrm{~B}$ we hear of his sending a message to Archytas of Tarentum, who subsequently made representations to Dion which resulted in Plato's being allowed to leave Syracuse. The interval required to obtain this answer to the message would doubtless be more than twenty days: I therefore conclude that the conversation of 319 A sqq., if it is to be looked for in Ep. vii must have been described in $350 \mathrm{~B}$ but it is not there.

And, in general, I believe that a careful comparison of the relevant part of vii with iii will show just that general agreement combined with variety of detail which might be expected in the case of two letters one written some five years later than the other.

Next there falls to be noticed a charge of internal inconsistency in this letter. As this has been clearly formulated in English by Richards following Karsten I will quote his words ${ }^{1}$ :"This is a curiously self-contradictory composition. No doubt Plato might contradict himself like other people, if he had a bad case : but would he have done it so very palpably? Dionysius (he says) has alleged that Plato, after preventing him

I. Classical Review, 1900, p. 336 . 
from settling new Greek cities in Sicily and from converting his tyranny into a kingdom, is now instigating Dion to do these very things. In answer Plato declares first that he never took part at all in Dionysius' political affairs except to the extent of writing preambles to some of his laws, and in self-defence he narrates the incidents of his intercourse with Dionysius down to the time of the expulsion of Heraclides. This is a brief version of what is set forth at length in letter vii. So far so good. But secondly he proceeds to tell a rather pointless story of an old conversation between Dionysius and himself, which is quite inconsistent with the first part of his answer. Dionysius had asked him whether he remembered that on first coming to sicily he had urged Dionysius to found or refound these Greek cities, and Plato replied in the affirmative. It is a calumny to say $\left(\mu \dot{\eta}^{\prime} \mu \varepsilon \cdot \delta \iota \dot{\beta} \beta \alpha \lambda \lambda \varepsilon \quad \lambda \dot{\varepsilon} \gamma \omega \nu, 3^{19} \mathrm{C}\right)$ that he had prevented it. The truth was $\dot{\varepsilon} \gamma \dot{\omega}$

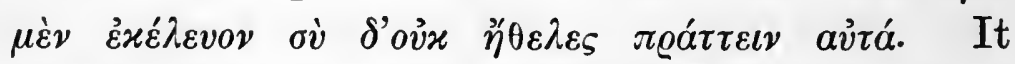
appears therefore that Plato had taken part in Dionysius' affairs and had not confined himself to the writing of philosophical preambles. But this is not all. Plato had also told Dionysiusand he claims to have reminded him of it in this same conversation, witnesses of which can be brought - that he must not try to carry out these schemes till he had been educated (3I9 C). Therefore as far as his advice went, he had prevented 
Dionysius from taking the steps in question. This is an obvious and double contradiction. Are we to put down such a shuffling and halting plea to Plato? It is as poor intellectually as it is morally."

I must apologise for the length of this quotation, but it needs to be given in full if we are to appreciate its fallacy. The argument is a good instance of the unjust treatment accorded to these Epistles by critics prejudiced in favour of their spuriousness. The fallacy lies in supposing that the words

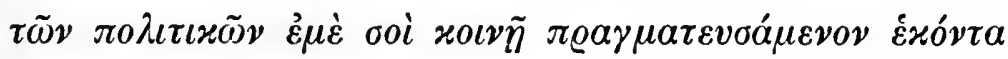

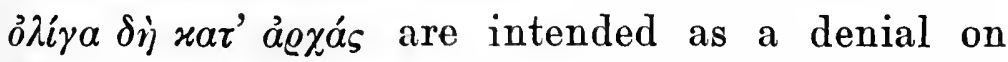
Plato's part of having discussed with Dionysius the re-establishment of the Siceliot eities. It is only inattention to the sequence of thought in 3I5 DE that could lead to this supposition: I have endeavoured to indicate that sequence in my summary, and it may be made clearer if we mentally enclose the passage $\ddot{\alpha} \delta \eta \nu$ yà $\varrho(3 \mathrm{I} 5 \mathrm{E})$ to

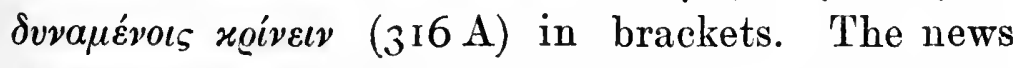
of this latest calumny on the part of Dionysius recalls to Plato's mind the earlier calumnies which had represented him as Dionysius' evil counsellor during his second visit to that tyrant. The sentence beginning ov̀ $\delta^{\prime}$ aútòs oủo $0 \alpha$ refers to these earlier calumnies alone, i.e., to the im-

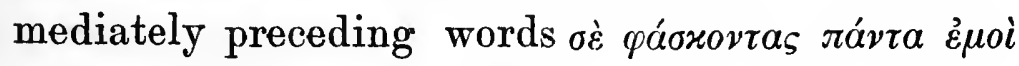
$\pi \varepsilon i \theta \varepsilon \sigma \theta a l . \quad$ "It is absurd," says Plato, " to represent me as having ever been intimately con- 
cerned in Syracusan internal politics. Such part as I ever did take in them was against my will: for Dionysius well knows that I showed my aims to be far other than those of political interference on my first arrival."

It shouid be remarked, however, that what is introduced as a digression-Plato's abstention from Syracusan politics-comes to be an integral part of the letter, the scheme of which comes thus to be changed, so that he conceives that $\pi \varrho o$ s $\delta v_{0}$

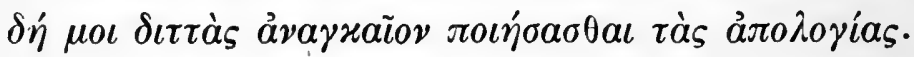

It is almost too obvious to point out how characteristic is this treatment of a "digression" of the author of the Sophist and Politicus.

So much for the first half of Richards' "double contradiction." The second half arises from a misconception of Plato's attitude. The whole point of the reported conversation in the garden is to show that the $\left.\delta \iota \alpha x^{\prime}\right) \lambda v \sigma \iota s$, which Dionysius regarded as Plato's was in reality his own. This is brought out, amongst other places, in the words

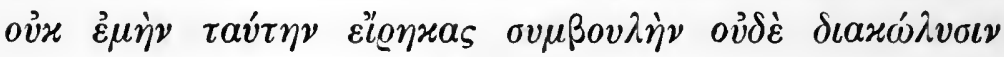
(316 B), a sentence which Richards(p. 98), seems to have misinterpreted by saying tnat it is unintelligible without the insertion of $\dot{\alpha} \lambda \eta \theta \tilde{\omega}_{\varsigma}$ after oux. What Plato says is that there was indeed a $\delta \iota x \omega \dot{\lambda} \lambda v \sigma \varsigma$ but that he was not the author of it.

Doubtless there is a good deal to be said for Dionysius' view of the matter: but Plato is only 
showing, as Grote pointed out long ago, that he was true to the fundamental principles of his "Republic." It is only a complete disregard of his point of view that finds moral and intellectual shuffling in the story of this Epistle.

Lastly, the opening paragraph with its distinc-

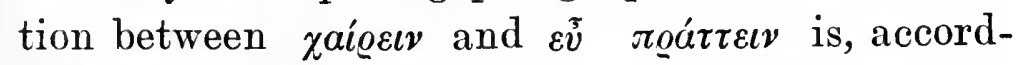
ing to Karsten, copied from Charmides I64 D. There can be no doubt, I think, that ev $\pi \varrho a ́ \tau \tau \varepsilon v v$ was really a formula of salutation regularly employed by Plato: else why should all the Platonic Epistles, supposing them to be good forgeries, employ it? The Republic concludes

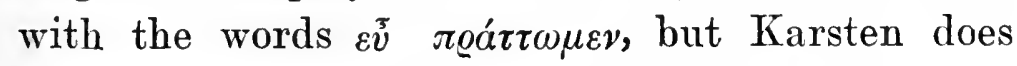
not suggest that that dialogue is a forgery.

I ought perhaps to refer to another general observation by Karsten (p. 88): "Plutarchus, in vita Dionis, ${ }^{1}$ narrat cum Dionysius Platonem ab ultimo itinere Athenas reversum rogasset, ne invidiosis de se sermonibus existimationi suae apud Graecos noceret, hunc respondisse: $\mu \grave{\eta}$

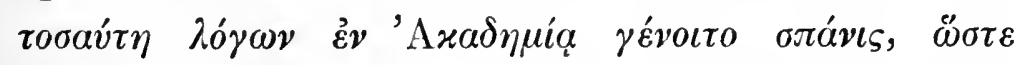
бov $\tau \iota v a \mu \nu \eta \mu o v \varepsilon \tilde{v} \sigma a l$. Idem scriptor animadvertit cum hoc Platonis dicto quae in epistolis leguntur parum concinere .... Neminem fore puto, quin id quod Plutarchus refert is quae in hac epistola leguntur longe anteponendum existimet."

I. C. I9. 
As to the last remark, opinions may differ: but it should be noticed that Diogenes Laertius (iii. 2I) has got hold of the same story as Plutarch, with the important difference that he assigns it to Plato's visit to the elder Dionysius in 387: (ov

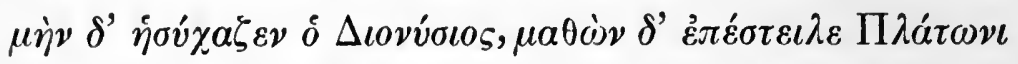

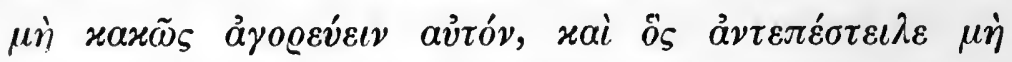

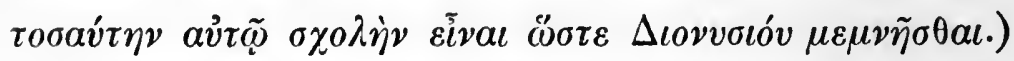

This discrepancy arouses our suspicions of this story, which savours of an epigrammatistic age. But why does Plutarch accept it, though aware that it is hardly reconcilable with Plato's own account in this Epistle? Simply, I believe, because he thinks it rather too good to give up. (I have made a similar suggestion as to Plutarch in discussing Ep. viii. See p. I39 infra.)

I pass now to the question of language. Not many objections have been raised on this score. The opinion of Richards, though he rejects the letter, is that " the Greek offers nothing to strike us."

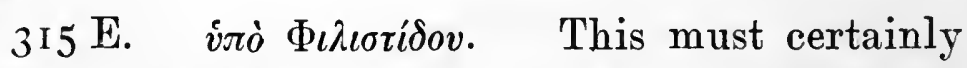
refer to the person commonly known as Philistus, the historian and opponent of Dion (Plut. Dion, I4). Possibly Фílıoros may be a "Kosenname"

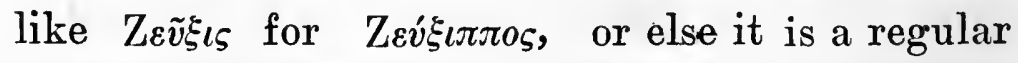
manuscript abbreviation, such as those noticed by Cobet (Var. Lect. Graec., 27I); e.g., Thuc. v. 90,

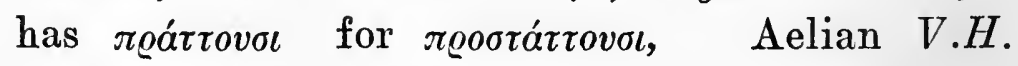

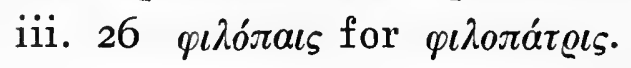


318 D. iva ovi $\tau$ s $\varepsilon i \pi \omega$ is objected to by Steinhart as being an unclassical equivalent of $\omega \varsigma$ हैं

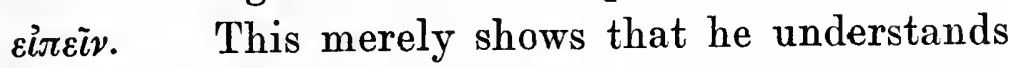

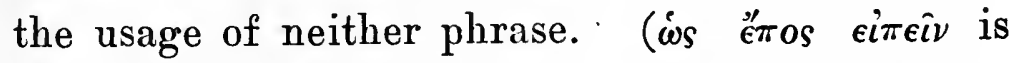
of course used to modify " universal" expressions, and = "almost"), iva ovi $\omega_{\varsigma}$ हli $\omega$ is rightly explained by Richards and Ritter, as meaning " to say the least."

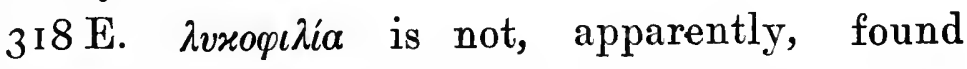
elsewhere in classical Greek. As a passage suggesting the likelihood of its being a genuine Platonic coinage Richards quotes Phaedrus

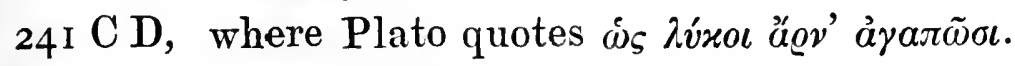

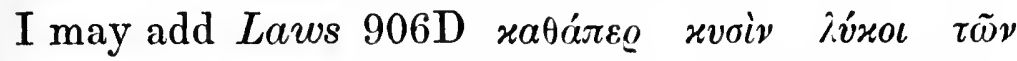
å

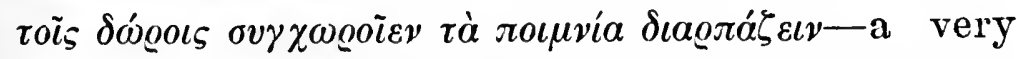

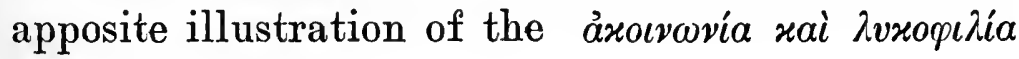
of our passage.

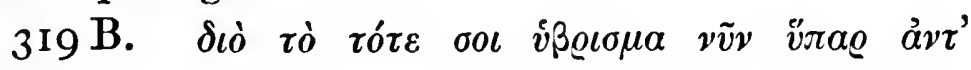

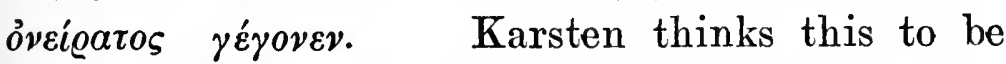
unintelligently copied from Politicus $278 \mathrm{E}$. He cannot see its meaning here, but Ritter has explained it (op. cit., p. 40I), as meaning: "Thus the utter foolishness of your contemptuous attitude of former days has been now clearly revealed -i.e., Dion has appeared on the scene as one who has fulfilled the preliminaries to political activity which Plato demanded, preliminaries laughed to scorn by Dionysius: the man who has gone through the stern schooling of Mathematics and 


\section{AUTHORSHIP OF PLATONIC EPISTLES}

Philosophy is now seen as Fortune's favourite." While not doubting that Ritter is right in saying

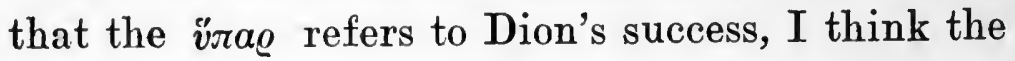
expression becomes much easier if we take $\tau \dot{o}$

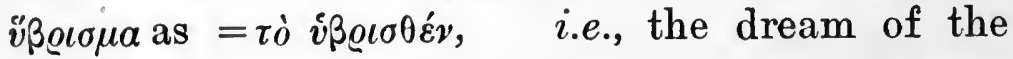
philosopher king. (For this use cf. Eurip. Orestes Iо38, "̋ßßı

This letter contains seven words not found in Plato elsewhere, viz.:-
I. ảxoเvผvía.
5. $\mu \varepsilon \mu \eta \nu \iota \mu \varepsilon \dot{\nu \omega s}$.
2. $\dot{\alpha} \nu \tau \alpha \varrho x \varepsilon ́ \omega$.

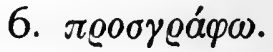

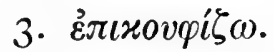
7. $\dddot{\jmath} \varrho \iota \sigma \mu \alpha$.

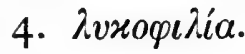

None of these, however, afford ground for suspicion.

(4) I have already noticed. The others all belong to various classes of words which we shall notice (App. A) as characteristic of Plato's latest style :-

(I) and (7) being abstract Nouns,

(2), (3) and (6) being relatively unusual compound Verbs,

(5) being an unusual Adverb in - ws.

The following table shows parallels with Platonic Dialogues:- 
3 I $5 \mathrm{~b}$.

For the pleonasm cf.

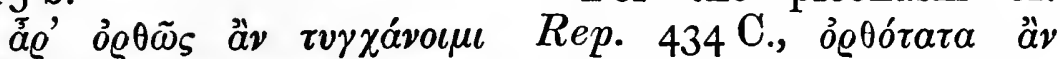

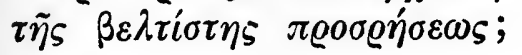

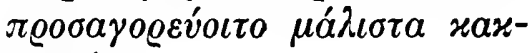
oveyía.

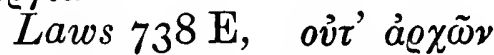

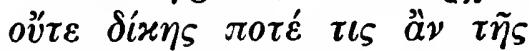

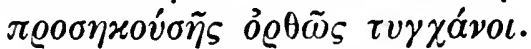

Vid. Appendix A, p. I93.

\section{I $5 \mathrm{C}$.}

Cf. Theaet. I76 A,

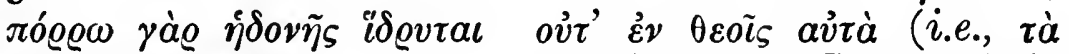

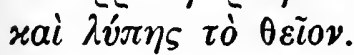

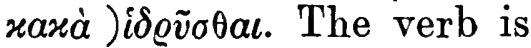
quoted by Ast as occurring I I times in the Laws, 3 in Timaeus, 2 in Locr., $I$ in Epin., out of 26 instances in all.

$3 \mathrm{I} 5 \mathrm{c}$.

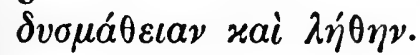

Cf. Timeaus 87a $\lambda \eta \dot{\theta} \eta \mathrm{s}$

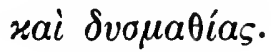

$315 \mathrm{~d}$.

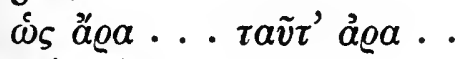

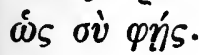

For the repetition cf. Laws 688 B, $\lambda \dot{\varepsilon} \gamma \omega .$. ö $\iota \iota \dot{\eta} \varphi \eta \mu \iota$.

\section{D.}

$\mu \varepsilon \tau \alpha \sigma \tau \eta \dot{\sigma} \alpha \nu \tau a$.
A strange instance of attraction of the participle which should not logically agree with $\sigma^{\prime}$ as it belongs to the preceding gen. abs, construction.

Somewhat similar is Phaedr. $276 \mathrm{E}, \pi \alpha \gamma \varkappa \alpha \lambda \eta \nu$

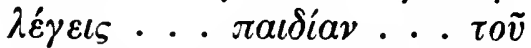

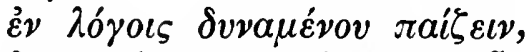

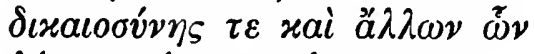

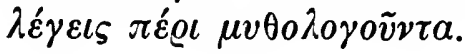


$3 \mathrm{I} 6 \mathrm{~b}$.

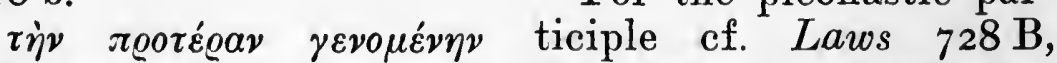
$\delta \iota \alpha \beta o \lambda \dot{\nu} \nu$.

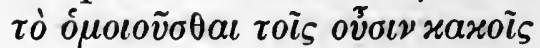

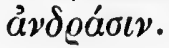

$3 \mathrm{I} 6 \mathrm{~b}$.

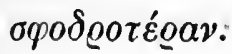

This is a favourite Platonic adj., mostly latePlatonic. (I3 out of Ast's I9 citations are from latest group.)

$3 \mathrm{I} 6 \mathrm{~b}$.

$\delta \iota \alpha x \omega \dot{\lambda} v \sigma \iota \varsigma$.

Elsewhere quoted only from Rep. $469 \mathrm{E}$.

For the apposition cf. $3 \mathrm{I} 6 \mathrm{~B}$.

$\delta \iota \alpha \varkappa \omega ́ \lambda v \sigma \iota \nu . . \dot{\varepsilon} \mu \pi о \delta \dot{\nu}$ $\dot{\varepsilon} \mu \dot{\varepsilon} \quad \gamma \varepsilon \gamma \varepsilon \nu \tilde{\eta} \sigma \theta \alpha$.

$316 \mathrm{c.}$

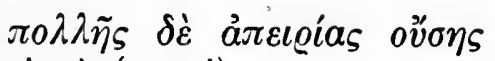
$\pi \varepsilon \varrho \dot{\imath} \sigma \dot{\varepsilon}(=\sigma o i)$.

$3 \mathrm{I} 6 \mathrm{~d}$.

$\mu \tilde{\omega} \nu$ ov $\chi$

$3 \mathrm{I} 6 \mathrm{~d}$.

$\dot{\varepsilon} \varkappa \tau \tilde{\omega} \nu \lambda o เ \pi \tilde{\omega} \nu$

(=in posterum).

3 I 7 a.

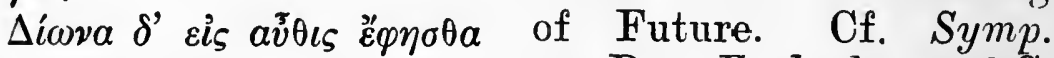
$\mu \varepsilon \tau \alpha \pi \dot{\varepsilon} \mu \psi \alpha \sigma \theta \alpha \iota$.

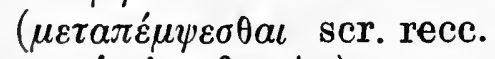
$\mu \epsilon \tau \alpha \pi \epsilon ́ \mu \psi \alpha \alpha \sigma \theta \iota$ Ao). I93 D, Euthyd. 278 C, Prot. 316 c (quoted in Riddell's Digest, p. I47), and also Ep. vii $338 \mathrm{~A}$.

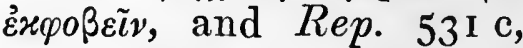
$566 \mathrm{~B}$, quoted in my note on vii, 324 A, p. 127.

For the periphrastic use of $\pi \varepsilon \varrho i$ see Appendix A, p. 192.

Quoted by Ast only from Soph. Polit. Phil. (once each).

The phrase has this most unusual sense (prob. not found elsewhere) in Laws $709 \mathrm{E}$.

Aor. Infin. in meaning and also Ep. vil 338 . 
317 E.

Cf. Epistle vii. $328 \mathrm{~B}$

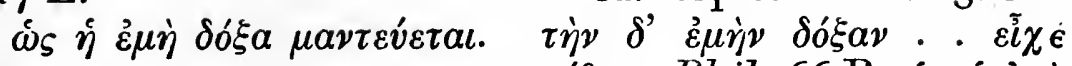
póßos, Phil. $66 \mathrm{~B}, \dot{\omega} s \dot{\eta} \dot{\varepsilon} \mu \grave{\eta}$ $\mu \alpha \dot{\nu} \tau \varepsilon \iota \alpha$.

$318 \mathrm{~A}$.

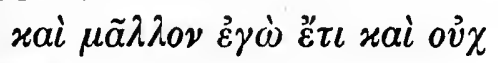
ทं $\tau \tau o \nu$.

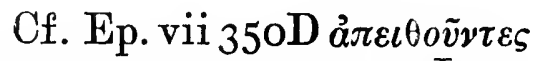
$\delta \dot{\varepsilon}$ xai ov̉ $\pi \varepsilon \iota \theta o ́ \mu \varepsilon \nu o l$ Laws

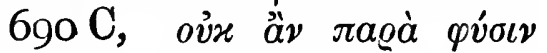

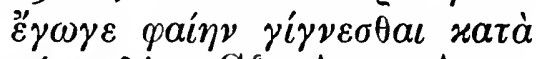
púouv dé. Cf. App. A, p. 194.

$318 \mathrm{D}$.

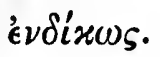

Only used in Prose by Plato. Ast's quotations are from Phil., Laws, Tim., Epin. and Ep. vii $335 \mathrm{D}$.

$318 \mathrm{E}$.

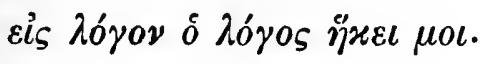

Cf. (with Raeder) Ep.

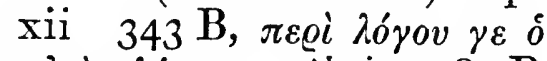
av̉òs hóyos. Épin. $983 \mathrm{D}$

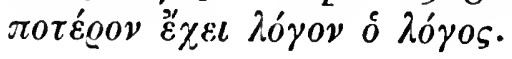

319 A.

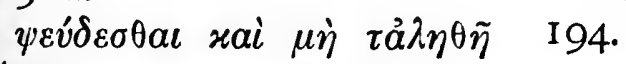
$\lambda \dot{\varepsilon} \gamma \varepsilon \varepsilon \nu$.

For the pleonasm see $\mathrm{p}$.

$319 \mathrm{~A}$.

This is a case of what

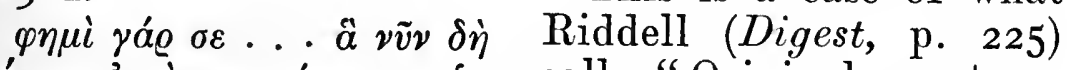

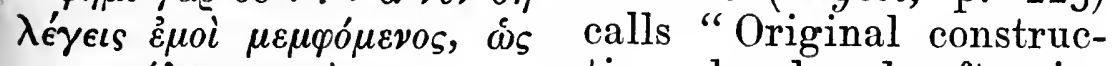
$\therefore \mu \varepsilon \dot{\lambda} \lambda o$. xai $\mu \varepsilon$. tion abandoned, after in-

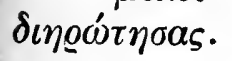
terposed clause, in favour of that of the interposed clause."

Cf. esp. (with Riddell)

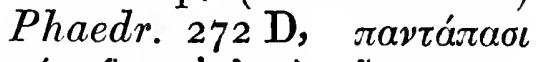

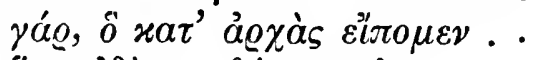

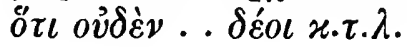




\section{AUTHORSHIP OF PLATONIC EPISTLES}

$319 \mathrm{c}$.

$\mu \alpha \dot{\lambda} a \pi \lambda a \sigma \tau \tilde{\omega} s$.

$319 \mathrm{c.}$

Ė@oov́oas.

$\tau \dot{\nu} \boldsymbol{\varepsilon} \varkappa \pi \lambda$.ovv.
Ast quotes the adverb only from Soph. $216 \mathrm{c}$, Laws 642 D, 777 D.

See my note on Ep. viii, p. I49 infra.

For the attraction of Antecedent to Relative see Riddell, Digest, p. I9I and cf. especially Polit. 2 I $7 \mathrm{c}$,

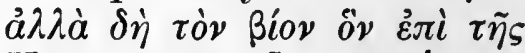

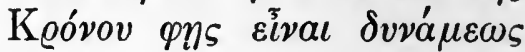

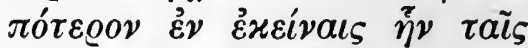

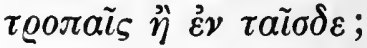

3 I $8 \mathrm{D}$.

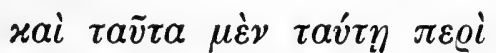

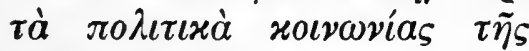
$\dot{\varepsilon} \mu \tilde{\eta} \varsigma$ xai $\sigma \tilde{\eta} \varsigma$.
For the loose Genitive of Reference see Campbell, Rep. vol. ii, p. I84, and cf Symp. 22 I C,

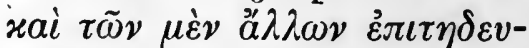

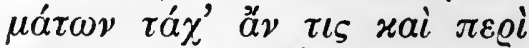

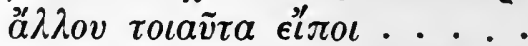
In both cases the gen. seems to be used to avoid repetition of $\pi \varepsilon \varrho i$. 


\section{EPISTLE IV.}

This is a letter obviously purporting to be written by way of advice to Dion after the coup of 357 B.C. Raeder suggests $355-4$ as the date, but the precise year is unimportant. It is clear that if genuine it must have been written some time between 357 and Dion's death in 353 B.c.

Plato reminds Dion of the enthusiastic support which he had given to his cause, now crowned with success. That success was meet, and for the present all is well, but a critical time lies ahead. Dion and his friends must let all men see the difference between those that base their power on the strong arm alone, and those that base it on justice and equity. He upon whom the eyes of the world are fixed must show himself like Lycurgus and Cyrus. Let there be no jealousies between himself and Heraclides and Theodotes, or if such there must be let him be the peace-maker. A friend's advice is excusable, like the shouts of encouragement to athletes contending in the games. After a request for news, Dion is gently reminded of the value of a complaisant nature, and warned that a self-willed man loses his friends.

Few objections have been made to this Epistle. Ritter, coupling it with $v$, ix and $x$ says that he 
cannot definitely exclude the possibility of authenticity. Even Steinhart admits that it is 'a composition not wholly wanting in cleverness.' Most

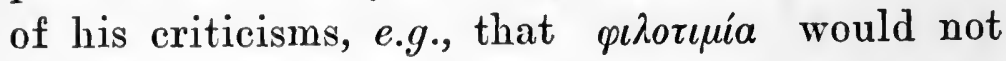
be recommended by Plato as a motive to action, that Dion needed no stimulus to $\dot{\alpha} \lambda \dot{\eta} \theta \varepsilon \iota \alpha$ of which he was already in possession, that Lycurgus and Cyrus would not have been held up as models to the governor of a free country, seem to merit little discussion. As to the first, I may point out what

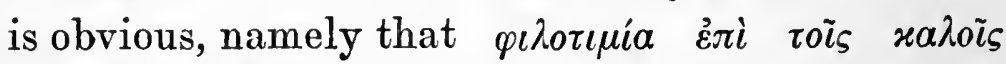

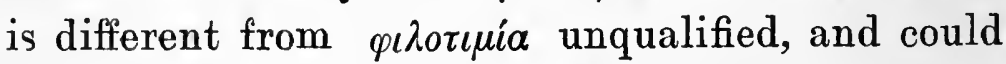
certainly find no opposition from Plato.

A more serious objection, noted by the same commentator, is that Plato's description of his zeal for Dion's cause, given at the beginning of the letter, does not tally with Ep. vii $350 \mathrm{C}-\mathrm{D}$, where Plato represents himself as having refused to take part in any scheme of violence against Dionysius. This has, however, been refuted, I think adequately, by Ritter (p. 376), who, following Grote and Raeder, points out that it is no more than natural that Plato should in the years 356-4, in the hour of Dion's prosperity, have seen his own actions in a different light from that in which he came to regard them after Dion's overthrow. Ritter further remarks that there is not in reality so much of a contradiction as had been supposed: for the words in $350 \mathrm{C}, \tau o \tilde{v} \varsigma \mu \dot{\varepsilon} \nu$ qílovs

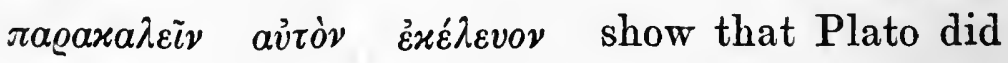


not wholly condemn Dion's enterprise, and did not even dissuade him from sharing it with friends other than those who had enjoyed the hospitality and intimate acquaintance of Dionysius.

With regard to style, Ritter's judgment is that "the language is unartificial, the tone throughout natural." He agrees with Raeder (p. 53I) that

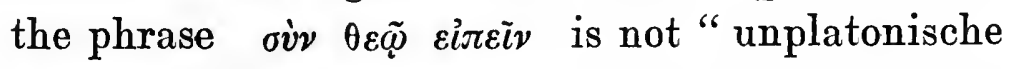
Frömmelei" as Steinhart would have it (the actual phrases occur at Laws $858 \mathrm{~B}$, and expressions like it abound in that dialogue): he shows

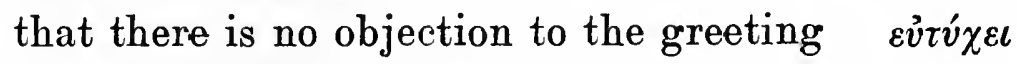
at the end of the letter-Plato as a good Socratic could use it side by side with $\varepsilon v^{\widetilde{v}} \pi \varrho a ́ \tau \tau \varepsilon$, as may be seen from the explanation of evirvia and

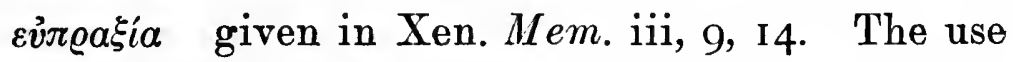
of $\mu \dot{\eta} \iota \iota \delta \dot{\eta}$ (32 I A), without a preceding negative, cannot apparently be paralleled from the dia-

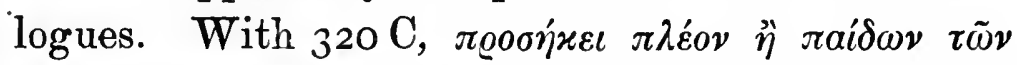

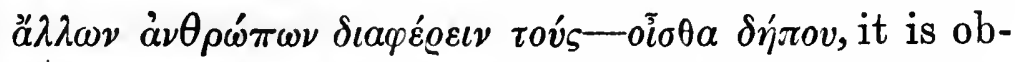

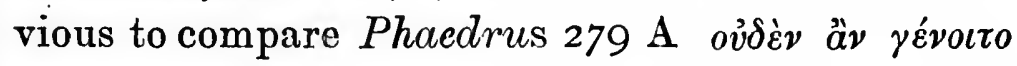

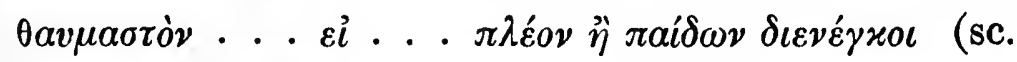

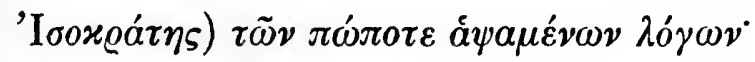

The rhythm suggests a hexameter verse from which both passages quote. The parallel obviously cannot be used as evidence for or against the authenticity of the letter. ${ }^{1}$

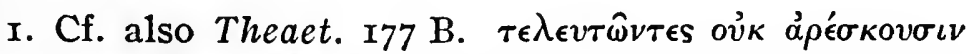

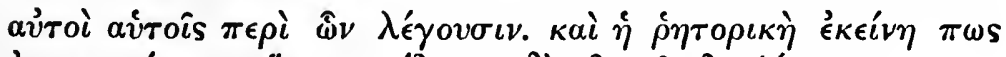

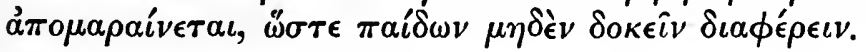


I add a few Platonisms in the language which seem worth noting.

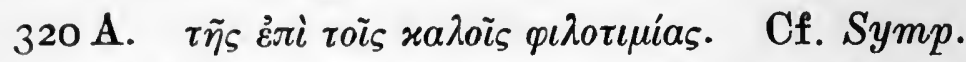

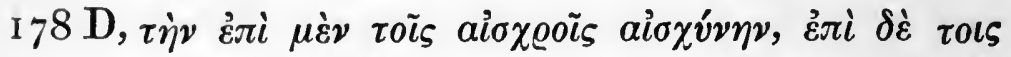

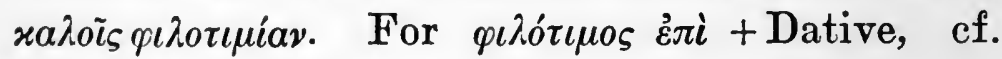
Laws 744 B, Protag. 343 C.

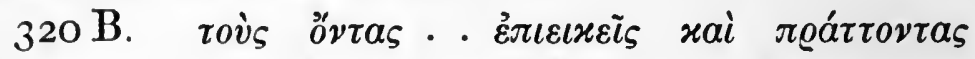
rocaṽ $\alpha$. This substitution of roıoṽos for a preceding adjective is a mannerism of Plato. Vid. Riddell's Digest, p. I37, which quotes several instances.

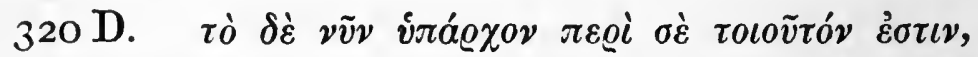

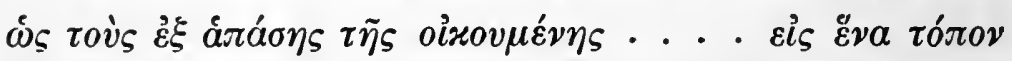

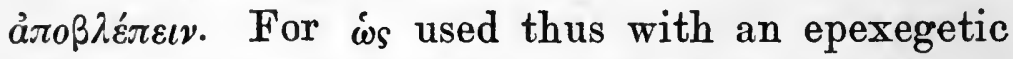
infinitive, approaching the meaning of $\omega \sigma \tau \varepsilon$ cf. vii,

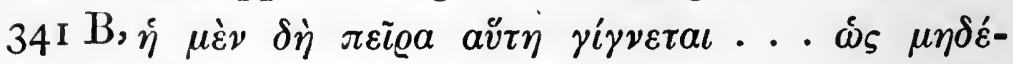

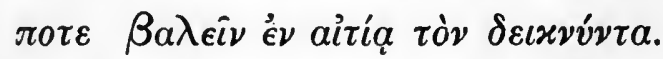

$\omega \varsigma$ is used for $\omega \sigma \tau \varepsilon$ in Rep. $365 \mathrm{D}$, Phaedo $108 \mathrm{E}$, Protag. $330 \mathrm{E}$.

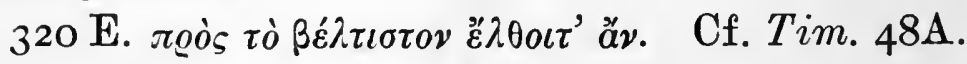

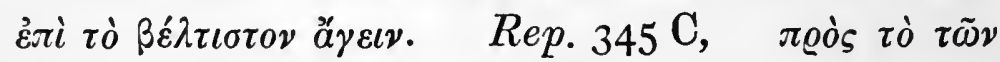

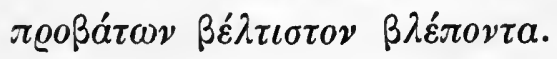

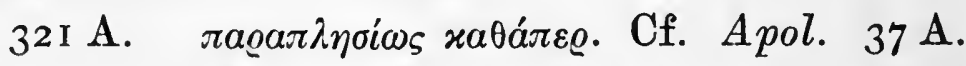

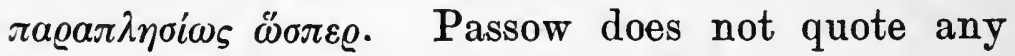

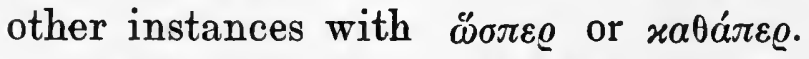

32 I B. $\dot{\varepsilon} \nu \delta \varepsilon \varepsilon \sigma \tau \dot{\varepsilon} \varrho \omega s$. The form occurs in Phaedo $74 \mathrm{E}, 75 \mathrm{~A}$. For the comparative in - $\omega s$ ef. Laws 867 B, 867 D, 876 D, 907 C, and App. A, p. I9I.

$\tau \tilde{\eta} \delta \dot{\varepsilon}$ (=here) occurs twice: see p. I9I. 


\section{EPISTLE V.}

This letter is addressed to Perdiccas of Macedonia, brother of Philip, who died in 360-59 B.c., and its purpose is to recommend the counsels of one Euphraeus. Every state must accommodate itself to the "voice" ( $\varphi \omega \nu \eta$ ) proper to its constitution, and Euphraeus will be of service in seeing that this is done.

If anyone hearing this object that Plato himself, though professing to understand the true interest of a democracy, never took part in Athenian public life, it should be replied that the Athenian democracy in his age was not in a fit state to benefit from his advice. If Perdiccas had seemed to Plato incurable, as Plato seemed to the Athenians, he would refrain from advice about him and his affairs. ${ }^{1}$

I. It is implied that Plato does not think Perdiccas incurable, and therefore has advised him : cf. the opening sentences of the letter.

I owe this interpretation of the difficult concluding sentences to Professor Henry Jackson. I had previously followed commentators in supposing Plato himself to be the subject of $\delta \delta^{\prime} \xi \alpha \iota \mu \in \nu$ in 322 B 6 : but the meaning is clearly that given above, and will be seen more clearly if we place inverted commas before $\Pi \lambda \alpha^{\prime} \tau \omega \nu \dot{o}^{\prime} \psi^{\prime}$ and after $\tau \alpha^{\prime} \epsilon \dot{\epsilon} \mu \grave{\alpha} \sigma v \mu \beta o v \lambda \hat{\eta} s$. 
There is no ground for objection to the situation presupposed in this letter, though we know nothing of any relations between Plato and Perdiccas from other sources with the exception of an allusion in Athenaeus (xi, 506 E), who, like our author, speaks of Euphraeus of Oreus as intermediary, adding that the latter won great influence over Perdiccas (Steinhart, p. 408).

The spuriousness is to my mind certainly proved from a clumsy copying of what is said in the

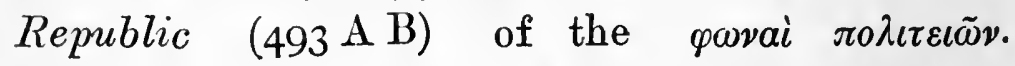
Richards ${ }^{1}$ does no more than give the reference, and none of the other commentators notice the point, perhaps because they thought there could be no relation between the two passages.

In the Republic passage Plato compares the Sophists in respect of their treatment of the democracy, their subservience to $\tau \dot{\alpha} \tau \tilde{\omega} \nu$ ro $\lambda \lambda \tilde{\omega} \nu$

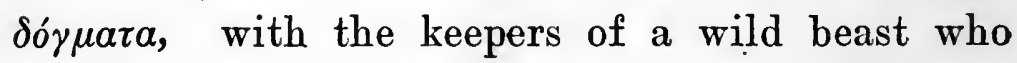
understand its different cries ( $\omega \omega \nu a i$ ), and the cries of others by which it is angered and soothed respectively. Plato has no conception of a single "key-note" appropriate to a particular form of government. It is, however, impossible not to suppose an imitation on the part of our author,

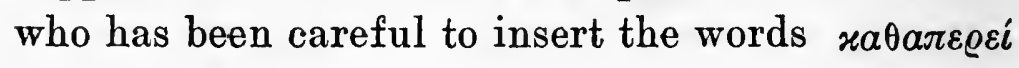
$\tau \iota \nu \omega \nu \zeta \omega \omega \nu$.

Moreover we plainly cannot conceive Plato to commend his disciple Euphraeus for possessing

I. Classical Review, Igoo, p. 337. 
just that kind of spurious knowledge which, not only in the Republic, but in many dialogues he condemns in the Sophists. The dialogue Sophist itself was in all probability composed about the same time at which we should have to date this Epistle, if it were genuine $(365-360$ B.c.- the limits of Perdiccas' reign).

The apology put into the mouth of Plato, in the third person, which forms the second half of the letter, seems to have very little logical connexion with the rest: it is not Plato but Euphraeus who is to be Perdiccas' adviser. The substance may be copied from Epistle vii (325 D sqq.)

The language is unquestionably a good imitation of Plato. There are two instances of $\varkappa \alpha \theta \dot{\pi} \pi \varepsilon \varrho$ (none of $\ddot{\sigma} \sigma \varepsilon \varrho$ ), a quite Platonic pleonasm (vid.

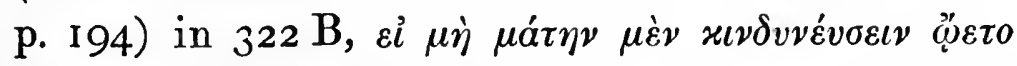

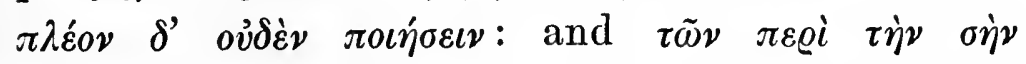
$\delta \iota a \tau \varrho \beta \dot{\eta} \nu$ oै $\nu \tau \omega \nu(322 \mathrm{~A})$ is an expression which

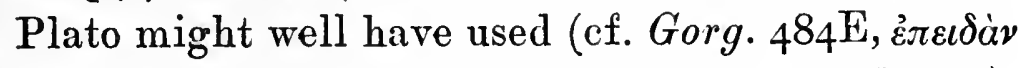

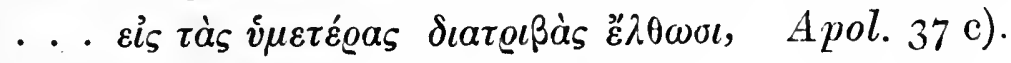

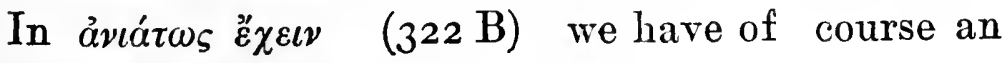
obvious Platonic reminiscence.

The Hiatus is avoided (Raeder's calculation gives the average as 3.33 ), and there are no äл $\alpha \xi$ $\lambda \varepsilon \gamma o ́$ $\mu \varepsilon v a$. 


\section{EPISTLE VI.}

This letter is addressed to Hermeias, Erastus and Coriscus, the two last being disciples of Plato mentioned by Strabo (xiii, 54, 57), who tells us that they came from Scepsis, and Hermeias from Atarneus. The last-named, he adds, heard Plato

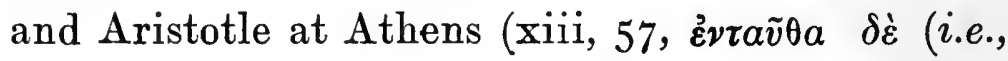

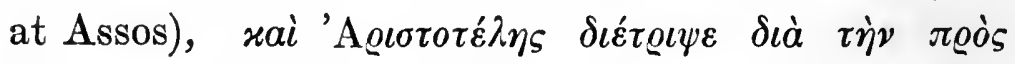

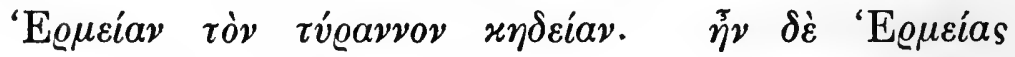

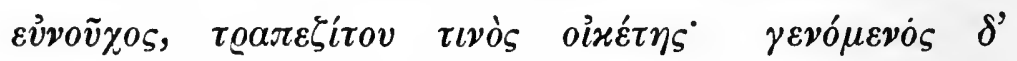

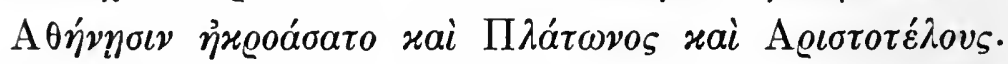

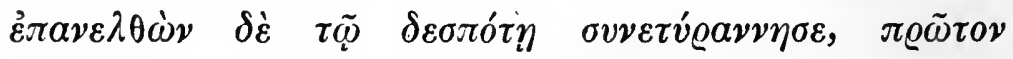

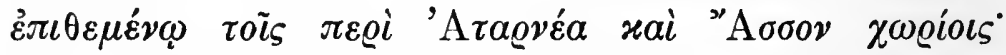

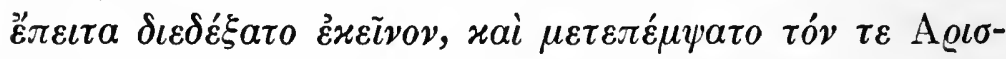

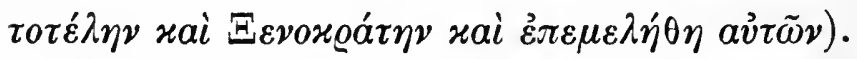

Plato is brought before us by the writer as a counsellor of friendship between these three, pointing out the advantages on both sides. Hermeias is reminded that true friends are better than riches, while Erastus and Coriscus are bidden not to despise the protection of one who has more worldly wisdom than themselves. In the event of any break in this desirable harmony, they are to apply to Plato, whose words have more power to reconcile than any binding spells.

Finally, this letter is to be read by the recipients again and again, by all three, if possible, 
or if not, by at least two together: it is to be regarded as a solemn bond, and its sanctity to be marked by an adjuration, half-serious and halfplayful, to the "Cause and Leader of all things and his Royal Father."

It is not obvious at what date this Epistle purports to have been written, and Raeder does not suggest any. Meyer (v. 504 A) holds that "the mediation of friendship between Hermeias, Erastus and Coriscus belongs naturally to Plato's latest years." But the point is of little moment, even if we suppose the letter authentic.

A mark of spuriousness is found by A. Böckh, ${ }^{1}$ followed by Ritter, in the words ö $\sigma \alpha \mu \eta \dot{\eta} \pi \omega$

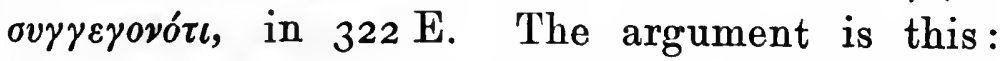
Clearly Hermeias is in possession of important power: he is plainly lord of Atarneus. It cannot be seriously doubted that he concluded his friendship with Aristotle and Xenocrates in Athens, and his Athenian sojourn must precede the time of his being raised to be the consort of his benefactor and former master Eubulus. Therefore he must have made the acquaintance of Plato before the supposed time of this letter.

I do not think much weight can be attached to this argument. I am not sure that the words

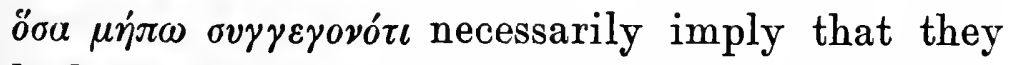
had never met: it may mean merely that they had not enjoyed ovvovoía. Moreover, they might

I. Kl. Schriften, vol. vi, p. Igo. 
conceivably not have met, though in Athens together; or again, Plato might have been absent at the time.

Apart from this, there seems nothing to object to in the substance of the letter until we reach the concluding paragraph. This, however, may well give us pause. Steinhart holds that the form of the invocation shows a "Judaeo-Alexandrian, Neoplatonic, or even Christian origin," in the last suggestion following some of the early Fathers, who quote it as an illustration of Plato's Christianity. But the Greek is too much like Plato for these conjectures to be considered. There is more plausibility in Raeder's suggestion, that the two gods are the World-Soul and the

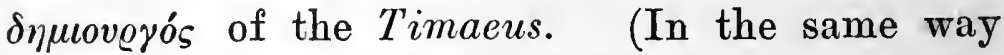
he explains the Trinity of Ep. ii 3 I $2 \mathrm{E}$ as the

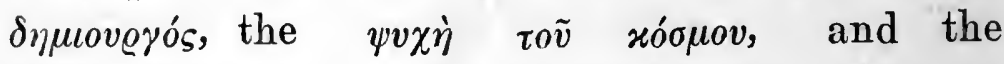

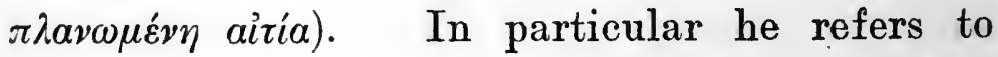
Tim. 37 A where the World-Soul is spoken of as

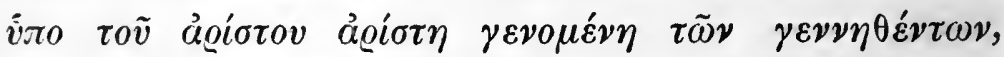
comparing Laws $896 \mathrm{~A}$ where it is $\pi \varrho \omega ́ \tau \eta ~ \gamma \varepsilon \dot{\nu \varepsilon \sigma \iota \varsigma}$

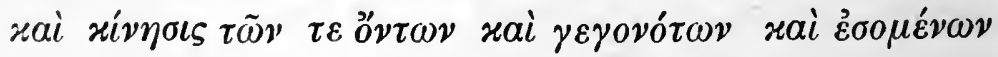

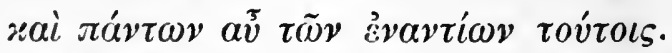

Now if we could suppose Plato to be the author, we should, I think, have to accept this explanation. Its real defect is that it does not account

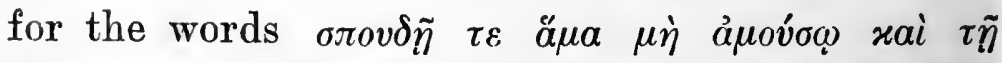

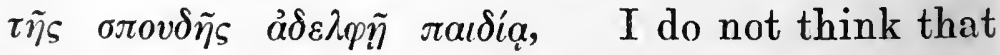
Plato could, even in jest, have referred to his deepest metaphysical beliefs in this way: he 
refers to his work in the Laws $(769 \mathrm{C})$ as $\pi a i \delta i a$, but that is quite another matter. Moreover is it not a trifle absurd to conceive of Plato exhorting

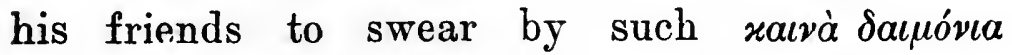
as the $\delta \eta \mu$ overós and the $\pi \lambda a v \omega \mu \varepsilon \dot{v} \eta$ airia.

Further, I agree with Richards ${ }^{1}$ that there must be something wrong in the text of the last sentence, with its repetition of the word $\dot{\varepsilon} \pi \circ \mu$ -

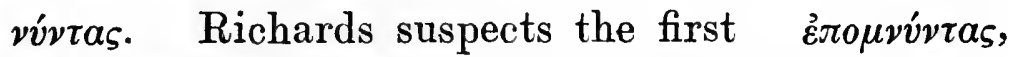
but I believe it is the second that requires emendation. Now if we can point to a passage in Plato which at once supplies a meaning to the invocation and a way out of the textual difficulty, we shall have very strong evidence for the spuriousness of the Epistle.

Such a passage $I$ find in the closing words of Agathon's speech in the Symposium (197 E) where

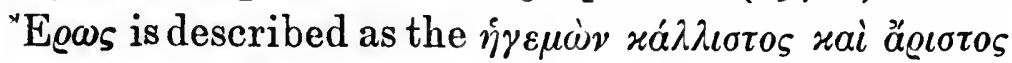

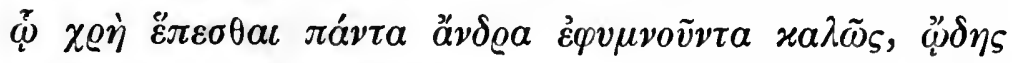

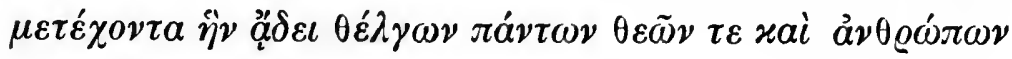
vón $\mu \alpha$ :

which is immediately followed by the peroration,

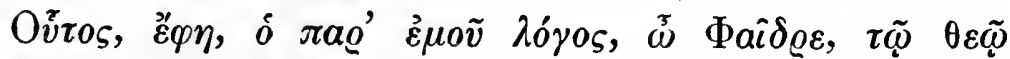

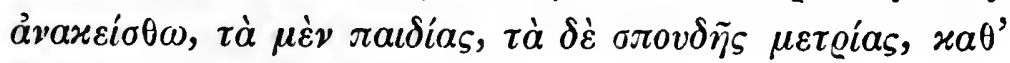

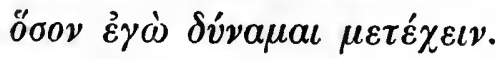

On the strength of this I would read $\dot{\varepsilon} \varphi v \mu \nu o \tilde{v} \nu \tau \alpha_{\varsigma}$

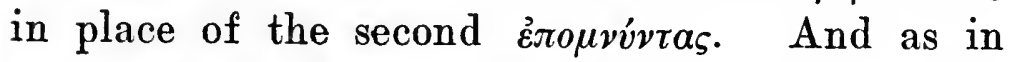

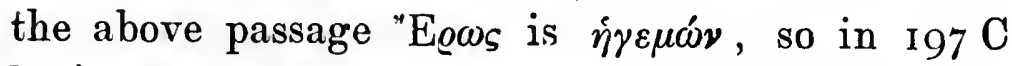

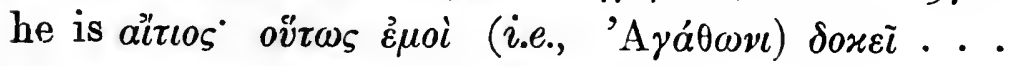

I. Classical Review, 19oo, p. 99. 


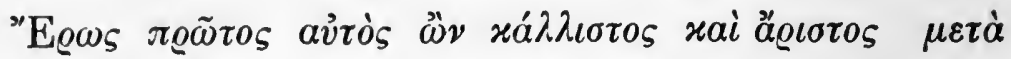

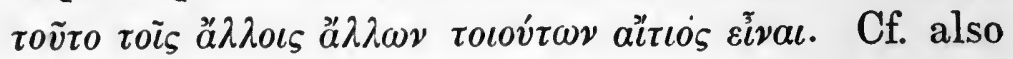
I97A where it is asked xai $\mu \dot{\varepsilon} \nu$ $\delta \dot{\eta} \tau \dot{\eta} \boldsymbol{\nu} \gamma \varepsilon \tau \tilde{\omega} \nu \zeta \omega \omega \nu$

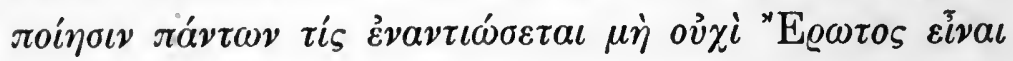

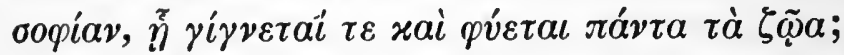

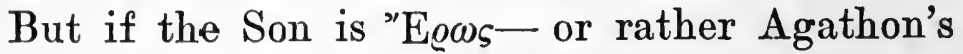
"Eows - who is the Royal Father? Agathon says nothing of Love's parentage, and the only father assigned to him in the dialogue is Poros, in the speech of Diotima. And at first one might perhaps be inclined to think that our author meant that if we follow the path of true philosophy we shall "come to know Plenty-the true riches." But xúoos is little appropriate to such a reference, and the language of the last clause rather suggests that the writer is thinking of the Idea

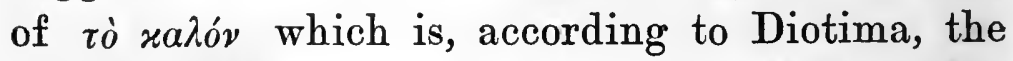
highest object of man's knowledge. My belief is that he has a confused memory of the Symposium

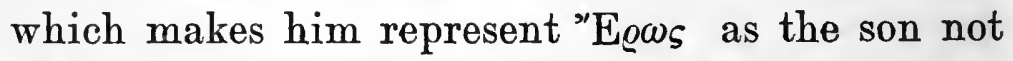

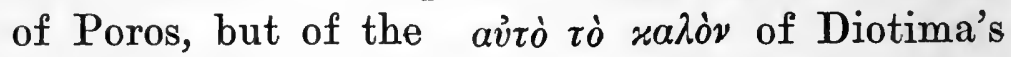
speech. The actual relation between them according to Diotima is given at $12 \mathrm{~B}$ : rov́cov $\tau o \tilde{v} x \tau \eta \dot{n} \mu a \tau$ (i.e., the possession of the beatific

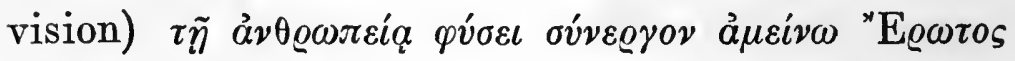

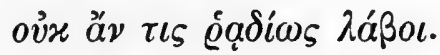

This supposition, however, of a misconception on the part of the borrower, makes it all the more necessary to give further justification for the theory of a borrowing from the Symposium. I therefore add several words and phrases from the 
rest of the Epistle which seem to support my theory.

With 322 D :-

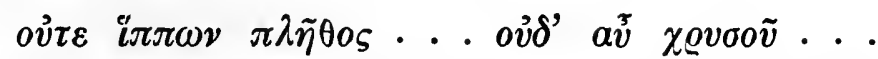

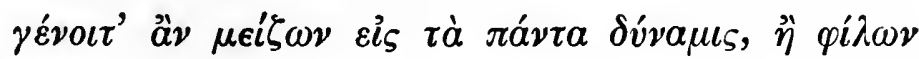

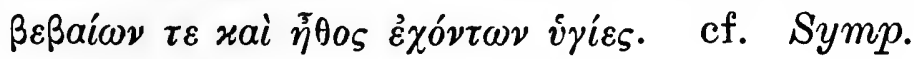
I $78 \mathrm{C}:-$

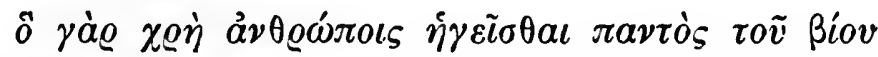

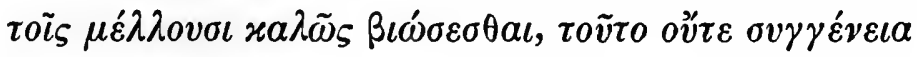

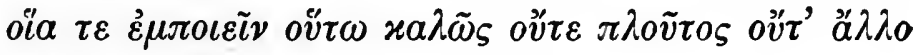

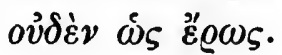

and $183 \mathrm{E}:-$

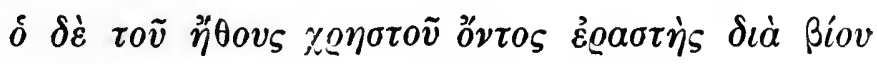

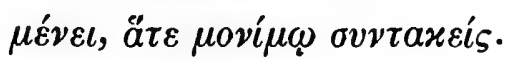

and $188 \mathrm{D}:-$

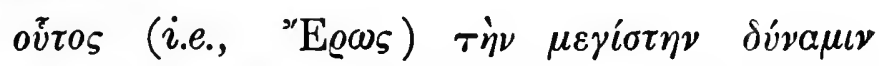

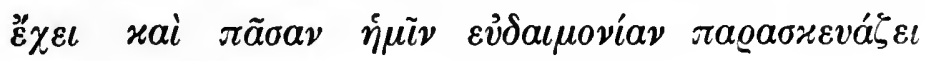

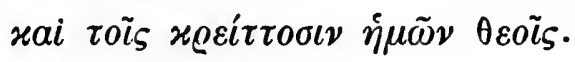

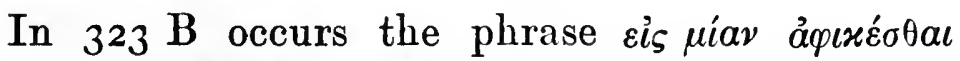

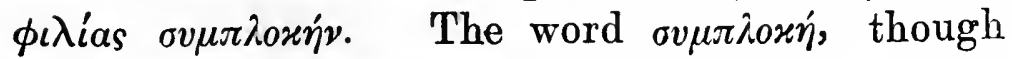
not rare in Plato, does not seem to be used by him in this tropical connotation. But it is suggested in the speech of Aristophanes, where we find four instances of the noun and its cognate verb within a page-in fact it is the vox propria

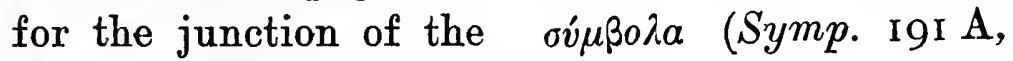

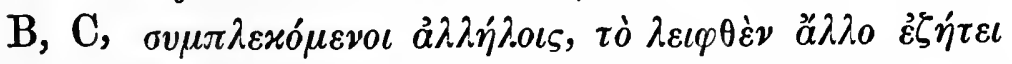

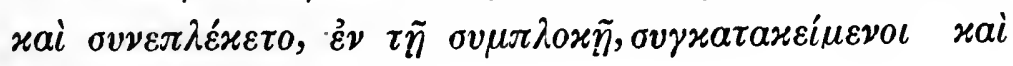

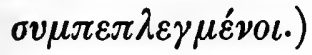




\section{AUTHORSHIP OF PLATONIC EPISTLES}

The phrase $\sigma v \mu \varphi \tilde{v} \sigma \alpha \iota$ «ai $\sigma v \nu \delta \tilde{\eta} \sigma a \iota \quad(323 \mathrm{~B})$ is a reminiscence of Hephaestus' words at $S y m p$. I92 F

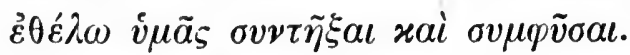

The thought that words coming from Plato have more power than a magic incantation $(323 \mathrm{~B})$ is taken from Symp. $215 \mathrm{C}$, ov̀ $\delta$ ' ėxeivov (i.e.,

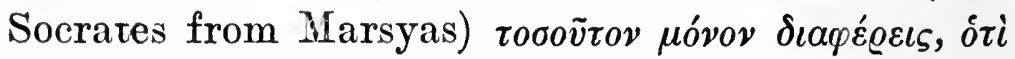

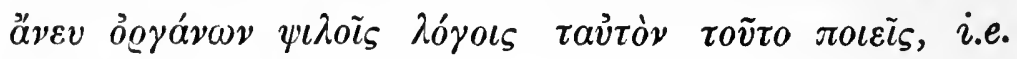

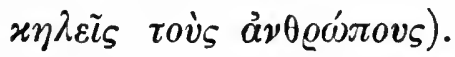

The rare use of $\pi a \varrho \varepsilon i x \varepsilon$ as impersonal

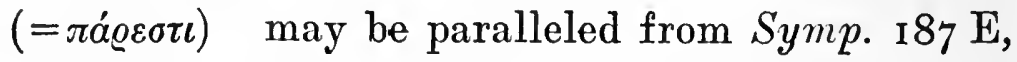

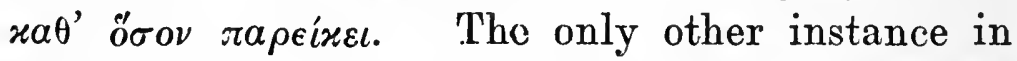
Plato seems to be Laws 734 B. Passow does not quote the impersonal use from any other author.

A few other points in language may finally be noted :-

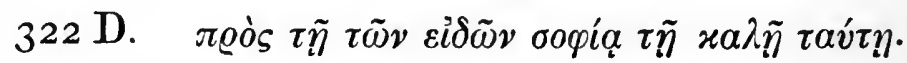

I do not agree with Ritter that Plato could not have written this. It is half in jest. For $x a \lambda \tilde{\eta}$

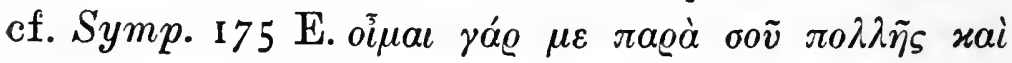

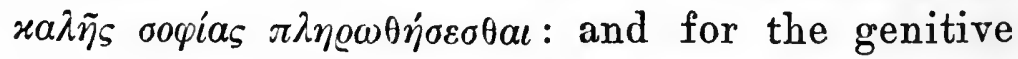

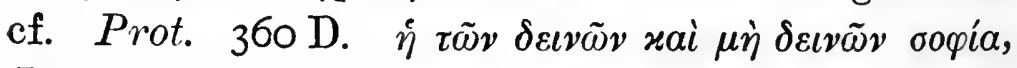

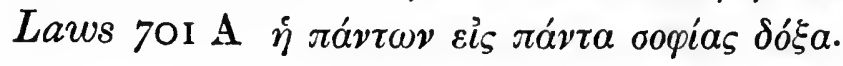

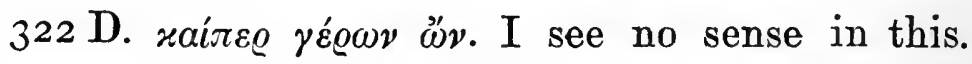

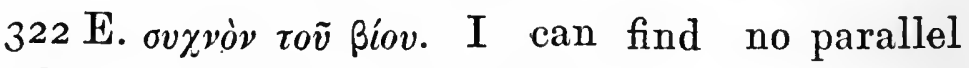
to the use of ovqvós + part. gen.

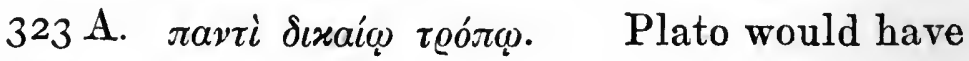

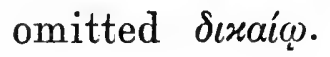




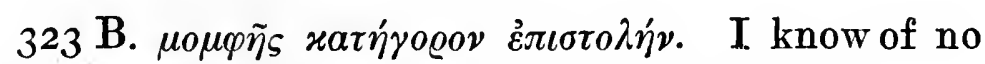

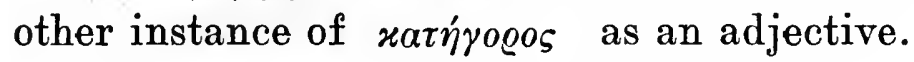

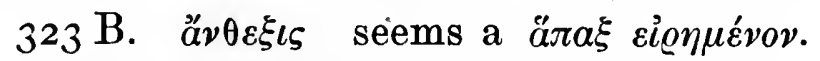

323 C I-3 contain a harsh anacoluthon, though perhaps not harsher than some in Plato. The text is perhaps wrong. 


\section{EPISTLE VII.}

The seventh letter is by far the most important and the longest of the collection. It is, moreover, believed to be authentic by a large number of scholars, and it is commonly employed by historians as containing valuable information with regard to the history of the period. The general correctness of its historical information has indeed never, so far as I am aware, been impugned, and those who reject the Platonic authorship are forced to concede that the writer must either have been a contemporary and close acquaintance of Plato, or have used Plato's own memoranda. The situation presupposed in the letter is clearly seen from the reference to Dion's downfall as a

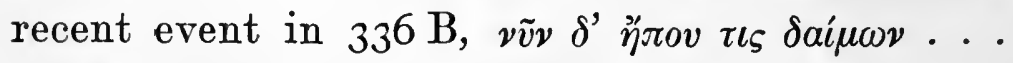

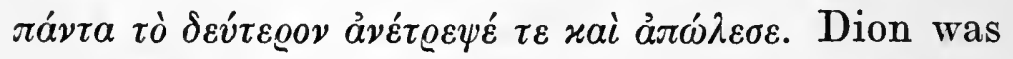
murdered by the Athenian Callippus in 353 B.C., and our Epistle therefore was, or purports to be, written in 353-2.

Meyer ${ }^{1}$ implies that the date of composition is 352 B.C. It was in this year that Callippus was overthrown by Hipparinus, son of the elder

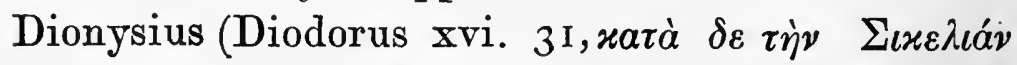

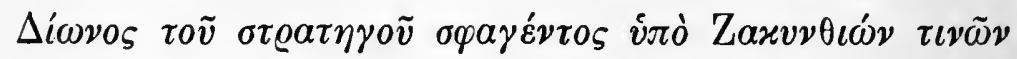

I. Vol. v, § 350 . 


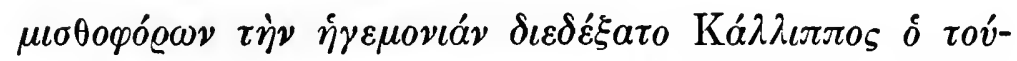

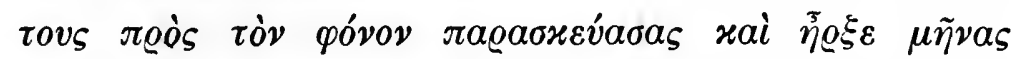

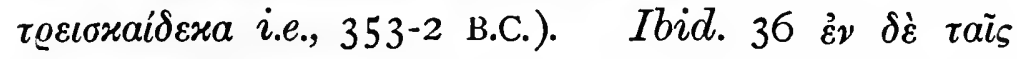

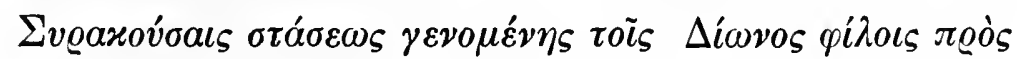

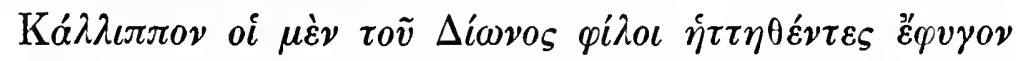

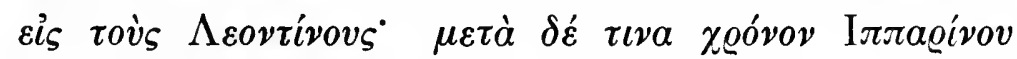

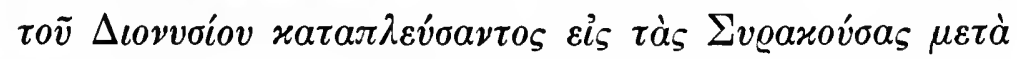

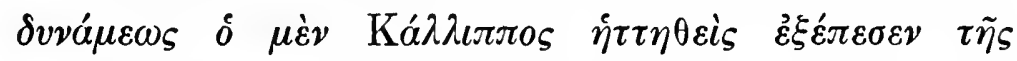

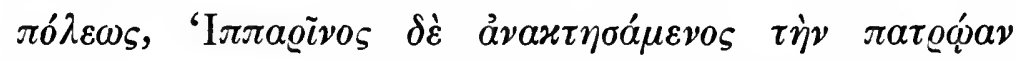

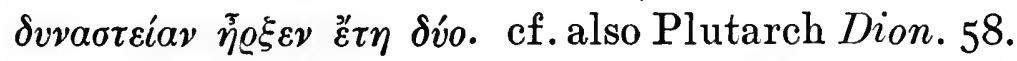

It does not seem clear whether Meyer takes Ep. vii. to have been written after the victory of Hipparinus or not. I am inclined to think it was written before this event, though there is no certain evidence: the tone seems to be more appropriate to a time when Dion's party were still under the domination of Callippus, and my interpretation is based on this assumption. Plato's recommendations both in Epp. vii. and viii. amount to the same thing-a settlement by consent: but his correspondents seem to be in a better position in viii.

The latter Meyer dates at 35 r B.c.: and it is to his acumen that we owe an almost certainly correct interpretation of the words $\chi \alpha$ $\varrho \iota \nu ~ \tau \tilde{\eta} s$

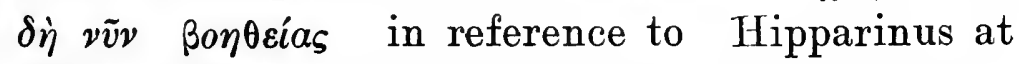
$356 \mathrm{~A}$ : he takes them to allude to the assistance given by Hipparinus to the friends of Dion in delivering them from Callippus. The words had been strangely overlooked by other commentators.

Meyer also refers to Polyaenus Strateg., v. 4- 
an important reference for our purposes, as it states that Hipparinus made his attack from Leontini, where, according to Diodorus, as quoted above, the friends of Dion were in exile:-

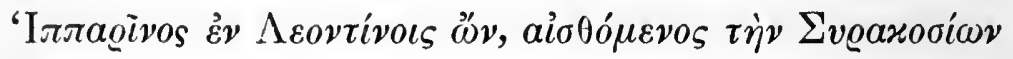

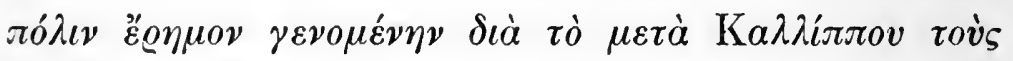

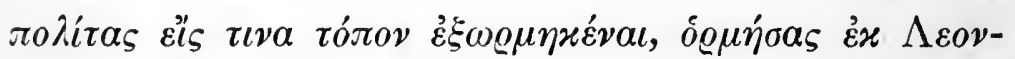

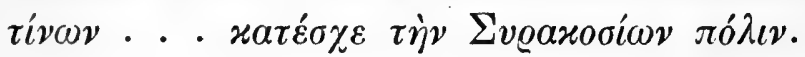

It should be admitted at the outset that the document deals with a large variety of topics, that it abounds in what may be called digressions, and is difficult to view as an artistic unity : though as a result of our discussion we shall, I hope, be enabled to see the line of thought which connects the whole. The apparent confusion will not be less in a summary: nevertheless it seems convenient to give an outline of the argument, for purposes of reference, as has been our plan with the other Epistles.

Plato replies to a letter received from the friends of Dion that he willingly places himself and his advice at their disposal, if their views are the same as those held by Dion himself. What those views were he himself knows well and will set forth. The method of his exposition (which he begins after a short incidental comparison of Dion and Hipparinus) is autobiographical: that is to say, he gives an account of his own Sicilian experiences, including the private and political experiences which brought him to visit Sicily 
originally. (The question as to how far this method is relevant and appropriate must for the present be postponed.)

As a young man, Plato says, he looked forward to a political career. Elated for a moment at the establishment of the Thirty, he was speedily undeceived, particularly owing to their treatment of Socrates. On their expulsion his political hopes revived, only to be speedily overthrown, this time wholly and finally, by the unjust condemnation of his master. He now realized the hopeless corruption of all contemporary forms of government, and was compelled to declare that the only salvation lay in the possibility of philosophers becoming kings or kings philosophers (326 B). Such were his views when he came to make his first visit to Italy and Sicily. The western Greek world he found as corrupt and hopeless as Greece itself: but it so chanced (was it more than chance, he asks) that he came to Syracuse and fell in with the young Dion. Inspired by the philosopher's enthusiasm, Dion determined to live a life of virtue amidst a world of sensualists. After the death of the elder Dionysius, Dion, wishing others besides himself to be converted, sent an urgent invitation to Plato to return to Syracuse: the younger Dionysius was to be made the philosopherking. After much urging Plato reluctantly came back to Syracuse, his ultimate reason being his desire to prove to his own conscience that he was more than a mere visionary theorist. On his 
arrival, however, he found Syracuse seething with sedition; and before four months were over Dion was banished on a charge of treason. Plato himself was retained in a kind of honourable captivity, while he made fruitless attempts to persuade the tyrant to a better mind (330 B).

Such then was his first visit to the court of Dionysius II. Before speaking of his second visit, and the reasons which induced him to make it, he will give Dion's friends the counsel that they ask for: so that he may not lose sight of the real present business owing to what is after all a digression on past events.

Instead of proceeding forthwith to advise certain definite political actions, as the reader might perhaps have expected him to do, Plato insists upon the antecedent condition under which alone any advice can or should be given. This is, briefly, a readiness on the part of the person advised to be obedient: advice is not to be forced upon anyone. To put the same thing in other words, the person must be genuinely seeking counsel, not merely asking for his own desires and passions to be gratified. This applies both to the physically and the morally sick, both to the individual and the state.

On these principles, then, he would advise them, as he had jointly with Dion advised Dionysius, in the first place to live their daily life with selfcontrol, and in such a way as to procure themselves true and trusty friends. Let them be 
warned by the example of the elder Dionysius, who came into difficulties owing to the treachery of his hireling confidants and the want of real friends.

It was with the father's example in view that Plato had warned the son and advised him to restore the ruined Greek cities in Sicily under constitutional government. But the slanders of Plato's detractors prevailed against him and sent Dion into exile. Nevertheless Dionysius, if he could not be corrected by words, was corrected by deeds, when Dion returned and made his coup. But the Syracusans treated him ill, accusing him of tyranny-seeking, and in the end he was murdered by two pretended friends from Athens-as to whom Plato says that their evil deeds must not be made a matter of reproach to Athens herself, for it was Athens that had sent Dion a true and loyal friend in the person of Plato himself $(334 \mathrm{C})$.

All this narrative of past events, Plato continues, has been by way of counsel to the present applicants therefor. That counsel, which he now gives for the third time, is that Sicily must be subjected, not to a despotism, but to a constitutional government. The failure to accept that advice had brought Dionysius to a dishonourable existence, and its acceptance had brought Dion to a noble death. For indeed his death was noble, Plato insists : no man is exempt from dying, and to suffer an unjust death is better than to live an unjust life, as only the mean-souled sensualist 
fails to recognise. This thought leads Plato on to an encomium on Dion, who would have done so much as a philosophic ruler, who would have given Syracuse and the whole of Sicily the blessings which come with the rule of Law. However fate ruled otherwise, and Dion's friends must strive to follow in his footsteps and pray for a happier fortune therein than Dion experienced himself. His hearers, Plato thinks, may regard all this as a salutary counsel of perfection indeed for the future, but as impracticable in view of their present and urgent difficulties. They must know that there will never be an end of those dificulties, there will never be an end of strife and bloodshed, until the victorious party cease to misuse their victory and to insist on measures of

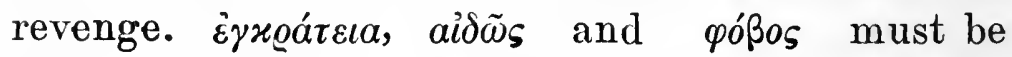
their watchwords. 'The victors, if they truly desire a settlement, must submit themselves to Law, and must take immediate measures to establish a constitution. This advice is not indeed identical with the project of a philosophic ruler which he and Dion had once fostered, but it approximates thereto, and is the most salutary counsel that can be given under present conditions (337 E).

So much for the advice and charge to the friends of Dion. Having narrated his experiences on his first visit to the younger Dionysius, Plato will now go on, as he promised, to describe his second visit. He had persuaded the tyrant to let him depart in 
366 owing to a war having broken out in Sicily, but he had agreed to return on the re-establishment of peace, and on the understanding that Dion was to be recalled from exile. Accordingly, the war coming to an end, Dionysius recalled him with earnest entreaties. Dion, however, he desired to remain away a while longer. Plato was moreover urged by Dion to obey the invitation of Dionysius, and it was represented to him that the tyrant's philosophical enthusiasm had revived. After considerable reluctance Plato consented to come, persuaded chiefly by Dion and his friends at Athens, by Archytas of Tarentum and by the mingled promises and threats of Dionysius. $\mathrm{He}$ felt that his first business was to test the genuineness of the tyrant's new-found enthusiasm for philosophical studies. The method of this testing was to set before Dionysius in plain terms the difficulties of the study, the labour and time needful for its pursuit. He found, however, that he could not say all he would on the topic, as Dionysius represented himself as already far advanced on the path of philosophy. The mention of this fact leads Plato to remark that he learnt afterwards that Dionysius had composed a kind of metaphysical handbook (34I B), in which he claimed to treat the subjects of Plato's teaching in a wholly original way. ${ }^{1}$

The pages of the Epistle which now follow

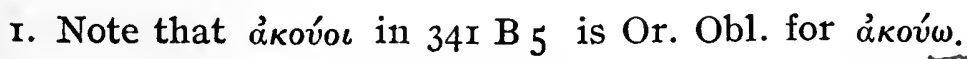


$(34$ I B-345 C) form a long digression, the relevance of which to the letter in general we must admit to be small : its object is to protest against this work written by Dionysius, and to show how completely he had failed to understand Plato in supposing that the highest mysteries of Plato's philosophy could or should be expressed in writing : this is shown more particularly in the philosophical passage extending from $342 \mathrm{~A}-344 \mathrm{D}-\mathrm{a}$ passage which it would be inconvenient to summarise at this point; it is sufficient to remark bere that it describes the true mode of apprehending the Ideas.

This long digression, if it be right so to style it, concludes with the remark that if Dionysius had really appreciated the Platonic philosophy he would never have dishonoured its author in the way that he did. How the tyrant dishonoured him, Plato will now relate $(345 \mathrm{C})$ : in other words he will resume the account of his experiences on the occasion of his visit to the Syracusan court in 36I-O B.C.

Having hitherto allowed Dion to retain his property and enjoy its revenues, Dionysius now prohibited his agents from sending them to the Peloponnese, as though he had completely forgotten about the agreement made in correspondence with Plato: the revenues, said Dionysius, should belong not to Dion, but to his son, Dionysius' own nephew. 'This was in the summer (of 36r). On Plato saying that he would not stay 
with this insult to Dion, Dionysius endeavoured to mollify him, but not succeeding therein he promised to facilitate his departure. Later, however, he found a device to retain him, making a proposal that Dion should retain his property and continue to reside in the Peloponnese, though not as an exile, and should be allowed to visit Syracuse 'when it should be jointly determined by Dion, his friends, including Plato, and Dionysius.' Plato, his friends and those of Dion, were to give guarantees for the observance of this agreement. This compact was agreed upon by Plato and Dionysius, and after reflection he agreed to remain, stipulating, however, that he was not to be held responsible for Dion's actions, but that Dion should be written to and asked whether he would assent to the compact.

Shortly afterwards, however, Dionysius turned round and asserted that half the property was to be Dion's, half his son's, and that he would sell it all and give half of the proceeds to Plato to convey to Dion. Plato, astounded, thought it absurd to argue any further, but nevertheless said that Dion's reply must be awaited; thereupon Dionysius sold the whole property to whom he would, without saying a word to Plato. The latter refrained from further expostulation: he was now ' like a bird in a cage,' trying to get away and scared back by the tyrant. Shortly after this Dionysius made an attempt to reduce the pay of his mercenaries, which caused a mutiny, for which 
Heraclides was charged as responsible. Heraclides escaped and Dionysius began to hunt for him, but unsuccessfully. A meeting ensued in the Garden between Dionysius, Plato and Theodotes. The two latter gained from the tyrant a promise not to molest Heraclides on the condition of his remaining in the Peloponnese. The next day Theodotes informs Plato that Dionysius has broken his word, and is seeking to arrest Heraclides. On being expostulated with, he repudiates the agreement altogether. Heraclides, however, got away to Carthage (349 C).

Hereupon Dionysius removes Plato from the Acropolis to the house of Archedemus, on the pretext that a women's festival is to be held in the Garden. Consultations here went on between Plato and Theodotes, in which Dionysius sees a fresh pretext for quarrelling: he complains, through a verbal message, of being slighted in favour of Dion and Dion's friends. After this, Plato, residing amongst the mercenaries, learns of an attempt to be made upon his life by the peltasts, and appeals for succour to Archytas of Tarentum, who sends a ship and requests Dionysius to let Plato go: which he now does.

On reporting his experiences to Dion, whom he found at Olympia, Plato was besought to join in an enterprise of Dion's against Dionysius, but refused to turn against one whose hospitality he had enjoyed, being disinclined to the proposal moreover for other reasons. The refusal of Dion 
and his companions to listen to Plato's proposals for reconciliation was the cause of all the subsequent disaster. Nevertheless Dion's projects for gaining political power had been just, and if he had succeeded as he hoped he would not have misused that power. Preferring the suffering to the doing of injustice, he met his death when on the verge of consummating his success.

The advice that is the outcome of his experiences, Plato concludes, has been already communicated. He has thought it proper to give the above account of his third visit, to meet the absurd and unreasonable misrepresentations made against him. He will be well content if he has succeeded in explaining his conduct as being more reasonable and defensible than had been imagined.

It is plainly our first business to discuss the form of this Epistle, which must strike every reader at first as perplexingly discursive and abounding in digressions.

At the outset the writer professes to be replying to a request for advice from the friends of Dion as to their future action. Why does he not answer that request in a straightforward manner with definite and clearly expressed counsel? Why does he go into a detailed account of his early political experiences in Athens, and then of his visits to Sicily, telling his readers 'their own dream'? Why are the 'digressions' so extensive that the actual $\sigma \nu \mu \beta o v \lambda \eta$ ' only extends from $336 \mathrm{E}-337 \mathrm{E}$ ? How can we defend the most irrelevant philoso- 
phical digression? 'Quid hoc aliud est nisi consulentes eludere?' indignantly asks Karsten, whose work is called by Ritter 'a veritable arsenal of criticism' against this letter.

Now these very real difficulties have been hardly dealt with at all save by critics who declare the letter spurious, notably Karsten and Steinhart. Supporters of its authenticity have been content with appealing to general impressions, the naturalness of the style, the Platonic diction, and the absence of internal contradictions. I would point out first what seems a very obvious fact, that what we call 'digression' is eminently characteristic of Plato. There is not one of the more important dialogues but has several subjects of equal interest for the discussion: and it is, I suppose, generally realised nowadays that it is a mistake to look for one primary theme and subordinate the rest thereto. It is an inadequate account of the Sophist to say that it seeks for a definition of the Sophist, or of the Phaedrus that it is a treatise on Rhetoric. Even the Republic is more than a demonstration of the superiority of Justice to Injustice, though that is its ostensible theme, and the thesis which binds the whole dialogue together. The metaphysical digression extending through the latter part of Book $v$ and the whole of vi and vii is proportionally longer than the metaphysical digression of our Epistle, though of course it is incorporated more artistically and led up to more gradually. 
Again, what of the famous Tenth Book of the Laws or the myth in the Politicus? It might, I think, be plausibly maintained that the habit of digression grew upon Plato more and more, and a consideration of the point would probably confirm the generally accepted sequence of groups of dialogues. When he wrote Ep. vii. Plato was about 76 , an age at which any letter-writer might be expected to digress.

But are the digressions after all so irrelevant as it is supposed? In answering this question we must take into account the letter from Dion's friends to which Plato is replying. Is it not very probable, as Ritter suggests, that that letter had contained reproaches, expressed or hinted, against Plato as the author of their disasters? Is it not natural that they should have made such unreasonable accusations in the first days of bitter disappointment after Dion's murder? Callippus had been a friend of Dion, they would exclaim, and so had Plato: they were both Athenians (cf. 334 B) : was not one as bad as the other?

I suspect, moreover, that the request for advice was couched in such terms as might be expressed more bluntly thus :- 'You got us into our present difficulties: it is your business to get us out again.' It is quite obvious, I think, both from $324 \mathrm{~A}$

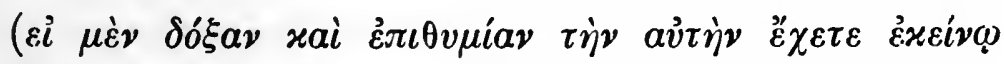
x. $\tau$. $\lambda$.) and from the passage $330 \mathrm{D}-33 \mathrm{I} \mathrm{D}$, where he distinguishes between the genuine applicant for advice and the pretended applicant, 
that the relations between Plato and his correspondents are delicate, and that he has to feel his way with great care. The reason why the $\sigma v \mu \beta \sigma v \lambda \eta^{\prime}$ is so long deferred and wrapped up in so much autobiographical explanation and historical narrative, is that the only $\sigma v \mu \beta \sigma v \lambda \dot{\eta}$ which Plato has to give is of a very different nature from what his correspondents expected. Dion's followers were not penetrated with Dion's spirit, or Plato's: their desire was for reprisal, revenge, and victory, whereas Plato saw that the only hope lay in settlement by compromise: they desired one of their number, probably, to be a monarch, more or less constitutional (perhaps Dion's son, Hipparinus), whereas Plato by this time realised that the project of a philosophical monarch who would rule constitutionally must be given up at Syracuse: he pins his faith now to

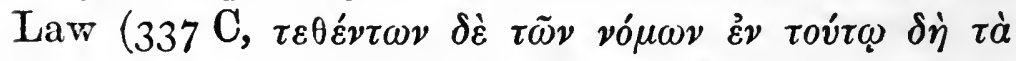

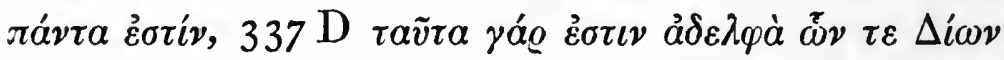

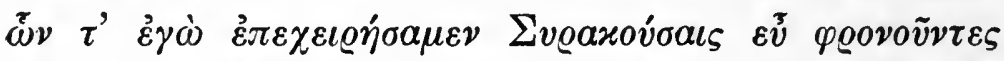

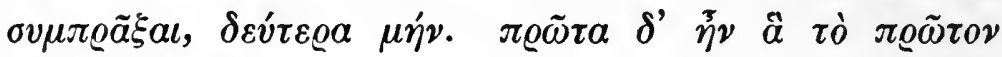

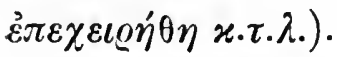

I have suggested above that Plato writes partly with the object of meeting charges brought against him. If we may accept Karsten's emendation of $\lambda \varepsilon \gamma \sigma \mu \varepsilon \dot{v} \omega \nu$ for $\gamma \varepsilon v o \mu \varepsilon \dot{v} \omega \nu$ in $35^{2} \mathrm{~A}_{4}$ (I take it that the copyist's eye had been caught by $\tau \dot{a}$ $\gamma \varepsilon v o ́ \mu \varepsilon v a$ in A 6), we have then a distinct statement to that effect.

The account of the second journey to Dionysius 
II. is given, Plato says, for the purpose of replying to these charges. It is to be noted, that it is only the account of the second journey that he regards as an apologetic: that is the ráogerov, whereas the account of the first journey he must regard as

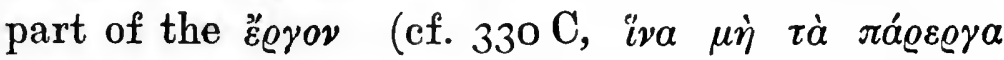

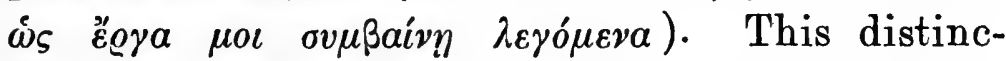
tion is perfectly just: the account of the second journey does nothing directly to further the Eqov, which is the advising of Dion's friends : the accounts of the first journey, and of the visit to the elder Dionysius, and of his earlier Athenian experiences, do further the "̋oyov, because the advice Plato has to give is 'Be like Dion,' and the narrative shows what Dion was like. This is quite clearly put in $324 \mathrm{~B}, \tau^{\prime} \delta^{\prime} \delta^{\prime} \eta^{j} \nu \delta$

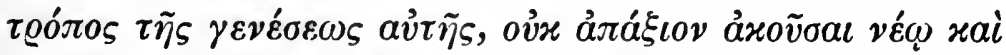

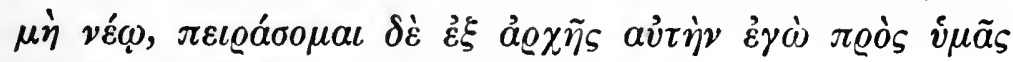
$\delta \iota \epsilon \xi \varepsilon \lambda \theta \varepsilon \tilde{\varepsilon} \nu$.

The account of the second visit to Dionysius II. does not show what Dion was like, for the very good reason that it did not bring Plato into contact with Dion, who was still in banishment.

These considerations, I think, enable us to understand the general scheme of the letter. There is more difficulty, however, in seeing the relevance of the philosophical digression which is incorporated in the account of the final visit to Syracuse. No doubt a digression in the dialogues is often an end in itself; nevertheless I think Plato must have considered this interlude as in 
some way relevant to the purpose announced in $35^{2} \mathrm{~A}$ as quoted above. We may reasonably suppose that his correspondents had complained or hinted that Plato was as much to blame as Dionysius for the quarrel between Dion and the tyrant, which had dashed to the ground the hopes entertained by Dion's followers of converting Dionysius into a constitutional monarch. Let us endeavour to regard events from their standpoint. It is fairly evident from 327 B-C that it was the ethical and political side of Plato's philosophy that had attracted Dion in the first place. Whether he was also deeply interested in the mathematical and metaphysical side we have perhaps not enough evidence to determine. But it is surely reasonable to suppose that many or most of the friends whom Dion gathered round him were solely attracted by projects of political reform.

We learn from Plutarch (Dion, c. I3) that at his arrival in Syracuse in 367 B.c. Plato plunged Dionysius and his court into mathematical studies, for which their enthusiasm was not long-lived; and on his own confession (Ep. iii. 3ig C,D), he actually dissuaded the tyrant from carrying out political reforms until his philosophic apprenticeship should be completed. Dion doubtless had himself enough confidence to trust in the wisdom of Plato's policy : but it is very natural that many of his followers were perplexed and dissatisfied by it. During the period of Dion's power (357 B.C.) 
these feelings would not have found any need of expression; but after Dion's murder in 353 we may imagine his party's feelings. They would represent to themselves that they were in a worse case than they would have been in if Plato had never appeared on the scene at all. What had Plato's philosophy done? Had it not been the cause of the alienation of Dion from Dionysius? Had it not dissuaded Dionysius from the projects which he shared in common with themselves and Dion? How much better would it have been to be under the rule of a reformed Dionysius than under the domination of a foreigner like Callippus who had treacherously murdered the man in whom all their hopes had rested? Besides, Dionysius, if his philosophical enthusiasm had waned at first, had shown himself once more enthusiastic in 36r B.C. So far as they could judge (cf. $339 \mathrm{~A}$, $\delta i x a \iota s s \dot{\eta} \lambda \dot{\varepsilon} \gamma \varepsilon \iota \nu x \tau \lambda$.$) he knew as much philosophy$ as Plato, more perhaps, for he had set down things in writing, intelligible for all to understand, which Plato had never done. The fact was, Plato was jealous of his attainments-that was the reason at the bottom of the quarrel.

Such, I conceive, were the feelings of Plato's correspondents in 353-2 B.C., and I do not see how they could well have been answered save in the way Plato has answered them. The cardinal point to realise is that Dion's party had come to regret Dionysius, and to see in his restoration the best chance of getting rid of Callippus. No doubt 
they were not all of one mind: some favoured Dion's son, others again the other Hipparinus, son of the elder Dionysius. But the supposition of a philo-Dionysian section amongst the late followers of Dion in 353-2 appears to me to throw a great deal of light on Epistle vii, and also to explain the proposal made in Epistle viii $356 \mathrm{~A}-\mathrm{B}$, to the effect that Dionysius should be one of three joint rulers,-a proposal, I may incidentally remark, most unlikely to have occurred to any forger.

Having then seen that the philosophical digression is not, properly speaking, irrelevant to the design of the letter, we may pass on to the difficulties connected with its substance. These may be admitted to be serious, for the language and its interpretation are both difficult. So much indeed is this so that Ritter, who is followed by Odau, would excise the whole of the passage from 34I A $8-345 \mathrm{C}_{3}$ (with the exception of one sentence) as a later interpolation. That this excision is impossible I shall endeavour subsequently to show : but in the first place I propose to paraphrase and explain the text.

The pretended knowledge which Dionysius had put forth in his book concerned $\pi 0 \lambda \lambda \grave{a}$ xai $\tau \grave{\alpha}$ $\mu \varepsilon ́ \gamma \iota \sigma \tau \alpha:$ : we are not at first given any more definite information as to its contents. There is not, and never will be, any writing of Plato's own

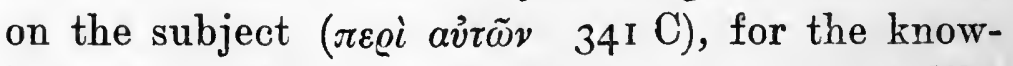
ledge thereof cannot be expressed in words like other knowledge. If it could be so expressed, 
Plato himself would be the fittest person to express it. To have done so would have been a noble

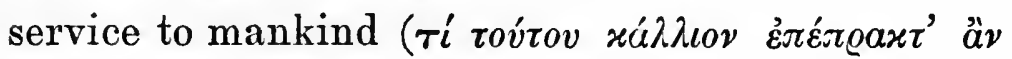

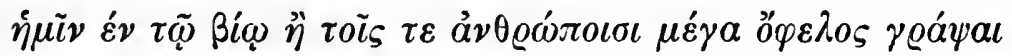

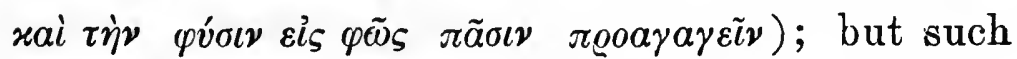
knowledge is only fitted for the few: the many will either laugh it to scorn or puff themselves up in a vain conceit of understanding.

From this whole description there is of course no doubt that what Plato refers to is a revelation of the nature of the Ideas. It is perfectly true to say that he had never attempted a description of them. In a well-known passage of Rep. vi, he confesses his inability to describe the Idea of Good, save in an image, and it is clear from the whole context there that the same applies to the other Ideas. All he can do is to describe a method which shall finally lead to their apprehension, the nature of which is incommunicable and intuitive.

'I propose,' he says in introducing his exposition, 'to speak at more length on the subject. For perhaps my assertion (of the incommunicable character of the apprehension of $\tau \dot{\alpha} \mu \dot{\varepsilon} \gamma(\sigma \tau \alpha)$ may be made clearer if I say what I have to say.'

The exposition is as follows:-

In regard to any objeet-of inquiry we may

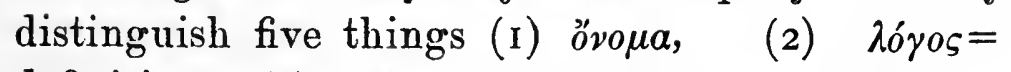

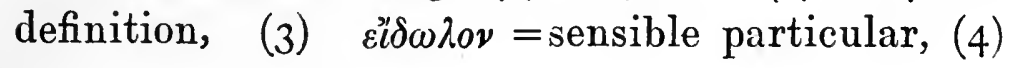




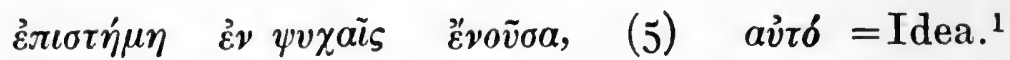
These distinctions may be exemplified in the case of Circle, but they apply to all objects of inquiry, without exception. Without grasping the first four we shall never attain to the apprehension of the fifth.

I pause here to comment on two difficulties raised by Karsten (pp. I9I-2). (I) This writer holds that 'fatendum hic dissimilia copulari' because 'óvora et hóros sunt cognoscendi instrumentum, $\epsilon \epsilon^{\prime} \delta \omega \lambda o \nu$ vero est pars ejus quod cognoscendum est.'

In saying this the writer wholly mistakes Plato's point of view. That which is to be known (quod cognoscendum est) is of course the Idea: and to speak of the $\varepsilon i \delta \omega \lambda \lambda_{0}$ or particular as a 'part' thereof is wholly unplatonic. As the word $\varepsilon$ i $\delta \omega \lambda$ is implies, and as every student of the Republic knows, the sensible particular is a partial and inadequate representation of the Idea. And it is the same with the hóros and the ovvora: these are no doubt in a sense ' cognoscendi instrumenta' but withal they are objects of a knowledge-a knowledge which is of course incomplete and inferior to that of the Idea. In point of fact the juxta-

I. In Laws $895 \mathrm{D}$ we have this classification incompletely and incidentally referred to :

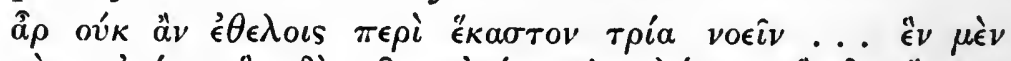

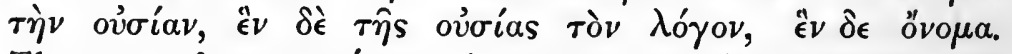
The use of $\pi \rho 0 \tau \epsilon i v \epsilon \iota \nu$ in $895 \mathrm{D}$ should be compared with its use in the Epistle. 


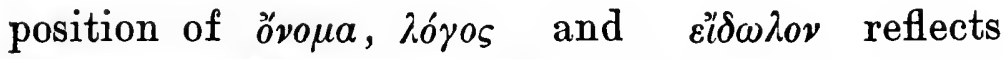
the views of three schools of philosophy. That reality was claimed for the oैvoua by a section of Neo-Heracliteans we know from Plato's critique in the Cratylus: the $\lambda$ óros or definition was regarded as representing the essential nature of an object by Socrates: ${ }^{1}$ while that which Plato called the $\varepsilon i \delta \omega \lambda o v$ possessed reality in the view of the Atomists. The juxtaposition then is perfectly natural.

(2) It is further objected that there is a confu-

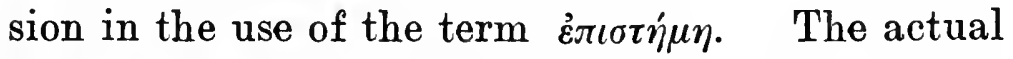
objections which Karsten urges seem indeed nugatory: but there is a real difficulty which he

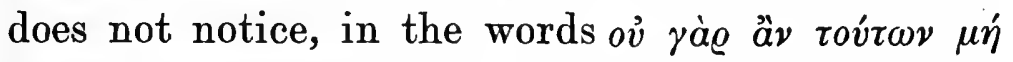

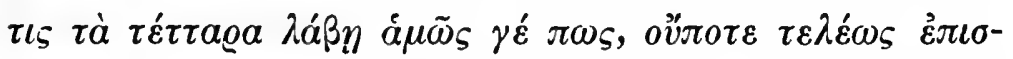

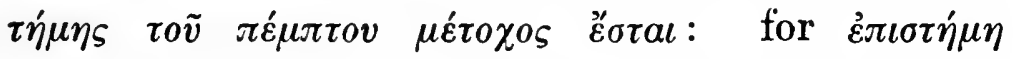

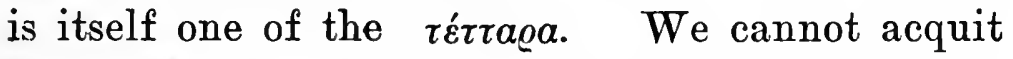
Plato of a certain unsatisfactoriness in the terminology here: he is, in fact, using $\dot{\varepsilon} \pi \sigma \tau \eta \dot{\mu} \mu$ first in the sense of scientific knowledge (commonly so called), and secondly of the apprehension of the Idea. It is natural that he should use it of the latter: but can we give any explanation of its use in reference to an inferior object of cognition? In answering this question we should note that

I. I should not be misunderstood as implying that Socrates himself conceived his position thus: all I would say is that, so far as his metaphysical position can be brought into line with Plato, the Atomists and the school of Cratylus, my statement is just. 


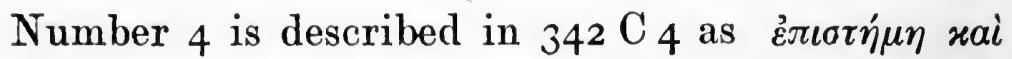

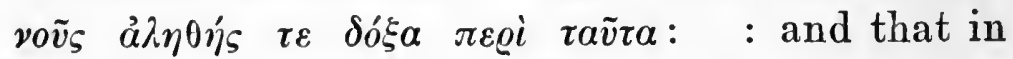

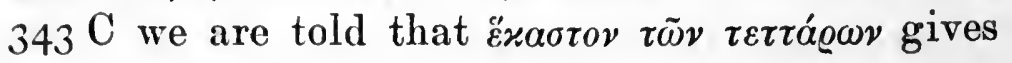
us an as object of cognition something which

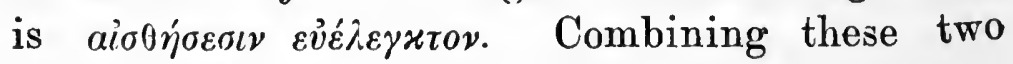

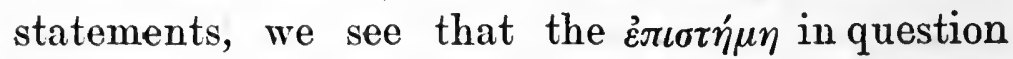
involves a sensible element, and yet is not the cognition of sensible particulars. Having seen this we may resume our paraphrase where it was left off, at $342 \mathrm{E} 2$.

Plato has just insisted that a grasp of the Four is essential to the knowledge of the Fifth (the Idea). He now proceeds to show why this is so. The reason is that the Four only give us rolóv $\tau \iota$, as opposed to $\tau \dot{\text { ò }} \boldsymbol{\nu} v$. He again takes 'Circle' as an illustration. Every circular object, every circle in a diagram, has an element of uncircularity. Again the name 'circle' has no fixity:

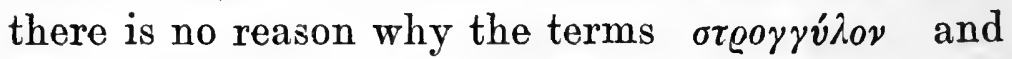
$\varepsilon \dot{v} \theta \dot{v}$ should not be interchanged. And the

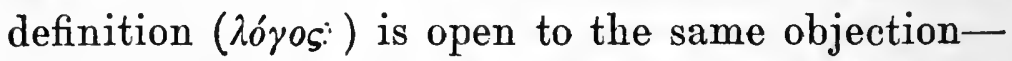
there is nothing ßéßalov about it. But of all the many inadequacies of the Four, the greatest is that just mentioned, namely that whereas the soul

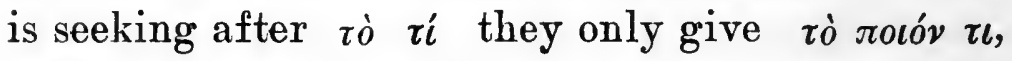
which being open to refutation by the senses fills the enquirer with the utmost perplexity. This perplexity, and the attendant discomfiture in the presence of interlocutors, does not of course arise when the enquirer is content to do without the truth (i.e., the knowledge of $\tau \dot{o} \pi \dot{\varepsilon} \mu \pi \tau o v$ ). But 
when he is required to 'show the Fifth' (i.e., to demonstrate the Idea) he appears as one foolish and ignorant to his questioners, who do not realise that the deficiency resides not in his mind but in the nature of the Four. Nevertheless a diligent and patient study and comparison of the Four will ultimately result in knowledge of the Fifth, provided the student be morally and intellectually akin thereto : otherwise such knowledge will never be attained. Metaphysical and ethical truth will come together, and it will come as a sudden flash of intuition.

Consequently, no serious thinker will put his most serious thoughts into writing, unless he is distraught.

It will be convenient now to resume our investigation of the meaning of the 'lower' $\dot{\varepsilon} \pi \iota \sigma \tau \eta \mu \eta$ (as we may call Number 4) in combination with the further question as to the signification of the лotóv $\tau \iota$. Is there any warrant for the distinction of $\tau \dot{o} \tau \dot{\imath}(=\tau \dot{o} \dot{o} v)$ and $\tau \dot{o} \pi o t o ́ v \tau$ in the dialogues?

Karsten (p. 197) states summarily that there is none, that the distinction originates with Aristotle, who moreover speaks not of $\tau \dot{j} \tau i$ but always of $\tau \dot{o} \tau \dot{\imath} \dot{\varepsilon} \sigma \tau \iota$. He further assumes that the distinction is identical with that between Idea and Particular. I believe him to be wrong in both points.

It is natural to think of the Theory of Knowledge expounded in the Sixth and Seventh books of the Republic. It will be remembered that in 
the Simile of the Line four mental states are

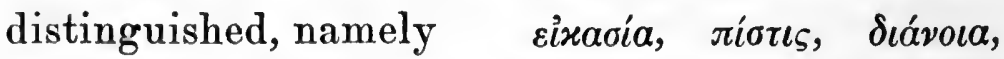

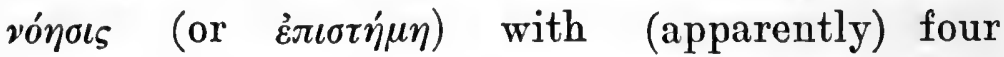
objects corresponding thereto. Sıávoıa is there used by Plato as a technical term for the cognition of the mathematician, which differs from that of the dialectician (vónoıs) in respect of its uncritical nature, its failure to test its hypotheses. In spite of this difference we learn at $533 \mathrm{C}$ that the mathematical sciences have some grasp of reality, though an incomplete grasp (ai $\delta \dot{\varepsilon}$ hoirai,

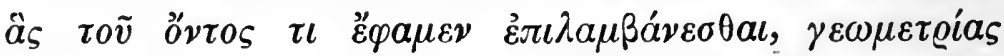

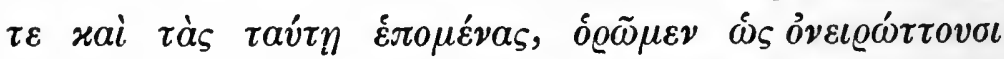

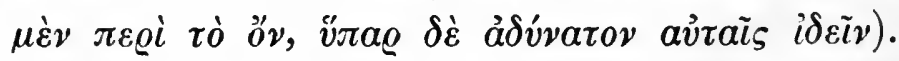

The mathematician, in fact, may be said to

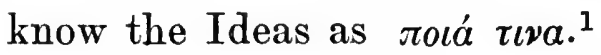

I. It may be objected here that $\tau$ ò ôv in the passage quoted refers not to the Ideas but to the whole of the upper half of the 'Line,' including the $\mu a \theta \eta \mu a \tau \iota \kappa a$.

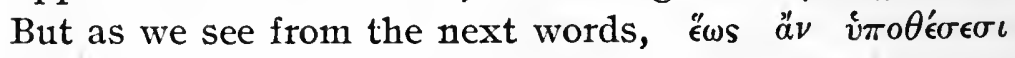

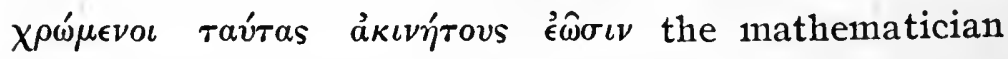
who adopts the method of validating his hypotheses becomes, ipso facto, a dialectician and sees $\tau o$ ö $v$ vँ $\pi \alpha \rho$. That is to say, although the $\mu a \theta \eta \mu a \tau i k a ́$ are, as Aristotle (Met. A. $987 \mathrm{~B}$ r4) tells us, $\mu \epsilon \tau a \xi \grave{v} \tau \hat{v} \nu$ aio $\theta \eta \tau \hat{\omega} v$, yet this intermediate nature, this incomplete reality, is derived from the attitude of the cognising subject. Throughout the Simile of the Line Plato inexplicitly projects the attitude of the subject into the object of cognition : the only reality of phenomena consists in their being partial representations of Ideas, their appearance in sensible form being due to the imperfect apprehension of the Ideas by the senses :

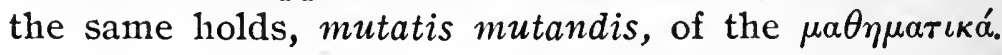


I take it then that $\pi o{ }^{\prime} v \tau$ includes $\tau \dot{\alpha}$ $\mu a \theta \eta \mu \alpha \tau \iota x \dot{a}$, and $\dot{\varepsilon} \pi \sigma \tau \eta \dot{\eta} \mu$ (No. 4) includes $\delta \iota a ́ v o \iota \alpha$ : but each has a wider significance. For $\pi o t o v$ is given us not only in the content of

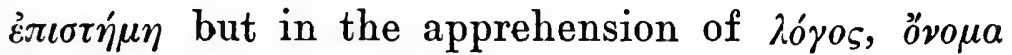

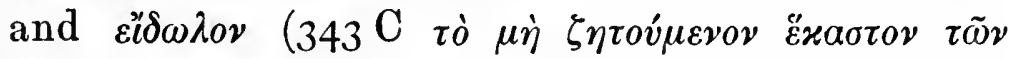

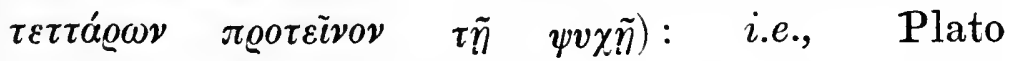
would now say that not only Theodorus, but

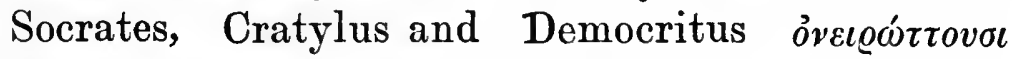

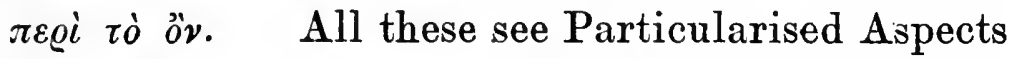
of Reality ( $\pi \circ \iota^{v} \tau \iota$ ). The fact is that Plato

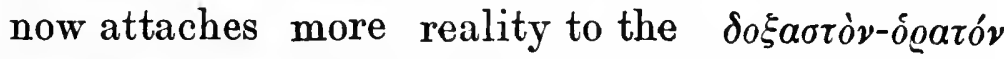
world than he did formerly. The early Platonism was concerned chiefly to insist on the severance between Noumena and Phenomena, the later, which we find in the Parmenides and subsequent dialogues, to bridge the gulf. But there is a further modification which we must note in the theory of Ep. vii, namely that the intuitive character of the apprehension of the Idea is much more insisted upon than in the Republic. The distinction is now not so much between Sense and Intellect as between Sense + Opinion + Discursive Reason, and, on the other side, Intuition. ${ }^{1}$ Nevertheless we must be careful not to exaggerate the change. It is true that Plato is not at pains to distinguish the process of Dialectic described in Rep. vi.-vii. from its result, the Discursive from

I. No doubt it was this line of thought that led to

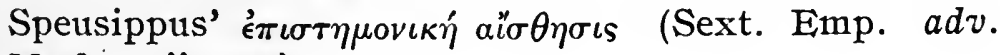
Math., vii, I45). 
the Intuitive: but this is really no more than a question of emphasis. For he was there more concerned to emphasise the process of study, than the result; he was there speaking less as metaphysician than as educationalist. The 'mystic vision' was not absent from his mind, any more than it had been when he wrote the Symposium, where he makes Diotima say that the vision of

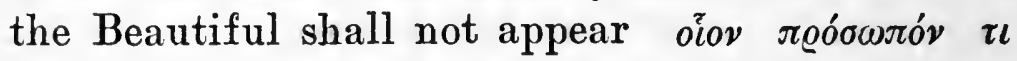

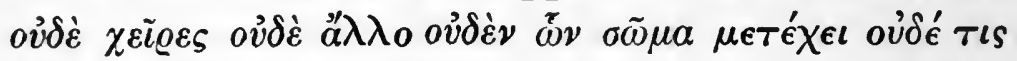

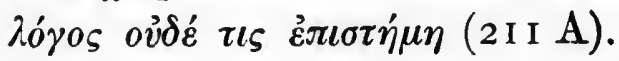

\section{SUPPOSED INTERPOLATIONS.}

(1) Ritter. 'This commentator proposes (Plato's Gesetze, p. 37 I $s q q$.) to excise as an interpolation the passage from 34I A $\pi \dot{\nu} v \tau \alpha \mu \dot{\varepsilon} \nu$ ov̉ $\nu$ to $\dot{\varepsilon} \gamma \dot{\omega}$ $p \in a^{\prime} \zeta o u \mu$ ' aै $\nu$, with the exception of the sentence

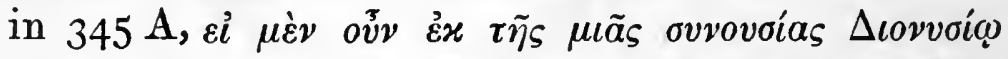

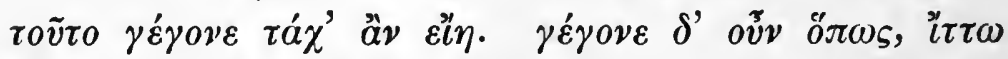

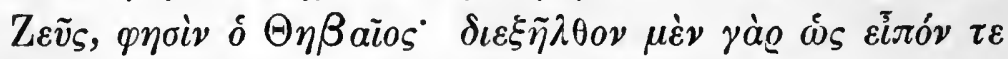

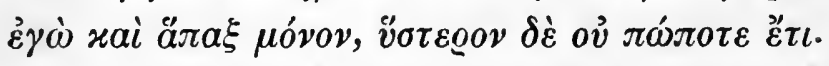

I do not think it necessary to transcribe in full Ritter's argument, which is ingenious but perverse. His supposition is that some opponent of the Academy (I suppose in the first half of the third century) had made capital out of the fact that Dionysius, the promising pupil, had had enough with one discourse from Plato: and that some faithful Academician, jealous for his master's fame, but insufficiently familiar with his teaching, adopted, as a method of apologetic, the 
device of fathering upon Plato a statement that he did not ever express his beliefs on the deepest philosophical themes.

Credat Judaeus Apella. Ritter's theory may appeal, despite its $\grave{a}$-priori character, to those who, like H. Richards, ${ }^{1}$ regard the philosophical digression as 'skimble-skamble': but not to anyone who takes the trouble to study its meaning. Whether the digression be the work of Plato or not, it is obviously written by someone who has a perfectly definite metaphysical and epistemological theory.

Ritter's text would run thus (I mark the gaps made by his knife by a vertical stroke) :-

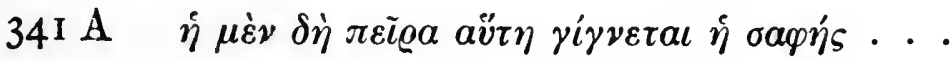

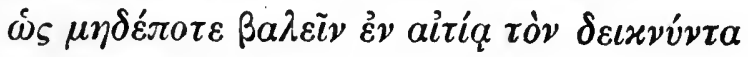

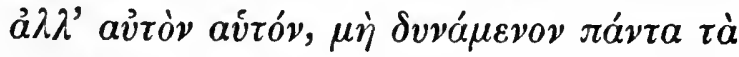

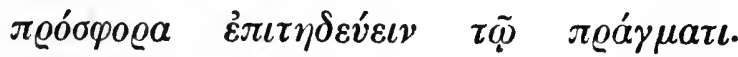

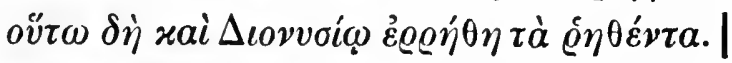

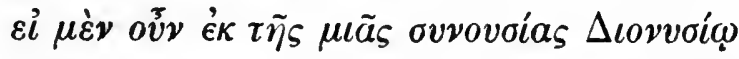

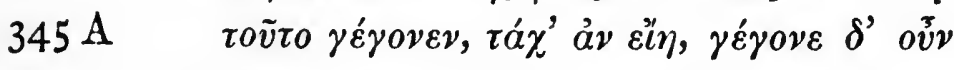

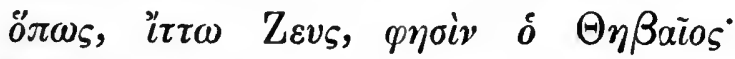

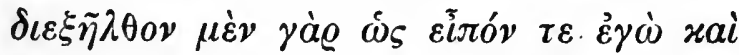

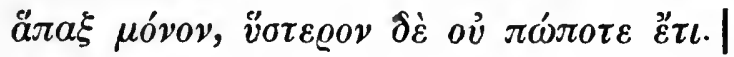

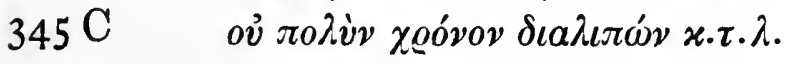

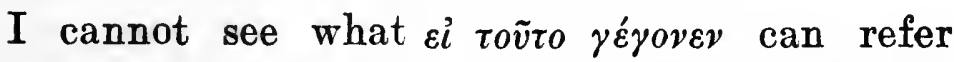
to with this text. The only meaning possible is 'If this test has worked' which it certainly does not mean. The strange thing is that it is these

I. Classical Review, I900, p. 338. 


\section{II2 AUTHORSHIP OF PLATONIC EPISTLES}

very words that provide Ritter with one of his objections to the text as we have it. "The obscurity,' he says, ' of the logical sequence that exists between the words $\varepsilon \dot{\imath} \mu \dot{\varepsilon} \nu$ ở $\nu$ at the beginning of $345 \mathrm{~A}$ and the preceding explanations, serves to confirm our conclusions : for what

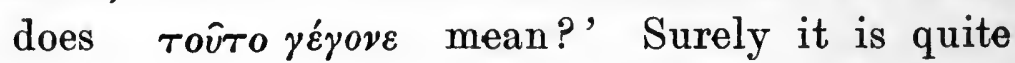

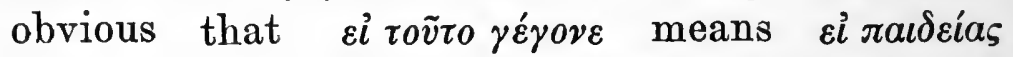

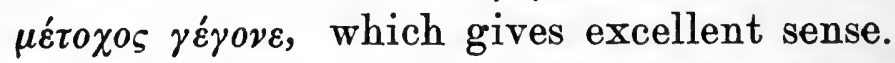

Lastly, I very much doubt whether the asyndeton, which occurs in the last sentence quoted above

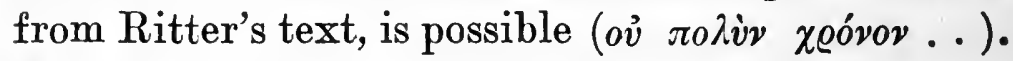
With the ordinary text it is of course quite normal, as the new paragraph begins a story promised in the last words preceding it.

(2) Odau (op. cit.) besides accepting the above excision, also cuts out $330 \mathrm{~A}-338 \mathrm{~A}$ - the whole

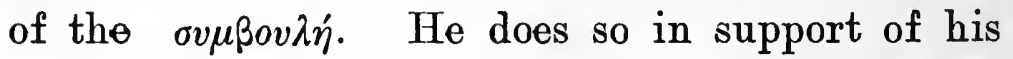
contention that vii. and viii. are really one Epistle, and that the $\sigma v \mu \beta o v \lambda \eta$, being contained in viii, cannot occur in vii. There is practically nothing to support this contention. Ep. vii. has a perfectly natural ending, and only one MS. omits the superscription of Epistle viii. (Vid. Burnet's critical note:-numerum et superscrip-

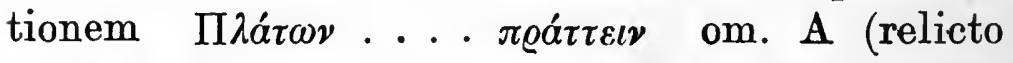
spatio). Nempe diorthota $\left(\mathrm{A}^{2}\right)$, qui hæc omnia cum Scholiis addidit, priori epistolæ hæc continuavit, ideoque omnes quæ sequuntur epistolas falso numero insignivit).

Odau complains that ' hac epistolæ parte narrationi secundi itineris ineptissime inserta contextus 
totius epistolæ vehementer interrumpitur.' I have no more to say on this topic than I have said above. It is perhaps worth while mentioning one argument, by which he sets great store. At $330 \mathrm{C}$ we have a statement that the second journey to Sicily is now done with, and that the third will be

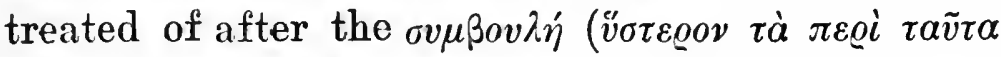

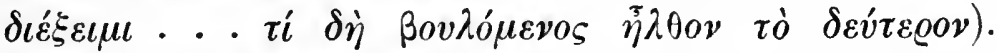
'Sed quæ sequuntur,' he complains, ' $\sigma v \mu \beta o v \lambda \eta v$ illam ( $338 \mathrm{~A} s q q$.) si cum his verbis comparaveris antecedentibus prorsus repugnare facile intelliges. Apparet enim sequi nonnulla quae ad primum ${ }^{1}$ iter pertinent.'

This is mere quibble. The sentences in $338 \mathrm{~A}$ which he alludes to are those describing Plato's manner of departure after his earlier visit to the younger Dionysius, and his conditional promise to return.

It is perfectly natural that this should be included in the narrative of the final visit, with which it is intimately connected.

I now propose to go through the Epistle twice, commenting first on noteworthy points as regards subject-matter, secondly on points of language, especially with a view to Platonic parallels.

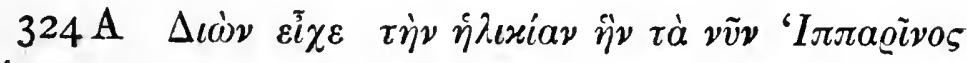

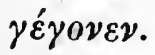

There has been much discussion as to the

I. i.e., the first visit to Dionysius II. 


\section{II4 AUTHORSHIP OF PLATONIC EPISTLES}

identity of the person referred to, whether he be the son of Dionysius I. or the son of Dion, who were both named Hipparinus. I have stated my belief, in commenting on Ep. viii. $356 \mathrm{~A}$, that Plutarch and Nepos are mistaken in saying that Dion's son died before his father: and I believe him to be meant in the present passage. Not only is it natural to suppose that Plato is comparing father and son, but the dates do not seem to admit of the reference being to the other Hipparinus. For Dion, being born in 408 B.c. (Nepos, Dion, $a d$. $f i n$.) was about 2 I years old on Plato's first visit to Sicily: therefore the person here mentioned was about $2 \mathrm{I}$ in 353-2 B.c., i.e., he was born in 374-3 B.c. Ed. Meyer (v, p. 523) thinks it impossible that the son of Dionysius $I$. and half-brother of Dionysius II., can have been born so late as this, rightly in my opinion. According to Diodorus, the simultaneous marriages of Dionysius I. with Doris and Aristomache took place in 398: and it is improbable that Hipparinus, the elder son of Aristomache, was born as long as 24 years after the marriage, although Plutarch (Dion. c. 3) tells us that she was long childless.

A further important evidence in favour of this view is the fact that in $328 \mathrm{~A}$ of this Epistle we have certain nephews of Dion spoken of as being promising subjects for philosophical instruction in the year 367 . These are almost certainly Hipparinus (Dionysii) and his brother Nysaeus : 
and clearly the language would be inappropriate to children of seven and under.

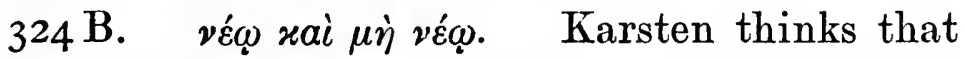
in these words the writer lets himself forget whom he is supposed to be addressing. I cannot see why: Dion's friends were presumably not all of an age.

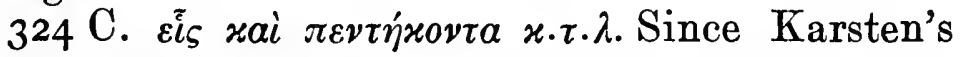
commentary appeared we have found confirmation of what Plato here says as to the Thirty

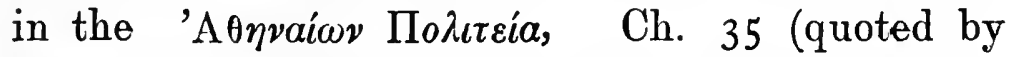
Raeder and Adam), where they are described as

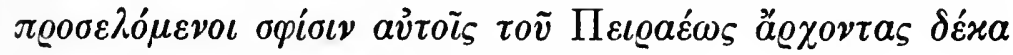

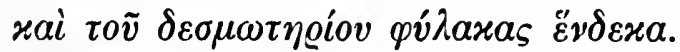

I think, however, that the words $\pi \varepsilon \varrho i \quad \tau \varepsilon$ áyo@à $v$

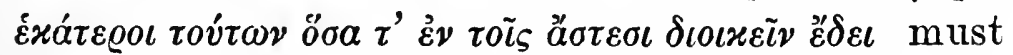
be rejected as a gloss. Karsten's objections (p. I $17 s q$.) are quite valid on this point: it is impossible to suppose that these associates of the Thirty were the regular Boards of áorvirouo and àyo@ávouol, of which there were five members each for Athens and the Piraeus. Moreover there seems to be no parallel for the use of $\tau \dot{\alpha}$ ă $\sigma \tau \eta$, ä $\sigma \tau v$ regularly meaning Athens as contrasted with the Piraeus.

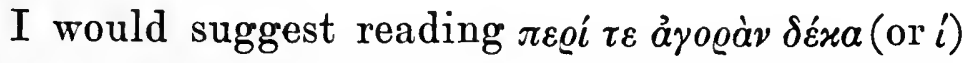

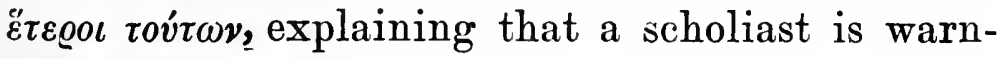
ing the reader against imagining the $\delta \dot{\varepsilon} x \alpha \dot{\varepsilon} v$

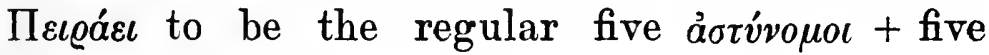

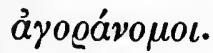

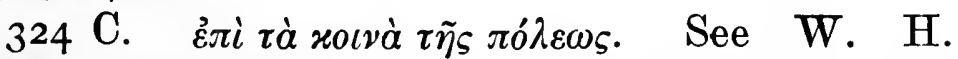
Thompson's Gorgias, pp. xxiii-xxx, for the 
reflexion in that Dialogue of Plato's political experiences here described.

324 D. pí Karsten thinks this implies that the writer supposes Socrates to need introduction to Dion's Sicilian friends, and objects accordingly. Cf. also Taylor, Varia Socratica, p. 52. 'The fate of Socrates is described in a way only intelligible on the supposition that he was all but an unknown quantity to Plato's Sicilian friends. He is introduced, and the language speaks volumes for the authenticity of the letter, as ' an elderly friend of mine.' It is amusing to note the opposite conclusions drawn from the same premiss. I do not agree with either commentator's inferences: but the language is perfectly natural.

Meyer also remarks (v, I7): "How scholars of taste can regard the beautiful words pílov aै $\nu \delta \varrho a$

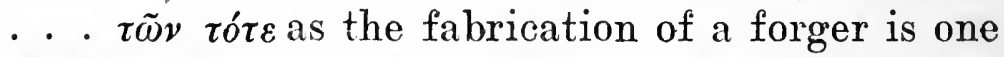
of the things that I can never understand."

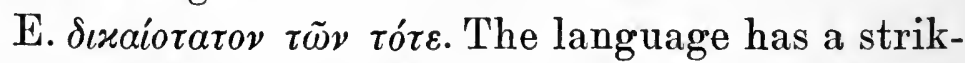
ing resemblance to the last words of the Phaedo,

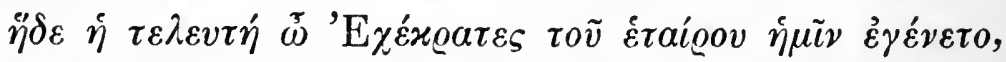

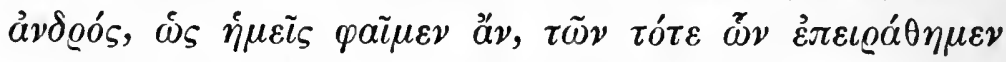

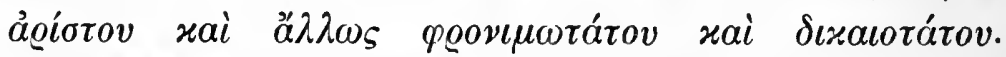
Probably the 'justest man of his day' was a phrase in which Plato often spoke and thought of his master. On the general question of Platonic repetitions, vid. App. B.

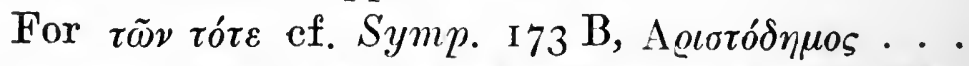

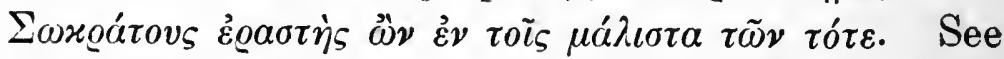
also Burnet's note on the Phaedo passage. 


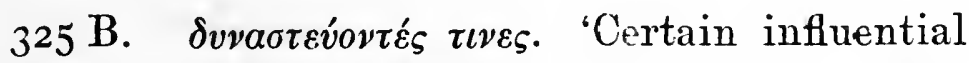
persons' refers to Meletus and Anytus. The word is not confined to the meaning of oligarchical power, as Karsten, seeing therein a historical error, maintains.

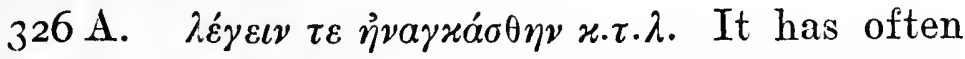
been remarked that the language here implies a reference to the sentiments actually expressed in Rep. 473 D, 501 E (Taylor, Varia Socratica, p. I 20, 'that the allusion is to a published work is made

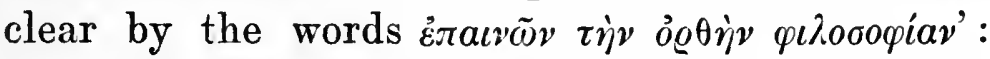
similarly W. H. Thompson, Gorgias, p. xxxvi, Ritter, R. Adam). I agree: but this does not imply that the Republic, as we have it, ${ }^{1}$ was written as early as 387 B.C.

327 E. For a similar method of quotation from a letter described as long, passing from direct to indirect, ef. $339 \mathrm{C}$.

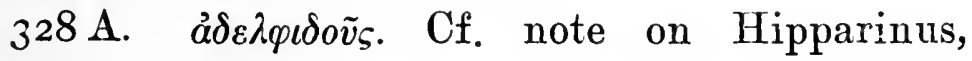
$324 \mathrm{~A}$.

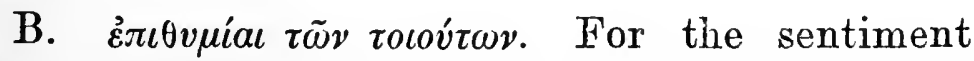
cf. Laws 929 C, quoted in my note on Ep. xiii, $360 \mathrm{D}$ (p. I 70 infra).

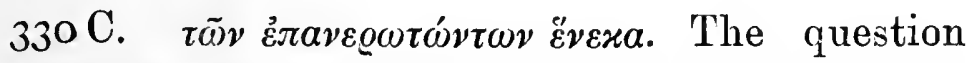
had no doubt been raised in the letter to which this is a reply.

r. There must be some foundation in fact for the statement of Aulus Gellius (xiv, 3) that 'duo fere libri' were published first. It seems impossible to draw any certain conclusion as to the relation of Rep. V to the Ecclesiazusae. 
$330 \mathrm{D}$. The thought and language, as Karsten notes, are a remarkable echo of Rep. 425-6. But the metaphor and the comparison are common enough in Plato. I may quote R. Adam (p. 36) criticising Karsten: 'There is certainly a surprising parallel not only in thought but in single expressions: but in the Republic all is concisely put, while Ep. vii enunciates the same principles with the greatest prolixity and redundancy, employing rhetorical ornaments. This is just the peculiarity of Plato's later writings: one notices just the same difference in the Laws when they spin out in prolix fashion a principle of the Republic.' Cf. Appendix B.

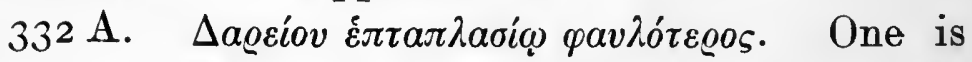
reminded of the way in which the Kingly man is shown to be 729 times happier than the Tyrannical in Rep. 587 B sqq. Darius, who divided his Empire into seven parts, is seven times better than

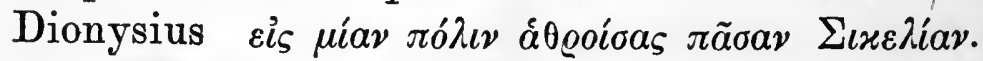

Karsten sees a contradiction between the reference to Darius in the present passage and that in Laws $695 \mathrm{C}-697 \mathrm{C}$, where again the seven-fold partition of the Empire is mentioned. But the

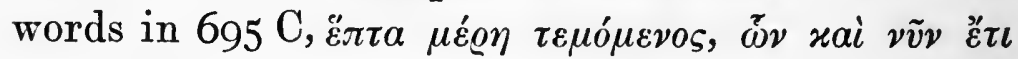

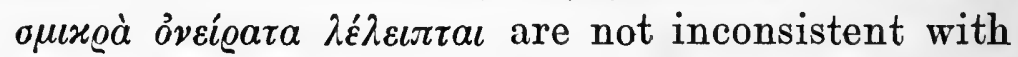

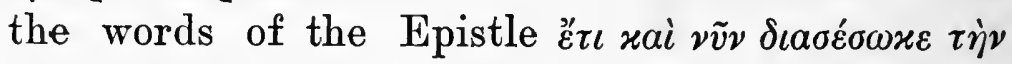
$\Pi \varepsilon \varrho \sigma \tilde{\omega} \nu \dot{\alpha} \varrho \chi \dot{\eta} \nu$. The apparent contradiction is quite explicable if we consider that Plato is comparing Darius and the Persian Empire with different things in the two passages: in the Laws the comparison is with an ideal polity, in the Epistle it is 
with the Empire of Dionysius. The further cita-

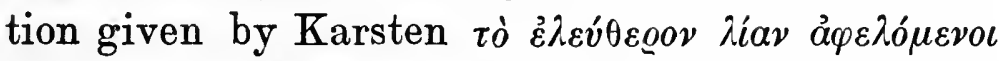

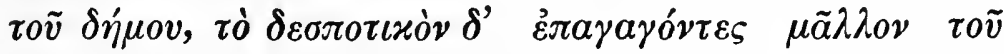

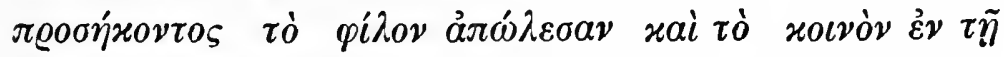
$\pi o ́ \lambda \varepsilon \varepsilon$ refers, not to Darius, but to subsequent Persian monarchs, and cannot therefore be adduced as contradictory to what is said of Darius' policy in the present passage.

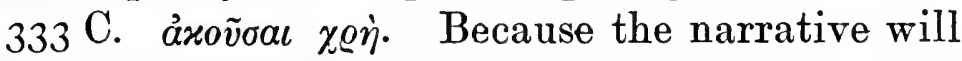
exemplify the difference between true and false friends, of which he has been speaking, and will reply to the reproach his correspondents had levelled against Athens (334 B).

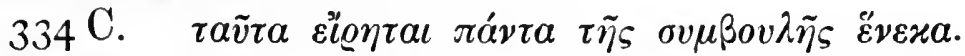
A similar quasi-apology for apparent digression is made in Philebus $34 \mathrm{C}$, where after a long psychological discussion the main argument is resumed thus:-

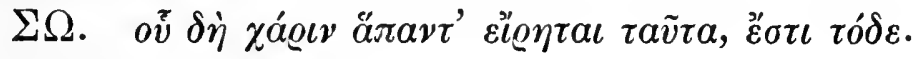

$\Pi \mathrm{P} \Omega$. Тò roĩov;

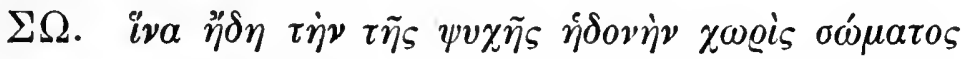

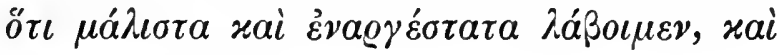

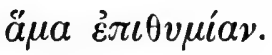

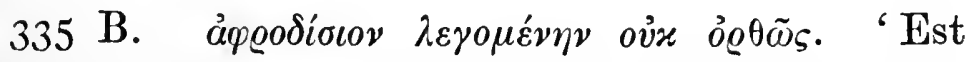
lepide dictum nostri scriptoris: Plato nunquam

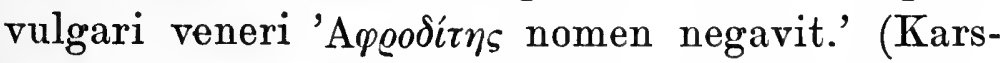
ten). Of course Plato ordinarily uses $\tau \dot{\alpha}$ áp@odíca in the ordinary way: but with this passage we

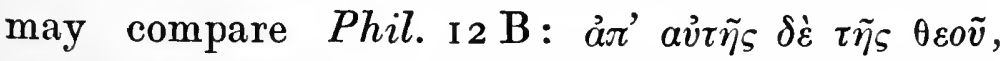

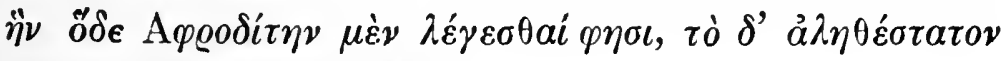

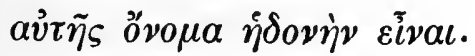




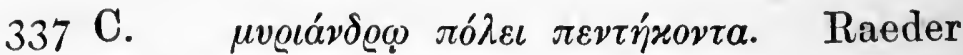

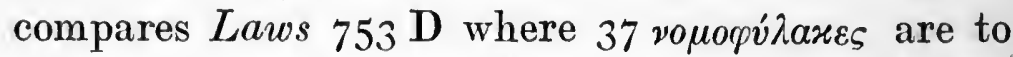
be elected for a state of 5040 families, and also points out that the conditions laid down for the law-givers here are similar to those which have to be fulfilled in the Laws by the Minister of

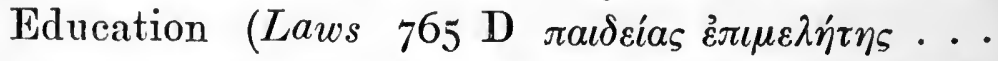

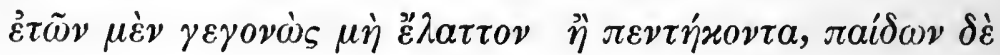
$\left.\gamma \nu \eta \sigma^{\prime} \omega \nu \pi \alpha \tau \dot{\eta} \rho.\right)$

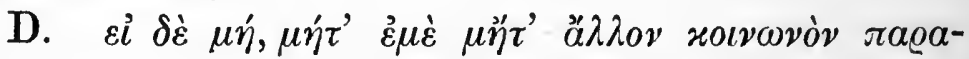

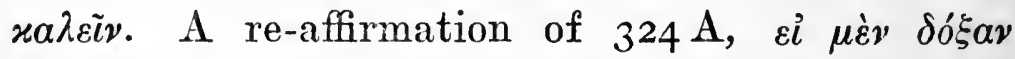

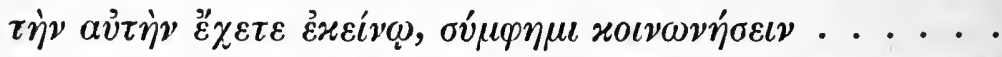
the $\delta o$ ' $\alpha$ having been in the interval explained. $\delta \varepsilon v ́ \tau \varepsilon \varrho \alpha \mu \eta \dot{v}$. The rule of Law is again contrasted with the ideal state of the philosophic ruler in Pol. 297 D-E :-

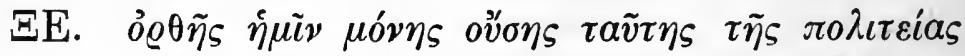

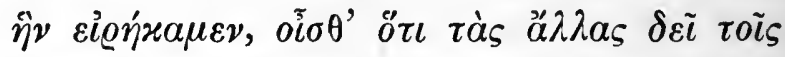

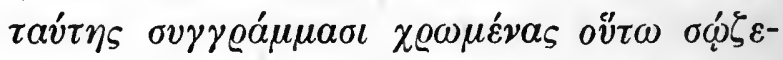

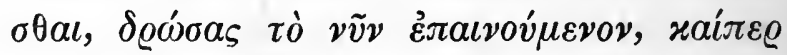

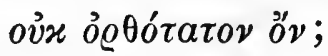

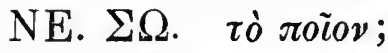

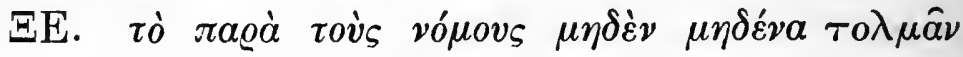

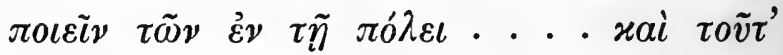

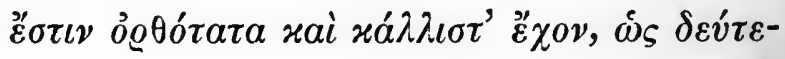

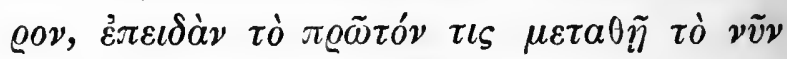
$\delta \dot{\eta} \varrho \emptyset \theta \dot{\varepsilon} v$.

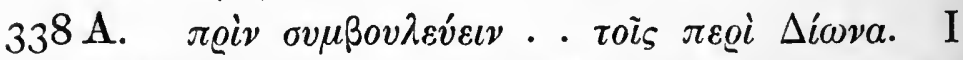
think Odau is right in rejecting this clause as a

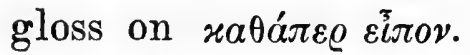

338 D. Éoriv. The sudden change to the present tense (Dionysius being of course still alive in 
353-2) seems to me one of those slight but allimportant evidences of authenticity in which this Epistle abounds. It would never have occurred even to the cleverest of forgers.

For the commendation of Dionysius here com-

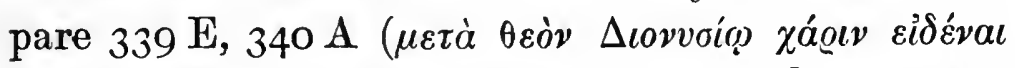
$\chi \varrho \varepsilon ́ \omega v)$. It is most unlikely that such passages would have been incorporated, in a document which consists very largely in a justification of Plato as against Dionysius, by anyone save Plato himself.

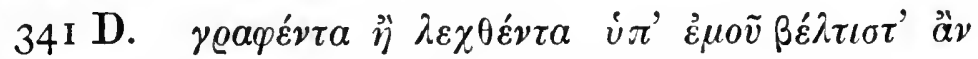
$\lambda \varepsilon \chi \theta \varepsilon i \eta$. This, says Ritter, 'Plato simply cannot have written. No one who knows anything of Plato can think it possible for him ever to have sunk to the level of such vain and foolish boastfulness.' The words may perhaps strike us at first as egotistic: but I think that, while remembering that ancient and modern views of egotism differ very widely, we may regard the sentence rather as a deliberate and dignified statement of what Plato was convinced of, namely that he was the fittest exponent of the Philosophy of Ideas. His position as such, I have suggested, had been challenged by his correspondents.

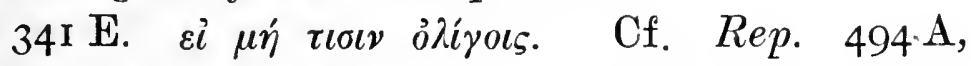

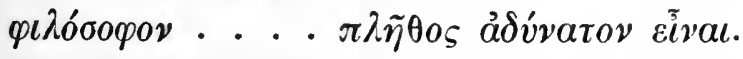

$342 \mathrm{~A}$. "E $\sigma \tau \iota v \tau \tilde{\omega} \nu$ oै $\nu \tau \omega \nu$. . . Though the fivefold enumeration does not occur elsewhere, it is

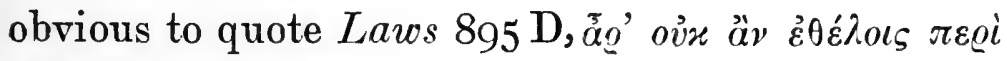

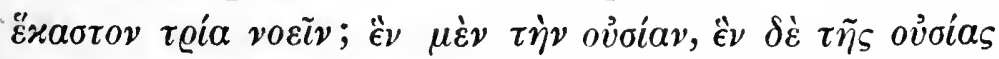

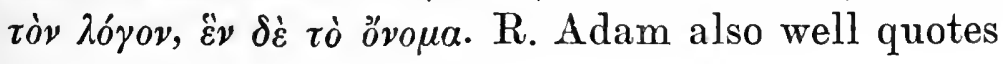




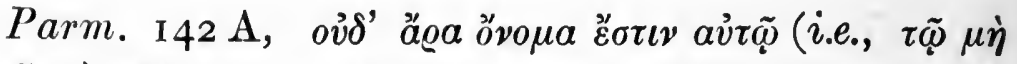

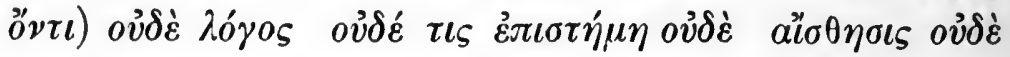
$\delta o ́ \xi \alpha$.

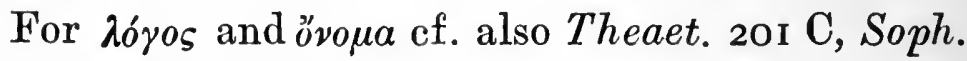
22 I B, Pol. 267 A, 27 r C.

342 B. The definition of Circle is similarly given in Tim. $33 \mathrm{~B}$, Parm. I37 E.

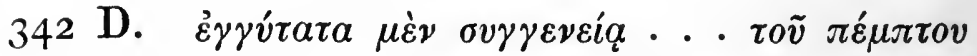

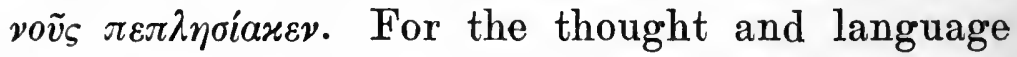

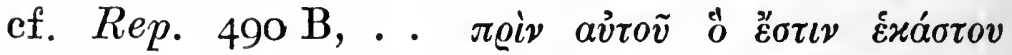

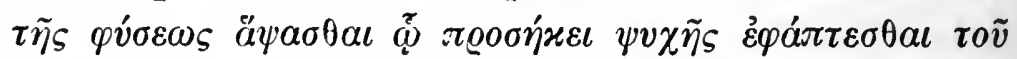

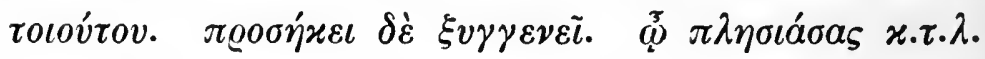

344 A. ov̉ $\delta^{\prime}$ àv ó $\Delta \hat{y} \gamma x \varepsilon v \varsigma$. . . . Karsten comments 'Ferebatur Lynceus tanta valuisse oculo-

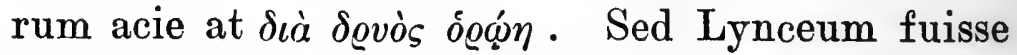
velut alterum Aesculapium, ó $\varphi \alpha \lambda \mu i \alpha \tau \varrho o \nu, ~ h o c$, opinor, eruditis erat ignotum.' This of course misses Plato's point, which is that, unless the student be $\sigma v \gamma \gamma \varepsilon \nu \eta$ s to his subject, even the sharpest-sighted teacher could do nothing for him. Cleverness in the teacher may go for most in the teaching of carpentry, but it will not go far in philosophy.

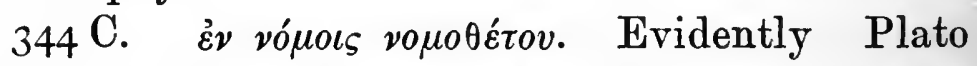
means that he does not regard his own Laws as

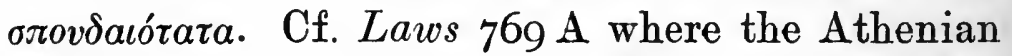

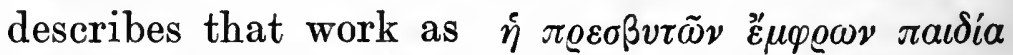
though Cleinias would call it $x a \lambda \dot{\eta} \sigma \pi \circ v \delta \dot{\eta}$. The

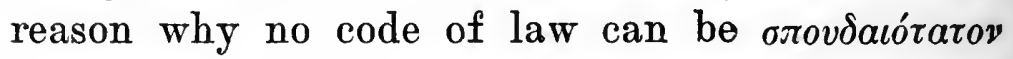

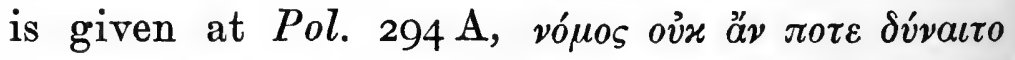

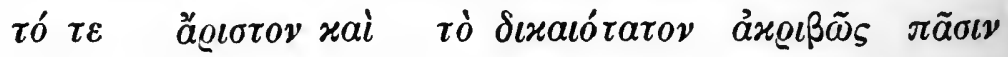

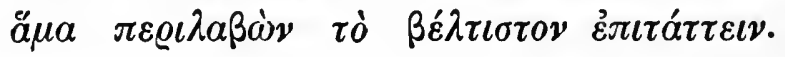


We are naturally surprised to hear Plato denying (by implication) that any of his writings are

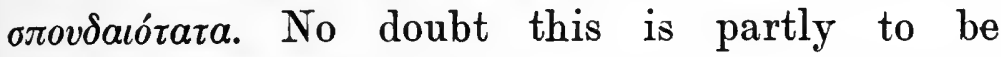
explained by what we may call $\dot{\eta} \tau o \tilde{v} \Pi \lambda a \dot{t} \omega \nu o_{\varsigma}$

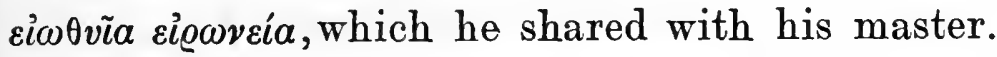
But we may also accept what Meyer (v, 359) says in allusion to our passage: 'Trotzdem hat Plato wieder und wieder zur Feder gegriffen, vor allem um sich selbst zur klarheit durchzuarbeiten, daneben um seine Lehren gegen andere zu vertheidigen und für sich Jungen zu werben .... Seine zahlreichen Schriften sind fast alle nur entweder propädeutischer Art, indem sie dem Leser das Problem verständlich machen und ihn $\mathrm{zu}$ weiter Untersuchungen anlocken sollen ... . In das innerste Heiligthum seiner Gedanken führen nur Andeutungen, namentlich in der Politik.'

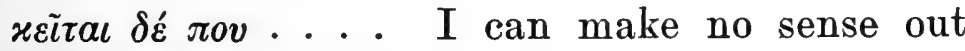
of this clause, nor apparently can Hercher (E pistol. Graeci), to judge from his translation 'Jacent autem inter sua, in regione pulcherrima.' Are they perhaps a gloss by an admirer of the Laws, who remarks: 'Yet I fancy they occur in the finest of this writer's works'?

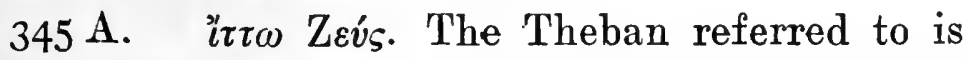
Cebes, who uses this dialectical form at Phaedo $62 \mathrm{~A}$.

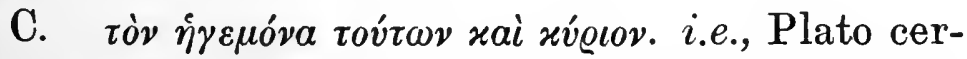
tainly, not Dion as has sometimes been supposed. Ritter objects to this description of Plato by 


\section{I24 AUTHORSHIP OF PLATONIC EPISTLES}

himself. The words do not, however, mean 'lord and master' but 'authoritative guide.'

Language.

On the side of language, a great deal of evidence for the authenticity has been produced by Raeder, in the first of his two papers. Out of the list of rare words which $I$ have referred to (p. xv) the following occur only in Ep. vii and the late dialogues, Sophist, Politicus, Timaeus, Philebus, Critias, Laws, Epinomis:-

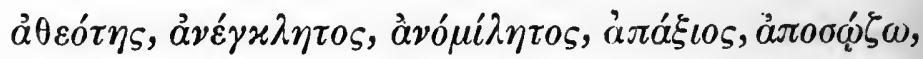

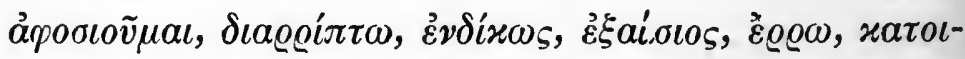

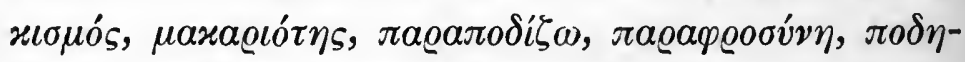

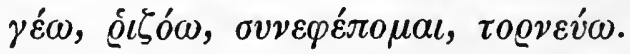

I note a few parallels in the usage of three of these :-

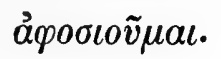

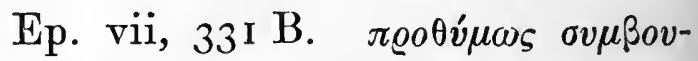

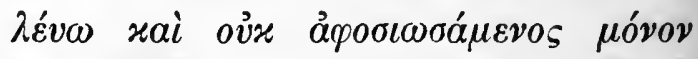

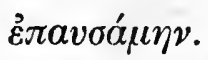

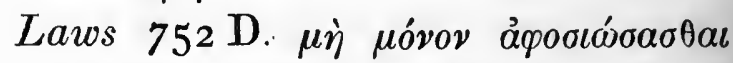

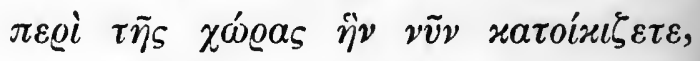

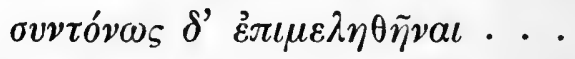

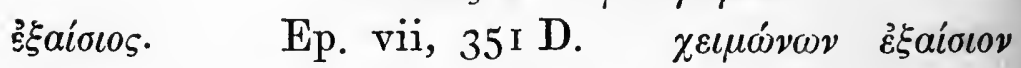
rai ảं

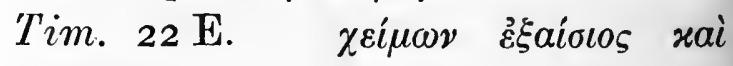

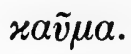

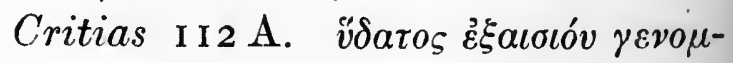
évov.

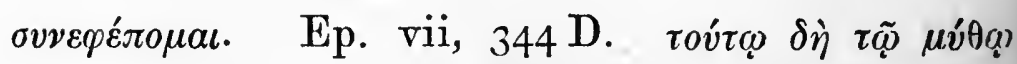

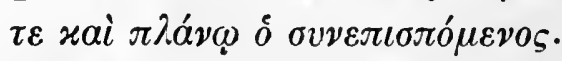

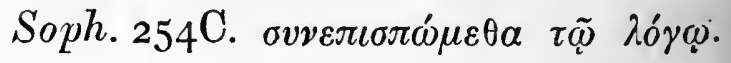


The following parallels concern the usage of words taken from Raeder's list of rare words, but not confined like the preceding to the late dialogues.

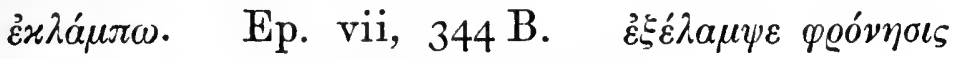

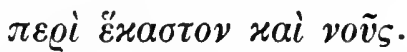

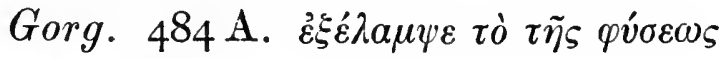
Sixalov.

(The Aorist in each case is 'instantaneous.')

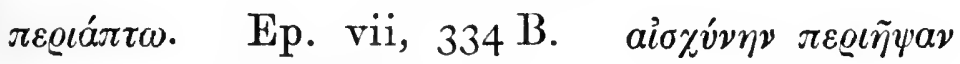
$\tau \tilde{\eta} \pi o ́ \lambda \varepsilon \iota$.

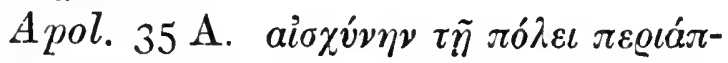
$\tau \varepsilon \iota \nu$.

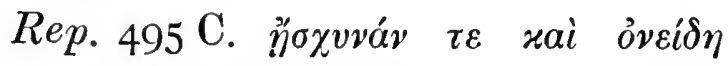
$\pi \varepsilon \varrho i \tilde{\eta} \psi \alpha$.

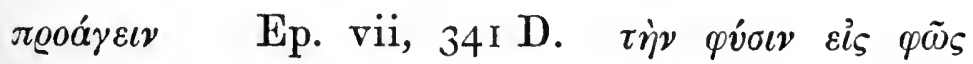

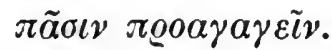

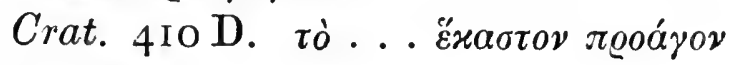

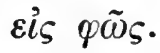

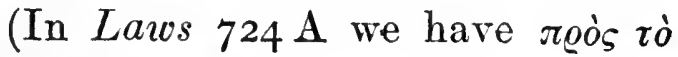

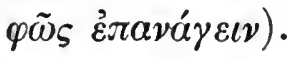

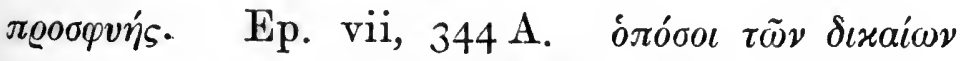

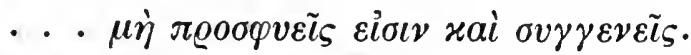

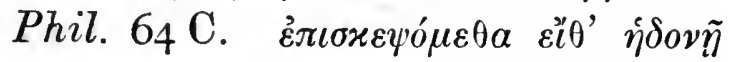

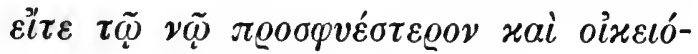

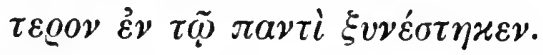

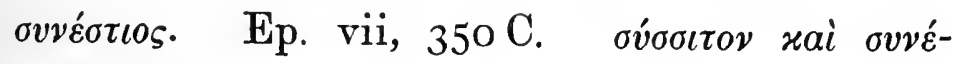

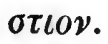

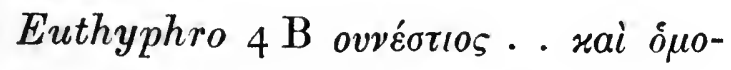

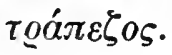




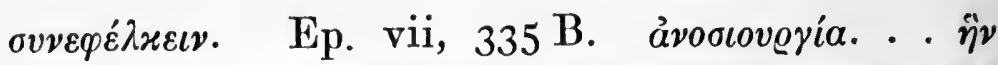

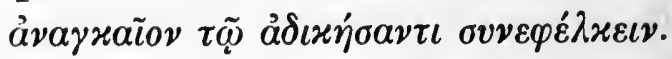

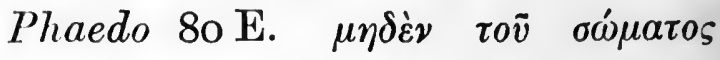

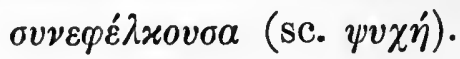

On pages $466-469$ Raeder has collected a large number of phrases and unusual turns of expression, the great majority of which are drawn from the Seventh Epistle, ${ }^{1}$ with parallels from the dialogues, particularly the Laws. It would be superfluous to transcribe them here: but it may be remarked that they go far to show the worthlessness of Karsten's linguistic criticisms : many of the phrases most objected to by Karsten are here shown to be characteristic of Plato's latest style.

Most of the points that Raeder notes seem to me not of a kind likely to be due to imitation. Although he has, in my opinion, done quite enough on the linguistic side to prove the Platonic diction of this letter, I may add a few additional points noted by myself. It will be most convenient to give these in tabular form, and as they are only intended as supplementary to Raeder's work, I shall be content with giving references in most cases for the Platonic parallels, instead of actual quotation.

r. Some also from Ep. viii, in discussing which I have several times referred to these pages of Raeder. 
324 A.

For the apposition of an

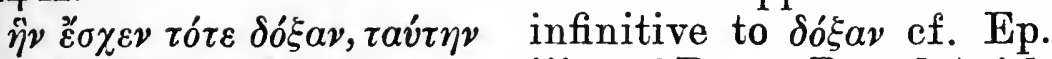
xai $\delta \iota \varepsilon \tau \varepsilon \dot{\varepsilon} \lambda \varepsilon \sigma \varepsilon \nu ~ \check{\varepsilon} \chi \omega \nu$. . . iii, 3 I $6 \mathrm{~B}, 3$ I $8 \mathrm{~B}$, and (with oľ $\sigma \theta \alpha \iota$.

Campbell, Rep. ii, p. I 77) Rep. 53 I C-

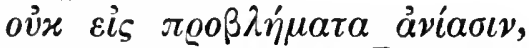

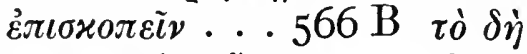

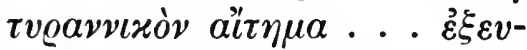

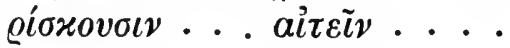

$324 \mathrm{D}$.

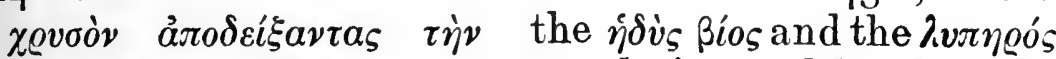

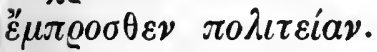
are designated by the substantives $\chi \rho v \sigma o ́ s$ and $\alpha \varrho \varrho \gamma v \varrho o s$ (rather than by adjectives).

$326 \mathrm{~A}$.

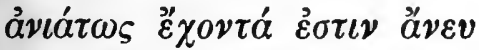

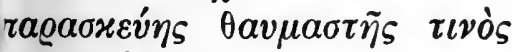

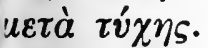

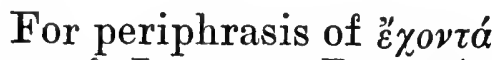

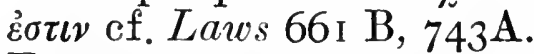
For $\mu \varepsilon \tau \dot{\alpha} \tau \dot{\chi} \chi \eta \varsigma$ cf. my note on viii $355 \mathrm{~B}$, p. I48.

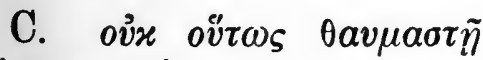

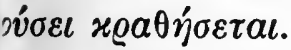

For the parenthesis cf. Laws $728 \mathrm{D}$, $905 \mathrm{~A}$.

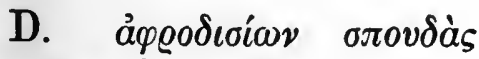

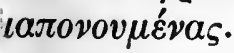

Verb used in Passive, Laws 857 C. Often in Laws in Act. and Mid.

$27 \mathrm{~A}$.

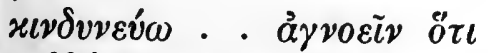

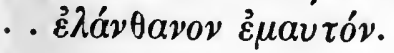

Vid. instances of Redundancy on p. I94 esp. Laws $688 \mathrm{~B}$, $\lambda \varepsilon \dot{\gamma} \gamma \omega \ldots$. . ö $\tau \iota \delta \dot{\eta} \phi \eta \mu$. 


\section{I28 AUTHORSHIP OF PLATONIC EPISTLES}

327 A.

This is quoted in Adam's

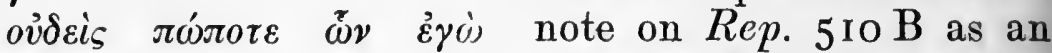

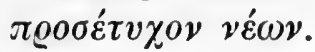
instance of the rare attraction of a relative in the dative; cf. with Adam, Gorg. 509A, Protag. 36 I E, Theaet. I44 A, Rep. 53 I E.

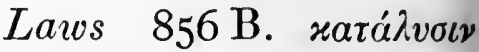

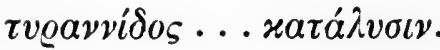

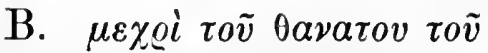

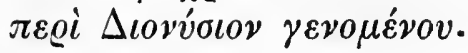

Laws $692 \mathrm{C}, \quad \dot{\eta} \pi \varepsilon \varrho i$ tò

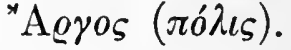

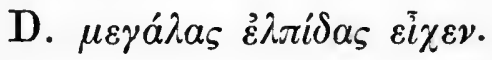

$328 \mathrm{~B}$.

$\tau \tilde{\eta} \nu \delta^{\prime} \dot{\varepsilon} \mu \dot{\eta} \nu$ $\delta o^{\xi} \alpha \nu \ldots .$.

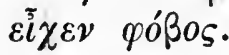

Epistle iii, 3 I 7 E,

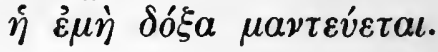

$328 \mathrm{~B}$.

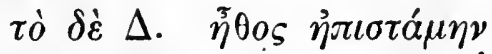

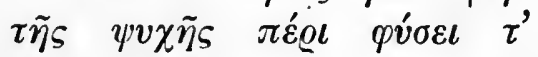
$\dot{\varepsilon} \mu \beta \varrho \iota \theta \dot{\varepsilon} \varsigma$ ö $\nu \ldots$

For $\eta^{3} \theta o s$ $\psi v \chi \tilde{\eta} s$, cf. Laws $650 \mathrm{~A}, 666 \mathrm{C}, 837 \mathrm{C}$, in addition to Raeder's passages.

329 A.

oủx हैorıv (answering a Rhetorical question).

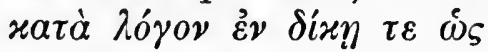

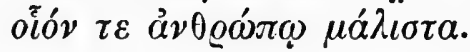

Laws $689 \mathrm{D}$.

See examples of Redundancy, p. 193.

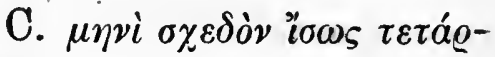
$\tau \omega$.

$\sigma \chi \varepsilon \delta \dot{\nu}$ ¿б$\sigma \omega s$. Laws $658 \mathrm{D}$,

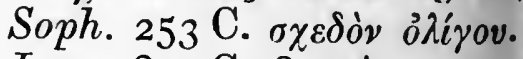
Laws $800 \mathrm{C}, 805 \mathrm{~A}$. 


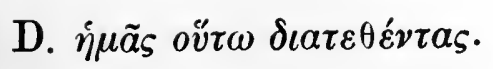

For $\delta \iota \varepsilon \tau \varepsilon \dot{\varepsilon} \theta \eta \nu$ instead of

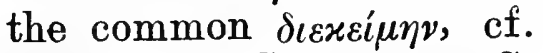
Theaet. I 5 I C, Laws $666 \mathrm{C}$. App. A, p. 195. ${ }^{1}$

${ }_{329}$ D. . . $\tau \dot{o} \delta \grave{\varepsilon} \mu \varepsilon \dot{v \varepsilon \varepsilon l \nu . ~}$

For this insertion of the second half of an antithesis where one would expect it to be omitted cf. Rep. 53 I D, Laws $690 \mathrm{C}$, 7 I5 D, $733 \mathrm{C} \mathrm{D}, 950 \mathrm{~B}$.

$330 \mathrm{~A}$.

$\tau \dot{o} \delta^{\prime} \varepsilon^{3} \chi \varepsilon v \delta \dot{\eta} \pi \tilde{\omega} s ;$

For the order cf. Phaed. $73 \mathrm{C}$, Laws $733 \mathrm{~A}$ -

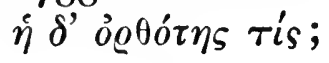

$330 \mathrm{D}$.

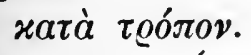

$$
\text { (= uno tenore.) }
$$

33 I A

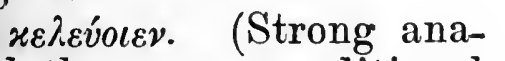
coluthon, a conditional participle balanced by an optative.)

33 I B.

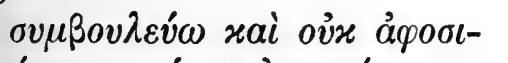

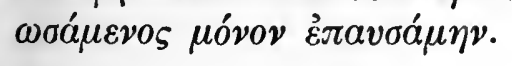




\section{AUTHORSHIP OF PLATONIC EPISTLES}

C. $(\chi \varrho \grave{\eta}) \lambda \dot{\varepsilon} \gamma \varepsilon \iota \nu \mu \dot{\varepsilon} v, \varepsilon \dot{\imath} \mu \dot{\eta}$

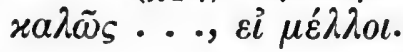

D. Bíav $\delta \dot{\varepsilon} \pi a \tau \varrho i ́ \delta \iota \pi o \lambda_{-}$ $\tau \varepsilon i \alpha_{\varsigma} \mu \varepsilon \tau \alpha \beta o \lambda \tilde{\eta} \varsigma \mu \dot{\eta} \pi \varrho o \sigma \varphi \varepsilon \varrho^{-}$ $\varepsilon \iota \nu$.

$332 \mathrm{C}$.

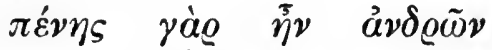
pí

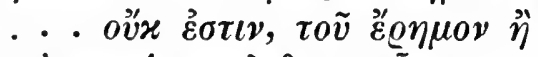

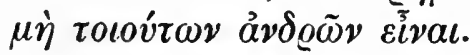

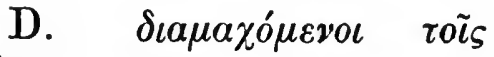

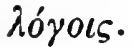

$335 \mathrm{E}$.

oî่ $\delta \alpha \ldots$. . . $\tau \iota . . \dot{\omega} \varsigma$.

$336 \mathrm{~B}$.

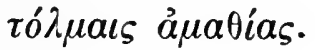

337 A.

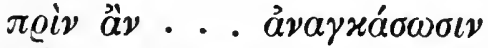

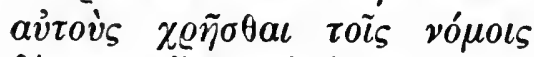

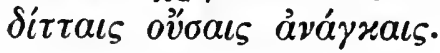

339 B.

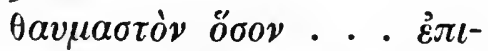

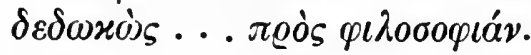

\section{$340 \mathrm{~A}$.}

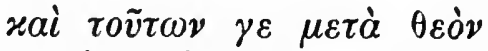

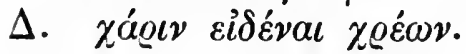

Double condition. Cf. Symp. 208 C, Laws 946 E.

See examples of $\mathrm{Ab}$ stract Expressions, p. 190. Cf. esp. Laws 672 D,925A, there quoted.

For the epexegesis of the Relative cf. Laws

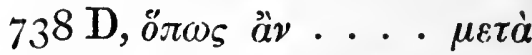

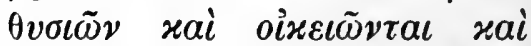
$\gamma \nu \omega \varrho i ́ \zeta \omega \sigma \iota v$, ov $\mu \varepsilon \tilde{i} \zeta o \nu$ ov̉dèv

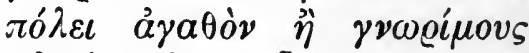

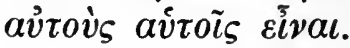

Theaet. I $58 \mathrm{D}$, Phaedo. I06 C, Prot. 325 C.

For the resumption of ö $\tau$ by $\dot{\omega} s \mathrm{cf}$. Rep. $470 \mathrm{~A}$.

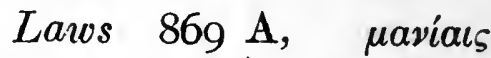
o้อ

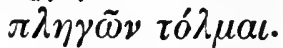

Laws $728 \mathrm{~B}$, $\tau \dot{o}$ ó $\mu о \imath \tilde{v}-$

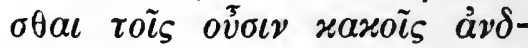

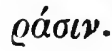

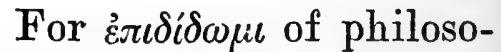
phical progress cf. Theaet.

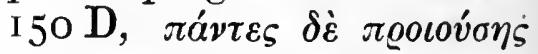

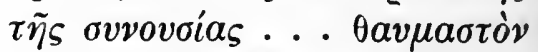

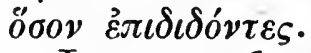

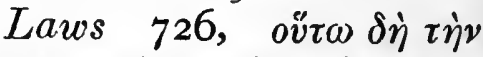

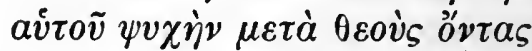

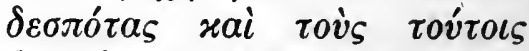

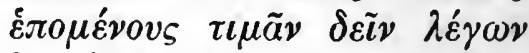

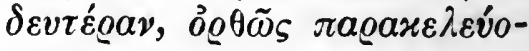
$\mu a l$. 
34 I A.

Laws 789 B. ởs yà

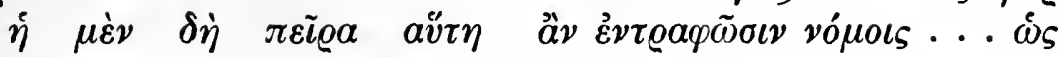

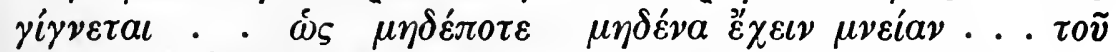

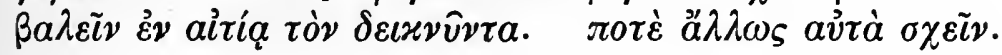

D. $\varepsilon \dot{v} \mu a \theta \tilde{\eta} \tau \varepsilon \varkappa a i \mu \nu \eta \dot{\eta} \mu \nu \nu a$.

Rep. 487 A, 503 C, Laws $747 \mathrm{~B}$.

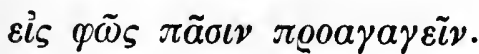

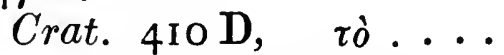

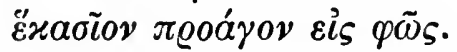

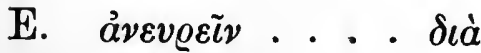

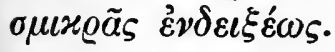

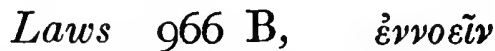
$\mu \dot{\varepsilon} \nu, \tau \dot{\eta} \nu \delta \dot{\varepsilon} \ddot{\varepsilon} \nu \delta \varepsilon \iota \xi \iota \nu \tau \tilde{\omega} \lambda \hat{\sigma}^{\prime} \gamma \omega$

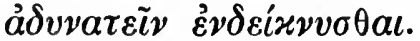

$\left(\check{\varepsilon}^{\prime} \delta \delta \varepsilon \xi_{l \varsigma}\right.$ is usually a technical legal term.)

\section{C.}

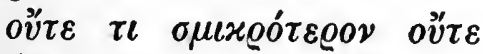

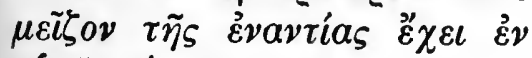

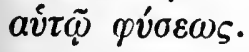

344 A.

$\delta v \sigma \mu a \theta \varepsilon \tilde{l}_{\varsigma} \delta \dot{\varepsilon}$ xai ả $\mu \nu \eta ́ n o-$ ขยs.

$344 \mathrm{C}$.

$\pi \circ \lambda \lambda o \tilde{v} \delta \varepsilon \tilde{\imath} \mu \dot{\eta} . . . \varkappa \alpha \tau \alpha-$

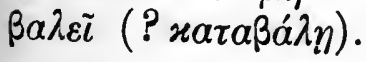

$344 \mathrm{E}$.

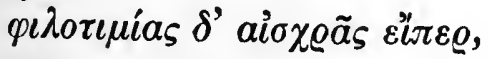
ยีขยนa.

See examples of Hyperbaton, p. I9I.

Tim. $88 \mathrm{~B}, \quad \tau \dot{o} \delta \dot{\varepsilon} \tau \tilde{\eta} \varsigma$

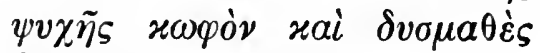

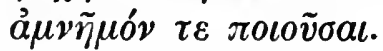

Gorg. $517 \mathrm{~A}, \quad \pi 0 \lambda \lambda \circ \tilde{v}$

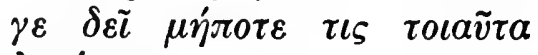

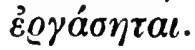

Laus 667 A, Parm. I $50 \mathrm{~B}$.

345 A.

rivu airíą;

35 I C.

For the dative cf. Lavos

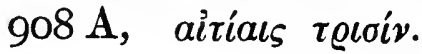

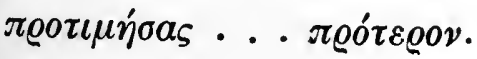

Laws 913 B. $\pi \varrho o \tau \mu \tilde{a} \nu$ $\pi \lambda \varepsilon o ́ v$, Laws 777 D. $\pi \varrho о \tau \iota \mu \tilde{\nu} \nu$

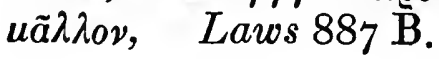




\section{EPISTLE VIII.}

This Epistle, like the seventh, purports to have been written shortly after the murder of Dion, which occurred in the year 353 B.c., and is addressed to the friends of Dion. ${ }^{1}$ Its object is again to advise them how to act in their present situation.

Plato now appears as a mediator, anxious to reconcile all parties at Syracuse. His advice will be such as to combine the greatest benefits to his friends with the least harm to his enemies. We cannot harm our enemies without harming our friends, as a recollection of recent events in Sicily shows only too clearly. Advice is difficult-it is rather a prayer to heaven that is called for.

Ever since the beginning of the war with Carthage Syracuse has been under the rule of one family, raised to power in the crisis of her destinies: Dionysius and the elder Hipparinus (father of Dion) were chosen as rulers, to the preservation of Sicily. Thus all should cherish gratitude to their dynasty. For its subsequent misdeeds the penalty has partly been paid, partly must still be paid.

It is not possible either for the supporters of

I. Meyer (v 89) gives the date as 35'r. The reasons for this are given on p. 85 supra. 
Dionysius or for the republican friends of Dion to gain the upper hand without great risk and infinite labour. Both parties should remember how often they had found that their expectations failed on the eve of fulfilment. Further bloodshed seems likely to wash out the name of Greek from Sicily, and bring her under the subjection of Phoenician or Italian. Surely all Greek Sicily should unite to find a remedy for this.

Plato then will speak as a mediator ( $\left.\delta \iota \iota \iota \eta \tau \eta^{\prime}\right)$ ). Tyrants, and those that would be tyrants, must shun the name and become constitutional monarchs, remembering the example of Lycurgus. Champions of freedom, on the other hand, must guard against extreme actions such as had paved the way for the tyrants in an earlier generation: prudence and moderation must be the watchword.

Such, continues the writer, is the advice that Dion himself in his lifetime would have given. For the remainder of the Epistle Dion is made to speak in his own person. The Syracusans are to submit themselves to a code of Laws based on a psychological ethics. They are moreover to effect a compromise between opposing factions ( $\mu \varepsilon \dot{\sigma o \nu}$ $\tau \dot{\varepsilon} \mu \nu \varepsilon(\nu)$, by establishing a constitutional rule of three kings: first, Hipparinus, son of Dion, in recognition of the services of his father and grandfather; secondly, Hipparinus, son of Dionysius I, because of his present good services and his upright character; thirdly, Dionysius II. himself, if he will consent to rule constitutionally. Their office, though exalted, is to be one of little 
political power, being chiefly the superintendence of religious matters. Questions of war and peace

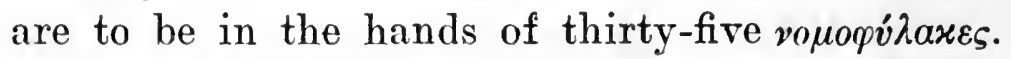
A few additional details as to the proposed constitution follow. The establishment of such a constitution at Syracuse and the refounding of the fallen Greek cities of Sicily were, says Dion, the aims of his life, and are what he would recommend to the friends he has left behind. Nor is all this impossible of fulfilment: if Hipparinus, son of Dionysius, and his namesake will but agree, the rest of Syracuse will follow. Let them pray then that this 'dream divine' become a reality.

\section{Notes on Subject-Matter.}

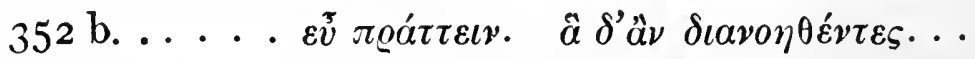
For the incorporation of the address with the actual letter cf. Epp. iii and xiii. The suggestion that this letter is not separate but a continuation of the last has been referred to under Ep. vii, supra p. I I 2.

This broadening of Plato's outlook and sympathy effected in the interval, probably, of a few months since the despatch of Ep. vii is perfectly natural. It would argue a considerable psychological insight on the part of a forger, supposing the two letters to be from the same hand.

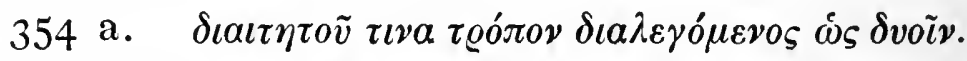

In Laws $627 \mathrm{E}$, Plato, discussing variance between members of a family, distinguishes three kinds of judges, (I) one who destroys 
the bad and appoints the good to govern themselves, (2) one who lets the bad live in voluntary submission to the good, (3) a mediator:-

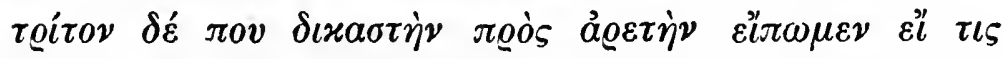

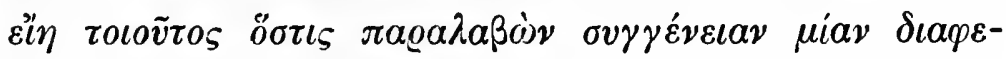

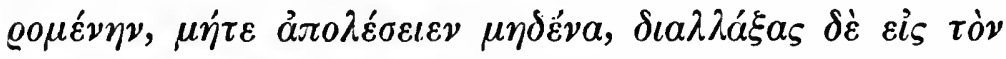

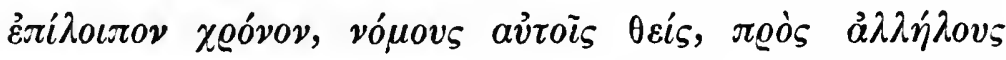

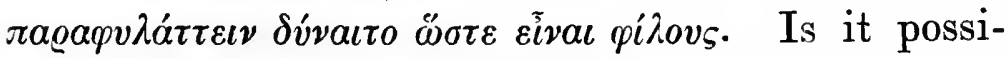
ble that Plato is here thinking of his own position as a $\delta \iota \iota \imath \eta \tau \eta \dot{~ a t ~ S y r a c u s e ? ~}$

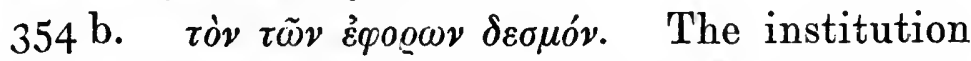
of the ephorate is here ascribed to Lycurgus, as well as that of the $\gamma$ eoovoía. On the other hand, in Laws 69I E, as Reinhold (p. 36) points out, 'institutio regum, senatus, ephororum tribus diversis auctoribus laudi vertitur'; while agreeing with him that the point is one ' de qua idem auctor haud magno temporis spatio interjecto diversa statuere potuerit' I am inclined to think that the divergent account of the Laws is due not so much to a desire for historical accuracy as to Plato's fondness in the Laws for tripartitions and triple classifications of all kinds, (cf. Laws 669 b, 837 d, 895 d, etc.). Vid. App. A, p. 196.

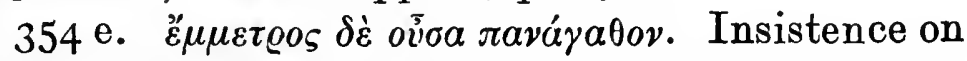
$\tau \grave{o} \mu \varepsilon \tau$ Qiov is a characteristic of the later dialogues of Plato. See especially Laws 7or e.

356 A. xáoıv . . óoíov roórov. It is unlikely that Hipparinus would have been referred to in such terms after he had shown his worthless character as tyrant (Aelian V.H., ii, 4I. Theopomp. apud Athen. $\mathbf{x}, 436 \mathrm{~A})$ : especially unlikely that these 
are the words of a writer contemporary with Timoleon.

The most serious objection of any kind that has been brought against this letter is concerned with the reference to the son of Dion at $355 \mathrm{E}$. For Plutarch, Nepos and Aelian agree in saying that this person was not alive at the time, having died before his father. Richards (C.R. I900, p. 340) takes it for granted that this objection holds good, and therefore rejects the Epistle, which on other grounds he would regard as authentic. He does not appear to have read Reinhold's excellent discussion of the point (l.c., pp. $9 s q q$.). Reinhold has collected and examined all the relevant passages, and I will therefore only summarise his arguments, which I accept unreservedly:-

(I) It is impossible to hold that two different sons of Dion are referred to (Grote's view). This supposition is based solely on the doubt expressed by Plutarch (Dion 3I) as to the name of Dion's son, Timaeus calling him Aretaeus, Timonides Hipparinus. None of the historians, however, (including the writer of the Epistles) know of a second son of Dion, except the posthumous son to whom Arete gave birth in prison and who was shortly afterwards murdered together with his mother by Callippus (Plutarch, Dion, 57). It is of course out of the question that he can be referred to by the writer of this Epistle. 
Thus the attempt to reconcile Plato with the historians breaks down.

(2) Plutarch, after relating the death of this Hipparinus, tells us that Callippus thereupon spread a rumour, for the purpose of discrediting Dion, to the effect that he, being now childless, proposed to adopt Apollocrates, son of Dionysius II, as his successor in the tyranny.

(3) The manner of Hipparinus' death is described (a) by Cornelius Nepos (iv. 3) as follows:-(Dionysius II) filium Dionis sic educari jussit, ut indulgendo turpissimis imbueretur cupiditatibus .... Is usque eo vitae statum commutatum ferre non potuit, postquam in patriam rediit pater (namque appositi erant custodes, qui eum a pristino victu deducerent), ut se de superiore parte aedium dejecerit atque ita interiit; (b) by Plutarch (Dion 55) in these words:-

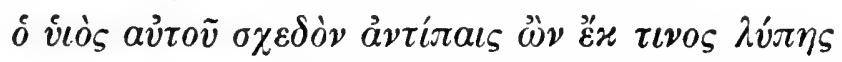

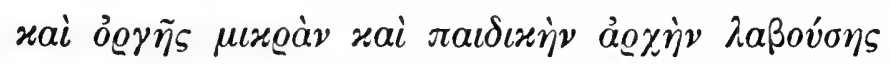

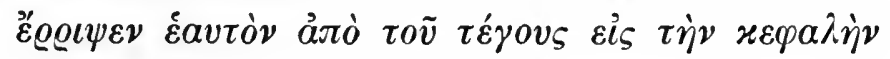
rai $\delta \iota \epsilon \phi \theta \dot{\varrho} \varrho \eta$.

This story, Reinhold thinks, has the appearance of being legendary: he doubts the credibility of Dionysius having corrupted his own nephew.

(4) Reinhold therefore concludes that the report of Hipparinus' death was concocted by Callippus as a necessary preliminary to his 
discrediting of Dion by the rumour of his adoption of Apollocrates.

(5) Lastly - and this seems to me a very strong argument-it is improbable that a forger so well informed on the details of Syracusan affairs as the writer of Ep. viii (and, I may add, so remarkably clever as an imitator of Plato's style) would have committed such an elementary blunder as is supposed.

(One admission, however, must be made. It is remarkable that Plutarch, who quotes from this Epistle several times, should not notice his divergence on this matter from its author-and that too although he does remark on another divergence from Plato (Dion I9 ad fin.).)

This explanation I believe to be substantially correct: and Reinhold is certainly right in rejecting the only alternatives, (I) that Plato had not heard of the death, (2) that Dion had two sons. Nevertheless he has not foreseen the obvious objection to his theory, which is that it would have been difficult for Callippus to gain credit for his tale, and that Dion would have produced the person of his son to confute it.

Now according to Plutarch (Dion 55), whose sources, namely Timaeus and Timonides, are probably the same as those of Nepos, the death of Hipparinus came as the fulfilment of a dream which Dion had of a Fury sweeping out his house. In his terror Dion sent for his friends and revealed to

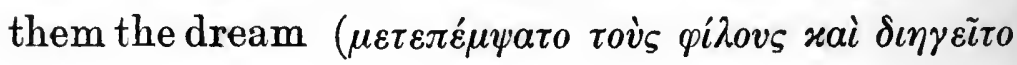


$\tau \dot{\eta} \nu$ oै $\psi(v$ av̉roī). Among these friends would certainly be Callippus, Dion's chief confidant (ch. 54). Is it not possible that it occurred to Callippus to fulfil the dream by removing the person of Hipparinus, who stood in the way of his projects? He secured, I would suggest, the youth and foisted the tale of his accidental death on Dion, who in his panic-stricken state would be only too ready to believe it. No doubt others believed it also. By the time that Plato wrote this letter, some three years later, Hipparinus must have got free, as he naturally would after Callippus had been deposed: but by that time the belief in his death had become so certain that he was regarded by many Syracusans, including the historians whom Plutarch follows, as an impostor. Consequently the report of his death was incorporated in history.

The only reason that I can suggest for Plutarch's failure to recognise his discrepancy with Plato, is that his love of the marvellous prevailed over his critical faculty, making him reluctant to give up such a good story as that of the dream and its fulfilment.

In his allusions to the rise of Dionysius I. to power, Plato has committed two inaccuracies, consciously in one case, unconsciously in the other.

(I) In $353 \mathrm{~B}$ he mentions Hipparinus (the father of Dion) as being associated with Dionysius in the possession of absolute power (avirox@áro@as rvoávvovs). Diodorus (xiii, 94), who is our principal authority for the history of this period, is 
silent as to Hipparinus, though his account is

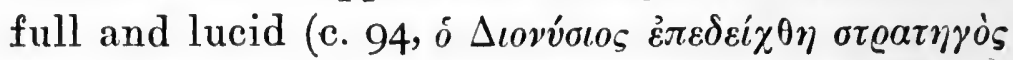

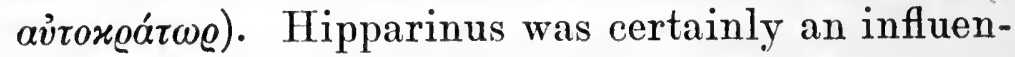
tial supporter of Dionysius (as was Philistus), and

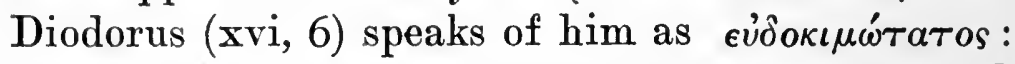
but it does not appear likely that he was accorded any recognised conjoint authority with Dionysius. Plato doubtless exaggerates his position, partly owing to an imperfect knowledge of the events of 406-5 B.C., partly out of a conscious desire to compliment Dion's family (cf. Meyer v, 77, 89).

Reinhold is probably right in thinking that the words $\ddot{\omega} s$ qaø in the text mean that rv́@avvo was a popular, not an official designation.

(2) In $354 \mathrm{D}$ Plato must be wrong in saying that the Syracusans stoned the generals who preceded the new board which included Dionysius. Diodorus (xiii, 92) merely says that they were

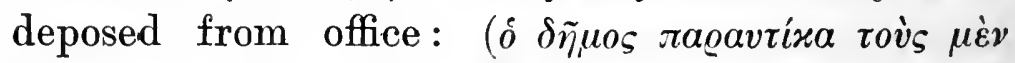

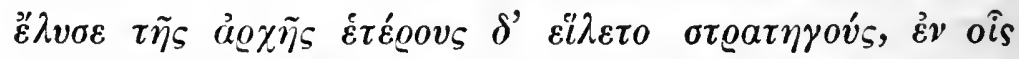
zai $\Delta$ covvócov). Moreover, Daphnaeus, who was one of the number and had held the chief command before Agrigentum (Polyaenus, v, 7), was only removed after Dionysius had become master of Syracuse (Diod. xiii, 96).

Plato is doubtless confusing the occasion with the similar events which had happened shortly before at Agrigentum, where the generals had been stoned to death (Diod. xiii, 87). This is the view of Grote and Meyer. Reinhold's opinion (p. 38), 'alios eosque paulo priores Sicilae tumultus hic spectari' has no evidence to support it. The 
lapse of memory in regard to events of over fifty years back, on the part of a writer of 75 , is, as Grote says, both conceivable and pardonable. It should, however, be noted that one MS. (o) has

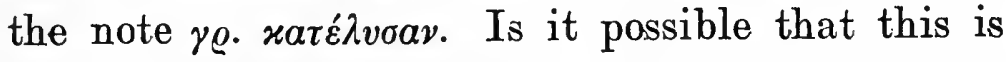
right and is what Diodorus read in the passage, and that $\beta a ́ d \lambda o v \tau \varepsilon s$ came in as a gloss on the false

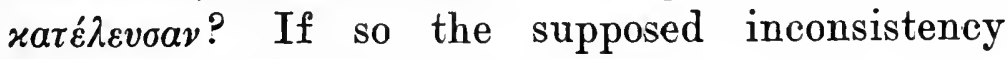
becomes a merely textual matter.

In addition to the several historical difficulties which have been dealt with in the preceding notes, the general criticism has been made by Rudolf Adam (l.c., p. 33) that the political situation of Timoleon's age is confused with that of Dion's. In what way this is so the writer does not state, and I am unable to detect the confusion. ${ }^{1}$ Adam declares that 'the author must have lived after 'Timoleon's restoration, perhaps under Agathocles.' If this is so, he has resisted very successfully the temptation to 'prophesy.'

x. I suppose however that it is a mere repetition from Steinhart who bases his objection on the supposition that in $352 \mathrm{C}$ the writer speaks of Tyrannies having been abolished throughout Sicily. But the words $\kappa a \tau \grave{\alpha} \Sigma_{\iota \kappa \epsilon \lambda i ́ a v} \pi \hat{\alpha} \sigma a \nu$ should be taken with $\dot{\epsilon}^{\prime} \sigma \theta^{\prime} \dot{v} \mu \hat{\imath} \nu$. 


\section{I42 AUTHORSHIP OF PLATONIC EPISTLES}

Adam also attacks this Epistle on the ground of numerous imitations of the Dialogues. I give the most important of his instances in parallel columns :-

Epistle viii.

(I) $352 \mathrm{c}$

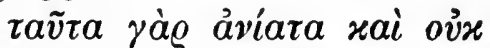

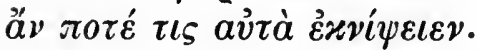

Dialogues.

(I) Gorg. 525. c.

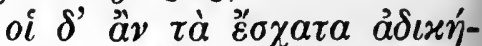

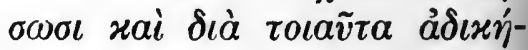

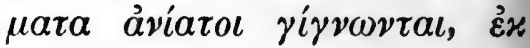

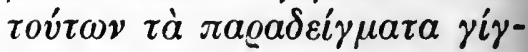

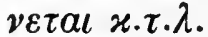

(2) Laws $768 \mathrm{E}$.

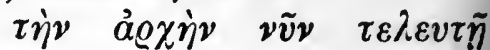

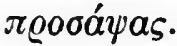

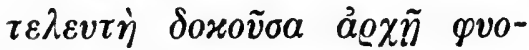
$\mu \dot{\varepsilon} \nu \eta \nu \dot{\varepsilon} a$.

(3) $354 \mathrm{~B}$.

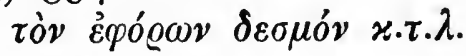

(4) $354 \mathrm{E}$.

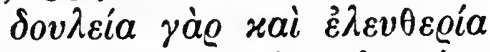

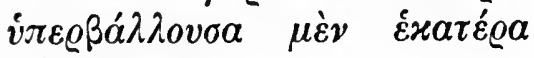

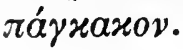

(5) $354 \mathrm{E}$.

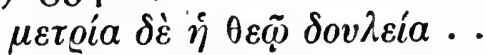

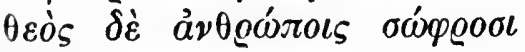
vópos.
(4) Rep. $564 \mathrm{~A}$.

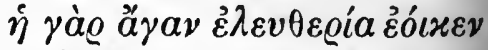

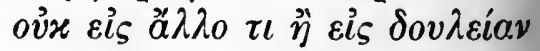
$\mu \varepsilon \tau \alpha \beta a ́ \lambda \lambda \varepsilon \iota \nu .$.

(5) Laws $762 \mathrm{E}$.

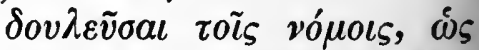

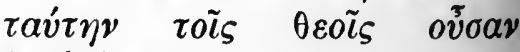

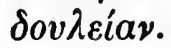

(3) Laws $690 \mathrm{D}-692 \mathrm{~A}$. 
(6) $355 \mathrm{c}$.

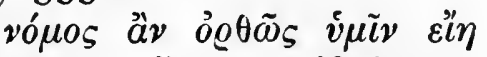

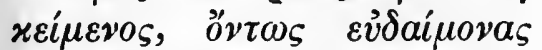

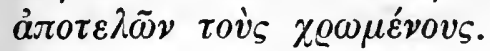

\section{(7) $357 \mathrm{D}$.}

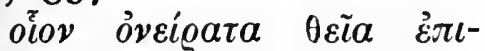

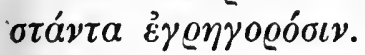

(6) Laws 63 I B.

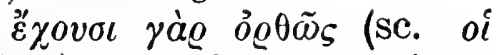

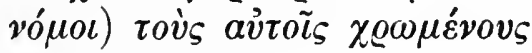

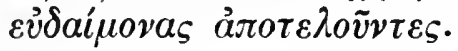

(7) Soph. $266 \mathrm{c.}$

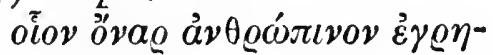

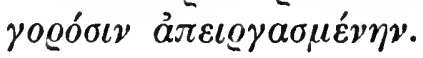

These parallels will doubtless impress different readers in varying degree. It may, however, be taken as a principle that we have no right to suppose a forger's imitation except where unusual thought or language is unnaturally inserted. This would not seem to be the case in any of the above passages.

As to (I) Adam himself notes that Laws $872 \mathrm{C}$ should be compared. He means, doubtless, $872 \mathrm{E}$,

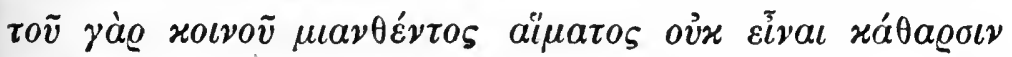

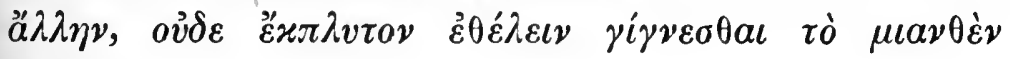
$\pi \varrho i v . .$.

Why should we not say that the author of the Laws is 'imitating' the author of the Gorgias? (See.App. B for other examples.)

In (2) the parallel is slight and the language in no way unusual.

(3) There is no reason why Plato should not refer twice to the institution of the Ephorate. Would a forger have resisted the temptation to retain the metaphor wádıov in $692 \mathrm{~A}$ ?

(4) can hardly be called a parallel at all. In the Republic passage Plato is saying that 'corruptio optimi pessima.' $\mathrm{He}$ is not saying so in the 


\section{I44 AUTHORSHIP OF PLATONIC EPISTLES}

Epistle. Moreover the doctrine of the mean is surely too much of a commonplace in Platonic, and indeed in Greek thought generally, to bear the weight of an 'imitation' argument.

(5) Adam protests that this ' cannot possibly be chance.' This is certainly a close parallel, but not more close than many parallels in accepted Dialogues. (See App. B.)

(6) The thought here is not unusual, for it underlies the whole of Plato's Ethics. As to the

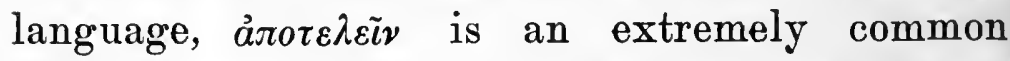
Platonic word (vid. Ast, the great majority of whose numerous citations thereof are from dialogues of the 'late' group). It is moreover used

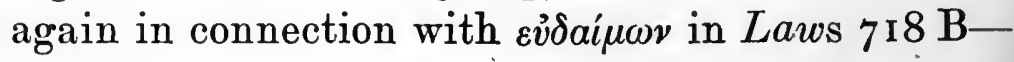

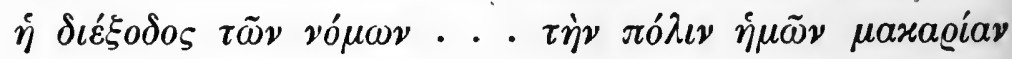

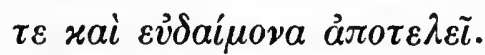

( 7 ) is a close parallel in language, but it hardly seems likely that the distinction between $\theta \varepsilon i \alpha$

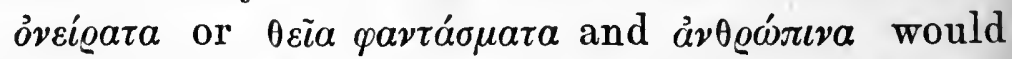
have occurred here to the hypothetical forger. The distinction, as we may see from a comparison of Rep. $532 \mathrm{C}$ and Sophist $266 \mathrm{C}$, is that $\theta \varepsilon i a$ are representations of 'natural' objects effected by natural media, whereas $\dot{\alpha} \nu 0 \varrho \omega ́ \pi \iota \nu \alpha$ are representations of 'artificial' objects by artificial media. The former are called $\theta \varepsilon i a$ because their originals are 'true' in the metaphysical sense, or 'real.' Dion's prophecy is a $\theta \varepsilon \tilde{\varepsilon} 0 v$ oै $v \varepsilon \varrho o v$ because it is (on his assumption) a representation of what will really come to pass. 
Thus, although our instance of the expression conforms to the Platonic distinction, yet it is such a specialised instance that it cannot be said to be an imitation of the Sophist passage.

The remaining parallels given by Adam are slighter than these. I have thought it worth while discussing these passages, as the argument of 'imitation' has been used against the authenticity of this Epistle more than is the case with any other. It will, I hope, be evident that such passages can prove little or nothing on either side.

I now pass to the positive arguments from language, and note Platonic parallels in parallel columns.

Of the 19 rare words given on p. 29 supra, the following 9 are used elsewhere by Plato only in Soph., Pol., Phil., Tim., Critias., Laws :-

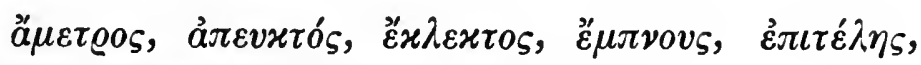

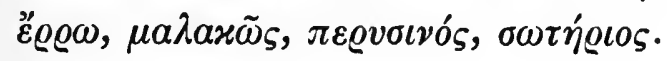

(The usage of some of these is illustrated below.)

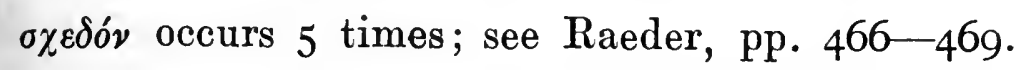

$352 \mathrm{~b}$.

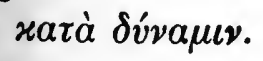

$52 \mathrm{C}$.

ảvootov@yós.
See Raeder, ibid.

äл $\lambda_{\xi} \lambda \gamma$. in Plato. See Campbell, Soph. and Pol.,

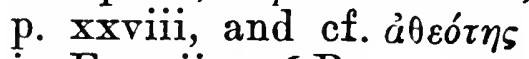
in Ep. vii, $336 \mathrm{~B}$. 


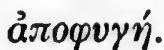

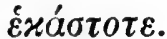

$352 \mathrm{~d}$.

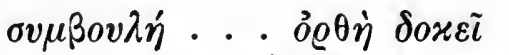
. . $\sigma v \mu \beta o v \lambda \varepsilon v ́ \varepsilon \iota v \delta \varepsilon \tilde{\imath} \nu$.

$\tau o ̀ ~ \delta \dot{\varepsilon}$ (whereas).

$\tau \tilde{\eta} \delta \varepsilon$

$352 \mathrm{E}$.

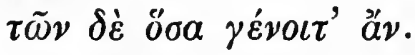

Occurs 5 times in Plato (3 times in latest group), viz., Phaedo ro7 c, Phil. 44 c, Laws 73 I d, 632 a, Ep. vii, 337 d.

Elsewhere quoted by $\mathrm{L}$. and $\mathrm{S}$. and Passow only once, from Thucydides.

Also in $35^{2} \mathrm{E}, 353 \mathrm{D}$; see App. A, p. 193.

$\delta \varepsilon \tilde{\imath} \nu$ redundant, cf. Rep.

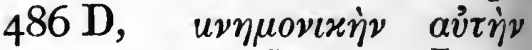

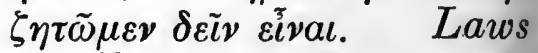

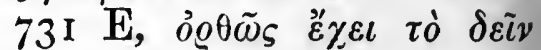

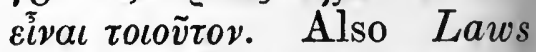

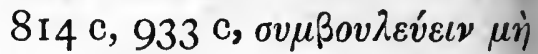

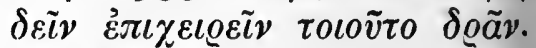
See App. A, p. I94.

Common throughout Plato.

This adverb, in the meaning of 'here,' seems confined to the later Platonic dialogues in Greek Prose.

Ast quotes instances from Phaedrus (2), Polit. Parm. Tim. (2), Laws (3)

Article as Demonstr. Pronoun Antecedent. See exx. in Riddell's Digest, p. I27, and add instances quoted in App. A, p. I96. Riddell remarks: "Jelf notices that this idiom is peculiarly Platonic, adding, however, one or two instances from the Orators." 


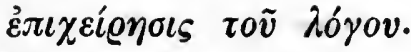

$353 \mathrm{~A}$.

$\dot{\varepsilon} \pi \iota \tau \varepsilon \lambda \dot{\eta} \zeta$.

$\tau o ́ \theta$ '̊̈

$353 \mathrm{~B}$.

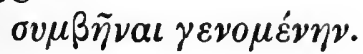

$353 \mathrm{c}$.

$\varepsilon \dot{v} \pi \varepsilon \tau \tilde{\omega} \varsigma$.

$353 \mathrm{E}$.

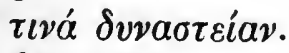

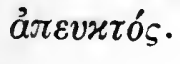

$353 \mathrm{D}$.

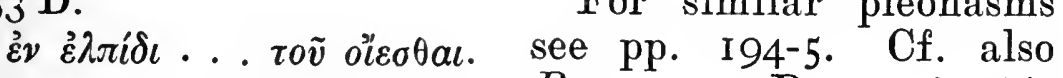
Rep., $330 \mathrm{D}, \quad \dot{\varepsilon} \pi \varepsilon 1 \delta a ́ v$

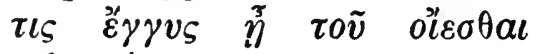
$\tau \varepsilon \lambda \varepsilon v \tau \dot{\eta} \sigma \varepsilon \iota \nu$.

See Raeder, pp. 466-9. Elsewhere in Plato only in Laws $628 \mathrm{c}$.

See Raeder, ibid.

For the abstractness of expression ef. Laws

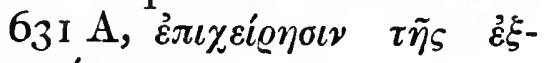
$\eta \gamma \eta \dot{\sigma \varepsilon} \omega \varsigma$.

\section{Cf. Laws 93 I E (in both passages used of ev̉xaí).

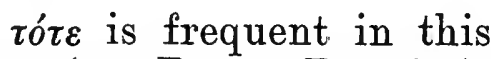 Ep. (354 D, 353 B twice). See p. 193.}

For the pleonasm cf. Laws 66I B, à0ávatov

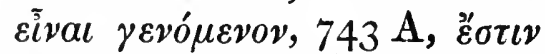

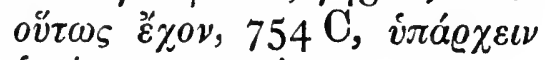

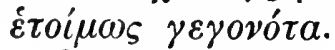

See App. A, p. 193.

Cf. Epistle vii, $327 \mathrm{D}$, Euthyd. 304c., Rep. 369A, Tim. 8I D, Laws $708 \mathrm{c}$. Rare in Prose, but not confined to Plato.

For similar pleonasms
354 A.

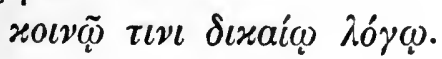




\section{I48 AUTHORSHIP OF PLATONIC EPISTLES}

$354 \mathrm{C}$.

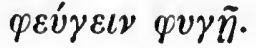

$354 \mathrm{C}$.

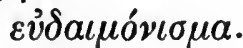

$354 \mathrm{E}$.

$\pi a ́ v \tau \eta \pi a ́ v \tau \omega s$.

$355 \mathrm{~A}$.

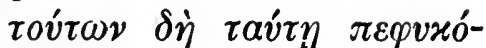
$\tau \omega \nu$.

$355 \mathrm{~B}$.

$\mu \varepsilon \tau^{\prime} \varepsilon \dot{\varepsilon} \pi \theta v \mu i a_{\varsigma}$.
Cf. Symp. 195 B,

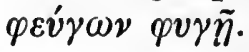

Only quoted elsewhere by L. and S. and Passow from Appian. Jowett (Laws, p. xxiv) notes P's. fondness in the Laws for substantives in $-\mu \alpha$ and $-\sigma l s$.

Cf. Epp. ii, 314 B, vii, 325 E, Laws 80 I A. (Vid. Raeder, l.c., p. 467.)

Cf. Laws $733 \mathrm{C}$ -

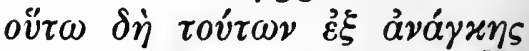
$\delta \iota \alpha \varkappa \varepsilon \varkappa о \sigma \mu \eta \mu \varepsilon ́ \nu \omega \nu . \quad 807 \mathrm{D}$,

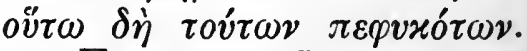

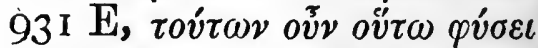

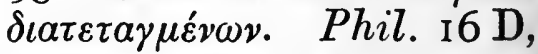

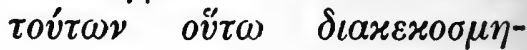
$\mu \dot{\varepsilon} \nu \omega \nu$.

$P$. is fond of filling out a verb or participle by appending $\mu \varepsilon \tau \alpha \dot{~}+$ genitive of an abstract noun at the end of the clause. Cf. Laws 869 A,

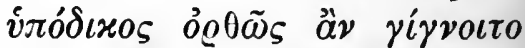

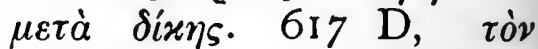

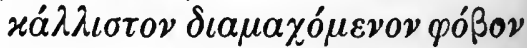

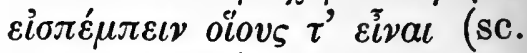

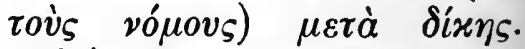

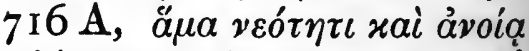

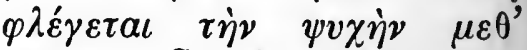
Ű 
$355 \mathrm{C}$.

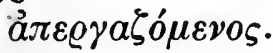

$\gamma \varepsilon v \dot{\sigma} \eta \sigma \theta \varepsilon$.

$355 \mathrm{D}$. $<\tau \dot{o}>\mu \dot{\varepsilon} \gamma \iota \sigma \tau o v$ ( $\tau \dot{o}$ add. use cf. Ep. vii, $336 \mathrm{~B}$. Burnet).

\section{$355 \mathrm{D}$.}

๕̊goovor.

$355 \mathrm{D}$.

$\chi^{\alpha \lambda \epsilon \pi o ́ \tau \eta \varsigma . ~}$

$355 \mathrm{E}$.

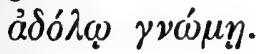

See p. I 84 .

P. frequently uses yevóna metaphorically. Vid. Ast.

For this parenthetical

This verb occurs in Ep. vii, 349 E, Phil. 24 D, Laws 677 C, E. Ep. iii, $319 \mathrm{c}$, not in earlier dialogues (according to Ast). Chiefly Tragic.

Cf. Laws 929 D. Used however several times by Isocrates.

$a \dot{\delta} \delta \dot{\lambda} \omega s$ occurs in Gorg. 45I E, Phaedrus 249 A. Outside Plato the word is almost entirely confined to the usage as a technical epithet of treaties.

Cf. Laws $938 \mathrm{~A}$, $\pi \varrho \grave{s}$

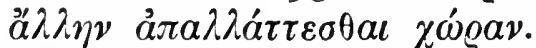
Elsewhere in Attic used with " ablative" Genitive.

For such collocations vid. Raeder (l.c.), p. 467 .

Cf. Laws 938 B, 948 A, $956 \mathrm{C}$. Once in Thucydides: not elsewhere in Attic Prose. 
$356 \mathrm{D}$.

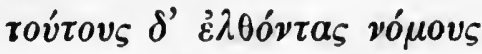

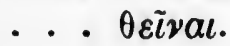

$357 \mathrm{~B}$.

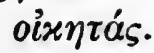

$357 \mathrm{C}$.

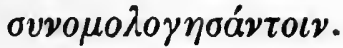

$\delta \varepsilon \bar{\imath}$ is here to be supplied from the preceding imperative $x a \lambda \varepsilon i \tau \varepsilon$. Cf. Republic, 467 C.

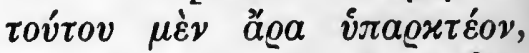

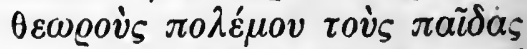

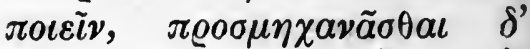
avizoīs ảopád $\varepsilon l a v$, where it is supplied from a preceding verbal.

Cf. Phaedo i I I B. Elsewhere once in Sophocles, and (perhaps) in Simonides.

Jowett (Lavs, p. xxiv) and Stallbaum (Proleg. de Legg. lxv.) note Plato's fondness in the Laws for such compound verbs. Of Ast's 25 citations, 14 are from Soph. Pol. Phil. and Laws, I from Epin., I from Ep. vii, $357 \mathrm{C}$.

Raeder gives the Hiatus-average for this Epistle as 8.72, the instances amounting to 34 . The distribution of these is fairly consistent, there being no noticeable 'blocks' of hiatus. The

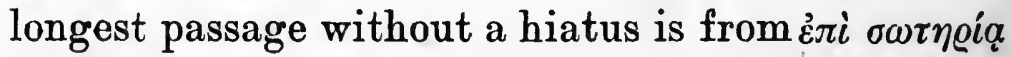
in $356 \mathrm{c}$ to है lines), while before this passage we have had 8 lines free from hiatus. Thus it is certain that the writer must have been consciously avoiding it.

Ritter, who allows the greatest claim to authen- 
ticity to Epp. iii, vii and viii, remarks that though there are numerous and sometimes close parallels between this letter and the Laws, yet the language is never identical. (He admits an exception in the parallel of $355 \mathrm{c}$ with Laws 63 I B, remarked above.) He further suggests that Plato may have actually drawn up this sketch of a constitution with Dion, which would give additional point to the personation.

Finally, I adduce what seems a striking confirmation of this letter's genuineness in a passage of the Laws, so far as I know not hitherto commented upon.

In $355 \mathrm{E}$ Plato, speaking as 'Dio personatus,' recommends a coalition government by three kings, namely, Hipparinus (Dion's own son), Hipparinus (son of Dionysius I) and Dionysius II.

In Laws iv, 709, the hypothetical legislator is asked this question:-

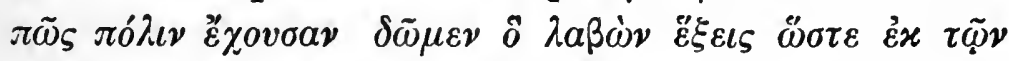

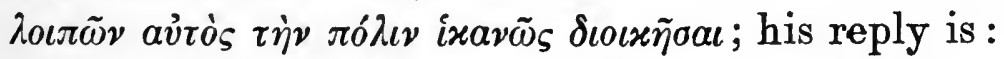

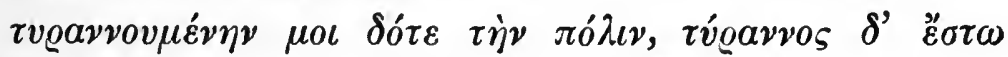

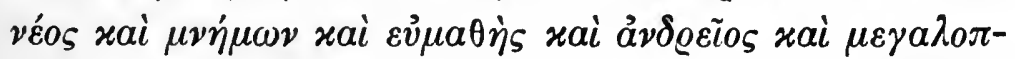

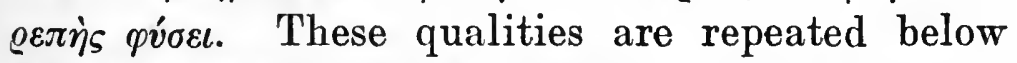

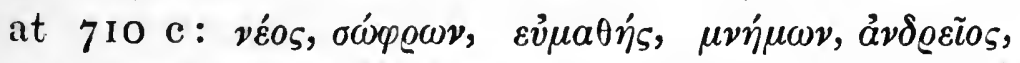
$\mu \varepsilon \gamma a \lambda$ ¿е́л $\eta \varsigma$ (with the unimportant addition of $\sigma \omega \dot{\varphi} \rho \omega v)$. This repetition is put into the mouth of the respondent Cleinias, the Athenian there-

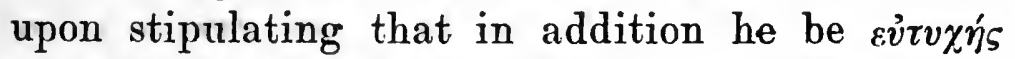
which is explained as meaning 'contemporary with a good legislator.' He continues thus:-

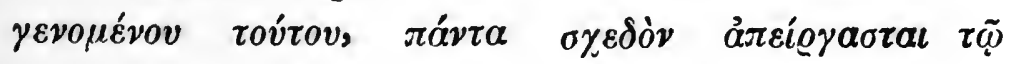




\section{I52 AUTHORSHIP OF PLATONIC EPISTLES}

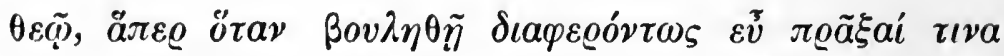

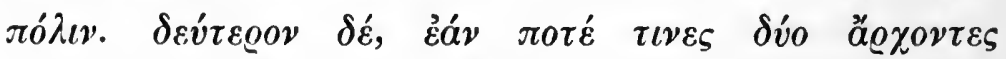

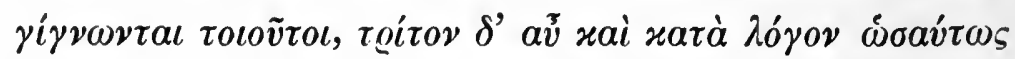

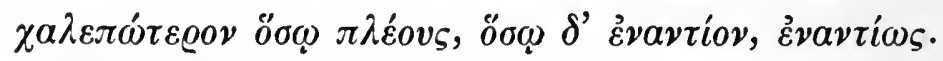

The introduction of the case of two or three or more tyrants seems unnatural: the Athenian is understood by Cleinias to be referring respectively to Tyranny, Oligarchy, and Democracy, though he only hazards this interpretation tentatively (cf. $\ddot{\eta} \pi \tilde{\omega} \varsigma \lambda \dot{\varepsilon} \gamma \varepsilon \iota \varsigma$. 7 IO E). The subsequent answer of the Athenian does not, it would appear, interpret his own previous words in the clause $\delta \varepsilon v ́ \tau \varepsilon \varrho o \nu ~ \delta \dot{\varepsilon} .$. but corrects a mistaken belief of Cleinias : for we cannot suppose the state governed by one tyrant to be differentiated from the state governed by two in the same way as rvoavvis from $\beta a \sigma \iota \iota x \dot{\eta} \pi о \lambda \iota \tau \varepsilon i a$.

It would therefore seem reasonable to assume

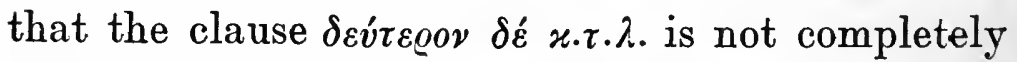
intelligible in itself: the difficulty finds a natural explanation if read as an allusion to an actual or possible condition of a contemporary state-viz., Syracuse-governed by two or three tyrants or kings.

To revert to the qualities of the hypothetical good tyrant, we are inevitably reminded of the description of the philosophic guardians in Rep. iv. $503 \mathrm{c}$ as

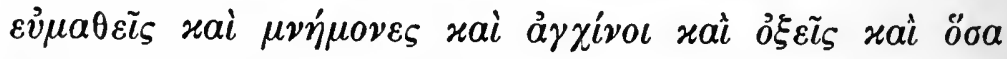

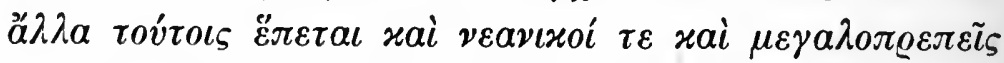

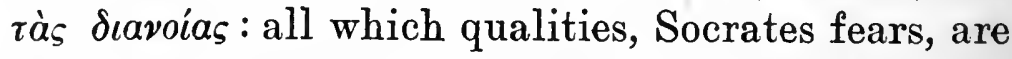

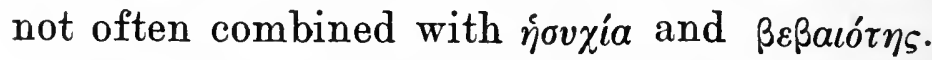

The significant additional quality in the enum- 
eration in the Laws is that of being véos. ${ }^{1} \quad$ Now in the first place it is obvious that Plato must have travelled a long way in the interval between the Republic and Laws before he could paint even a hypothetical tyrant in the colours of the philosophic guardians: and it would hardly be contested that the change of attitude reflects his personal experiences at the court of Dionysius II. Thus far, then, we might be inclined to actualise the hypothetical tyrant in the person of this monarch or perhaps of Dion. I am inclined, however, to think that this is incorrect, for the following reasons.

In 7 IICD we are told that the tyrant will effect the desired change by the combined methods of compulsion and persuasion. But the requisite combination of wisdom and power is seldom to be found. There are no Nestors in real life (7 I I E:

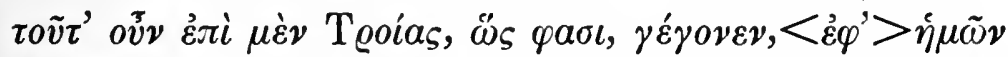

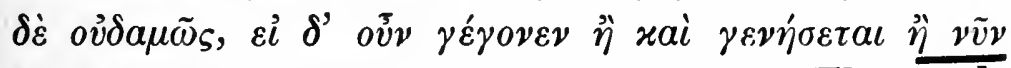

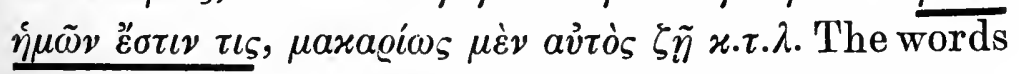
underlined will suggest to those familiar with the style of Plato's allusions that the hypothetical ruler is alive at the moment of writing. If this be so may we not reasonably find him in the Hipparinus (son of Dion) named by 'Dio personatus' in Ep. viii (loc. cit.) as the first of the three candidates recommended for the joint

I. vєavıкós has quite a different implication. Moreover, it is noticeable that veós is the first quality mentioned in both the enumerations of the Laws. 
monarchy, and referred to in such hopeful terms in Ep. vii (which letter, if genuine, must have been written some few months earlier than Ep. viii)? I refer to the passage $324 \mathrm{~A}:-$

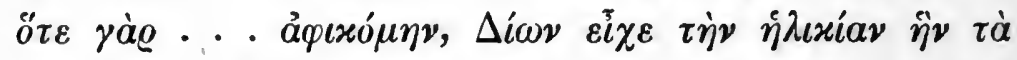

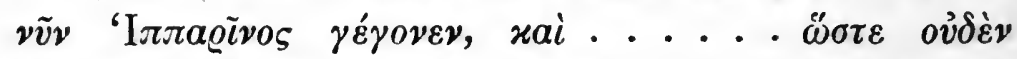

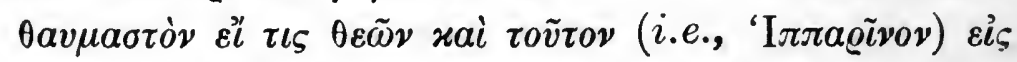

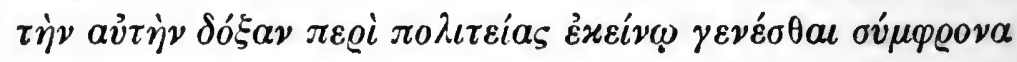

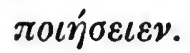

This conjecture would fix the date of the composition of Laws iv at 354-3 B.C. We know from the allusion at $638 \mathrm{~B}$ to the Syracusan conquest of Locri ${ }^{1}$ that Bk. I cannot have been written earlier than 356 B.C.

x. Locri was seized by Dionysius on his expulsion from Syracuse (Justin, xxi, 2). 


\section{EPISTLE IX.}

In this letter the writer is replying to Archytas of Tarentum, who has complained of the burdensomeness of state affairs. $\mathrm{He}$ is reminded that a man must not live only to himself, but must recognise the claims of friends and country. If the call to public life be not listened to, there is a danger that worse men may step in. A concluding sentence mentions the writer's friendship for Echecrates.

There is very little evidence either for or against the authenticity of this Epistle. It is not discussed by Ritter: Steinhart admits that it is 'not uncleverly composed' and praises the definiteness with which the writer keeps to the point: he has taken 'warning, thinks this commentator, by the 'rambling' character of the Syracusan letters. He further admits that the advice given here as to the necessity for taking part in public life is consistent with Plato, and refers to obvious parallels in Rep. i. 347, vii. 540. to which may be added vi, $52 \mathrm{I}$. His criticism is that here, where Plato is speaking, not through the mouth of Socrates to all the world, but personally as friend to friend, a piece of advice is given which is in surprising contrast to his own withdrawal from public life. Moreover, Archytas, 


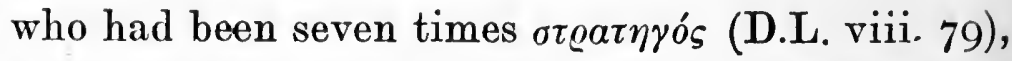
little needed such advice, which indeed would come more appropriately from him to Plato.

I do not think there is any force in this. Plato explains clearly in Ep. vii the exceptional circumstances which had induced him reluctantly to stand aloof from Athenian politics: and the fact that Archytas had been seven times General is a good reason for his being weary of that office.

Steinhart's remaining objection is that Echecrates, whom he assumes to be the Echecrates of Philius to whom Phaedo narrates the story of the death of Socrates in the Phaedo, could not be called veavioxós even in 389 (he should say 387 ), the earliest date to which we could assign this Epistle. The identification, however, is doubtless incorrect, for as Archer-Hind points out (Phaedo, p. xxiii) a Tarentine Pythagorean of the same name is mentioned in Iamblichus' list of Pythagoreans (Iamb. Vit. Pythag., ad fin.), as distinct from the Phliasian.

There is no possibility of fixing the date, and the letter is too short for Raeder's Hiatus-average $(7.50)$ to have any weight. There are three words

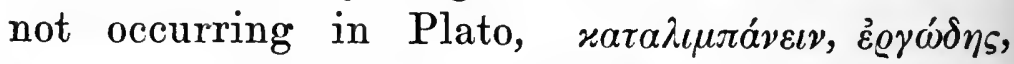

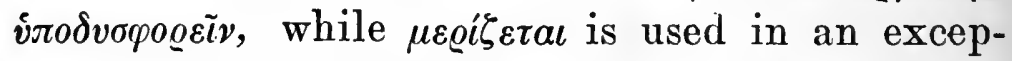
tional sense ( $=$ 'claims a share in '). It is perhaps worth noting, in view of the not inconsiderable medical and physiological knowledge shown in the

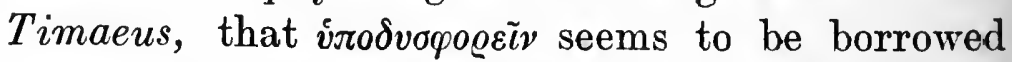
from the language of medicine: it occurs once, and the corresponding adjective twice, in the 
Corpus of Hippocrates (Epid. iii, I098, I IOI; Prorrh. 70, Coac. 124 Foesius).

The following turns of expression seem Platonic:

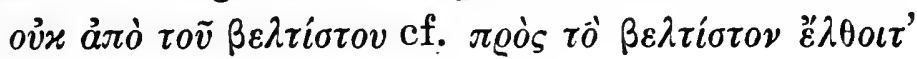
$\ddot{\alpha} \nu$ (Ep. iv, $320 \mathrm{E}$ ).

Also (quoted on that passage) Tim. $48 \mathrm{~A}$, Rep. $345 \mathrm{C}$.

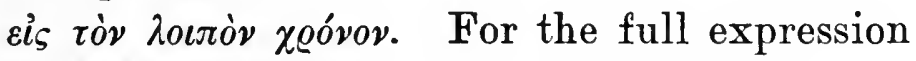

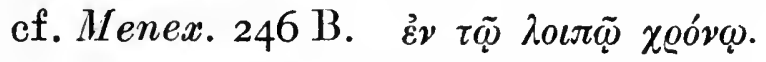

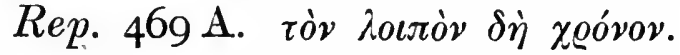

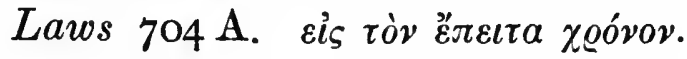

I have referred to the parallelism between $358 \mathrm{~A} \mathrm{~B}$ and Rep. i, 347. It is undoubtedly striking, but a careful comparison leads me to think that this is not a case of copying, chiefly because it is the thought only, and not the language, that recurs: (e.g., cf. $\tau \tilde{\eta} \varsigma$ $\delta \dot{\varepsilon} \zeta \eta \mu i a_{\varsigma} \mu \varepsilon \gamma i \sigma \tau \eta$

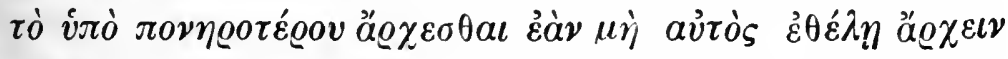

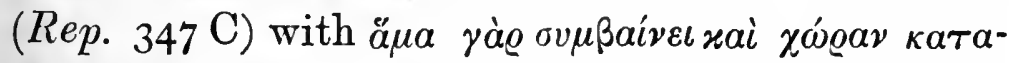

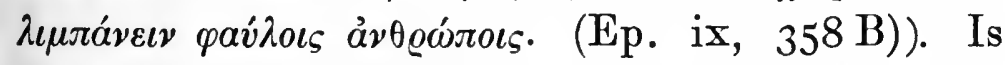
it possible that Plato was thinking of Archytas when writing the Republic passage?

There does not appear to be enough evidence to pronounce on either side as to the authenticity of this letter. 


\section{EPISTLE X.}

This letter, the shortest of the collection, commends the disposition of a friend of Dion named Aristodorus.

There is again too little evidence for us to decide as to authorship. The tone and style, however, are Platonic, and it is difficult to see why any forger should have thought it worth while to compose the document: it could hardly fetch a

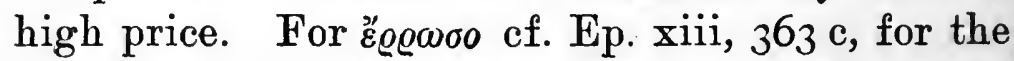

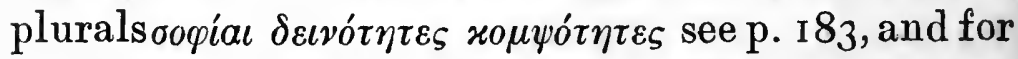
the general thought and language cf. Theaet. I 76c,

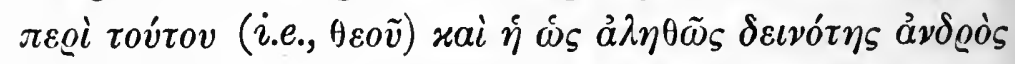

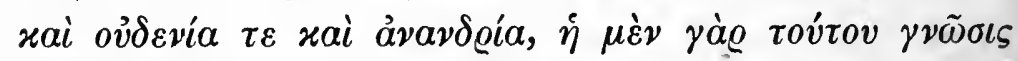

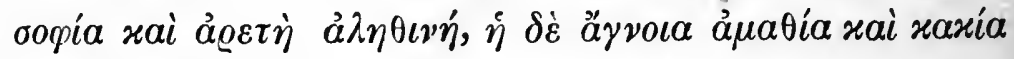

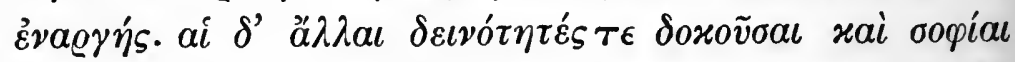

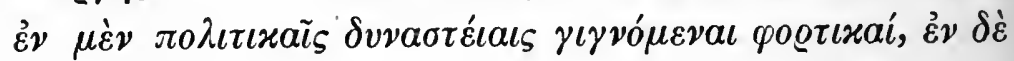

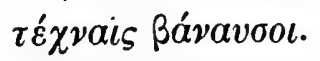

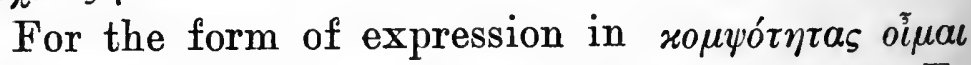

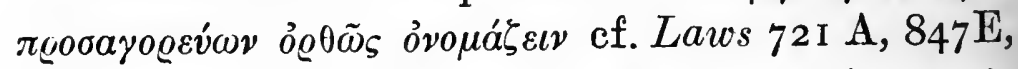

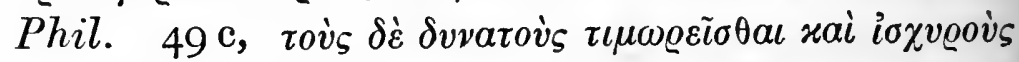

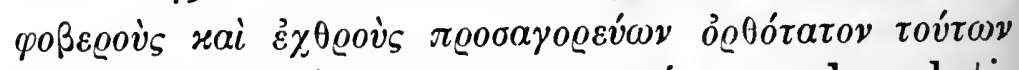

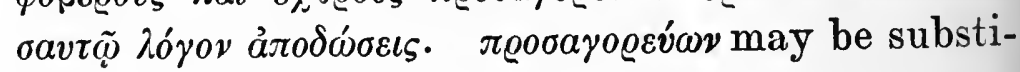

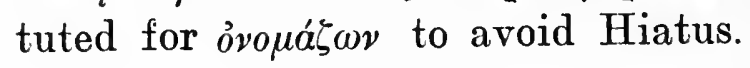




\section{EPISTLE XI.}

This is a reply from Plato to Laodamas, who has consulted him in regard to the founding of some colony. Plato cannot come to see him, first because he has little hope for the success of Laodamas' schemes and does not wish to be concerned in a failure, secondly because he is old and infirm and cannot risk the voyage. The advice he has to give is that even the best laws cannot secure the success of a state unless there is some supreme ruling authority. If there are men ready to hand who are fitted for such rule, well and good: but if they have to be created, Plato fears they will lack both instructor and pupil, and must be content to pray that some one may be sent. There have been instances in history when a strong and righteous man has been raised up to his country in a time of stress. Let Laodamas bear this advice in mind and not err through oversanguine haste.

There are no means of determining the identity of Laodamas, though there seems no objection to identifying him with Plato's pupil of that name, to whom (according to Diog. Laert. iii, 24) Plato first revealed the method of Analysis. Nor can we fix the date, as we do not know the situation of 
the projected colony (the suggestions of Raeder (p. 440) and Meyer (v, 48I, 503) that Crenidae or Datos are intended are purely conjectural).

We are naturally astonished at the mention of Socrates as being alive in Plato's old age. Steinhart suggests (apparently in all seriousness) that the writer is parodying the anachronisms which he found in other Epistles of our collection, by inserting one that could hardly go unnoticed. I do not imagine this suggestion will find much favour: the Socrates here mentioned is doubtless another than the son of Sophroniscus, and may be, as Ast suggested, the same as the "Young Socrates" of the Sophist and Politicus.

Steinhart, in discussing the advice here ascribed to Plato, holds that the letter is proved to belong to the Macedonian period by what he calls its "insistence on the monarchical principle." The advice, he says, differs completely from the proposals of the Athenian in the Laws. But in point of fact the writer does not insist on there being a

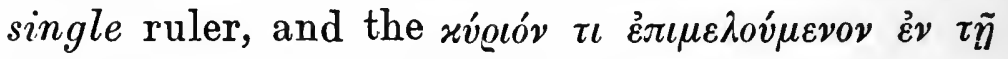

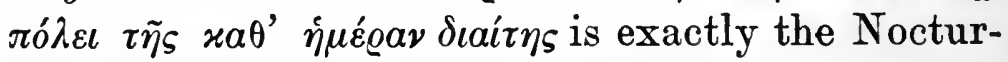
nal Council of Laws xii, 951, 961.

In the plea made at $358 \mathrm{E}$ that Plato would be ashamed to be concerned in a failure Ritter sees "a strong testimony to the spuriousness" of the letter. But this is assuming a more intimate knowledge of Plato than we possess, even taking the genuine Epistles into account. Nor do I agree with the same commentator in finding an un- 


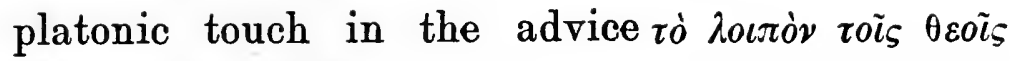
$\varepsilon \ddot{v} \chi \varepsilon \sigma \theta \varepsilon$ in $359 \mathrm{~B}$.

An instance of an application similar to that of Laodamas, that Plato should legislate for a new city, is given in Diog. Laert., iii, 23:-

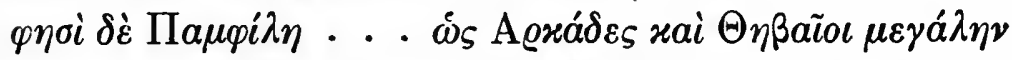

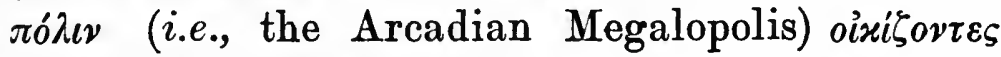

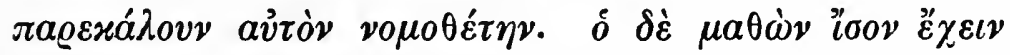
ov $\theta \dot{\varepsilon} \lambda o \nu \tau \alpha_{\varsigma}$, ov่x $\dot{\varepsilon} \pi \circ \varrho \varepsilon v \dot{\theta} \eta$. (But of course it may be argued that this story suggested the topic of the present letter to its forger.)

Ritter notes a few difficulties of language, viz.,

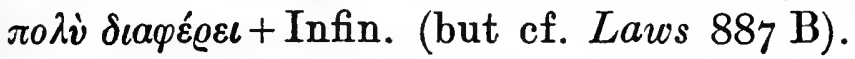

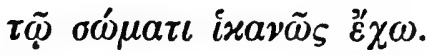

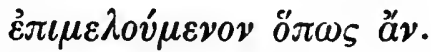

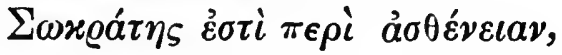

and sees a suspicious resemblance between

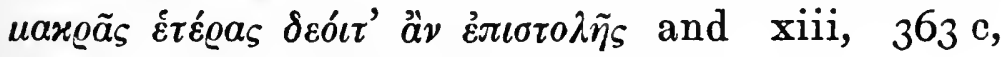

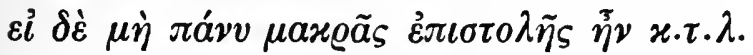

This seems to me no more than an accidental similarity.

The following words and phrases may be noted:

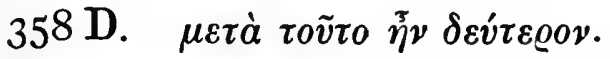

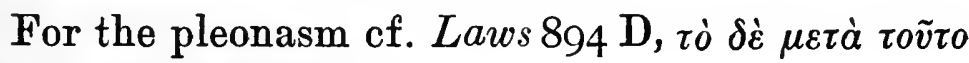

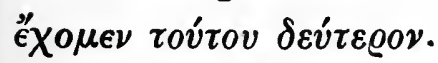

$358 \mathrm{E}$. oia åravtâ. The verb is seldom used of

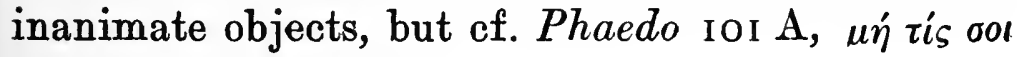

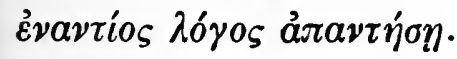

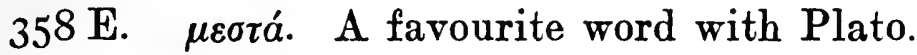


I62 AUTHORSHIP OF PLATONIC EPISTLES

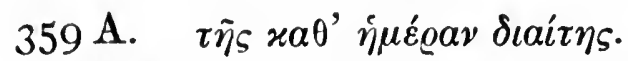

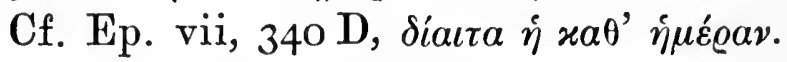

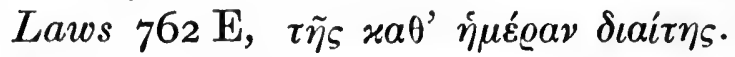

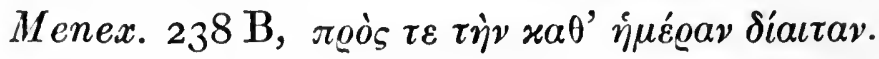

359 c. ávontaiveıv. The only other instance quoted by Passow or L. and S. is in Philebus I 2 D. It is not used by any Attic Prose writer.

We are again unable to decide the question of authenticity. 


\section{EPISTLE XII.}

This short letter, from Plato to Archytas,

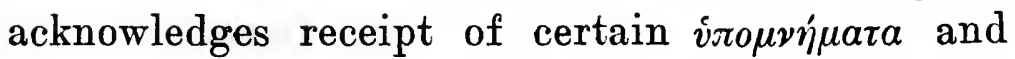
commends their author. It also refers to

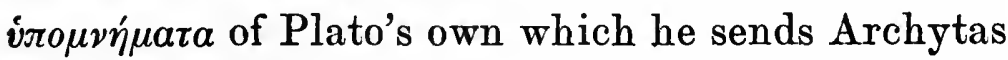
in an unfinished state. No cautions, he adds, are needed with regard to their safe-keeping, as to which he and their recipient are agreed.

There seems to be no means of deciding whether

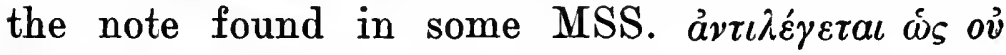

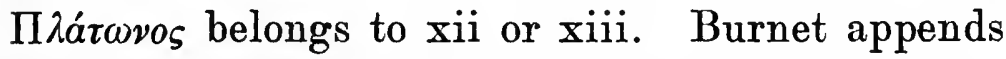
it to xii, and I think him right, because it is very much more natural to suspect xii to be spurious than xiii.

According to Diogenes Laertius (viii, 80) the

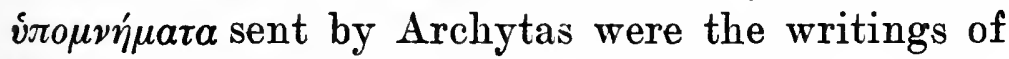
the Pythagorean Ocellus, of Lucania. It is perhaps worth quoting the passage, which occurs in the Life of Archytas:-

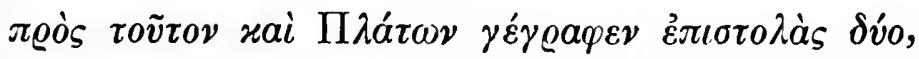

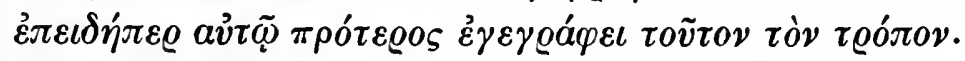

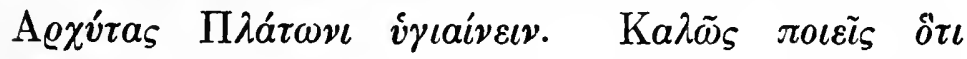

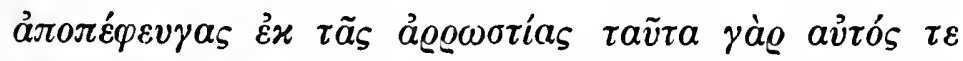

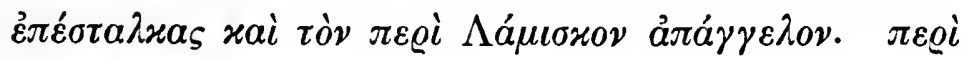

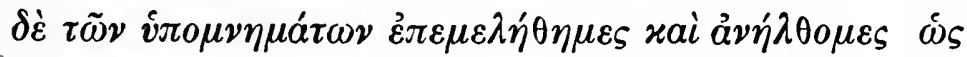

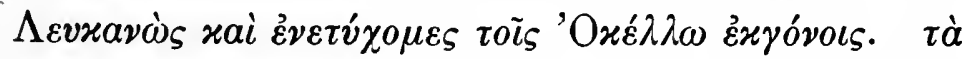

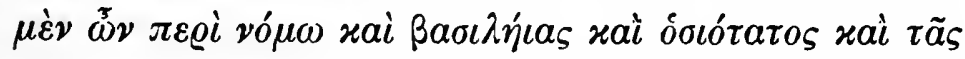

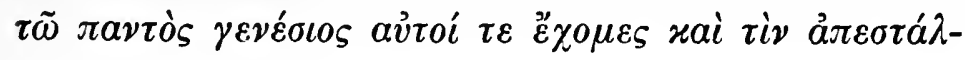




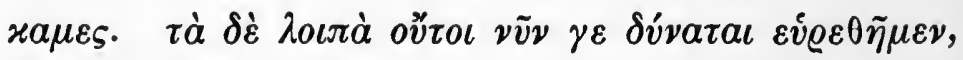

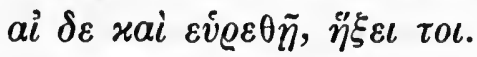

Diogenes then gives as the reply of Plato our Epistle in practically identical form.

Now these writings of Ocellus are universally admitted to be spurious. ${ }^{I}$ Zeller (Gesch. d. Phil., iii, 2, III) thinks they were composed shortly before 50 B.c., and conjectures that the forger may have written, to accompany them, a covering letter from Archytas to Plato and a reply from Plato to Archytas. "By means," adds Steinhart, " of the sacred authority of Plato, on whom he fathers the reply, he desired to impress the stamp of genuineness on his forgery."

This conjecture seems highly probable.

Ritter, who would (on what seem inadequate stylometric grounds) group Epp.ii, vi, xii, and xiii as being of the same authorship, suggests that

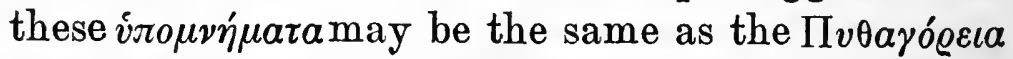
which Plato sends Dionysius in Ep. xiii, 360 B. Believing as I do that xiii is genuine, I think it

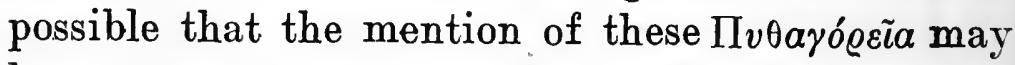
have suggested to the pseudo-Ocellus the complete plan of forging the fragments and a recognition of them in a letter from Plato.

I. The work ascribed to the same author entitled

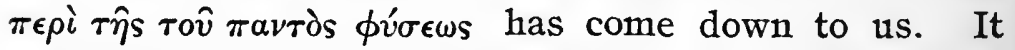
makes use of Arist., De Generatione. Cf. Diels, quoted by Susemihl, op.cit. p. 334 : 'Aristotelis non ipsum de generatione librum illum adhibuisse, sed excerptum et explanatum a juniore quodam Peripatetico, quos constat Stoicis coloribus parum pepercisse.' 
The only noticeable point in the language is

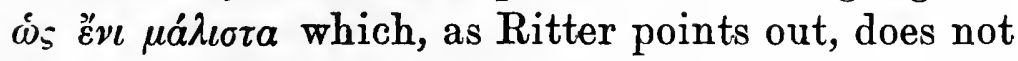
occur in Plato, though we find it in Hyperides

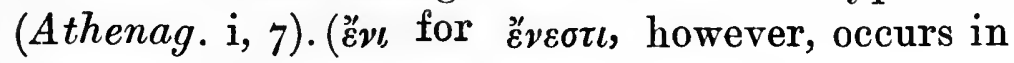
Laws 646 D.)

The writer seems wrong in his mythology, as to which I quote Steinhart's note (p. 4I2). "According to the usual story Laomedon, father of Priam, was murdered with all his sons save Priam after the first capture of Troy: of a Trojan colony which was founded in Italy under Laomedon we hear nothing elsewhere." 


\section{EPISTLE XIII.}

This letter differs from the rest of the Syracusan letters in being of a purely private character. The writer begins by recounting a scene at a Syracusan banquet where Dionysius had. shown his admiration for Plato. This attitude should be preserved for the furthering of their mutual benefits. Dionysius receives together with the letter certain philosophical writings and also a geometer named Helicon, whom the writer introduces in enthusiastic language.

Reference is next made to the execution of certain commissions by Plato, and to certain presents he is sending to the wife and children of the tyrant: after which we find an account in some detail of the expenditure which Plato foresees for himself and for which he proposes to use the funds supplied to him by Dionysius: in particular he mentions the provision of dowries for his great-nieces, and of a sum for his mother's burial.

As to the money for executing Dionysius' own commissions, the writer reports that it is difficult to secure advances from Athenian bankers, with whom the tyrant's credit stands low. $\mathrm{He}$ is exhorted to be more careful and prompt in regard to his finances, in order to avoid a reputation for bad faith. 
Dion is now briefly referred to as having shown reluctance in entertaining some proposal made to him on Dionysius' behalf by Plato.

The rest of the Epistle consists of brief disjointed references to presents for Cratinus and the daughters of Cebes, to a "token" whereby serious letters of introduction from Plato might be discriminated from non-serious, to certain ambassadors, etc. The last sentence bids the recipient of the letter to preserve the original or a copy thereof.

It is quite evident that the date at which this Epistle purports to have been written is $366-5$ B.C. ; Plato is on perfectly good terms with Dionysiusthat is to say, he writes before the final visit to Syracuse-and the reference to the child under a year of age, whose mother had died during his sojourn at court, proves that less than a year has elapsed since his return.

The present letter was the first of the collection to be impugned. It was not included in the translation of Ficinus, who appears to have

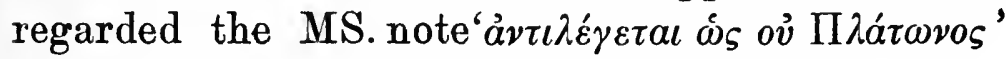
as applying to Ep. xiii, rather than to Ep. xii to which Burnet and others refer it. It is rejected after a lengthy examination by Ritter (pp. 328599 of his Neue Untersuchungen) and by Wilamowitz (in Hermes, I898, p. 496), and of course by Karsten and Steinhart. Raeder accepts it, but with little discussion, while Reinhold hardly refers to it. 
Wilamowitz's arguments, which he puts summarily, are as follows:-

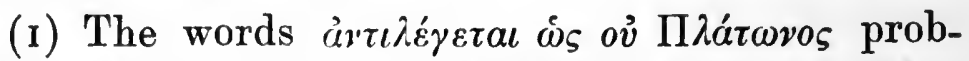
ably refer to xiii, as it is natural for a doubtful piece to come at the end of the collection. On the other hand, if they refer to xii, xiii is likely to be spurious as having come into the collection after a doubtful letter.

(2) As Plato is 62 years old, it is improbable, though not impossible, that his mother, who had borne two elder sons at least (viz., Glaucon and Adimantus), should be still alive.

(3) In any case her burial would be no concern of Plato's since she had taken a second husband, Pyrilampes, and had by him at least one son, Antiphon (vid. Parmenides, ad. init.).

To my mind these arguments, even when taken in their cumulative force, are not enough to make us reject the possibility of Platonic authorship. (3) in particular is weak. Pyrilampes might quite as reasonably be expected to be dead as his wife: and if he were, why should not the funeral expenses devolve upon Plato, wholly or in part? We know nothing as to the survival of the other sons.

Ritter's criticisms on the subject-matter are numerous, and of varying worth. ${ }^{1}$ I discuss them in order:-

I. It is clear that Ritter's desire to prove the letter spurious is due to his belief that it shows Plato in an unworthy light. 
(I) It would seem natural to suppose, from the account given by Plutarch (Dion 19) of Helicon's prediction of an eclipse in 360 , that he visited Syracuse for the first time on that occasion as one of the young companions accompanying Plato.

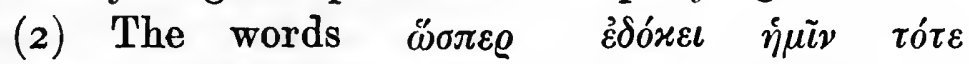
(360 B.c.), implying that Plato had before his departure promised to send Dionysius a geometer, are hard to reconcile with the accounts of Ep. vii, 338 A B, Ep. iii, 316 E sqq., and Plutarch, Dion 16. In these places Plato is represented as promising to return to Syracuse when peace was restored. "It would be senseless," says Ritter, "or at any rate surprisingly foolish, to demand a substitute for Plato, if the latter had expressed himself as ready to return so soon as there should be leisure for studious pursuits. That Dionysius during the war should take lessons in geometry from Helicon could not have occurred as a suggestion to either of the contracting parties."

(3) The connexions of Helicon with Isocrates and Bryson the Megarian are hardly such as would recommend him to Plato.

(4) 36I A implies that the sculptor Leochares was still unknown to Dionysius. Pliny (Hist. Nat., xxxiv, 5o) puts his "floruit" at $372-367$ B.c., which implies that some chef d'oeuvre had been accomplished before that date. It is therefore unlikely that Dionysius should not have heard of him.

(5) The anxiety displayed by Plato in securing a dowry for a child less than a year old is 
strangely inconsistent with our impressions of his character derived from the dialogues. Again, how could Plato have needed to go into such detail as to possible disbursements in the distant future, if he intended soon to return to Dionysius?

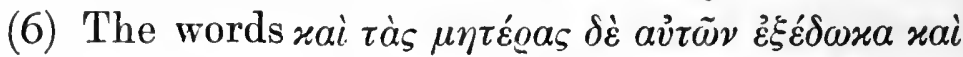

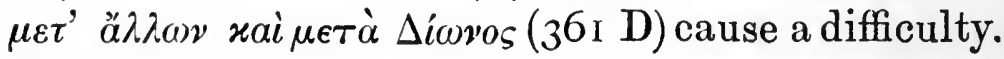
The eldest of these mothers must have been married about twenty years earlier, i.e., soon after Plato's first Sicilian journey. It is unlikely that he was then on such terms with Dion as to be assisted by him in the manner here described.

(7) A sum of 30 minae could hardly be called a

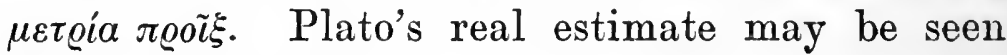
from Laws $774 \mathrm{D}:-$

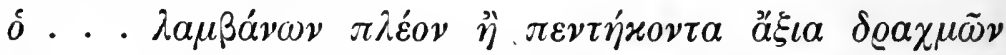

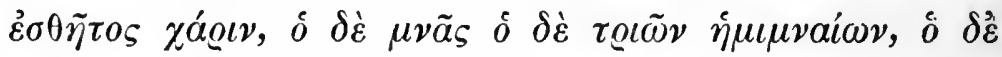

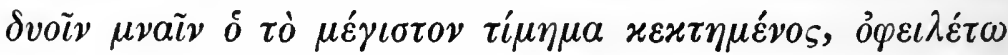

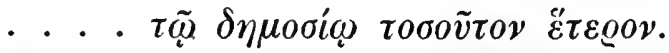

Again in this letter the funeral expenses of Plato's mother are estimated at "not more than Io minae," whereas in Laws 959 D, 5 minae is laid down as the maximum.

(8) The references to Dionysius' lack of financial credit at Athens, at the beginning of his reign, are astonishing when we remember the riches he had inherited from his father. There could surely be no difficulty in finding an Athenian banker ready to recommend himself to such a powerful applicant by means of a small advance.

(9) The enigmatic reference to Dion in $362 \mathrm{E}$ is understood by Plutarch (Dion 2I) and most 
moderns to allude to a proposal made by Dionysius to marry Dion's wife to another. It is incredible that Plato should have consented to sound Dion upon this topic, especially when we remember that according to Epp. iii and vii Plato's whole energies between 366 and $36 \mathrm{I}$ were devoted to effecting a reconciliation between Dionysius and Dion, this being in fact the only thing that induced him to return in 36r. In any case, even if Plutarch's interpretation be wrong, Plato could hardly have dismissed the topic of Dion with "ein paar nichtssagenden Worten."

(Io) As regards the reference to Cebes in $363 \mathrm{~A}$ Ritter accepts Steinhart's objections. These are, first that Cebes must have been heard of by Dionysius previously, secondly that the Phaedo is not referred to by its secondary title of $\pi \varepsilon \varrho i \quad \psi v \chi \tilde{\eta} \varsigma$ until long after this date ("erst lange nach Platons Zeit").

(I I) The discrimination of letters of introduction by beginning with $\theta_{\epsilon o}$ s or $\theta \epsilon o i$ is extraordinary.

(12) In general, the character of the Plato of this letter is wholly discrepant with the Plato of the dialogues.

This summary, I believe, enumerates all Ritter's objections on the score of subject-matter which are of any moment. I will discuss them in the same order :-

(I) On this I can say nothing except that the supposition is purely conjectural. 
(2) The assumption underlying this argument is that Plato left Syracuse in 366 primarily because Dionysius was too much occupied with the war to continue his philosophical studies. It is quite as likely that the outbreak of the war was made a pretext for his departure by Plato himself. Dionysius, according to Ep. vii, was or pretended to be enthusiastic in his studies up to the time of Plato's departure, and it is very natural that he should have assented to Plato's proposal to send out a substitute. Moreover, although the philosopher had promised to return, we know from the accounts of Epp. vii and iii that he subsequently showed great reluctance in fulfilling that promise.

(3) The bad feeling of Plato towards Isocrates has probably been very much exaggerated: in particular the numerous supposed references to Isocrates in the Republic are all fanciful. A good discussion of the subject will be found in an Appendix to W. H. Thompson's edition of the Phaedrus, from which I take the following points :

(a) It is clear from many passages in the Philippus, Antidosis, and Panathenaicus, that Isocrates cherished a resentment against Plato even after the latter's death.

(b) On the other hand, the sole reference to Isocrates by name in Plato is commendatory (Phaedrus 279 A). This reference, combined with the fact that it is Lysias rather than Isocrates, who is singled out for criticism in the Phaedrus leads us to sup- 
pose that Plato was deliberately atoning for an attack made on Isocrates in the well-known passage of the Euthydemus (ad fin.) and (by implication) in the Gorgias.

(c) Cicero, who records in more than one place the feud between Isocrates and Aristotle, believes that Isocrates and Plato were the best of friends ${ }^{1}$ (Brutus xiii, 42, Exagitator omnium rhetorum hunc (i.e., Isocratem) miratur unum. Me autem qui Isocratem non diligunt una cum Socrate et Platone errare patiantur.).

(d) The tradition of a quarrel between the two would not have escaped the slander-monger Athenaeus.

These arguments are enough to show that it is quite impossible to base any argument upon a supposed bad feeling of Plato towards Isocrates in the year 366.

Secondly, as to the association of Helicon with Polyxenus and Bryson. All that is known of these two is collected by Bäumker in Rhein. Mus., 34, p. $64 s q q$. The most important information about Polyxenus is that given by Alexander Aphrod. (on Ar. Met. 990 B i5), who tells us that according to Phanias (an immediate disciple of Aristotle and friend of Theophrastus) he invented

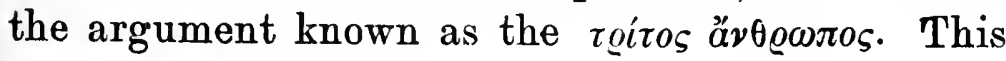

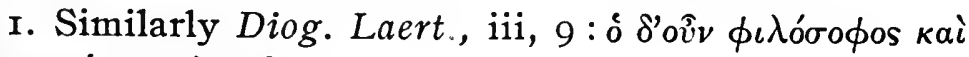
'I $\sigma \circ \alpha \rho \alpha ́ \tau \epsilon \iota \phi \iota \lambda$ os $\hat{\eta} \nu$. 


\section{I74 AUTHORSHIP OF PLATONIC EPISTLES}

is of course the argument which Plato himself uses (through the character Parmenides) in Parm. I3I-r33. This surely betokens respect on Plato's part for Polyxenus, so that we have no right to suppose it unlikely that Helicon should be recommended as associated with him.

As to Bryson "the Sophist" (Ar. Hist. An., vi, 5; ix, II; Rhet., iii, 2), we know that he was a pupil of Socrates and a fellow-student of Euclides

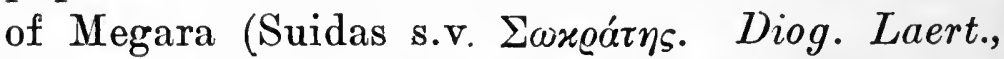
ii, I 12. Cf. Pauly-Wissowa, Real-Encycl., iii, 929). Plato was also a friend of Euclides, with whom he is said to have stayed at Megara after Socrates' death. Like Helicon himself, Bryson was a mathematician, ${ }^{1}$ who claimed to have squared the circle (Ar. Anal. Post., i, 9; Soph. El. I I). Finally, his association with the Academy seems to be implied in Athenaeus (vi, $509 \mathrm{c}$ ), who quotes a passage in which the comic poet Ephip-

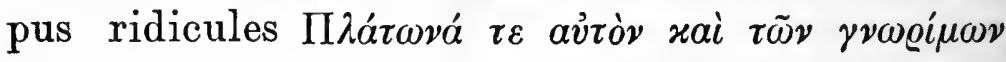
$\tau \iota \nu a ́ s$, beginning thus :-

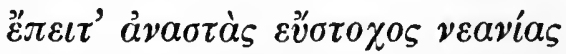

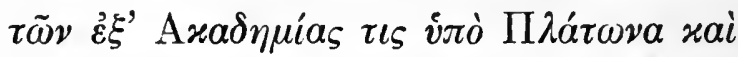

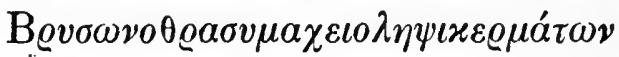

$$
\begin{aligned}
& \pi \lambda \eta \gamma \varepsilon i_{\varsigma} \text { ảvá } \gamma \varkappa \eta \ldots .
\end{aligned}
$$

In regard to both Isocrates and Bryson, I may say that it is a mistake to assume that Plato was a bitter personal enemy of everyone who was

r. It was doubtless 'propaedeutic mathematics' in which Dionysius was to be instructed by Helicon. 
known under that name of many meanings,

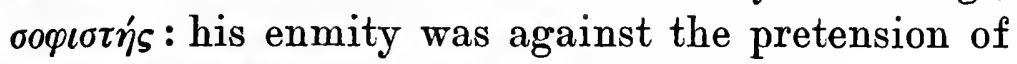

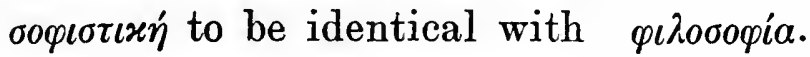

(4) I see no reason why Plato should assume Dionysius to be familiar with the names of contemporary Athenian sculptors. From what we know of Plato's views on art it is unlikely that he discussed such topics with the tyrant.

(5) It is not always safe to draw inferences as to a man's character from his writings: but in any case, if the passage shows Plato as overanxious for the distant future, it also shows him as unselfish. I believe that excessive carefulness for the provision of the "dot" is characteristic of the French to-day. Moreover, if the thought were unlikely to occur to Plato, it would have seemed not less unnatural to the hypothetical forger.

(6) On the other hand, we know that Plato made a deep impression ${ }^{1}$ on Dion during his visit in $387-$ an impression which led him to wish for the philosopher's return twenty years later. Cf. Ep. vii, 327 A,

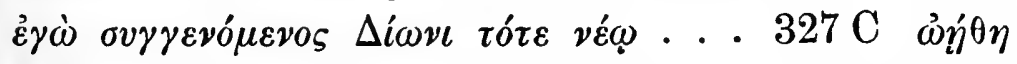

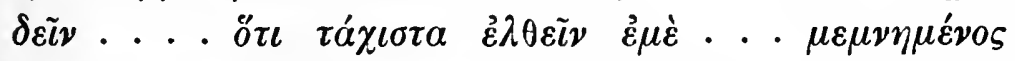

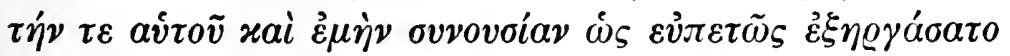

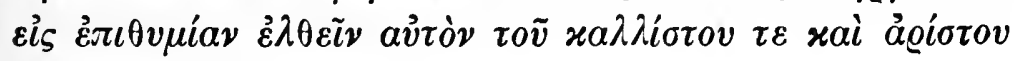
Bíov.

(7) The average dowry seems, on the contrary, to have been about 30 minae; cf. the following passages in the Orators:-

I. Ritter himself mentions the story of Diogenes (iii, I4) that Dion in 387 offered to repay to Anniceris the sum provided for Plato's ransom from slavery : and he gives no reason for rejecting it. And I see none. 


\section{I76 AUTHORSHIP OF PLATONIC EPISTLES}

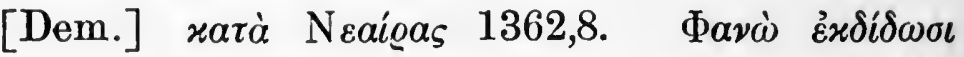

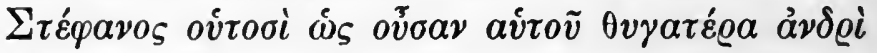

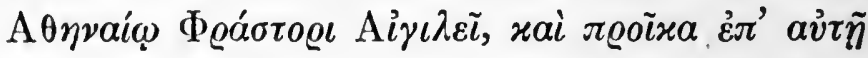

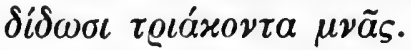

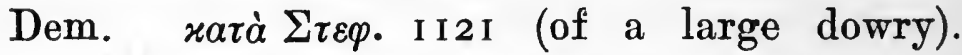

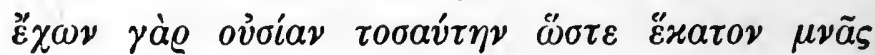

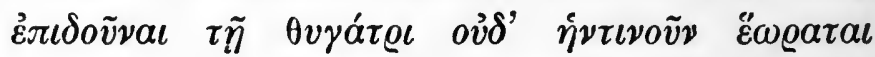

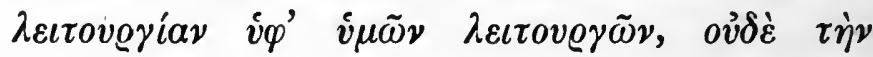

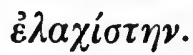

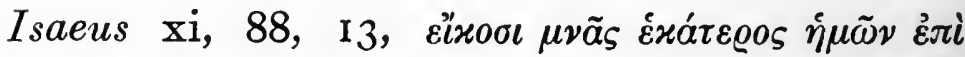

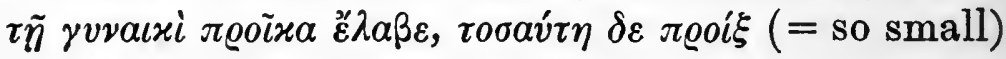

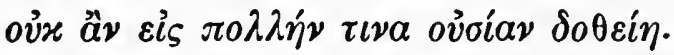

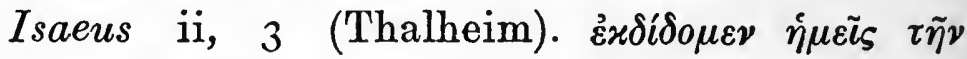

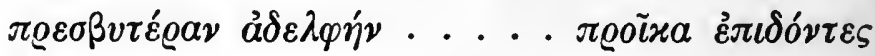

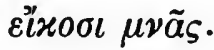

Plutarch (Aristides 27) says that the daughters of Aristides received from the state as a portion "only" 30 minae each.

Ritter's reference to Laws $774 \mathrm{D}$ is beside the point, and indeed involves a serious blunder: he

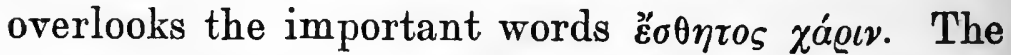
sums mentioned in $774 \mathrm{D}$ are for "pin-money," whereas the dowry proper is expressly prohibited

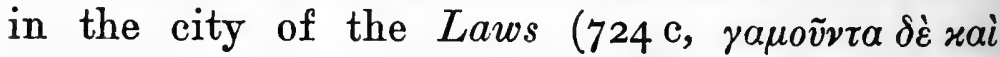

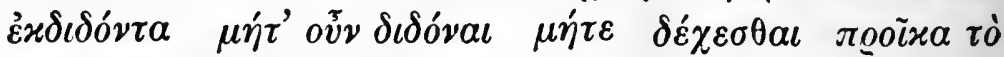
$\left.\pi \alpha \varrho a ́ \pi \alpha \nu \mu \delta^{\prime} \dot{\eta} \nu \tau \iota \nu o \tilde{v} v\right)$.

It is of course irrational to expect Plato to adhere in Athens to all the regulations that he lays down for Utopia: and so we find him providing dowries and spending larger sums than, 
as a theorist, he thought proper in funeral expenses.

(8) It is true that the elder Dionysius died in the possession of great wealth, but it is not at all necessary that the financial credit of the father should pass to the son. It is quite possible that the younger Dionysius may have acquired the reputation of being $\delta v \sigma \sigma v \mu \beta 0 \lambda \sigma_{s}(362 \mathrm{E})$-dilatory in meeting his obligations-during his father's lifetime. Again, the outbreak of the war in 366 may have caused him financial embarrassment: and according to Ep. vii (348 A) he made an attempt in the year 360 to reduce the pay of the veteran mercenaries, an attempt which produced mutiny. This was doubtless due to a desire for retrenchment.

(9) If we suppose Plutarch's interpretation to be correct yet we know too little of the reasons behind Dionysius' proposal to accept Ritter's inferences, which are wrapped up in a good deal of sentimental indignation. No doubt Dionysius had good reasons for desiring the divorce, and if it should pave the way to Dion's return from exile, Plato, whose regard for the inviolability of the marriage-tie was not that of the Roman Catholic Church, may quite well have entertained the proposal for a time.

With regard to the contention that we should expect more to be said about Dion in this Epistle, I need only say that there is no reason to suppose that Plato in 366 doubted that Dionysius really intended Dion's banishment to 
to be merely temporary (cf. Ep. vii, $338 \mathrm{~A}$,

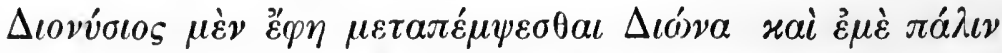

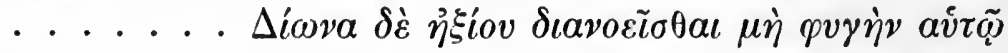

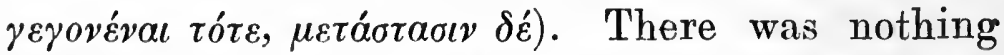
fresh to be said on the subject at this time. Ritter unnecessarily assumes this to be the first communication between Plato and Dionysius since his return from Sicily.

(Io) That Dionysius knew Cebes at all events primarily through the Phaedo seems very probable. Our own knowledge of him is entirely derived from that dialogue, and we have no reason for supposing that his fame had penetrated to Syracuse (see Archer-Hind's Phaedo, Introd., p. xxv).

With regard to the citation of the Phaedo as $\delta \pi \varepsilon \varrho i$ $\psi v \chi \tilde{\eta} s$, it is true that Aristotle does not, so far as I know, use this secondary title. But the citation of the Menexenus in Rhet. iii, I4I I A, as

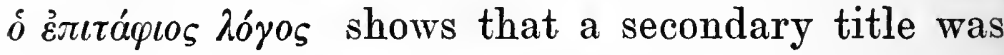
in use for at least one dialogue.

Steinhart's "Erst lange" is vague: I do not know whether he remembers the well-known epigram ${ }^{1}$ of Callimachus whose last line is :-

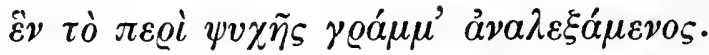

(II) If we accept the credibility of a $\sigma v \mu \beta o \lambda o v$ at all-and $I$ think it a very natural device if Plato was pestered with applicants for letters of introduction-this would quite naturally have

I. Anth. Pal., vii, 47I. 
occurred to one who, while a monotheist at bottom, did not definitely reject the gods of Olympus.

(I 2) The general argument cannot of course be definitely refuted, though it has, I think, been largely met in dealing with particular instances. I may, however, sum up my impression of the letter by saying that I find it harder to believe that a forger, clever enough to produce the effect of naturalness that he does produce, would not have drawn his character of Plato true to life, than to regard the letter as genuine.

There is not very much to be said as to the language. It cannot, I think, be held that the general style is distinctively Platonic, but of course the writer does not aim at being "literary." There is, however, nothing, so far as I can see, that Plato might not have written, though I have not found any parallel in Plato or elsewhere to

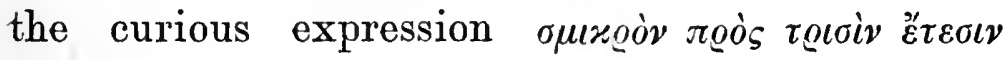
in $36 \mathrm{I} \mathrm{D}$.

According to Raeder (op. cit.) the letter has If words not occurring in the dialogues, viz.:-

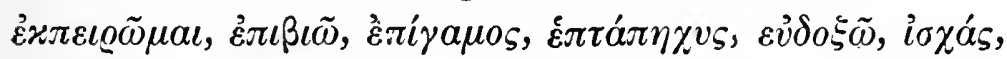

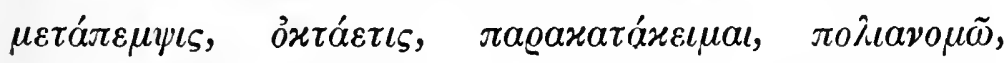

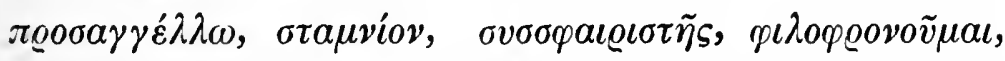

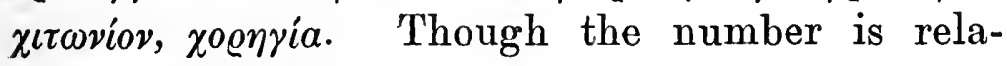
tively large, I do not think we can base on it any inference for or against authenticity, when we remember the great extension of vocabulary made in the Sophist, Politicus, and Laws. Chance is

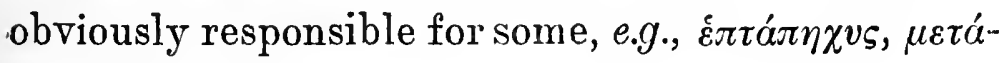


$\pi \varepsilon \mu \psi \iota \varsigma, ~ i \sigma \chi \alpha ́ \varsigma, ~ o ̉ \varkappa \tau a ́ \varepsilon \tau \iota \varsigma, ~ \sigma \tau \alpha \mu i ́ v ~: ~ \pi o \lambda \iota \alpha v o \mu \omega^{1}$ is technical, $\mu \varepsilon \tau \dot{\alpha} \pi \varepsilon \mu \psi \iota \varsigma$ is an abstract characteristic of Plato's later style, while many instances of new com-

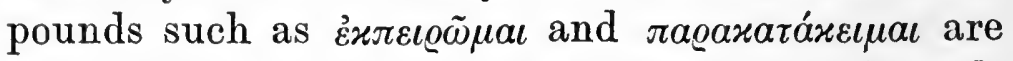
to be found in the Laws (see page 150). According to Raeder's table there are 86 faulty hiatus, giving an average of 29.66 a page : that is to say, the hiatus is not consciously avoided. But as I pointed out in my General Introduction, we have no right to draw Raeder's inference of genuineness and early date from this: it is equally compatible with the supposition of a forgery. I have indeed not found anything in Raeder's two papers that really tends to establish the authenticity of this Epistle.

Ritter's criticism on the language is chiefly a general attack on Raeder's stylistic calculations, and these I have already commented upon. At page $355 s q q$. of the Neue Untersuchungen, however, he brings forward some particular objections, viz.:-

(I) There is a monotonous repetition of certain particles of transition: e.g., in $36 \mathrm{I} \mathrm{C}$ we have

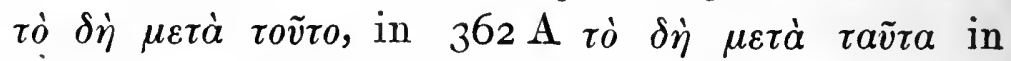
$3 \dot{6} 2 \mathrm{E} \tau \dot{\alpha} \mu \varepsilon \tau \dot{\alpha} \tau \alpha \tilde{v} \tau \alpha, \delta \dot{\eta}$ occurs 8 times, and ovै introduces an imperative 4 times $(\delta \dot{o} \varsigma$ oṽ $\nu$ 36I $\mathrm{A}$,

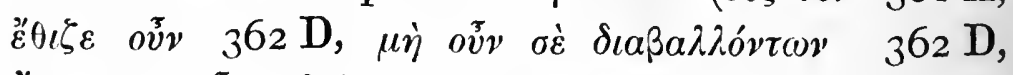

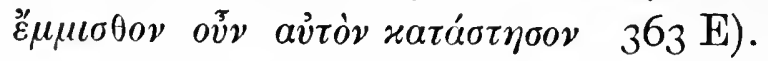

I. We learn from C.I.G., iii, 5774, 5775, that the magistrates of Heraclea at the end of the 4 th century bore the name $\pi$ o $\lambda_{\iota a ́}$ vouo (Raeder). 
(2) The word for "friend" is always $\varepsilon \pi \iota \tau \eta \dot{\delta \varepsilon} \iota$ s. $^{\circ}$ cüvovs is used twice close together $(363 \mathrm{AE})$, $\tau o ́ \tau \varepsilon$ is frequent (8 instances).

(3) Several expressions are strange, such as

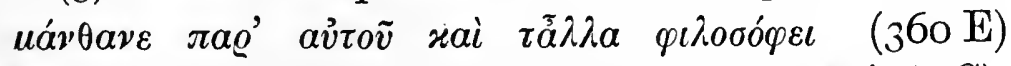

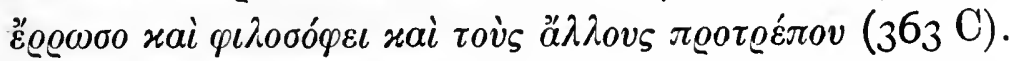

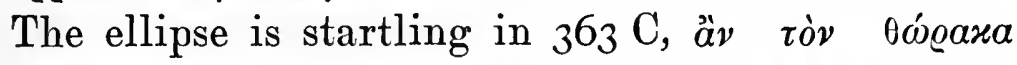

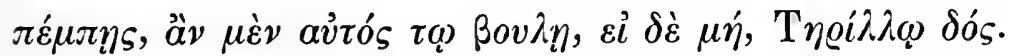
(The shortened expression $\varepsilon \dot{\imath} \delta \dot{\varepsilon} \mu \dot{\eta}^{\prime}$ is common

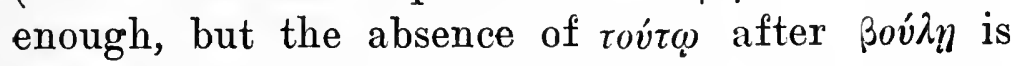

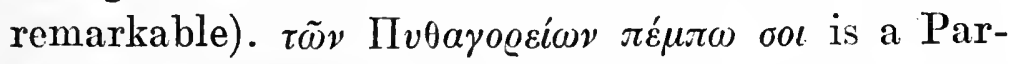
titive Genitive unparalleled in Plato. $\chi_{\alpha}^{\alpha \varrho \iota \varepsilon ́ v \tau \omega \varsigma ~} \tilde{c}^{\prime} \chi \omega$ is used in $360 \mathrm{C}$ as a term of commendation, as also is yaoicıs in $36{ }_{3} \mathrm{C}$, whereas ordinarily Plato uses zao'sıs in an ironical sense.

(4) In general, the writer appears to be acquainted with many private matters affecting Plato and Dionysius, and so produces the impression of genuineness. But it is just in this that a forger's art lies: one may compare the sidelights on each other's life in the speeches of Demosthenes and Aeschines, which are pure invention.

On the other hand it may be urged:

(I) Although Plato employs a great variety of particles, yet he does not seem to mind frequent repetitions of them in a small space. The triple use of $\tau \dot{o} \mu \varepsilon \tau \dot{\alpha}$ $\tau o \tilde{v} \tau o$ or the like does not seem to me very remarkable, certainly not more so than the

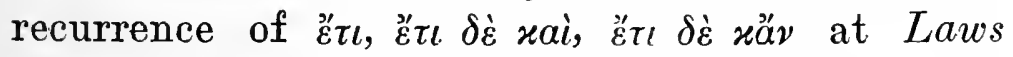
633 B C, within 9 lines of Burnet's text. The repetition of ov̉ is far more striking in (e.g.) the 
conversation between Socrates and the slave in the Meno, and $\delta \dot{\eta}$ is a monotonously recurrent transition-particle in many parts of the Laws, as one can see after reading two pages of the First Book. $^{1}$ I have also chanced to notice, in reading the Gorgias, that $\mu \dot{\varepsilon} \nu$ ov̉ $\nu$ occurs 4 times within I 3 Teubner lines $(465 \mathrm{D})$ apparently without any special reason.

(2) Ritter himself points out that Ast's instances of $\dot{\varepsilon} \tau \iota \tau \dot{\delta} \delta \iota \iota_{\varsigma}$ in this sense are all from early dialogues (the Phaedo probably is the latest of them). So far as this goes it corresponds to the relatively early date of the Epistle. On the other hand the frequency of $\tau$ ó $\tau \varepsilon$ is a mark of Plato's later style (see p. 193, and especially Laws 685-6). I do not think we need be disturbed by this apparent contradiction: we should expect a transitional style in 366 B.C.

(3) I see nothing strange in the first two passages referred to. As to the ellipse, Riddell (Digest, p. 2I7) gives instances of curtailment of the Protasis with $\varepsilon \dot{\imath} \delta \dot{\varepsilon} \beta o ́ v \lambda \varepsilon \iota$, which are very simi-

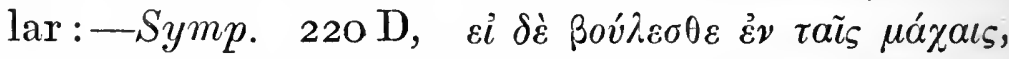

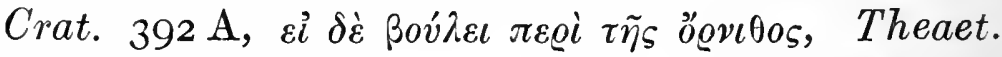
I96 E, $\varepsilon \grave{\imath} \delta \dot{\varepsilon} \beta o v \lambda \varepsilon \iota . . . * \varepsilon \chi \varrho \eta \dot{\mu} \mu \varepsilon \theta$. The partitive genitive may be paralleled from Rep. $445 \mathrm{E}$,

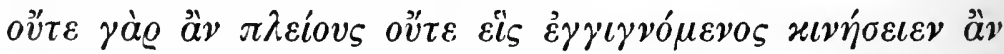

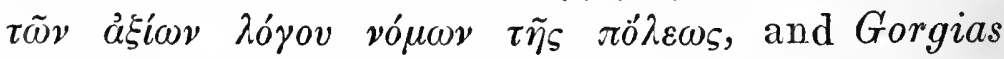

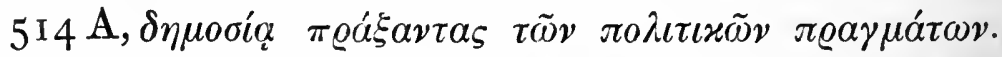
za@ísı is used in a serious sense at Rep. 602 D,

I. Also in Epp. vii. and viii. e.g. vii. 346-5o. ov̂v with Imperative or its equivalent occurs 4 times in Ep.iv. 


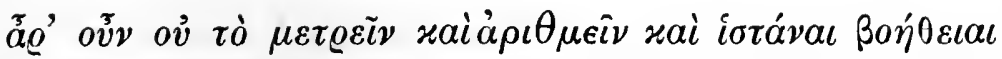

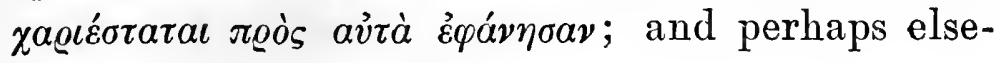
where.

(4) The pictures of the orators are not really a parallel, for they are in the majority of cases either distortions of fact or repetitions of common gossip. At the same time, I would not contest Ritter's statement that a forger might quite probably have aimed at an effect of the kind described.

A few words and phrases in addition to those incidentally noticed above may be remarked upon.

There are five instances of xai . . . xai where $\tau \varepsilon$ rai would seem more natural, viz., $360 \mathrm{~B}$,

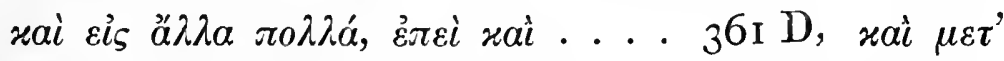

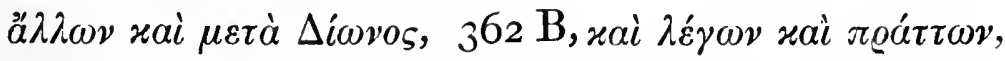

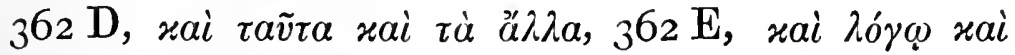

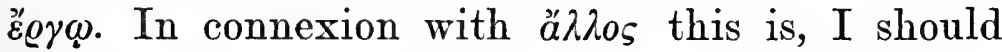
say, very uncommon: Riddell quotes two instances from the Laches, I8 1 a, äoı

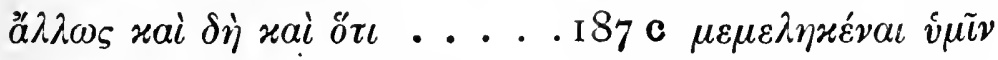

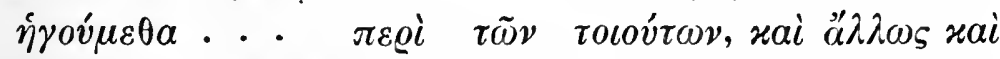

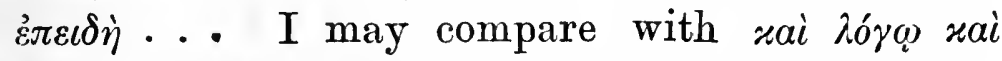

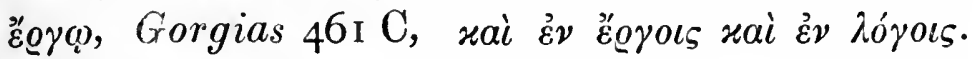

In $360 \mathrm{c}$ we have $\varepsilon$ " $\lambda$ apoos used in a "tropical" sense of a person. This seems a rare usePassow's Lexicon quotes only Isocr. $239 \mathrm{~B}$, and Theocr. ii, I24, as instances from classical Greek, outside Plato. Theognis 884 seems, however, a similar usage. ${ }^{1}$ But in Laws $657 \mathrm{D}$ we have a

x. Vid. Harrison, Studies in Theognis, p. 154 . 
very similar connotation :-

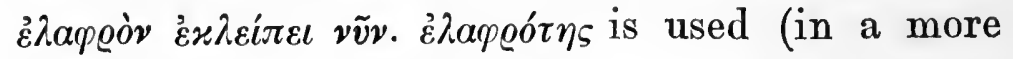
literal sense) in Laws $795 \mathrm{E}$.

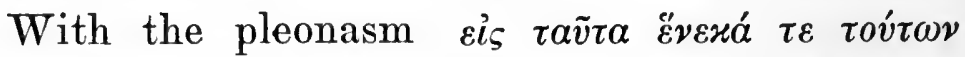

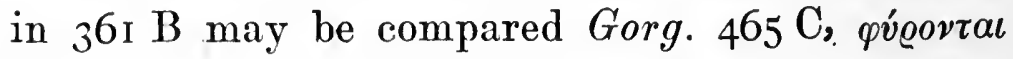

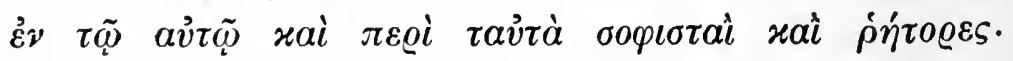

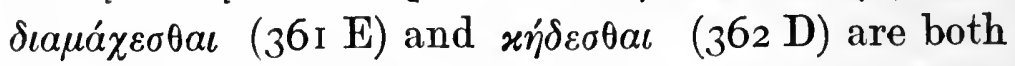
favourite words with Plato, as may be seen from Ast. $\tau \theta^{\prime} \theta^{\prime}$ ő $\varepsilon \quad(363$ c) is a collocation frequently used in the Laws (e.g., $645 \mathrm{E}, 667 \mathrm{E}, 893 \mathrm{E}$ ).

In the description of Helicon at $360 \mathrm{C}$,

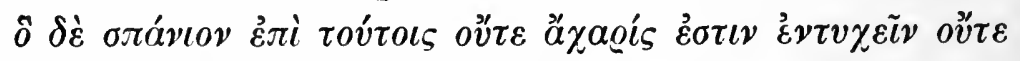

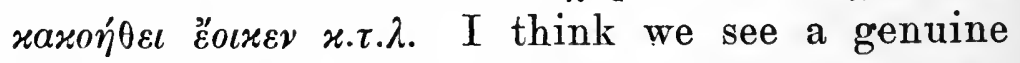
Platonic touch. Plato seems to have been impressed with the difficulty of combining opposite qualities in one person, as witness the insistence at the end of the Politicus on the duty of the statesman to effect a fusion by scientific mating. ${ }^{1}$

With the present passage, cf. especially

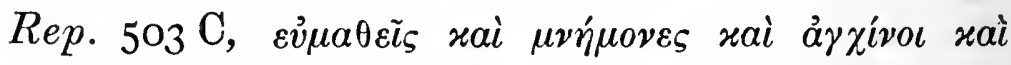

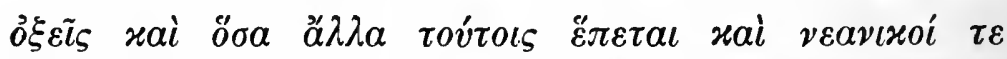

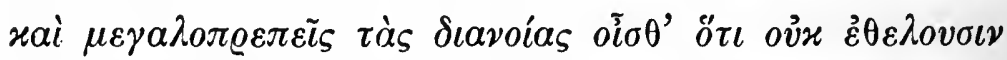

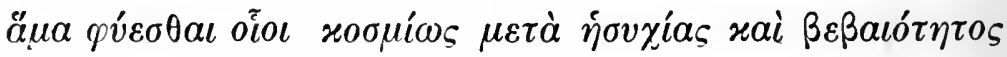

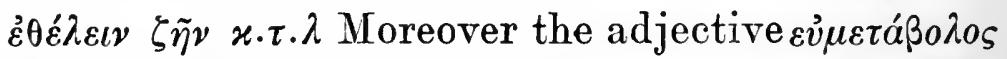
occurs a few lines lower, just as it does in our Epistle. The parallel is, I think, near enough for

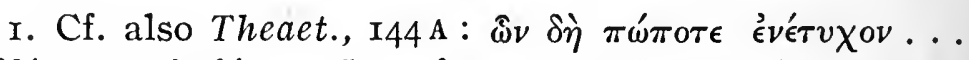

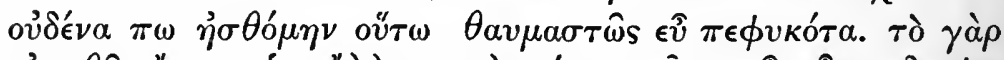

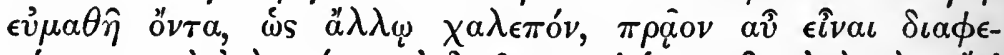

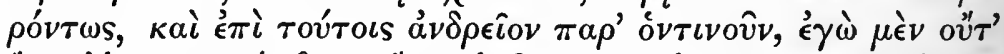

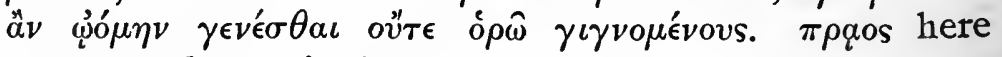
corresponds to ov่k ä $\chi \alpha$ ápıs. 
us to infer a reminiscence, but not near enough to suppose deliberate copying.

In illustration of the remark that Man is a

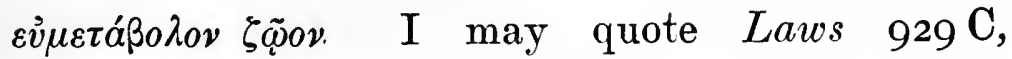

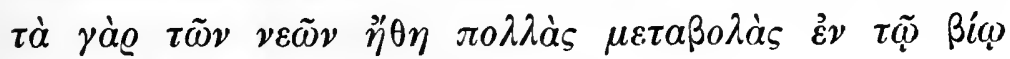

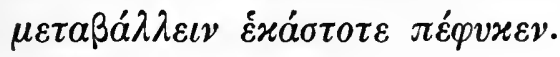

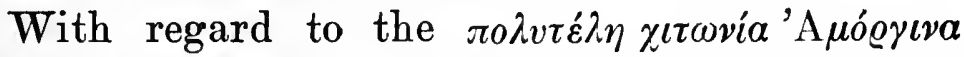
of $363 \mathrm{~A}$, silk from Amorgos is regularly referred to as the finest and most expensive. Cf. Aristoph. Lysistr., I49

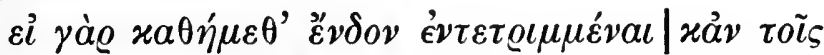

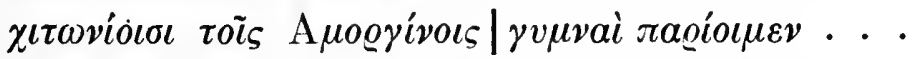
and other references in Stephanus s.v. "A

For the custom of sending $\chi ı \tau \omega v i a$ as presents, cf. the story in Plut. Lysander, c, 2, where Dionysius I. sends Lysander $\tau о \lambda v \tau \varepsilon \lambda \tilde{\eta}$ q $\tau \tau \omega \nu i ́ a ~ \tau \tilde{\omega} \nu$ $\Sigma \iota x \varepsilon \lambda \varkappa \tilde{\omega} \nu$. (Perhaps Plutarch is wrong as to the origin of the garments.)

It is possible that Plato may be thinking of the personal circumstances referred to in this letter when writing $R e p .554 \mathrm{CD}$, where he mentions

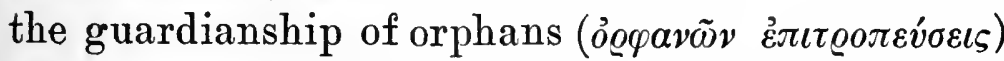
and the spending of other people's money

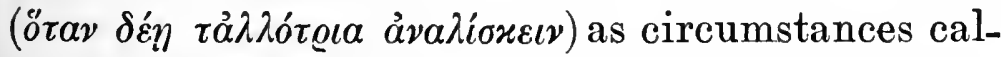
culated to show the true character of the oligarchical man. His position with regard to his

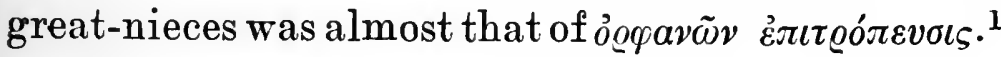

I. On the other hand it seems far-fetched to see, with Gomperz (Greek Thinkers, iii, p. 313, quoting Christ), an allusion to $362 \mathrm{~B}$ in Ar., Met., Ior5A 25, where an

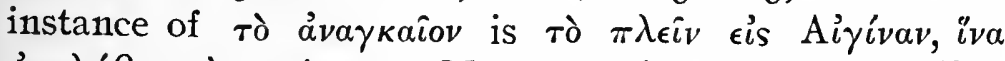

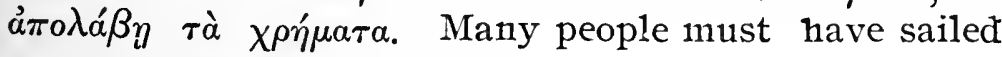
to Aegina for the purpose. 
Finally there is the reference to $\tau \dot{a} \Pi v \theta a \gamma o$ og $\varepsilon a$

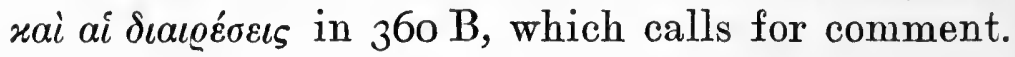

It is discussed at length by Karsten (op. cit.), who comes to this conclusion (p. 224):- "Aristotelis aetate et proximo deinceps tempore doctorum manibus tritum fuisse commentarium Platonis nomine insignitum, cui titulus esset ärøapa

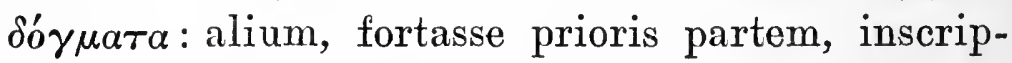

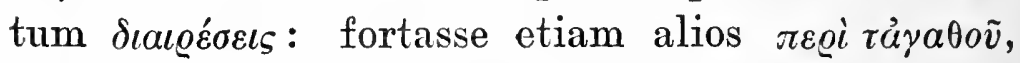

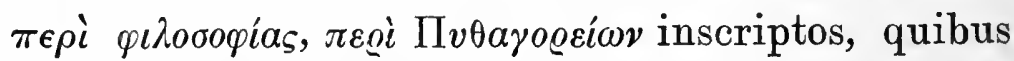
continerentur decreta et definitiones e Platonis sive scholis sive dialogis deprompta." His con-

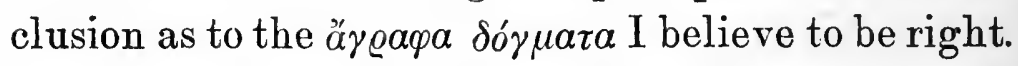
They are referred to by Aristotle, Physics, iv, 2,

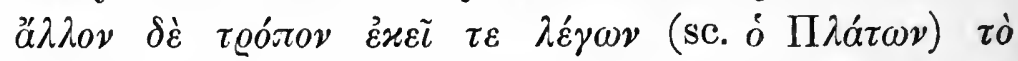

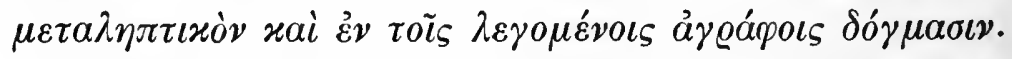

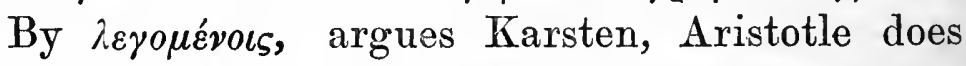
not intend any implication of spuriousness, but means that the dóruaza were "inscripta hoc titulo, quo indicetur dogmata illa in scholis explicita non memoriter tantum prodita sed etiam litteris notata esse." (I would add that if Aristotle had supposed the work "spurious" he would not have troubled to refer to it.)

Now if this be right, and Aristotle can talk of $\Pi \lambda \dot{a} \tau \omega \nu \lambda \varepsilon_{\gamma} \omega \nu$ in a work which he did not write,

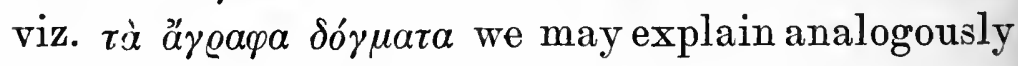

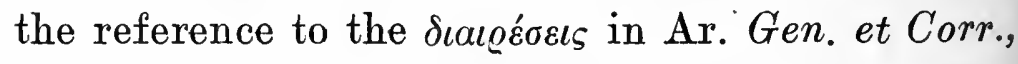
ii, $3,330 \mathrm{~B}$, where speaking of $\mu$ i $\gamma \mu a \tau a$ he says:

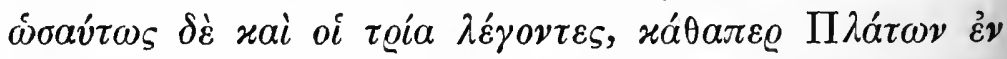

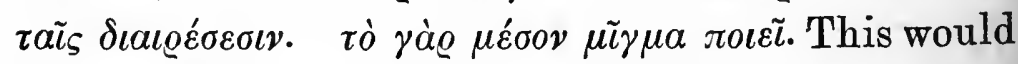
account for the opinion of Philoponus that the 


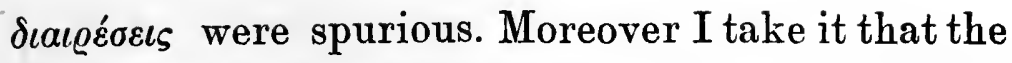

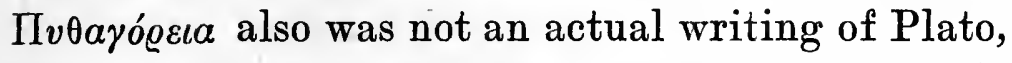
but a publication of the Academy bearing his "cachet": which supposition enables us to understand why there is no trace of a Platonic work called by the title. Especially I would call attention to the fact that all the commentators seem to take it for granted that the Plato or pseudo-Plato of Ep. xiii implies that the works despatched are his own compositions : in point of fact he does not imply this at all.

The suggestions of Christ that the writer refers to extracts from the Sophist, Politicus, and Timaeus is to my mind most unlikely. It is a little ludicrous to imagine Plato tearing a few pages out of his dialogues to make a book of "easy selections." 1 Raeder holds that the works are in the nature of "Vorstudien" to these dialogues-a supposition not incompatible with the explanation given above.

I. Raeder argues that the non-avoidance of hiatus proves this Epistle to be earlier than the dialogue in question. 


\section{CONCLUSION.}

The result to which we have been led by the foregoing discussion is that we may hold five of the Platonic Epistles genuine, viz., iii, iv, vii, viii, xiii, that we must reject five, viz., i, ii, v, vi, xii, and that the remaining three, $i x, x$ and $x i$, must be left doubtful. Our estimate of Plato would certainly not be raised by the inclusion of the rejected letters: and indeed on no ground is there any cause to regret their rejection. We should have been sorry to leave any possibility of believing that Plato's character was such as that ascribed to him in $i$ and ii. $v$ and vi present no objections of this kind, but they do not possess any great interest, whether historical or biographical: one may give them the credit of being fairly clever forgeries. xii of course occupies an exceptional position. $i$, ii, v, vi are united by the commmon characteristic of borrowing from Plato for their general idea (i and ii from Ep. vii, $\mathrm{v}$ from the Republic, vi from the Symposium). By whom and at what date they were composed we cannot tell: but it seems reasonable to think that they date from the early days of the Alexandrian or Pergamene libraries.

The interest and importance of iii, iv, vii, viii, 
and xiii no one will deny: nor do I think that any exception can be taken to the portrait of Plato which they paint, provided that they be read with judgment and a true historical perspective. Peculiarly interesting to my mind is xiii, where we see the philosopher in undress. 


\section{APPENDIX A.1}

Containing examples of certain characteristic words and expressions found in the Laws which have analogies in the Epistles:-

(I) Abstract Forms of Expression.

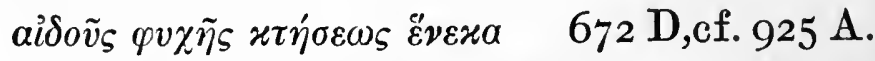

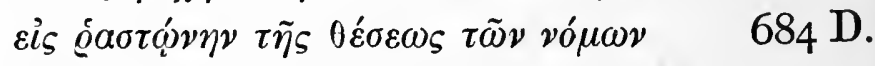

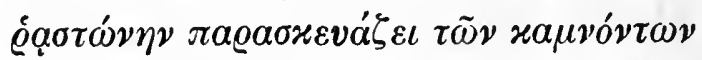

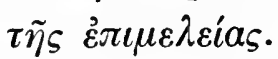
$720 \mathrm{C}$.

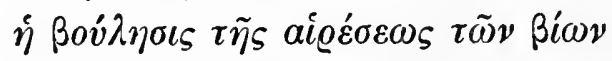
$734 \mathrm{C}$.

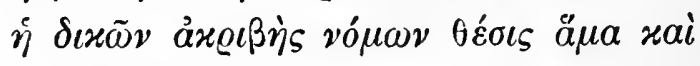

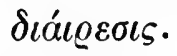

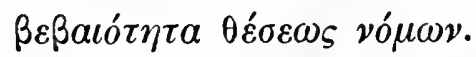
$768 \mathrm{C}$.

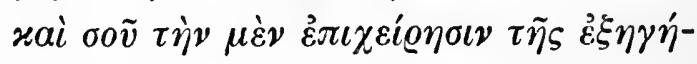

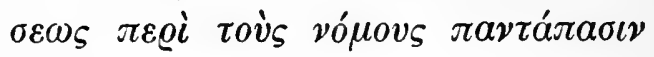
äyaual. $790 \mathrm{~B}$.

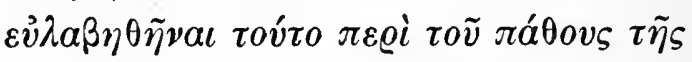
$\gamma \varepsilon \nu \varepsilon \dot{\sigma \varepsilon} \omega \varsigma$

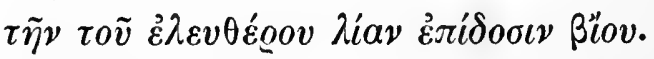

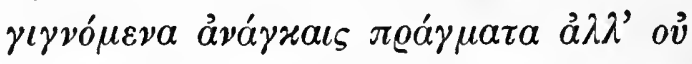

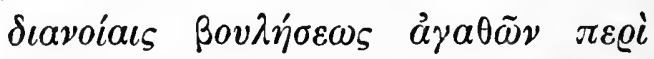

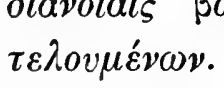

I. This Appendix is based on a personal study of the Laws made in pursuance of Raeder's suggestions. 
(2) Rare Adverbs. (Esp. comparatives in - $\omega_{\varsigma}$ ).

$\delta \varepsilon v \dot{\tau} \varepsilon \varrho \omega \varsigma$.

$\mu \varepsilon \iota \zeta o ́ v \omega s$.

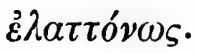

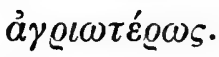

$\dot{\eta} \mu \varepsilon \varrho \omega \tau \varepsilon \dot{\varepsilon} \omega \varsigma$.

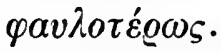

$\nu \varepsilon \omega \tau \varepsilon \dot{\varepsilon} \omega \varsigma$.

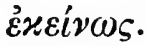

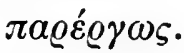

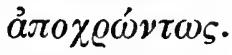

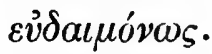

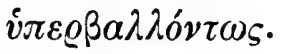

$\varepsilon \pi о \mu \varepsilon \dot{\varepsilon} \omega \varsigma$.

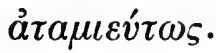

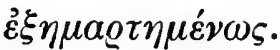

àvayraíws.

$\varepsilon \dot{\varepsilon} \psi \varepsilon v \sigma \mu \varepsilon \dot{\varepsilon} v \omega s$.

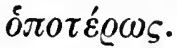

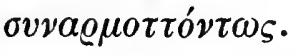

$\tau \tilde{\eta} \delta \varepsilon \quad$ (=here)
739 A, 84I B, 885 A, 955E.

$789 \mathrm{~B}, 867 \mathrm{~B}, 930 \mathrm{~A}, 932 \mathrm{~B}$.

$867 \mathrm{~B}$.

$867 \mathrm{D}$.

$867 \mathrm{D}$.

$876 \mathrm{D}$.

$907 \mathrm{C}$.

$719 \mathrm{C}, 822 \mathrm{~A}$.

$793 \mathrm{E}$.

804 A.

816 D, 829 A, 840 C.

$836 \mathrm{~A}$.

844 E.

$867 \mathrm{~A}$.

$891 \mathrm{D}$.

895 B.

$897 \mathrm{~A}$.

$933 \mathrm{~B}, 937 \mathrm{D}$.

$967 \mathrm{E}$.

$906 \mathrm{~B}, 958 \mathrm{D}$.

(3) Hyperbata.

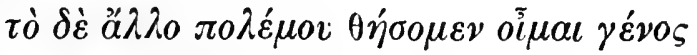

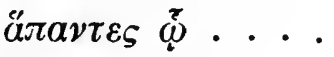

$629 \mathrm{D}$.

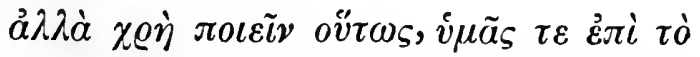

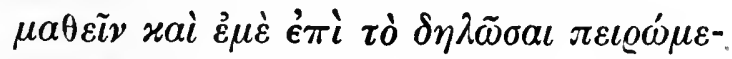

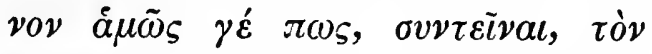

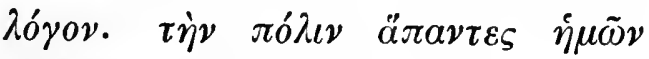

"Е

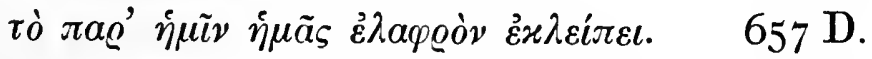

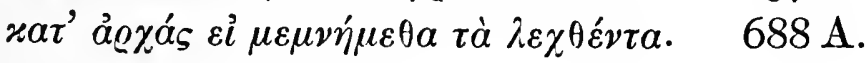




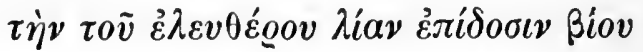

$700 \mathrm{~A}$.

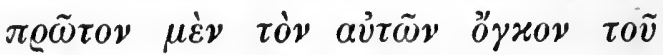

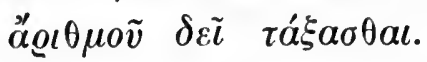

$737 \mathrm{C}$.

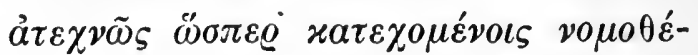

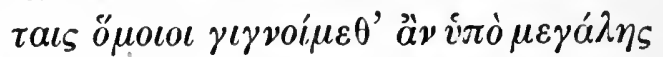

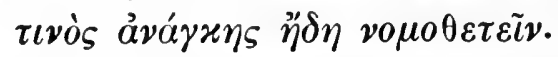

$858 \mathrm{~A}$.

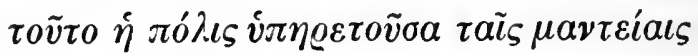

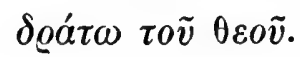

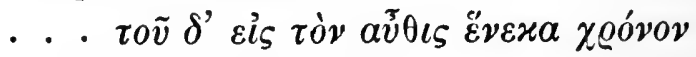

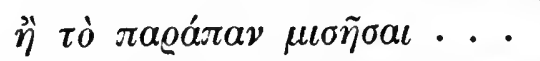

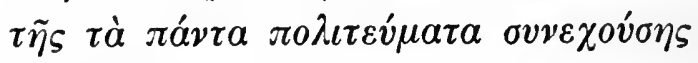

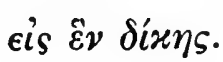

(4) Periphrastic expressions.

(a) Prepositional.

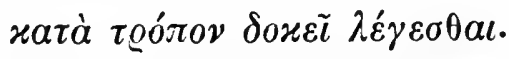

$635 \mathrm{D}$.

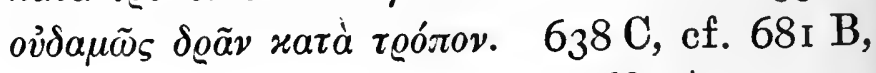
$687 \mathrm{~A}$.

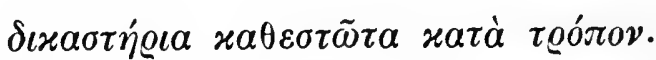

$766 \mathrm{D}$.

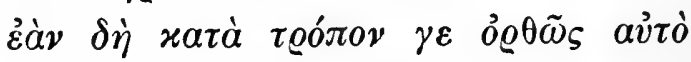
$\theta \varepsilon \varrho a \pi \varepsilon \dot{v} \eta$ \& $x \varepsilon x \tau \eta \mu \varepsilon ́ v o \varsigma$.

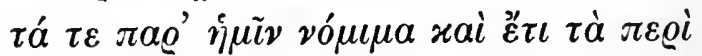

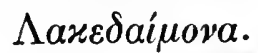

$\dot{\eta} \pi \varepsilon \varrho i$ to "A

93 I A.

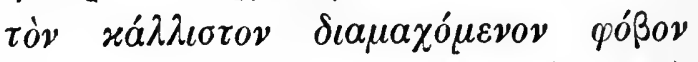

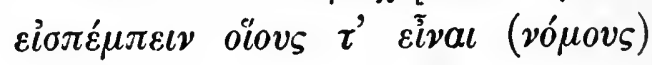

$\mu \varepsilon \tau \dot{\alpha} \delta^{\prime} \dot{x} \eta s$.

67 I D.

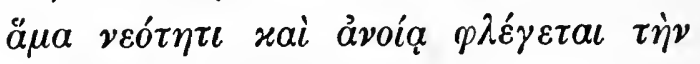

$\psi v \chi \dot{\eta} \nu \mu \varepsilon \theta^{\prime}$ ข̋ß

$628 \mathrm{E}$.

$69_{2} \mathrm{E}$.

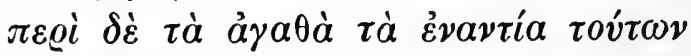

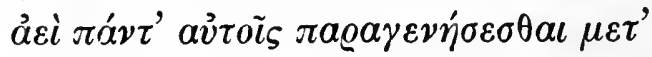

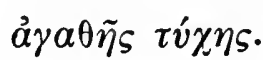




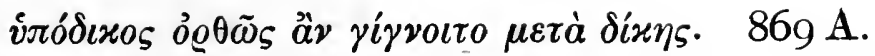

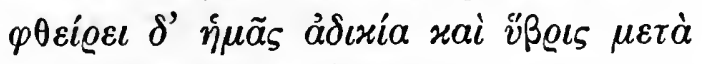

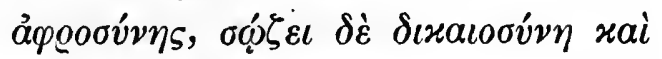

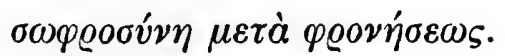

(b) Participial.

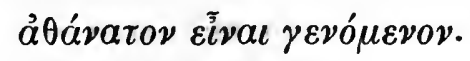

$906 \mathrm{~A}$.

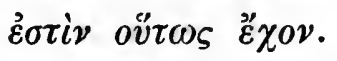

66 I B.

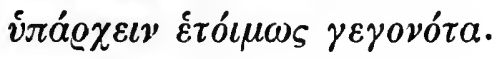

$743 \mathrm{~A}$.

$754 \mathrm{C}$.

(c) Substantival.

$\tilde{\eta}^{\tilde{\eta}} 005 \psi v \chi \tilde{\eta}$. $\quad 650 \mathrm{~A}, 666 \mathrm{C}, 793 \mathrm{E}, 837 \mathrm{C}$. $837 \mathrm{C}$.

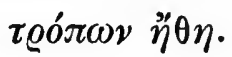
$930 \mathrm{~A}, 968 \mathrm{D}$.

(5) Redundancy.

(a) Of Temporal Adverbs.

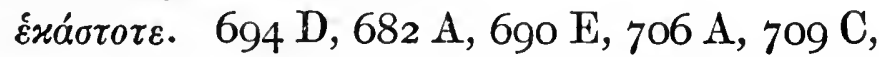
$727 \mathrm{BC}, 73 \mathrm{I} \mathrm{DE}, 742 \mathrm{~B}, 753 \mathrm{E}$, $755 \mathrm{C}, 757 \mathrm{D}, 75^{8} \mathrm{C}, 762 \mathrm{~A}$, $774 \mathrm{E}, 792 \mathrm{C}$.

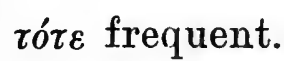

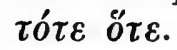

$685-6,699$. $645 \mathrm{E}, 667 \mathrm{E}, 893 \mathrm{E}$.

(b) For expression of superlative notions.

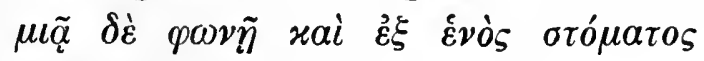

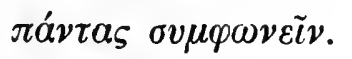

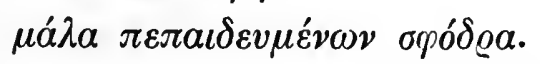
$634 \mathrm{D}$.

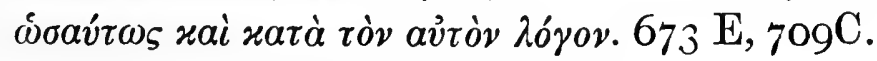

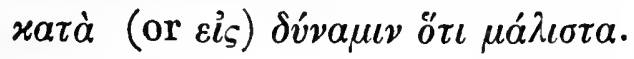

$$
7 \text { I6 C, } 766 \mathrm{~A}, 777 \mathrm{D} \text {. }
$$

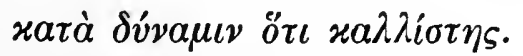
$8 \mathrm{I} 7 \mathrm{~B}$.

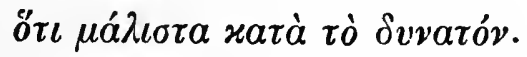

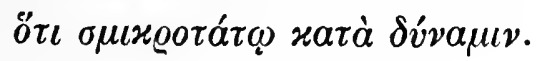
$77 \mathrm{IE}$. $919 \mathrm{C}$. 


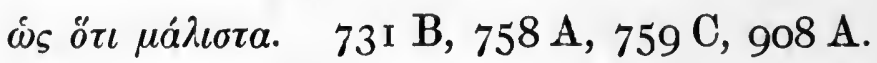
(And many similar expressions elsewhere.)

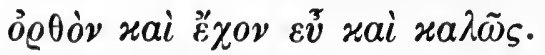

$876 \mathrm{C}$.

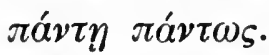

$801 \mathrm{~A}$.

Other collocations of $\pi \tilde{a} s$, etc., $66_{3} \mathrm{E}, 709 \mathrm{~A}$, $718 \mathrm{~A}, 925 \mathrm{~B}, 919 \mathrm{E}, 934 \mathrm{E}$.

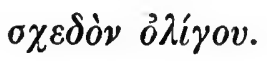
$805 \mathrm{~A}, 800 \mathrm{C}$.

(c) Of completed antithesis.

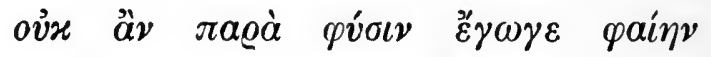

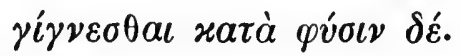

$690 \mathrm{C}$.

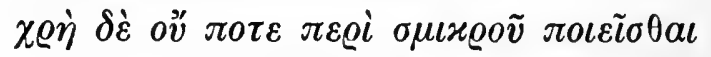

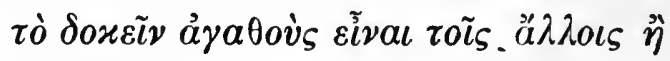

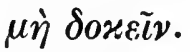

$950 \mathrm{~B}$.

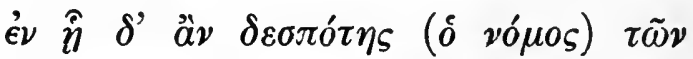

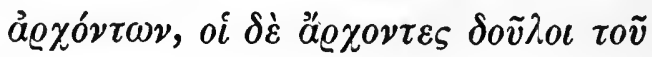

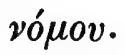

Cf. also several examples in $733 \mathrm{CD}$.

(d) of $\delta \varepsilon \tilde{\imath} \nu$.

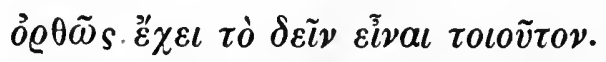

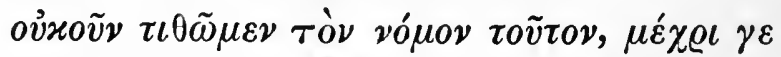

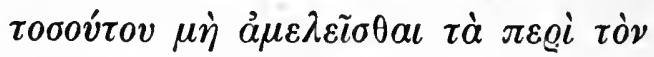

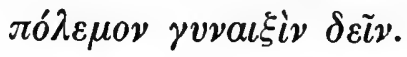

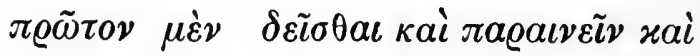
$\sigma v \mu \beta o v \lambda \varepsilon v \dot{\varepsilon} \iota \nu \quad \mu \grave{\eta} \quad \delta \varepsilon \tilde{\imath \nu} \quad \dot{\varepsilon} \pi \iota \chi \varepsilon \iota \varrho \varepsilon \tilde{\imath} \nu$

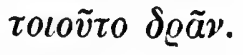

(e) Miscellaneous.

$\lambda \varepsilon \dot{\gamma} \omega \ldots$. . ö $\tau \iota \delta \eta^{\prime} \phi \eta \mu \iota . .$.

688 B.

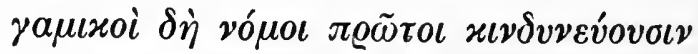

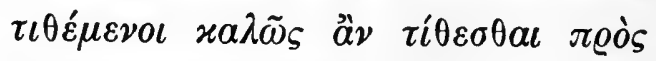

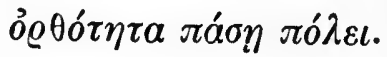




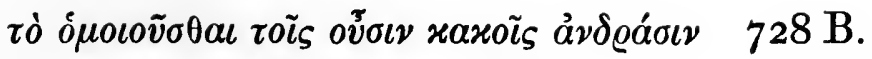

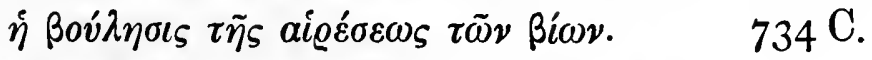

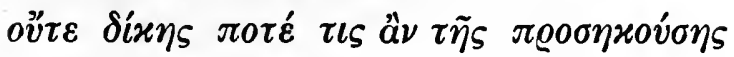

ỏ $\theta \tilde{\omega} \varsigma \tau v \gamma \chi a ́ v o \iota$.

$738 \mathrm{E}$.

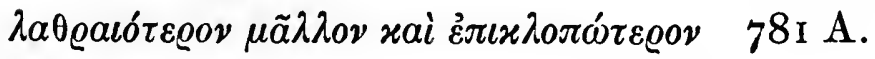

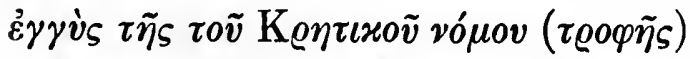

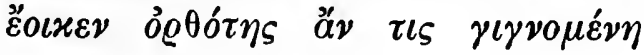

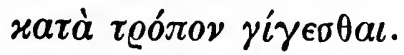

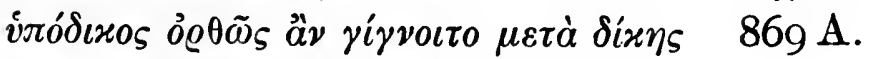

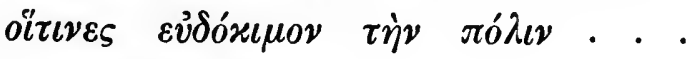

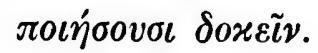

$950 \mathrm{E}$.

(6) Plurals of Abstract Nouns.

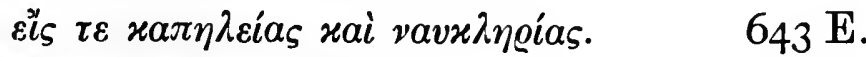

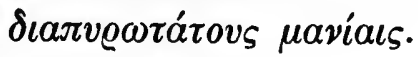

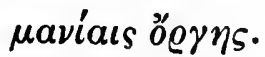

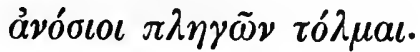

$783 \mathrm{~A}$.

869 A.

88 I A.

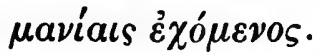

88I B.

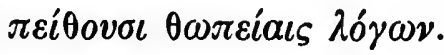

$906 \mathrm{~B}$.

(7) Verbs.

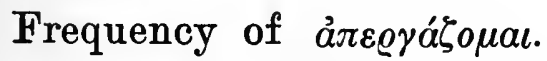

(a) + adjective. $683 \mathrm{~B}, \quad 704 \mathrm{C}, 7 \mathrm{I} 3 \mathrm{E}$, $718 \mathrm{~B}, 7$ I $8 \mathrm{D}, 720 \mathrm{D}, 727 \mathrm{~A} \mathrm{C}, 730 \mathrm{~B}$, 73 I B, 761 B, $777 \mathrm{~A}, 778 \mathrm{~A}, 783 \mathrm{~A} \mathrm{E}$, etc.

(b) without adjective. $647 \mathrm{~B}$ (twice), 656E, $657 \mathrm{~A}, 658 \mathrm{~B}, 667 \mathrm{D}, 695 \mathrm{~A}, \quad 7$ ro D, 7 I I D, 7 I9 A, $729 \mathrm{~A}, 734 \mathrm{E}$ (twice), $739 \mathrm{D}$, etc.

$\delta \iota a \tau \varepsilon \theta \tilde{\eta} \nu a \iota$ preferred to $\delta \iota a \varkappa \varepsilon \tilde{\sigma} \sigma a \iota$.

666 c, 7 I9 C, 864 E, 928 C, 958 A. 


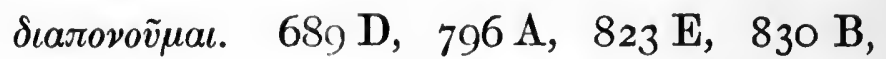
$846 \mathrm{D}, 847 \mathrm{~A}, 857 \mathrm{C}, 966 \mathrm{CD}$.

$\pi \varrho o \tau \iota \mu \tilde{\alpha} \nu+\pi \varrho o ́$.

$727 \mathrm{D}$.

$+\pi \lambda \dot{\varepsilon} 0 \nu$.

$777 \mathrm{D}$.

$+\mu \tilde{a} \lambda \lambda o \nu$.

$887 \mathrm{~B}$.

$+\pi \varrho o ́ \tau \varepsilon \varrho o \nu$.

9 I3 B.

(8) Miscellaneous.

(a) Tripartitions and insistences on the number Three.

$669 \mathrm{~B}, 664 \mathrm{~B}, 685 \mathrm{~A}, 69_{2} \mathrm{D}, 837 \mathrm{D}$, $848 \mathrm{~B}, 864 \mathrm{~B}, 892 \mathrm{D}, 895 \mathrm{D}, 898 \mathrm{E}$, 90 г C, $908 \mathrm{~A} \mathrm{~B}, 920 \mathrm{~A}, 960 \mathrm{C}$.

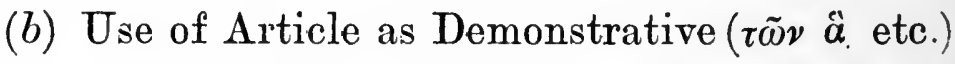
7 I 4 E, $866 \mathrm{D}, 873 \mathrm{E}$, 901 D, $905 \mathrm{~B}$, 922 D, 949 A, 968 D.

(c) Rhetorical question answered.

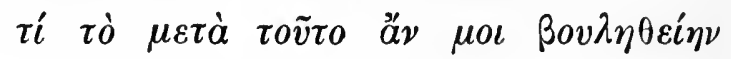

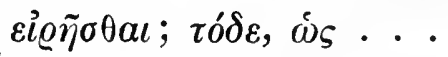

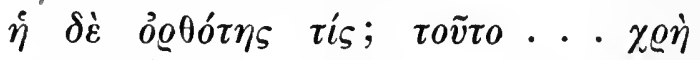

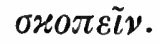

$723 \mathrm{~B}$.

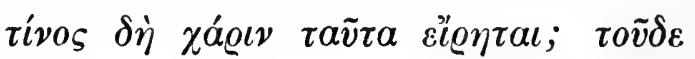

Cf. also $689 \mathrm{D}, 809 \mathrm{E}, 919 \mathrm{C}$.

733 A.

$780 \mathrm{~A}$.

(d) Parenthesis.

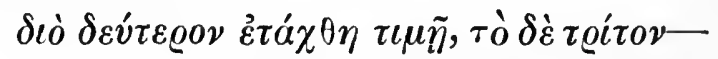

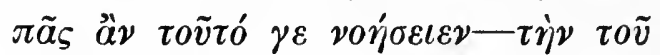

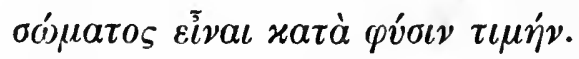

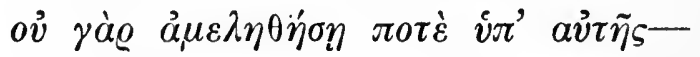

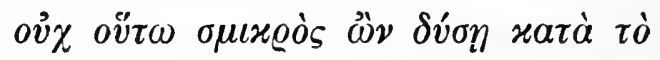

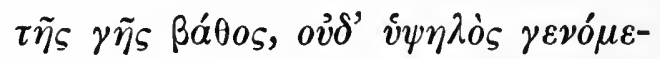

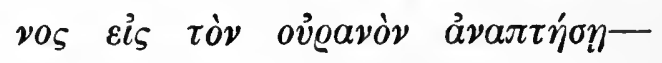
$\tau \varepsilon i ́ \sigma \varepsilon \iota \varsigma \delta \dot{\varepsilon} . . \quad \tau \iota \mu \omega \varrho i ́ a v$.

$728 \mathrm{D}$. 


\section{APPENDIX B.}

On Parallel Passages in the Dialogues.

(The following parallels, showing various degrees of similarity in thought and language between one dialogue (or part of a dialogue) and another, are adduced as a caution against the hasty and uncritical acceptance of arguments alleging fraudulent imitation of Plato in the Epistles.)

(I) Symp. $173 \mathrm{~B}$.

ở $\mu \varepsilon ́ v \tau o \iota ~ \dot{a} \lambda \lambda \dot{a}$ xai $\Sigma \omega x-$

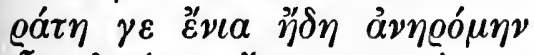

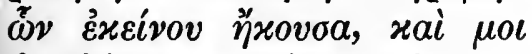

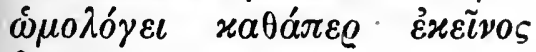

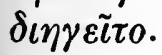

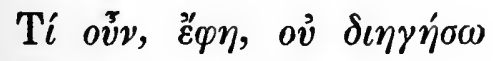
$\mu o \iota$;

(2) Rep. $368 \mathrm{~A}$.

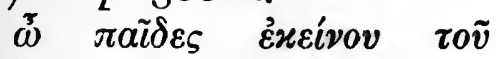
ảvd@ós.

(3) Laws $888 \mathrm{~A}$.

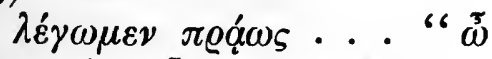

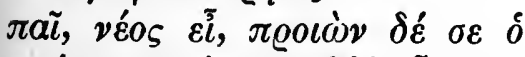

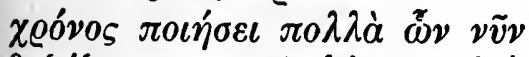

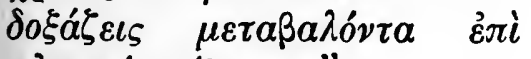

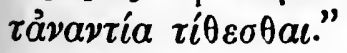

Prot. 3iо A.

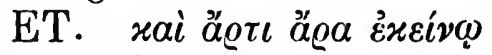

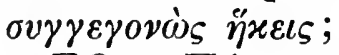

$\Sigma \Omega$. Пávv $\gamma \varepsilon \pi 0 \lambda \lambda \dot{a}$ xai

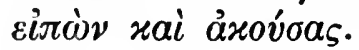

ET. Tí ov̉v ov $\delta \imath \eta \gamma \eta \dot{\eta} \sigma \omega$

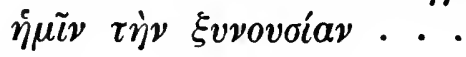

Phil. $36 \mathrm{D}$.

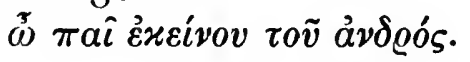

Parm. I30 E.

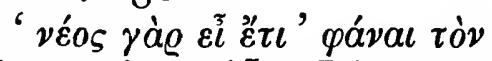

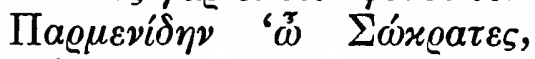

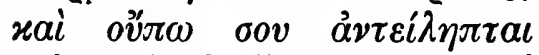

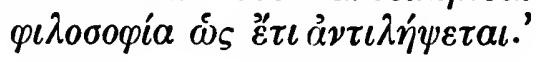




\section{I98 AU'THORSHIP OF PLATONIC EPISTLES}

(4) Laws $733 \mathrm{C}$.

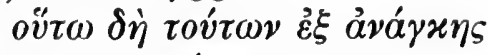
$\delta \iota \alpha x \varepsilon \varkappa о \sigma \mu \eta \mu \varepsilon ́ v \omega \nu$.

(5) Laws $959 \mathrm{~B}$.

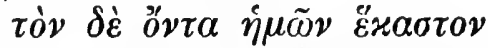

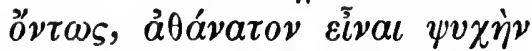

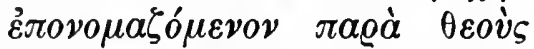

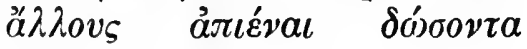

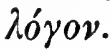

(6) Laws $72 \mathrm{I}$ C.

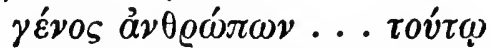

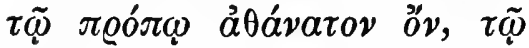

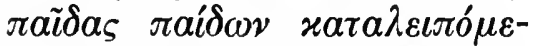

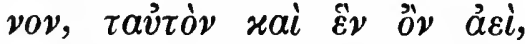

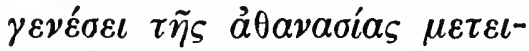
$\lambda \eta \varphi \varepsilon ́ v a \iota$.

(7) Laws 747 B.

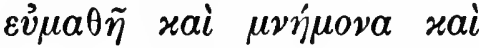

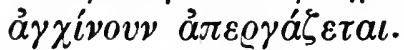

(8) Laws $889 \mathrm{D}$.

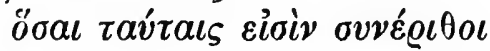
$\tau \dot{\varepsilon} \chi \nu \alpha \iota$.
Phil. I6 D.

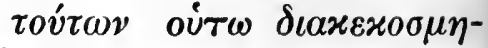
$\mu \varepsilon ́ v \omega \nu$.

Laws 93 I E.

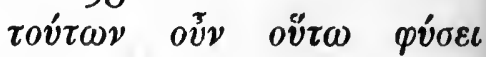
$\delta \iota \alpha \tau \varepsilon \tau \alpha \gamma \mu \varepsilon ́ v \omega \nu$.

Laws 807 D.

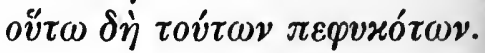

Phaedo 63 B.

$\varepsilon \dot{\imath} \mu \dot{\varepsilon \nu} \mu \dot{\eta} \stackrel{\omega}{\mu} \mu \eta \nu \quad \ddot{\eta} \xi \varepsilon \iota \nu$

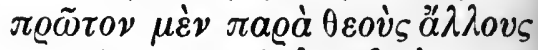
oopov́s $\tau \varepsilon$ rai à $\gamma \alpha \theta$ oús...

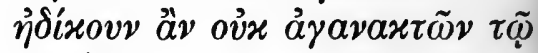

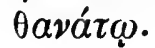

Symp. 207 D.

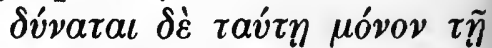

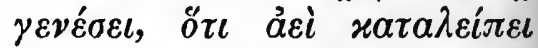

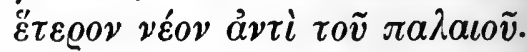

Rep. $503 \mathrm{C}$.

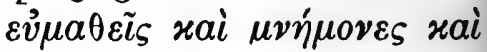
àyxívoเ.

Rep. $533 \mathrm{D}$.

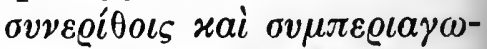

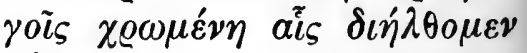

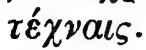




\section{APPENDIX C.}

Chronological Table.

B.C.

428.

Birth of Plato.

387.

Plato visits Italy and Sicily, where he meets the elder Dionysius of Syracuse, and makes the acquaintance of Dion.

367. Death of Dionysius I and accession of Dionysius II.

367-366. Plato's second visit to Syracuse. Dion banished.

-366-365. Epistle XIII.

361-360. Plato's third visit to Syracuse.

360. Plato meets Dion at the Olympic Games.

357. Expedition of Dion against Dionysius.

Epistle III.

355-354. Epistle IV.

Composition of the Laws probablybegun.

353. Dion is murdered by the Athenian Callippus.

352. Epistle VII. Callippus is overthrown by Hipparinus, son of the elder Dionysius.

351. Epistle VIII.

347. Death of Plato. 



\section{INDEX.}

Academy, date of foundation, 51 Adam, Rudolf, ix, 2, 3, 4, 5, 1243 , $44,45,46,54,115,117,118,121,128$, 141

Elian, 1, 62, 135

Alexander of Aphrodisias, 173

Apollocrates, 138

Archedemus, 94

Archer-Hind, R. D., 156, 178

Archytas of Tarentum, 57, 91, 155, 156, $157,163,164$

Aristodorus, 158

Aristophanes of Byzantium, 1, 2

Aristotle, 76, 77, 107, 108, 173, 186

Ast, F., ix, 5, 6, 8, 65, 66, 67, 68, 184

Athenæus, 74, 173

Bäumker, C., 173

Bentley, R., 5

Blass, Fr., 11, 13

Böckh, A., 5, 77

Bryson, 169, 173, 174

Burnet, Prof. J., 116, 163, 167
Campbell, Lewis, ix, 9, 10, 16, 68, 145

Cebes 178

Christ, W., 10, 187

Cicero, 5, 173

Cobet, C. G., 62

Coriscus, 76, 77

Cratylus, 105

Cudworth, R., 5

Cyrus, 70171

Diels, H., 164

Diodorus, 84, 114, 139, 140

Diogenes Laertius, 1, 62, 159, 163, 164

Dion, 36, 38, 43, 52, 56, 62, 63, 64, 69, $70,71,84,86,87,88,89,91,92,93$, $94,95,97,98,99,100,101,114,123$, $132,133,134,136,137,138,139,144$, $151,167,171,175,177$

Dionysius of Halicarnassus, 4

Dionysius, the younger, $88,89,90,91$, $92,93,94,100,101,102,110,121,132$, $137,140,166,170,171,172,175,177$, 178,185

Callippus, 84, 85, 97, 101, 137, 138, $139 \mid$ Echecrates, 156 
Erastus, 76, 77

Euclides, 174

Euphraeus of Oreus, 74, 75

Ficinus, 5, 36, 167

Gomperz, Th., 185

Grimm, 0., 5

Grote, G., ix, 2, 17, 41, 70, 136, 140

Harrison, E., 183

Helicon, 166, 169, 173

Heraclides, 58, 69, 94

Hercher, F., 123

Hermann, K. F., 6, 19

Hermeias, 76, 77

Hipparinus, 84, 85, 98, 102, 114, 117, $133,134,137,139,140,153$

Holm, Adolf, 42

Iamblichus, 156

Isocrates, $169,172,173,174$

Jackson, Professor Henry, 73

Jowett, B., 150

Karsten, H. T., ix, 7, 8, 9, 12, 42, 57, $61,63,96,98,104,105,107,115$, $116,117,118,119,122,126,167,186$

Laodamas, 159, 161

Laomedon, 165

Leochares, 169
Lina, T., 16

Lutoslawski, W., 16, 17

Lycurgus, 70

Meyer, Ed., 11, 18, 77, 84, 85, 114, 116 $123,132,140,160$

Nepos, Cornelius, 137

Nysaeus, 114

Ocellus of Lucania, 163, 164

Odau, M., 11, 102, 112, 120

Passow, F. L., 72, 82, 162, 183

Perdiccas of Macedonia, 73, 74, 75

Plutarch, 5, 62, 100, 114, 138, 170, 1i

Polyxenus, 173

Proclus, 4

Raeder, Hans, ix, 12, 14, 15, 18, 1 $20,21,42,47,50,67,69,70,71,7$ $78,115,120,126,145,147,149,15$ $156,160,167,179,180,187$

Reinhold, H., ix, 10, 42, 135, 136, 13 138,140

Richards, H., ix, 12, 57, 60, 62, 63, * 79, 111,136

Riddell, James, ix, 66, 67, 68, 72, 1Ł, 182, 183

Ritter, Constantin, ix, 10, 11, $16,17,18,38,42,46,50,63,64,1$ $70,71,77,82,96,97,102,110,1$ : $117,121,123,150,155,160,161,11$ $165,167,168,171,175,176,177,1$, $180,182,183$ 


\section{INDEX}

Ichanz, M., 16

iocrates, 116, 160

ocher, J., 6

peusippus, 109

tallbaum, G., 6, 150

teinhart, Karl, ix, 9, 12, 36, 38, 51, 63, Uberweg, Fr., 6

$70,71,74,78,141,155,156,160,164$, $165,167,171,178$

trabo, 76

usemihl, Franz, ix, 3, 164

aylor, Prof. A. E., 116, 117

'Thirty,' the, 115

Thompson, W. H., 115, 117, 172

Thrasyllus, 1, 2

ennemann, W. G., 5

heodotes, 56, 69, 94

heophrastus, 173

Zeller, E., 164

Wiegand, F., 6

Wilamowitz, U. v., 167, 168

Xenocrates, 77 



\section{A List of Some Other Publications of the University of Manchester.}

\section{CELTIO SERIES.}

No. 1. AN INTRODUCTION TO EARLY WELSH. By the late

Prof. J. Strachan, LL.D. Demy 8vo, pp. xvi. 294. 7s. 6d. net.

(Publication No. 40, 1908.)

"The Grammar as a whole is of course a very great advance on the pioneer work of Zeuss; Dr. Strachan had fuller and more accurate texts to work with, and possessed a knowledge probably unsurpassed of the results of recent progres, in Celtic philology, which he himself did so much to promote."-Professor Morris Jones in the Manchester Guardian.

"The work is an excellent introduction to the study of early Welsh. We can strongly recommend it to Welsh students; it is undoubtedly a work which no student of Celtic literature can afford to be without."

-North Wales Guardian.

"The work is destined, of course, to become the text-book in early Welsh wherever taught.,"-Western Mail.

No. II. THE LANGUAGE OF THE ANNALS OF ULSTER. By Tomás O’Márlde, M.A., Professor of Irish in University College, Galway. Demy 8vo, pp xiii. 220. 7s. 6d. net.

(Publication No. 53, 1910.)

The objects of this dissertation are firstly to investigate the date at which certain old-Irish phonological developments took place, and secondly to give an acco unt of old-Irish declension as evidenced by the language of the Annals of Ulster. An Appendix on the analysis of Irish personal names is appended.

"As a valuable book, the work of an excellent scholar, as treating of a most interesting period of the Irish language, as containing apart from its very great academic use a surprising amount of matter that must fascinate all who have any feeling for the blend of old and new in Modern Irish, this elaborate treatise must be welcomed with joy. .... Learned the book is, patiently methodical, full of the invaluable statement of "document," widely enlightening for the scholars, and they already know that, and need no pushing towards the book, for which they and their special works have been impatiently waiting."

-Freeman's Journal.

"A painstaking and accurate piece of work, and does honour to its author and the University which has printed it." ---The Athenoum. 


\section{SHERRATT \& HUGHES}

\section{MANCHESTER UNIVERSITY PUBLICATIONS. CELTIC SERIES.}

"A work of fine scholarship, which will prove of great service to the student of early and middle Irish, and it is a valuable testimony of the interest which is being taken in our day in Irish letters." -Scotsman.

"Obviously we have here an invaluable guide to the early history of the language. The book is carefully indexed, and will be found invaluable as a work of reference."-Irish Times.

"One of the most important contributions to old Irish studies issued in recent years. The author had the enormous advantage of knowing modern Irish from childhood, and his investigations of the language of the annals are evidence of the advantage." - Irish Independent.

\section{CLASSICAL SERIES.}

No. I. A STUDY OF THE BACCHAE OF EURIPIDES. By G. Norwood, M.A., Professor of Greek in University College, Cardiff. Demy 8vo, pp. xx, 188 . 5s. net.

(Publication No. 31, 1908.)

"The interest of Mr. Nor"vood's book, which ... is a very welcome addition to the bibliography of Euripidss, and a scholarly and interesting prece of work, displaying erudition and insight beyond the ordinary, lies in the way in which, by applying Dr. Verrall's methods .... he first shows up difficulties and inconsistencies, some of which have hardly been noticed before ... and then produces his own startling theory, which he claims is the great solvent of all the perplexities." - Saturday Review.

"Unless very strong evidence can be produced against Mr. Norwood's view, it must be accepted as the true solution of the problem. . . . Mr. Norwood is generally clear, and abounds in illuminating thoughts. He has added a full bibliography (running to twenty-three pages) of writings on Euripides, and for this every scholar will offer his sincere thanks. . . He has done a very good piece of work."-Athenreum.

"This volume forms the first of a Classical Series projected by the Manchester University, who are to be congratulated on having begun with a book so original and full of interest. It is admirably argued, and is instinct with a sympathetic imagination. It is, at the very least, an extremely able attempt to solve a very complex problem." - Manchester Guardian

"Has even in the eyes of a sceptic the considerable merit of stating the hypothesis in a very thoroughgoing and able manner, and at least giving it its full chance of being believed."-Pros. Gilbert Murray in the Nation.

"L'interprétation de M. Norwood est certainement très ingénieuse; elle est même très séduisante."-Revue Critique.

THE AUTHORSHIP OF THE PLATONIC LETTERS. By $R$. Hackforth, M.A., Fellow of Sidney Sussex College, Cambridge.

[In the Press. 


\section{SHERRATT \& HUGHES}

\section{MANCHESTER UNIVERSITY PUBLICATIONS. EDUCATIONAL SERIES.}

No. I. CONTINUATION SCHOOLS IN ENGLAND \& ELSEWHERE. Their place in the Educational System of an Industrial and Commercial State. By Michael E. Sadier, M.A., LL.D., Professor of the History and Administration of Education. Demy 8vo, pp. xxvi. 779. 8s. 6d. net.

(Publication No. 29, 1907.)

This work is largely based on an enquiry made by past and present Students of the Educational Department of the University of Manchester. Chapters on Continuation Schools in the German Empire, Switzerland, Denmark, and France, have been contributed by other writers.

".... gives a record of what the principal nations are doing in the prolongation of school work. It is invaluable as a corpus of material from which to estimate the present position of the world-so far as its analogies touch Britain-in 'further education,' as the phrase is."

-The Outlook.

"The most comprehensive book on continuation schools that has yet been issued in this country "-Scottish Review.

"The subject of the work is one that goes to the very heart of national education, and the treatise itself lays bare with a scientific but humane hand the evils that beset our educational system, the waste of life and national energy which that system has been unakle in any sufficient degree to check."-The Spectator.

"It is a treasure of facts and judicious opinions in the domain of the history and administration of education."-The Athenceum.

No. II. THE DEMONSTRATION SCHOOLS RECORD. No. I. Being Contributions to the Study of Education from the Department of Education in the University of Manchester. By J. J. Finduax, M.A., Ph.D. Sarah Fielden Professor of Education. Demy 8vo, pp. viii. $126.1 \mathrm{~s}$. 6 d. net.

(Publication No 32, 1908.)

"Professor Findlay and his skilled and experienced collaborators give an interesting account of the uses of the demonstration classes, the nature and scope of the work done in them, and the methods adopted (as well as the underlying principles) in some of the courses of instruction."-The Athencum.

"The book gives an instructive account of the attempts made to correlate the subjects of school instruction, not only with each other, but also with the children's pursuits out of school hours. ... The problem Professor Findlay has set himself to work out in the Demonstration School is, How far is it possible by working with the children through successive culture epochs of the human race to form within their minds not only a truer conception of human history, but also eventually a deeper comprehension of the underlying purpose and oneness of all human activities?"--Morning Post.

33, Soho Square, London, W. 


\section{SHERRATT \& HUGHES}

\section{MANCHESTER UNIVERSITY PUBLICATIONS. EDUCATIONAL SERIES.}

No. III. THE TEACHING OF HISTORY IN GIRLS' SCHOOLS IN NORTH AND CENTRAL GERMANY. A Report by Eva Dodge, M.A., Gilchrist Student. Demy 8vo, pp. x. 149. 1s. 6d. net. (Publication No. 34, 1908.)

"We cordially recommend this most workmanlike, and extremely valuable addition to pedagogic literature."-Education.

"Miss Dodge has much of interest to say on the limitations and defects of history-teaching in girls' schools, but the real contribution of this book is its revelation of how the history lesson can be made a living thing."-Glasgow Herald.

No. IV. THE DEPARTMENT OF EDUCATION IN THE UNIVERSITY OF MANCHESTER, 1890-1911. Demy 8vo, 146 pp. 1s. 6d. net, paper; 2s. 6d. net, cloth.

(Publication No. 58, 1911.)

Published in commemoration of the twenty-first anniversary. of the Education Department.

No. $V$. OUTLINES OF EDUCATION COURSES IN MANCHESTER UNIVERSITY. Demy 8vo, pp. viii., 190. 3s. net.

[Yublication No. 61, 1911.

No. VI. THE STORY OF THE MANCHESTER HIGH SCHOOI FOR GIRLS, 1871-1911. By Sara A. Burstall, M.A. Demy 8vo., pp. xx. 214, with 18 Plates. 5s. net. (Publication No. 63, 1911.) THE DEMONSTRATION SCHOOLS RECORD, No. 2. [In the Press.

\section{ENGLISH SERIES.}

No. I. THE LITERARY PROFESSION IN THE ELIZABETHAN AGE. By Ph. Sheavyn, M.A., D.Lit., Special Lecturer in English Literature and Tutor for Women Students; Warden of the Hall of Residence for Women Students.

A series of brief studies dealing with the conditions amidst which the profession of literature was pursued under Elizabeth and James I. It treats of their relations with patrons, publishers, and reading public, and with various authorities exercising legal control over the press; and discusses the possibility of earning a sufficient livelihood, in this period, by the proceeds of literary work. Demy 8 vo, pp. xii. 221 . 5s. net.

(Publication No. 49, 1909.)

".... scholarly and illuminating book. It opens a new series ir the Manchester University publications, and opens it with distinction. A more elaborately documented or more carefully indexed work need not be desired. The subject is an engrossing one; and, although the author has aimed rather at accuracy and completeness than at the arts of entertainment, the result remains eminently readable."

-Manchester Guardian.

34, Cross Street, Manchester 


\section{SHERRAT'T \& HUGHES}

\section{MANCHESTER UNIVERSITY PUBLIGATIONS. ENGLISH SERIES.}

No. II. BEOWULF : Edited, with Introduction, Notes, and Glossary, by W. J. SedGefield, Litt.D., Lecturer in English Language. Demy 8vo, pp. xii. 300. 9s. net. (Publication No. 55, 1910.)

"It is his carefulnoss in this matter of the text that will win Mr. Sedgefield the chief thanks of students. This record of variants is full and accurate, and the fuller notes which follow the text itself should be very helpful both to the pupil and the expert. In the glossarial index Mr. Sedgefield has accomplished a task hitherto unattemntea in England. . . . Mr. Sedgefield's edition of "Beowulf" maintains admirably the standard of scholarliness in the English series of Manchester UTniversity" studies, and we need no longer reproach ourselves with the necessity of going to Germany for a fully edited text of the greatest monument cf our early literature. All scholars must be grateful."-Manchester Guardian.

"Too often, the philologist and the man of letters find themselves at variance, and it is rare indeed to find the two combined in one personality, but, brief as Mr. Sedgefield's introductory essays necessarily are, they suffice to show that the poem appeals to him in its literary as well as in its linguistic aspect. His criticisms are admirably suggestive, and his notes on the metre, origin, authorship and date are models of clearness and condensation. The Bibliography and Glussary are admirably full."-Guardian.

"It is a scholarly piece of work, embodying the results of the latest researches and containing an excellent bibliography. The introduction provides an admirable analysis of the composition and structure of the poem. It is the best English edition available of the oldest extant epic of the English tongue."-Scotsman.

"A great step forward in the study of Beowulf in particular and the general popularisation of the study of Anglo-Saxon in general. It may be said that in each of its various sections the introduction, the notes, the glossary, and the appendices, this work is much more complete than any other English edition which has hitherto been published, and it should prove the greatest help to students of this grand old epic poem . . . a work which essentially conforms to the spirit of modern science."

-Commentator.

No. III. PATIENCE: A West Midland Poem of the Fourteenth Century. With an Introduction, Notes, and Glossary, by HarTLEY Bateson, B.A.

(Publication No. 70, 1912.)

No. IV. THE EARLY LIFE AND DEVELOPMENT OF GEORGE ELIOT. By Miss Mary H. Deakin, M.A.

[In the Press.

THE POETICAL WORKS OF WILLIAM DRUMMOND OF HAWTHORNDEN. Edited by L. E. Kastner, M.A., Professor of French.

[In the Press.

33, Soho Square, London, W. 


\section{SHERRATT \& HUGHES}

\section{MANCHESTER UNIVERSITY PUBLICATIONS. HISTORICAL SERIES.}

No. I. MEDIAEVAL MANCHESTER AND THE BEGINNINGS OF LANCASHIRE. By James TaIt, M.A., Professor of Ancient and Mediæval History. Demy 8vo, pp. x. 211. 7s. 6d. net.

(Publication No. 3, 1904.)

"Patient and enlightened scholarship and a sense of style and proportion have enabled the writer to produce a work at once solid and readable."-English Historical Review.

"A welcome addition to the literature of English local history, not merely because it adds much to our knowledge of Manchester and Lancashire, but also because it displays a scientific method of treatment which is rare in this field of study in England."-Dr. Gross in American Historical Review.

"La collection ne pouvait débuter plus significativement et plus heure. usement que par un ouvrage d'histoire du Moyen Age dû à M. Tait, car l'enseignement mediéviste est un de ceux qui font le plus d'honneur à la jeune Université de Manchester, et c'est à M. le Professeur Tait qu'il faut attribuer une bonne part de ce succès."-Pevue de Synthése historique.

No. II. INITIA OPERUM LATINORUM QUAE SAECULIS XIII., XIV., XV. ATTRIBUUNTUR. By A. G. Lirte, M.A., Lecturer in Palæography. Demy 8vo, pp. xiii. 273 (interleaved). (Out of print.) (Publication No. 5, 1904.)

"Whoever has attempted to ascertain the contents of a Mediæval miscellany in manuscript must often have been annoyed by the occurrence of a blank space where the title of the treatise ought to be. Mr. Little has therefore earned the gratitude of all such persons by making public a collection of some 6,000 incipits, which he arranged in the first instance for his private use, in compiling a catalogue of Franciscan MSS."

-English Historical Review.

No. III. THE OLD COLONIAL System. By Gerald Berkeley Hertz, M.A., B.C.L., Lecturer in Constitutional Law. Demy 8vo, pp. xi. 232 . $5 \mathrm{~s}$ net.

(Publication No. 7, 1905.)

"Mr. Hertz gives us an elaborate historical study of the old colonial system, which disappeared with the American Revolution. . . He shows a remarkable knowledge of contemporary literature, and his book may claim to be a true history of popular opinion."-Spectator.

"Mr. Hertz's book is one which no student of imperial developments can neglect. It is lucid, fair, thorough, and convincing."

-Glasgow Herald.

“Mr. Hertz's 'Old Colonial System' is based on a careful study of contemporary documents, with the result that several points of no small importance are put in a new light ... i it is careful, honest work .... The story which he tells has its lesson for us."-The Times.

33. Soho Square, London, W. 


\section{MANCHESTER UNIVERSITY PUBLICATIONS. HISTORICAL SERIES.}

No. IV. STUDIES OF ROMAN IMPERIALISM. By W. T. ARNold, M.A. Edited by EDwari) FidDes, M.A., Lecturer in Ancient History, with Memoir of the Author by Mrs. Humpery Ward and C. E. Montagee. With a Photogravure of W. T. Arnold. Demy 8vo, pp. cxxiii. 281. 7s. 6d. net.

(Publication No. 16, 1906.)

"Mrs. Humphry Ward has used all her delicate and subtle art to draw a picture of her beloved brother; and his friend Mr. Montague's account of his middle life is also remarkable for its literary excellence."

"The memoir....tenderly and skilfully written by the "sister and friend,' tells a story, which well deserved to be told, of a life rich in aspiration, interests, and friendships, and not without its measure of actual achievement."-Tribune.

"Anyone who desires a general account of the Empure under Augustus which is freshly and clearly written and based on wide reading will find it here."-Manchester Guarainan.

"Nothing could be better than the sympathetic tribute which Mrs. Humphry Ward pays to her brother, or the analysis of his work and method by his colleague Mr. Montague. The two together have more stuff in them than many big books of recent biography."

The Memoir may be had separately, price $2 \mathrm{~s} .6 \mathrm{~d}$ net -Westminster Gazette.

No. V. CANON PIETRO CASOLA'S PILGRIMAGE TO JERUSALEM IN THE YEAR 1494. By M. M. NewetT, B.A., formerly Jones Fellow. Demy 8vo, pp. viii. 427. 7s.6d. net. (Publication No. 26, 1907.)

"Tra mezzo ai tanti likri esteri di semplici divulgazione su fatti $\theta$ figure della storia italiana, questo emerge piacevalmente e si legge volontieri. E diverso di carattere e di trattazione. Esume . . . . dalla polvere degli archivi e delle biblioteshe qualche cosa che ha un valore fresco ed interessante, un valore storico e un valore umano." -A.A.B. in the Archivio Storico Italiano.

"L'introduction se termine par toute une dissertation du plus grand intérêt documentée à l'aide des archives vénitiennes, sur le caractère commercial des pelérinages, dont les armateurs de Venise assumèrent, jusqu 'au XVIIe siècle l'entreprise."

-J.B. in the Revue de Synthèse historique.

"Miss Newett has performed her task admirably, preserving much of the racy humour and shrewd phrasing which mark the original, and adding, in the introduction, a general treatise on the Venetian pilgrim industry, and in the notes copious illustrations of the text."

-Horatio Brown in the English Historical Review.

33, Soho Square. London. W. 


\section{SHERRAT'I \& IIUCiIES}

\section{MANGHESTER UNIVERSITY PUBLICATIONS. HISTORICAL SERIES.}

"Miss Newett's introduction is an admirable bit of work. She has studied carefully what the archives of Venice have to say about pilgrim ships and shipping laws, and her pages are a mine of information on such subjects."-Dr. Thomas Lindsay in the Scottish Historical Review.

"This is a deeply interesting record, not merely of a Syrian pilgrimage, but of Mediterranean life and of the experiences of an intelligent Italian gentleman at the close of the Middle Ages--two years after the discovery of America. It would not be easy to find a more graphic picture, in old days, of a voyage from Venice to the Levant."

\section{-American Historical Review.}

Nc.VI HISTORICAL ESSAYS. Edited by T. F. Tout, M.A., Professor of Medireval and Modern History, and JAMES TAIT, M.A., Professor of Ancient and Mediæval History. Demy 8vo, pp. xv. 557. 6s. net. Reissue of the Edition of 1902 with index and New Preface

(Publication No. 27, 1907.)

"Diese zwanzig chronologisch geordneten Aufsätze heissen in der Vorrede der Herausgeber Festchrift, behandeln zur Hälfte ausser-englische Themata, benutzen reichlich festländische Literatur und verraten überall neben weiten Ausblicken eine methodische Schulung die der dortigen Facultät hohe Ehre macht."-Professor Liebermann in Deutsche Literaturzeitung.

"Imperial history, local history, ecclesiastical history, economic history and the methods of historical teaching - all these are in one way or another touched upon by scholars who have collaborated in this volume. Men and women alike have devoted their time and pains to working out problems of importance and often of no slight difficulty. The result is one of which the university and city may be justly proud." - The late Professor York Powell in the Manchester Guardian.

"Esso contiene venti lavori storici dettati, quattro da professori e sedici da licenziati del Collegio, e sono tutto scritti appositamente e condotti secondo le più rigorose norme della critica e su documenti."-R. Predelli in Nuovo Archivio Veneto.

"Le variété des sujets et l'érudition avec laquelle ils sont traités font grand honneur à la manière dont l'histoire est enseigné à Owens College.

--Revue Historique.

"Par nature, c'est un recueil savant, qui témoigne du respect et de l'émulation que sait exercer pour les études historiques la jeune et déjà célèbre université."-Revue d'histoire scclésiastique (Louvain).

"All these essays reach a high level; they avoid the brsetting sin of most of our present historical writing, which consists of serving up a hash of what other historiains have written flavoured with an original spice of error. . . . They are all based on original research and written by specialists."-Professor A. F. Pollard in the English Historical Review.

The index can be purchased separately, frice $6 \mathrm{~d}$. net. 


\section{SHERRATT \& IIUGHES}

\section{MANGHESTER UNIVERSITY PUBLICATIONS. HISTORICAL SERIES.}

No. VII. STUDIES SUPPLEMENTARY TO STUBBS' CONSTI TUtional HISTORY. Vol. i. By Ch. Petit-Dutallits, Litt.D., rector of the University of Grenoble. Translated from the French by W. E. Rhodes, M.A., and edited by Prof. James TaIt, M.A. Demy 8vo, pp. xiv. 152 . 4s. net.

(Publication No. 38, 1908. Second Edition, 1911).

"This task has been carefully and well pertormed, under the supervi. sion of Professor Tait, who has written a short but adequate introduction. This little book, ought, without delay, to be added to every public or private library that contains a copy of the classic work to which it forms an indispensable supplement."

-Dr. W. S. McKechnie in the Scottish Historical Review.

"C'est un complément indispensable de l'ouvrage de Stubbs, et l'on saura gré à l'Université de Manchester d'avoir pris l'initiative de cette publication."-M. Charles Bémont in Revue Historique.

"These supplementary studies impress one as a discreet and learned attempt to safeguard a public, which is likely to learn all that it will know of a great subject from a single book, against the shortcomings of that book."-Professor A. B. White in the American Historical Review.

"Ce sont des modèles de critique ingénieuse et sobre, une mise au point remarquable des questions les plus importantes traitées jadis par Stubbs."-M. Louis Halphen in Revue de Synthèse historique.

" $\mathrm{Zu}$ der englischen Uber'setzung dieser Excurse, durch einen verdienten jüngeren Historiker, die durchaus leicht wie Originalstil fliesst, hat Tait die Vorrede geliefert und manche Note, die noch die Literatur von 1908 berücksichtigt. Die historische Schule der Universität, Manchester, an Rührigkeit und strenger Methode von keiner in England übertroffen, bietet mit der Veröffentlichung der werthvollen Arbeit des Franzosen ein treffliches Lehrmittel."-Professor F. Liebermann, in Deutsche Literaturzeitung.

No. VIII. MALARIA AND GREEK HISTORY. By W. H. S. Jones,

M.A. To which is added the History of Greek Therapeutics and the Malaria Theory by E. T. Withingrox, M.A., M.B. Demy 8vo, pp. xii. 176 . 5s. net.

(Publication No 43, 1909.)

"Mr. W. H. S. Jones is to be congratulated on the success with which he has conducted what may be described as a pioneering expedition into a practically unexplored field of history .... the publishers are to be congratulated on the admirable way in which the book has been turned out-a joy to handle and to read."-Manchester Guardian.

"[The author]... has amassed a considerable store of valuable information from the Greek classics and other sources which will prove extremely useful to all who are interested in his theory."

-Birmingham Daily Post.

33. Soho Square, London, W. 


\section{SHERIRA'T \& HUGHES}

\section{MANCHESTER UNIVERSITY PUBLICATIONS. HISTORICAL SERIES.}

No. IX. HANES GRUFFYDD AP CYNAN. The Welsh text with translation, introduction, and notes by Arthur Jones, M.A., Jones Fellow in History. Demy 8vo, pp. viii. 204. 6s. net.

(Publication No. 50, 1910.)

"No Welsh historian of the future can afford to neglect this scholarly atteinpt to give the work of Griffith ap Cynan a true historical setting. The introduction is an ideally well-balanced estimate of a singularly quaint and beautiful piece of history."-Glasgow Herald.

"Mr. Jones prints the Welsh text in a scholarly recension, and accompanies it page by page with a faithful version into English, explains its obscurities and personal and local allusions in notes always concise and to the point, and brings it in with an interesting introduction, which treats fully of the transmission of the text, of its value as an historical document, and of its relation to other remaining original authorities for the history of the Norman Conquest."-Scotsman.

"Mr. Jones's enterprise is the result of the hapny union in the University of Celtic and of historical studies. . . The textual editing, the annotations, and the translation have all been admirably done, and the work is a credit aliks to the author, the University, and to the Press."-Manchester Guardian.

"Hearty thanks are due for a most useful and satisfactory edition."

- Archooologia Cambrensis.

"The Editor has prefaced his text with a comprehensive and nearly always convincing introduction of more than 100 pages, besides copious notes. Nearly every page of both contains matter of Irish history, sometimes really new, since taken from the document never deeply studied before, and always valuable from the new light thrown by the collation of independent, 'international' testimonies. ... It will at once be seen that we have here a document of the first interest to ourselves; the University and the Editor have put us in their debt for a valuable contribution to our history."-Freeman's Journal.

No. X. THE CIVIL WAR IN LANCASHIRE. By Ernest Broxap, M.A. Demy 8vo, pp. xv. 226. 7s. 6d. net.

(Publication No. 51, 1910.)

“Mr. Broxap's monograph must be welcomed as the most important of those hitherto given to history to illuminate the county aspect of the Civil War. ..... The whole book is very carefuıy revised and accurate in its details, full and satisfactory, and the order in which the story is told is excellert. The index is also sufficient, and the whole study is amply annotated. Altogether, both the author and the Manchester University Press are to be thoroughly congratulated upon the volume."-Morning Post. 


\section{SHERRATT \& HUGHES}

\section{MANCHESTER UNIVERSITY PUBLICATIONS. HISTORICAL SERIES.}

"By a judicious use of it he has produced an eminently readable and informing work. ... The University of Manchester, which, but for the pressure of the political situation, would have been founded in 1642 , is to be congratulated upon its choice of an historian of the war in Lancashire."-Athenceum

"It is clear that Mr. Broxap has minutely studied all available original materials and that he uses them with care and discrimination. ... the highest praise that can be given to the author of a historical monograph is that he set out to produce a book that was wanted, does that extremely well, and does nothing else, and to this praise Mr. Broxap is fully entitled."-Westminster Gazette.

No. XI. A BIOGRAPHY OF THOMAS DEACON, THE MANCHESTER NON-JUROR. By Henry Broxap, M.A. Demy 8vo, pp. xix. 215, 2 plates. 7s. 6d, net. (Publication No. 59, 1911.)

"It has the signal merit, as history, of dealing with real historical questions and bringing research and historical methods to bear upon them. The author's motive has never been to concoct a book for the circulating library, but to illustrate by a single instance the strong and noble characteristics of a sect which Johnson and Macaulay despised."-Manchester Guardian.

"The materials for a biography of Thomas Deacon are not too plentiful, but Mr. Broxap has made the best possible use of the available sources, and weaves into his story many interesting glimpses of the social and religious life of the period."-Glasgow Herald.

No. XII. THE EJECTED OF 1662: Their Predecessors and Successors in Cumberland and Westmorland. By B. Nightingale, M.A. In two volumes, demy 8vo, pp. xxiv. 1490. 28s. net.

(Publication No. 62, 1911.)

No. XIII. GERMANY IN THE NINETEENTH CENTURY. Lectures by J. Holland Rose, Litt.D., C. H. Herford, Litt.D., E. C. K. Gonner, M.A., and M. E. SADLER, M.A., LL.D. With an Introductory Note by Viscount Haldane. Second Edition. Demy 8vo, pp. xxi. 142. 2s. 6d. net.

(Publication No. 65, 1912.)

No. XIV. A HISTORY OF PRESTON IN AMOUNDERNESS. By H. W. Clemesha, M. A. Demy 8vo., 7s. 6d. net.

(Publication No. 67, 1912.)

33, Soho Square, London, W. 


\section{SHERRATT \& HUGHLS}

\section{MANCHESTER UNIVERSITY PUBLICATIONS. MISTORICAL SERIES.}

No. XV. A SHORT HISTORY OF TODMORDEN. By J. Holden, M.A. Crown 8vo, pp. xiv, 242. Cloth $2 /$ - net, or cloth extra $2 / 6$ net.

(Publication No. 68, 1912.)

THE LOSS OF NORMANDY, 1189-1204. By F. M. Powicke, M.A., Professor of History "in the University of Belfast. [In the Press.

DOCUMENTS RELATING TO IRELAND UNDER THE COMMONWEALTH. By RoBerT DUNLOP, M.A., Lecturer on Irish History. In 2 volumes, demy $8 v o$.

This work will consist of a series of unpublished documents relating to the History of Ireland from 1651 to 1659 , arranged, modernized, and edited, with introduction, notes, etc., by Mr. Dunlor.

THE NAVAL MUTINIES OF 1797. By Conrad Gill, M.A, As Assistant Lecturer in History. [In the Press.

\section{THEOLOGICAL SERIES.}

No. I. INAUGURAL LECTURES delivered during the Session 1901-5, by the Professors and Lecturers of the Faculty of Theology, viz. :-

Prof. T. F. Tout, M.A.; Prof. A. S. Peake, B.D.; Prof. H. W. Hogg, M.A; Prc T. W. Rhys Davids, LL.D.; Rev. W. F. Adeney, D.D. ; Rev: A. Gordon, M.A.; Rev. L. Hassé, B.D. ; Rev. Canon E. L. Hicks, M.A.; Rev. H. D. Lockett, M.A.; Rev. R. Mackintosh, D.D. ; Rev. J. T. Marshall, D.D. ; Rev. J. H. Moulton, D. Litt.

Edited by A. S. Peake, B.D., Dean of the Faculty.

Demy 8vo, pp. xi. 296. 7s. 6d. net. (Publication No. 9, 1905.)

"The lectures, while scholarly, are at the same time popular, and will be found interesting and instructive by those who are not theologians. .... The entire series is excellent, and the volume deserves a wide circulation."-Scotsman.

"The lectures themselves give a valuable conspectus of the present position of Theological Research. . . . They are, of course, not addressed to experts, but they are exceedingly valuable, even when allowance is made for their more or less popular form."-Examiner.

"This is a most interesting and valuable book, the appearance of which at the present moment is singularly significant. . . . But it is impossible in a brief review to indicate all the treasures of this rich volume, to read which carefully is to be introduced to the varied wealth of modern Biblical scholarship."-Baptist. 


\section{MANCHESTER UNIVERSITY PUBLICATIONS. \\ LECTURES.}

No. I. GARDEN CITIES (Warburton Lecture). By RALPH Neville, K.C. 6d. net.

(Lecture No. 1, 1905.)

No. II. THE BANK OF ENGLAND AND THE STATE (A Lecture). By Sir Felix ScHUSTER. 6d. net.

(Lecture No. 2, 1905.)

No. III. BEARING AND IMPORTANCE OF COMMERCIAL TREATIES IN THE TWENTIETH CENTURY. By Sir THOMAS BARCLAY. 6d. net.

(Lecture No. 3, 1906.)

No. IV. THE SCIENCE OF LANGUAGE AND THE STUDY OF THE GREEK TESTAMENT (A Lecture). By JAMES HOPE Modlton, M.A., Litt.D. 6d. net. (Lecture No. 4, 1906.)

No. V. THE GENERAL MEDICAL COUNCIL: ITS POWERS AND ITS WORK (A Lecture). By Donald Macalister, M.A., M.D., B.Sc., D.C.L., LL.D. 6d. net.

(Lecture No. 5, 1906.)

No. VI. THE CONTRASTS IN DANTE (A Lecture). By the Hon. William WARReN Vernon, M.A. 6d. net. (Lecture No.6, 1906.)

No. VII. THE PRESERVATION OF PLACES OF INTEREST OR BEAU'TY (A Lecture). By Sir Robert Hunter. 6d. net.

(Lecture No. 7, 1907.)

No. VIII. ON THE LIGHT THROWN BY RECENT INVESTIGATIONS ON ELECTRICITY ON THE RELATION BETWEEN MATTER AND ETHER (Adams.on Lecture). By J. J. Thomson, D.Sc., F.R.S. 6d. net.

(Lecture No. 8, 1908.)

No. IX. HOSPITALS, MEDICAL SCIENCE, AND PUBLIC HEALTh (A Lecture). By Sir Clifford Allbutt, K.C.B., M.D. (Cantab.). 6d. net.

(Lecture No. 9, 1908.)

No. X. ENGLISH POETRY AND GERMAN PHILOSOPHY IN THE AGE OF WORDSWORTH (Adamson Lecture). By A. C. Bradley, Litt.D. 6d. net.

(Lecture No. 10, 1909.)

No. XI. THE EVOLUTION OF SURGERY. By William THORBURN, F.R.C.S. 6d. net. (Lecture No. 11, 1910.)

No. XII. LEIBNIZ AS A POLITICIAN. By A. W. Ward, Litt.D., F.B.A. 6d. net. (Lecture No. 12, 1911.)

Nos. XIII and XIV. OLD TOWNS AND NEW NEEDS, by PaUL WATERHouse, M.A., F.R.I.B.A., and THE TOWN EXTENSION PLAN, by RAYMond UNwIN, F.R.I.B.A. 1 volume. Illustrated. 1s. net.

(Lectures Nos. 13 and 14, 1912.)

33, Soho Square. London, W. 


\section{SHERRA'TT \& HUGHES}

CALENDAR OF THE VICTORIA UNIVERSITY OF MANCHESTER. Session 1904-5. Demy 8vo, 1100 pp. 3s net.

(Publication No. 17.)

CALENDAR OF THE VICTORIA UNIVERSITY OF MANCHESTER. Session 1905-6. Demy 8vo, 1200 pp. 3s. net.

(Publication No. 18.)

CALENDAR OF THE VICTORIA UNIVERSITY OF MAN. CHESTER. Session 1906-7. Demy 8vo, 1300 pp. 3s. net.

(Publication No. 19.)

GALENDAR OF THE VICTORIA UNIVERSITY OF MANCHESTER. Session 1907-8. Demy 8vo, 1400 pp. 3s. net.

(Publication No. 28.)

CALENDAR OF THE VICTORIA UNIVERSITY OF MANCHESTER. Session 1908-9. Demy 8vo, 1460 pp. 3s. net.

(Publication No. 37.)

CALENDAR OF THE VICTORIA UNIVERSITY OF MANCHESTER. Session 1909-10. Demy 8vo. 1470 pp. 3s. net.

(Publication No. 48.)

CALENDAR OF THE VICTORIA UNIVERSITY OF MANCHESTER. Session 1910-11. Demy 8vo, 1550 pp. 3s. net.

(Publication No. 56.)

CALENDAR OF THE VICTORIA UNIVERSITY OF MANCHESTER. Session 1911-12. Demy 8vo, 1570 pp. 3s. net.

(Publication No. 60.)

CALENDAR OF THE VICTORIA UNIVERSITY OF MANCHESTER. Session 1912-13. (New Series, No. 9).

(Publication No. 69.)

THE CATALOGUE OF THE CHRISTIE LIBRARY. [In the Press.

THE REGISTER OI GRADUATES OF THE UNIVERSITY OF MANCHESTER UP TO JULY 1908. 2s. 6d. net, cloth 3s. 6d. net. (Publication No. 36.) 




\section{PLEASE DO NOT REMOVE \\ CARDS OR SLIPS FROM THIS POCKET}

\section{UNIVERSITY OF TORONTO LIBRARY}


